Mônica de Moraes Oliveira

O caráter multidisciplinar da Comunicação Visual em hospitais

São Paulo

2012 
Mônica de Moraes Oliveira

\section{O caráter multidisciplinar da Comunicação Visual em hospitais}

Tese apresentada ao Programa de Pós-Graduação em Ciências da Comunicação, Área de Concentração "Interfaces Sociais da Comunicação", Linha de Pesquisa "Políticas e Estratégias da Comunicação", da Escola de Comunicações e Artes da Universidade de São Paulo, como exigência parcial para obtenção do Título de Doutor em Ciências da Comunicação, sob a orientação da Profa. Dra. Sandra Maria Ribeiro de Souza.

São Paulo 
Autorizo a reprodução e divulgação total ou parcial deste trabalho, por qualquer meio convencional ou eletrônico, para fins de estudo e pesquisa desde que citada a fonte.

\section{Catalogação na publicação Serviço de Biblioteca e Documentação \\ Escola de Comunicações e Artes da Universidade de São Paulo}

Oliveira, Monica de Moraes

O caráter multidisciplinar da comunicação visual em hospitais / Monica de Moraes Oliveira. -- São Paulo : M. M. Oliveira, 2012. 190 p. : il.

Tese (Doutorado) - Escola de Comunicações e Artes/ Universidade de São Paulo.

Orientadora: Profa. Sandra Maria Ribeiro de Souza.

1. Comunicação visual 2. Hospitais 3. Ambiência 4. Humanização 5. Multidisciplinaridade I. Souza, Sandra Maria Ribeiro de II. Título. 
Nome: OLIVEIRA, Mônica de Moraes

Título: O caráter multidisciplinar da Comunicação Visual em hospitais

Tese apresentada à Escola de Comunicações e Artes da Universidade de São Paulo para obtenção do título de Doutor em Ciências da Comunicação

Aprovada em:

\section{Banca Examinadora}

$\operatorname{Prof}(\mathrm{a}) . \operatorname{Dr}(\mathrm{a})$ Instituição:

Assinatura:

$\operatorname{Prof}(\mathrm{a}) . \operatorname{Dr}(\mathrm{a})$. Instituição:

Assinatura:

$\operatorname{Prof}(\mathrm{a}) . \operatorname{Dr}(\mathrm{a})$ Instituição:

Assinatura:

$\operatorname{Prof}(a) . \operatorname{Dr}(a)$. Instituição:

Assinatura:

Prof(a). Dr(a). Instituição:

Assinatura: 
Ao meu irmão, Pelópidas; aos meus pais Nilo e Anna, in memoriam 


\section{Agradecimentos}

Recebi, ao longo de quatro anos, muito apoio, indicações, sugestões e críticas. Todas as contribuições foram importantes, mesmo as que não puderam ser seguidas, por qualquer motivo que seja.

Agradecimentos especiais seguem-se:

- à minha orientadora, Profa. Dra. Sandra Souza, pelo voto de confiança, pelos conselhos, pela paciência em suportar meus momentos de indecisão (que, diga-se de passagem, não foram poucos), por ter compreendido minhas limitações, por compartilhar seus conhecimentos e, acima de tudo, pela amizade;

- à banca de qualificação, Prof. Dr. Issao Minami e Prof. Dr. Hugo Fortes, pelas sugestões apontadas;

- às minhas madrinhas, Cecília Gonçalves e Albertina Margarida, pelas preces e proteção espiritual;

- a minha ex-professora de Português, Rachel G. Moraes, pela revisão desta tese;

- aos amigos que compartilharam comigo, de alguma forma, trajetos em hospitais: Sônia Beraldo; Sueli Íris e Marco Bezerra; Eliana e Maria Aparecida de Oliveira; Ângela e Dora Pinheiro; Alexandra Chaptiska;

- aos amigos que me apoiaram e me incentivaram;

- às pessoas que cuidaram de minha saúde física e espiritual: Dra. Maria Fátima Paula Ramos; Dra. Ana e Dr. Flávio Furukawa; Maísa Intelisano;

- às pessoas que compartilharam seus conhecimentos sobre hospitais: Vivian Lee, Demóstenes Augustus Lopes de Freitas, Cláudio Habara, Anamaria Amaral Rezende;

- à CAPES, pelo apoio financeiro. 


\section{RESUMO}

A Comunicação Visual em hospitais tem o poder de tornar o espaço agradável e acolhedor, pois suas peças, quando dispostas de maneira planejada e sistematizada, podem formar um conjunto chamado de "ambiência hospitalar". Essas peças (placas, banners, totens, displays, fachadas etc.) cumprem funções de sinalização, identidade visual e transmitem informações administrativas e funcionais. O objetivo desta pesquisa é evidenciar que 0 ambiente hospitalar, por ser extremamente complexo, necessita de um projeto de Comunicação Visual com caráter multidisciplinar. A metodologia adotada partiu de uma pesquisa bibliográfica relacionada a diferentes áreas envolvidas com a Comunicação Visual aplicada ao tema hospital. Foram realizadas entrevistas informais com produtores e fornecedores, além de visitas de prospecção a hospitais. Não foi adequado fazer estudos de caso, por não terem sido autorizados registros fotográficos. Tendo sido necessário recorrer a fontes indiretas para obtenção de instrumentos de exemplificação, optou-se por um levantamento iconográfico, utilizando referências disponíveis em meios impressos e digitais para caracterizar os elementos da teoria. Dada a complexidade do tema, não existe uma literatura específica consolidada e, na literatura das áreas afins, os conceitos ainda são divergentes e incipientes. A contribuição desta pesquisa está na organização dos estudos na interface de Comunicação Visual aplicada a outras áreas, pois hospitais são organismos complexos, dinâmicos e flexíveis que exigem soluções que acompanhem e respeitem essas características.

Palavras-chave: Comunicação Visual, hospital, ambiência, humanização, hospitalidade 


\section{ABSTRACT}

Visual Communications in hospitals can make the space agreeable and welcoming, since, when arranged in a planned, systematic manner, the pieces can form an assemblage that is denominated as the "hospital ambience". These pieces (signs, banners, totems, displays, façades etc.) have signaling and visual identity functions and convey administrative and functional information. The purpose of this study is to show that the hospital environment, for being extremely complex, requires a multidisciplinary approach to Visual Communications. The adopted methodology was based on a review of the available literature related to different areas involved with Visual Communications applied to the hospital theme. Informal interviews were held with producers and suppliers, and prospecting visits made to hospitals. It was not appropriate to undertake case studies, since photographic records were not authorized. Since it was necessary to resort to indirect sources to obtain tools for exemplification, a decision was made to use an iconographic survey using references available in print and in digital media to characterize the elements of the theory. Given the complexity of the theme, there is not a specific consolidated body of literature to refer to, and concepts are still divergent and incipient in the literature of related areas. The contribution this research project can make is in organizing studies at the interface of Visual Communications applied to other areas, because hospitals are complex organisms that require flexible, dynamic solutions that not only follow, but also respect these characteristics.

Key words: Visual Communications, hospital, ambience, humanization, hospitality 


\section{LISTA DE FIGURAS}

Figura 1 - Representação do Hotel-Dieu de Beaune ...................................... 31

Figura 2 - Evergreen Hospital Medical Center ............................................. 34

Figura 3 - EHMC: Dep. Cirurgia e Emergência .............................................. 34

Figura 4 - Vista aérea do Hospital das Clínicas - SP .................................. 35

Figura 5 - Fachada do Hospital Sírio-Libanês.............................................. 36

Figura 6 - Hosp. do Aparelho Locomotor ................................................... 38

Figura 7 - Abbotsford Regional Hospital \& Cancer Centre.............................. 39

Figura 8 - Hospital Offenbach, Hessen, Alemanha ........................................ 43

Figura 9 - Comunicação bilíngue - Hosp. Sírio-Libanês................................. 48

Figura 10 - Revista Veja São Paulo, 08 de julho de 2009 ............................. 51

Figura 11 - Espaços flexíveis para adequar equipamentos modernos............ 59

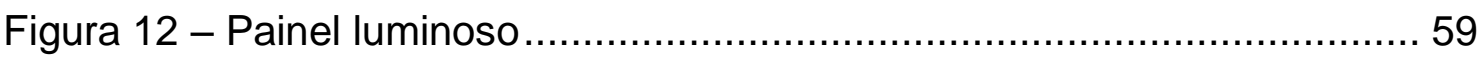

Figura 13 - Cafeteria do Providence Newberg Medical Center (Oregon) ........ 62

Figura 14 - Recepção do Centro Pediátrico da Lagoa ................................... 64

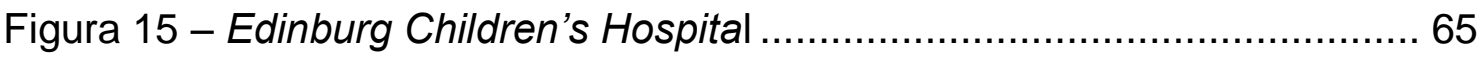

Figura 16 - Instituto Clínico Humanitas (Itália) ........................................... 67

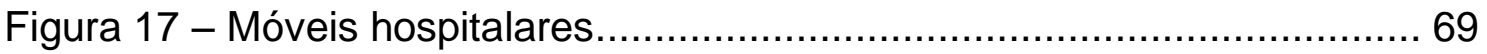

Figura 18 - Cleveland Clinic Lou Ruvo Center for Brain Health ...................... 71

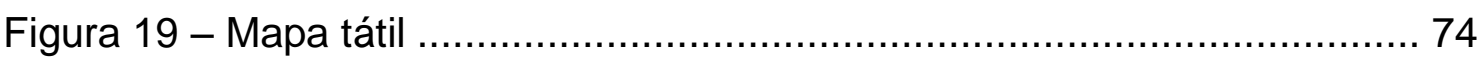

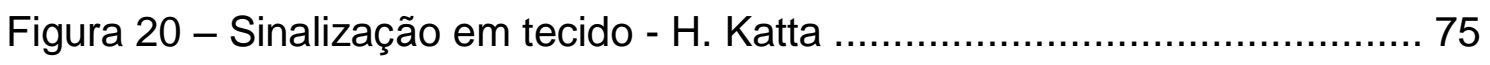

Figura 21 - Sinalização em algodão - H.Katta ............................................. 75

Figura 22 - llustração de CV em emergência ............................................. 77

Figura 23 - Exemplo de placas de sinalização............................................... 78

Figura 24 - Sinalização com logotipo do hospital....................................... 80

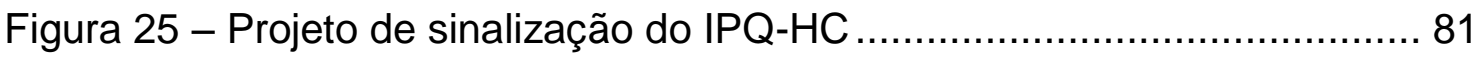

Figura 26 - Painel de identificação do IPQ-HC ............................................. 82

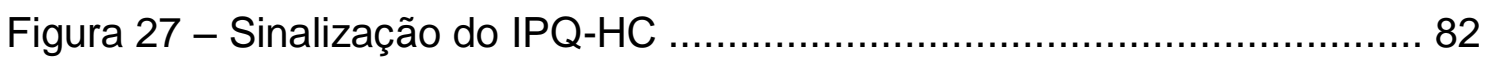

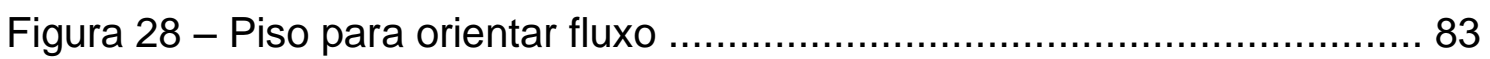

Figura 29 - Exemplo de ilustração pictórica em sinalização ……………........ 83

Figura 30 - Exemplo de fotografia em sinalização ……………………........ 83

Figura 31 - Aplicação do sistema de sinalização ......................................... 85 


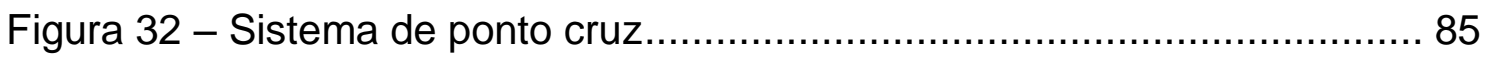

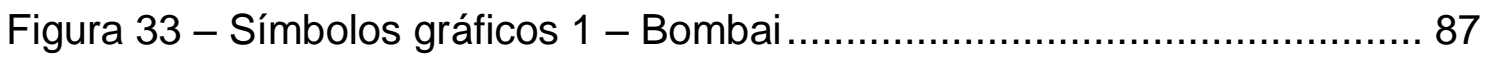

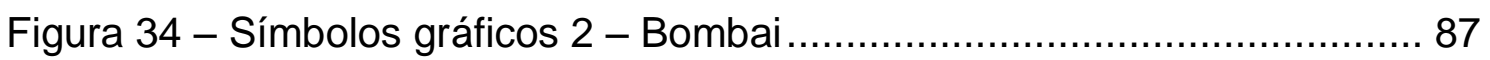

Figura 35 - Símbolos para teste - Hablamos Juntos .................................... 88

Figura 36 - Símbolos gráficos - Hablamos Juntos ……………………........ 89

Figura 37 - Exemplo de ponto de decisão ……........................................ 90

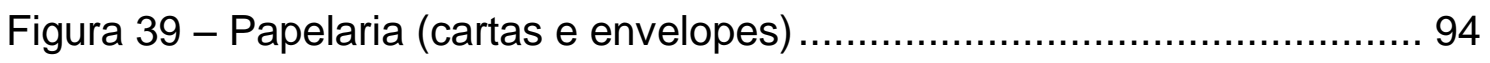

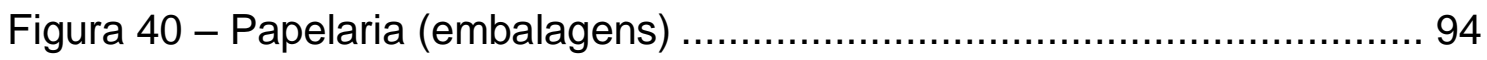

Figura 38 - Logotipos do H. Sírio-Libanês .................................................. 94

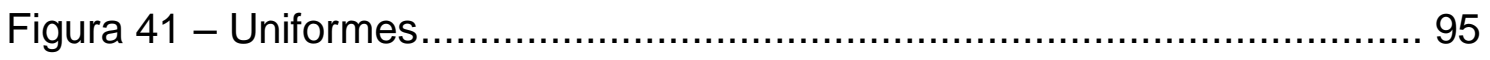

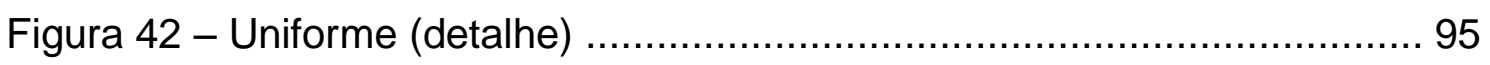

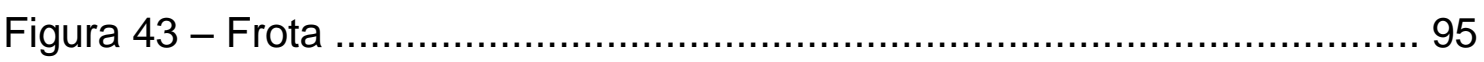

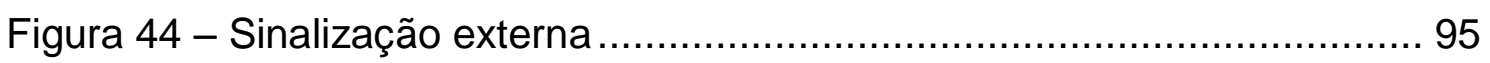

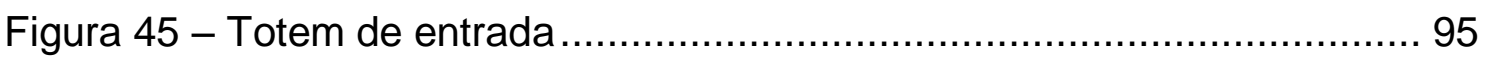

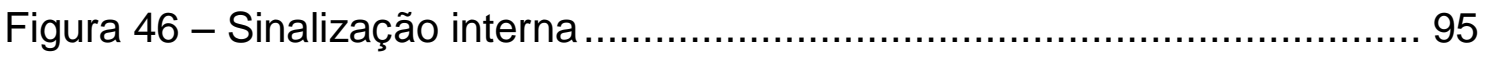

Figura 47 - Entrada H. A.C. Camargo ……………............................... 96

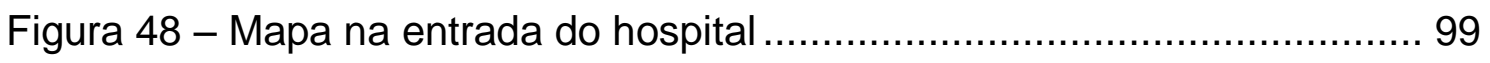

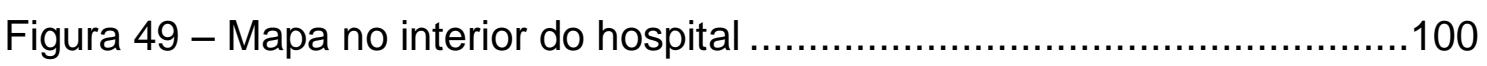

Figura 50 - Exemplo de trajeto de um hospital ........................................101

Figura 51 - Display touchscreen - M.D. Anderson Cancer Center (EUA)......103

Figura 52 - Sistema "Access" - M.D.A. Cancer Center (EUA) .......................105

Figura 53 - Símbolos e locais de referência do M.D.A. Cancer Center...........105

Figura 54 - Identificação de pavilhões: MultiCare Tacoma General Hospital.106

Figura 55 - Sinalização de enfermagem no banheiro .................................108

Figura 56 - Equipamentos de proteção e segurança ....................................109

Figura 57 - Explicações: controle de infecção …………...........................110

Figura 58 - Mapa de risco de uma clínica cirúrgica.....................................111

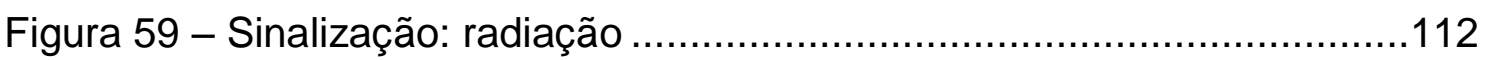

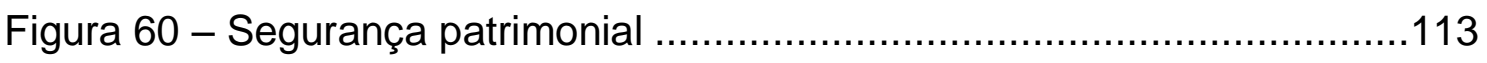

Figura 61 - Display do Hosp. São Camilo ..............................................114

Figura 62 - Campanha do H. A. Oswaldo Cruz .........................................115

Figura 63 - Material de divulgação do "Access"..........................................116

Figura 64 - St. Joseph's Area Health Services .........................................117

Figura 65 - Recepção do Hosp. Santa Catarina ........................................118 
Figura 66 - Exemplos de sinalização em um hospital .................................121

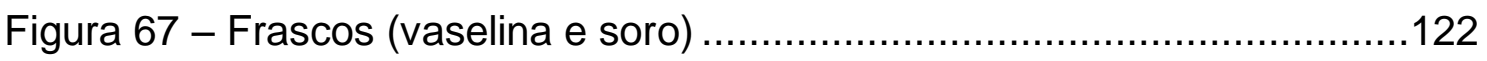

Figura 68 - Área de lazer e convivência - The Children's Hospital.................125

Figura 69 - Dublin Methodist Hospital..................................................127

Figura 70 - Maternidade Dona Regina (Palmas / TO) - antes.......................129

Figura 71 - Maternidade Dona Regina (Palmas / TO) - depois ....................129

Figura 72 - Hosp. Rede Sarah Jacarepaguá …………............................132

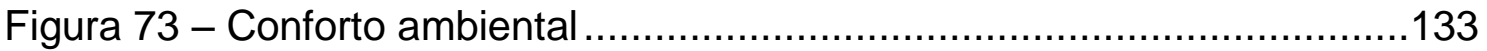

Figura 74 - Quarto da Cleveland Clinic Foundation, EUA ...........................134

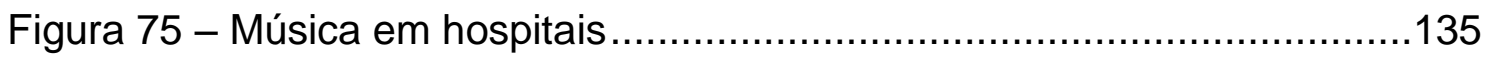

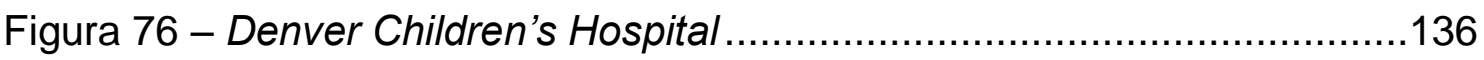

Figura 77 - Queen Elizabeth Hospital ..................................................137

Figura 78 - Limpeza e higienização de hospital ......................................139

Figura 79 - H. A. Oswaldo Cruz (Unid. de Especialização - Campo Belo) .....141

Figura 80 - Ressonância magnética com ambientação .................................143

Figura 81 - Hospital Infantil Sabará ...................................................146

Figura 82 - Logomarca anterior do H. IGESP .........................................147

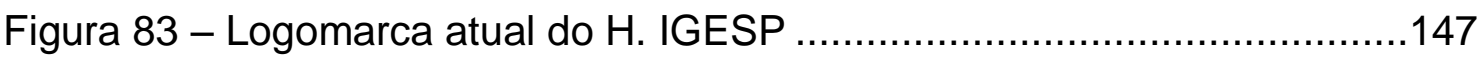

Figura 84 - Logomarca anterior do H. Oswaldo Cruz.................................148

Figura 85 - Logomarca atual do H. Oswaldo Cruz ......................................148

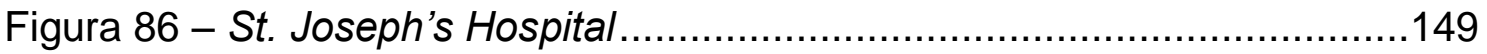

Figura 87 - Recepção do Inst. da Próstata (H. A. Oswaldo Cruz) ...................151

Figura 88 - Exemplo de aplicação adequada e não adequada de CV ...........153

Figura 89 - Exemplos de sinalização do H. Sírio-Libanês..............................154

Figura 90 - Recepção e espera do Hosp. Albert Einstein .............................156

Figura 91 - Equipamento interativo do H. Georges Pompidou ......................157

Figura 92 - Núcleo de Assistência à Mulher do H. Igesp ............................158

Figura 93 - Terraço do 7o. Pavimento do Hosp. Sabará................................159

Figura 94 - Logotipo do Hosp. Samaritano aplicado no prédio ......................161

Figura 95 - Totem do Hosp. Samaritano.....................................................162

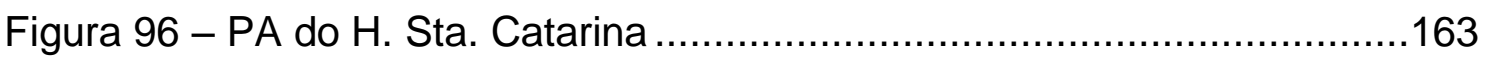

Figura 97 - H. Sta. Catarina: fachada em 1980 .......................................164

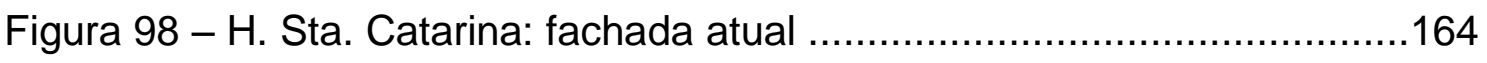

Figura 99 - Muro do H. Sta. Catarina........................................................164 


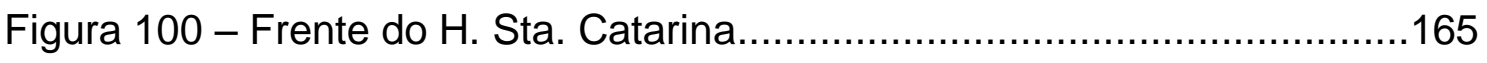

Figura 101 - Estacionamento do Allen Hospital - Waterloo (lowa) .................166

Figura 102 - Sinalização de estacionamento do MultiCare Tacoma General

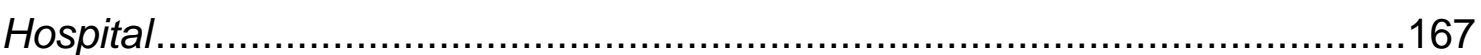




\section{LISTA DE ESQUEMAS}

Esquema 1 - CV em hospitais ........................................................... 18

Esquema 2 - Características de um hospital ............................................ 21

Esquema 3 - Áreas relacionadas à estrutura hospitalar ............................... 24

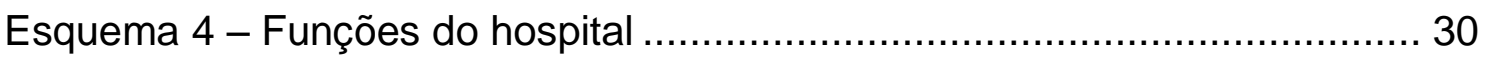

Esquema 5 - Qualidade em hospitais ...................................................... 53

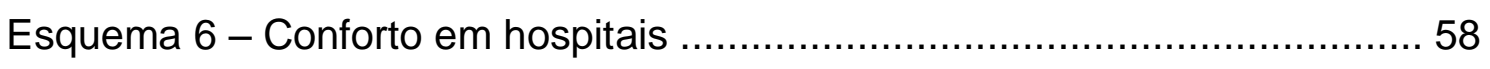

Esquema 7 - Segurança em hospitais ......................................................107

Esquema 8 - Ambiência hospitalar ....................................................131

Esquema 9 - Aspectos internos relacionados à ambiência hospitalar ...........155

Esquema 10 - Aspectos externos relacionados à ambiência hospitalar ........160

Esquema 11 - Hospitais e a CV..........................................................172

Esquema 12 - Sistema de CV e Ambiência ...............................................174

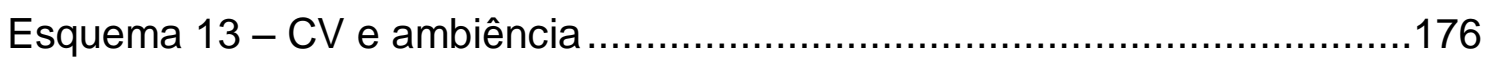

Esquema 14 - Áreas relacionadas ao estudo de CV hospitalar ......................177

Esquema 15 - Integração: peças, projeto, sistema .....................................179 


\section{SUMÁRIO}

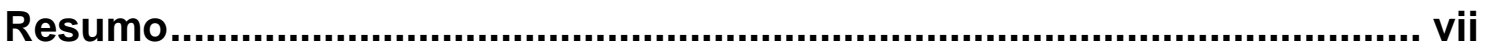

Abstract

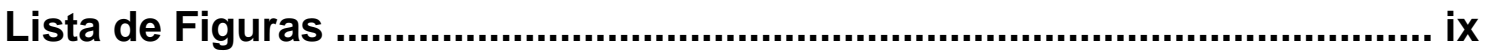

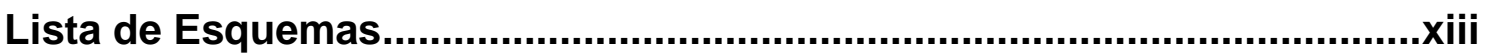

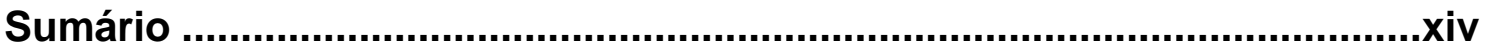

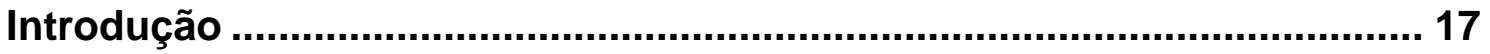

Cap. 1 Hospital: centro promotor de saúde ................................................. 29

1.1 Estabelecimentos Assistenciais de Saúde (EAS)............................ 29

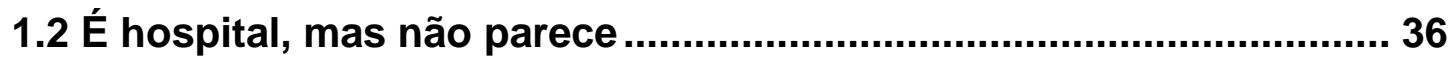

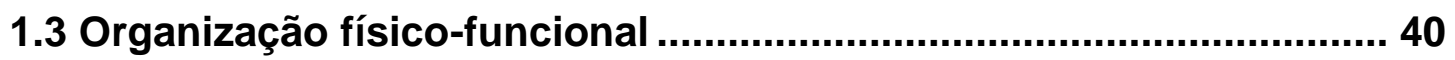

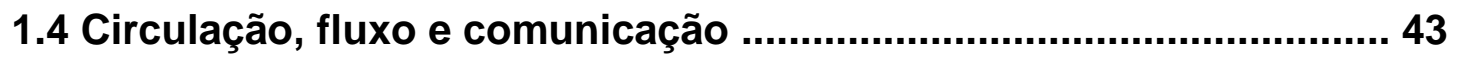

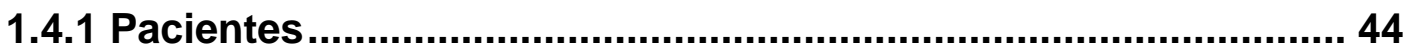

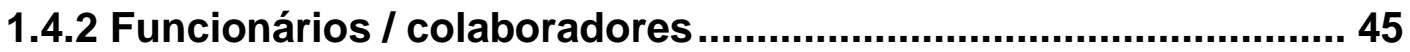

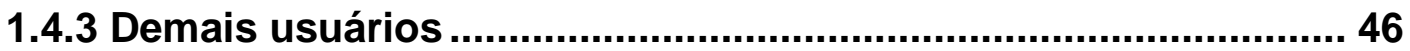

1.5 Turismo de saúde e expansão dos hospitais ..................................... 47

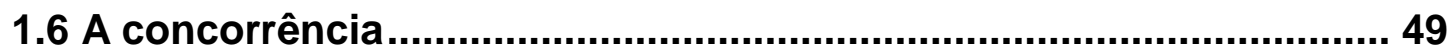

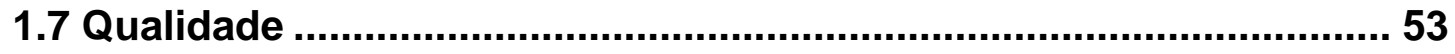

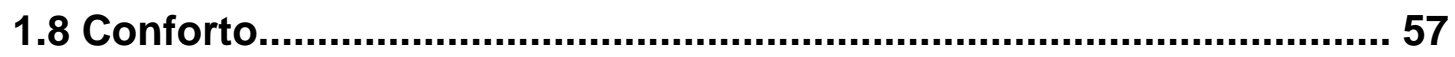

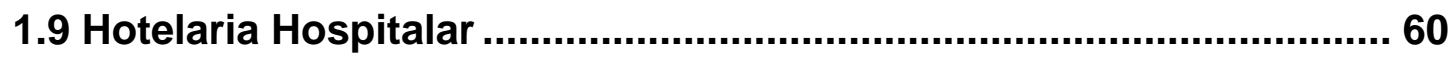

1.10 Ambiente hospitalar: ambiente terapêutico ...................................... 65

Cap. 2 Comunicação Visual em hospitais .................................................... 68

2.1 Especificidades da Comunicação Visual em hospitais...................... 68

2.1.1 Flexibilidade e possibilidades de alterações dos espaços ........ 69

2.1.2 Necessidades de normas específicas ....................................... 72

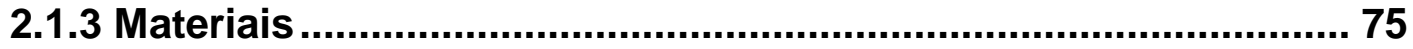




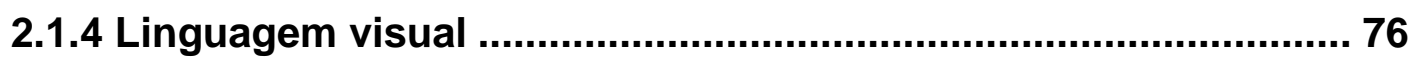

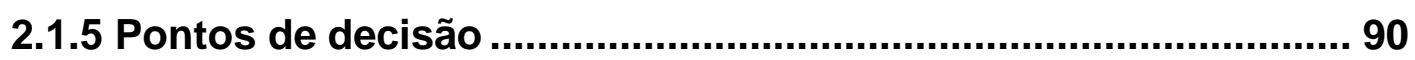

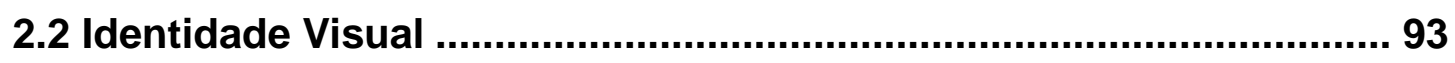

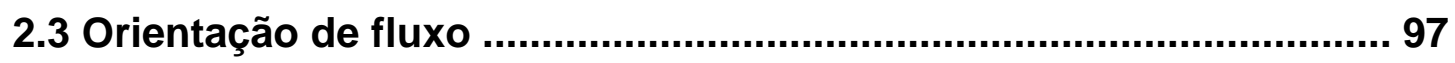

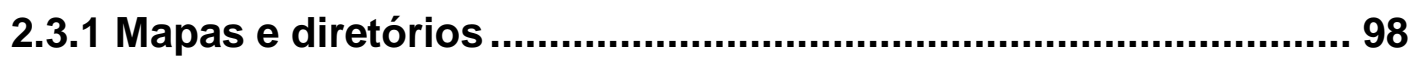

2.3.2 Sinais de localização e identificação ........................................104

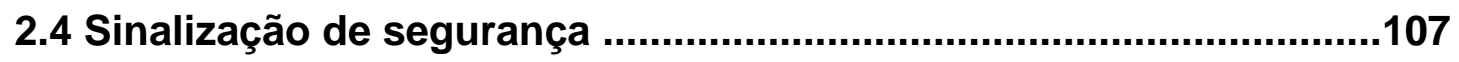

2.4.1 Segurança estrutural ..............................................................108

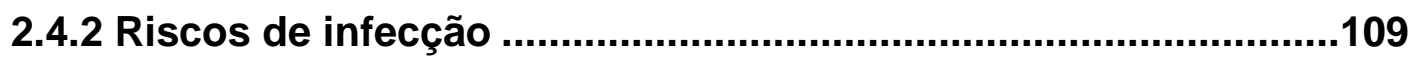

2.4.3 Segurança patrimonial .................................................................113

2.5 Demais informações ......................................................................114

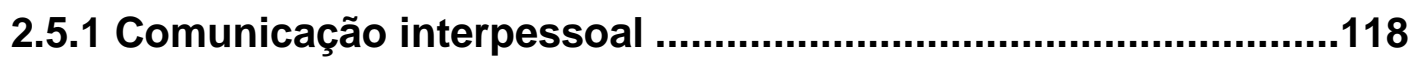

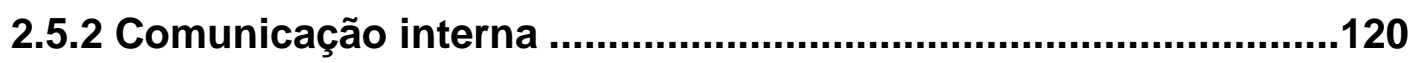

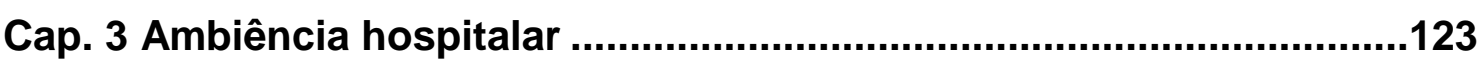

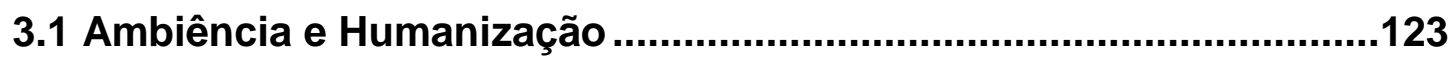

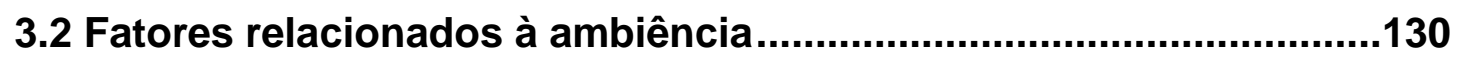

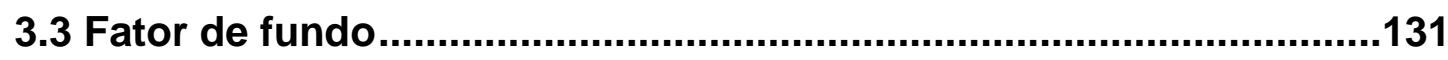

3.3.1 Dimensões espaciais..................................................................131

3.3.2 Conforto ambiental e acústico..................................................133

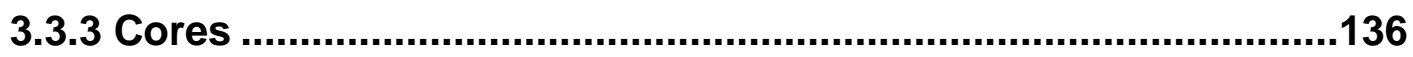

3.3.4 Aromas e sabores.......................................................................138

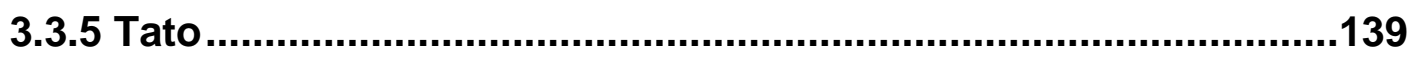

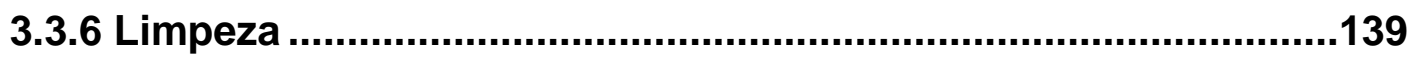

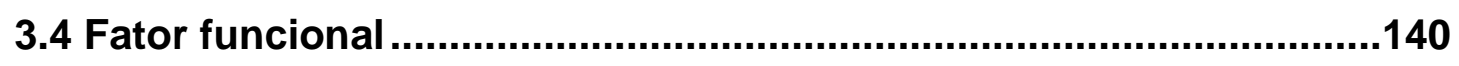

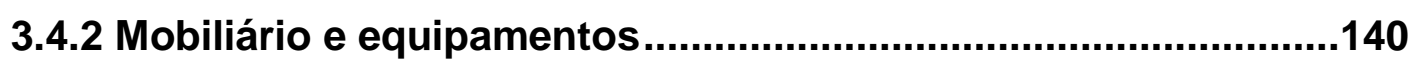

3.4.3 Revestimentos de pisos e paredes ............................................141

3.4.4 Serviços de hotelaria hospitalar ...............................................142 


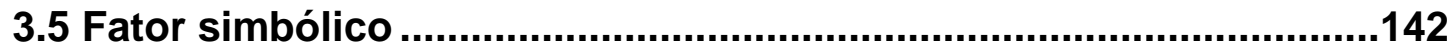

3.5.1 Aparência estrutural ..................................................................142

3.5.2 Objetos decorativos e a Sinalização .............................................143

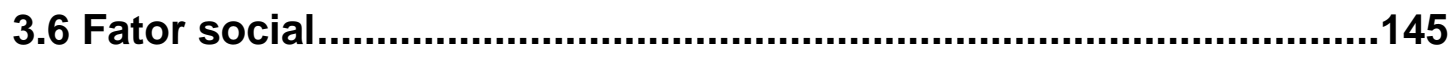

Cap. 4 A Comunicação Visual e a ambiência hospitalar...............................146

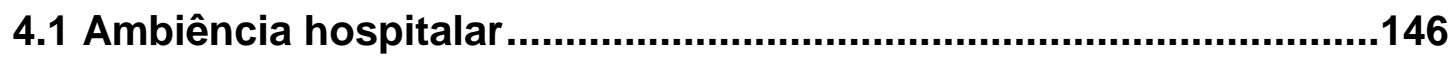

4.2 Comunicação visual e a construção da ambiência ..........................151

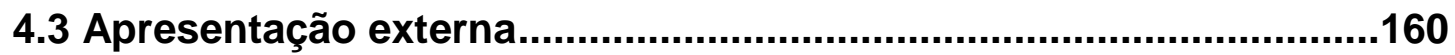

4.4 Comunicação Visual como reflexo de hospitalidade e humanização ..167

Considerações finais ..............................................................................171

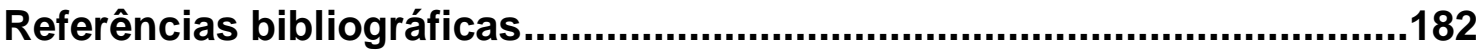




\section{INTRODUÇÃO}

O que é Comunicação Visual (CV) em hospitais? Suas características são diferenciadas das de outros ambientes? Esta tese centrou-se na coleta e tratamento de informações teóricas e em práticas observadas no mercado sobre este assunto com o objetivo de mostrar que este tema é mais amplo e complexo do que pode parecer.

A CV em hospitais se caracteriza por auxiliar usuários que geralmente se encontram em condições diferenciadas, vivenciando situações de desconforto físico e/ou emocional e, ainda assim, tendo que tomar decisões e ter acesso a várias informações. Por causa da ampla estrutura física e organizacional dessas instituições, mesmo quem frequenta seus ambientes todos os dias, dificilmente o conhece por inteiro. Assim, pessoas relacionadas ao staff de um hospital também podem se perder ou não localizar um ambiente diferente do habitual.

A CV desempenha um importante papel ao sistematizar informações nos vários setores de um hospital. A relevância do estudo desse tema está na complexidade e especificidade desse ambiente. Segundo Ribeiro (2009, p. 17), a característica de ambientes complexos (geralmente edifícios de grande porte) é que "requerem uma rede clara e bem elaborada de informações para orientar seus usuários". Essa autora menciona a questão da necessidade de orientar os usuários em ambientes complexos, apontando como problema que esta é negligenciada, algumas vezes, pelos administradores do ambiente, como o caso de alguns edifícios públicos, complexos empresariais privados ou até mesmo cidades (idem, p. 18).

O objeto de estudo desta tese é a CV num tipo de ambiente específico: hospital. Segundo Munari (1997) "comunicação visual" é tudo o que os nossos olhos veem e ocorre por meio de mensagens visuais, podendo ser casual ou intencional (quando há intenção de transmitir uma informação precisa, com a utilização de um código preciso). O enfoque deste trabalho é a CV intencional em hospitais, ou seja, o conjunto de mensagens visuais apresentadas com a intenção de transmitir informações diversas. Nesse contexto, suas funções 
relacionam-se a orientar o fluxo (direções e circulação); indicar itens de segurança; indicar acessos restritos e demais proibições; identificar e diferenciar ambientes e setores; identificar a instituição; fornecer informações diversas (sobre a instituição, missão, valores, história e visão; sobre prevenção de doenças; sobre eventos e campanhas; sobre procedimentos a serem realizados etc.); divulgar a marca e fazer publicidade e propaganda da instituição e de seus serviços e, acima de tudo, acolher os usuários com um ambiente propício a interações.

Essas funções possibilitam que os usuários tenham condições de permanência no ambiente hospitalar, de modo seguro e com mais autonomia e conforto. Pessoas que vão a um hospital pela primeira vez podem ter dificuldades para localizar seu destino nos espaços internos da instituição, sobretudo nos casos em que há separações estruturais em vários blocos, torres e prédios, daí a importância da CV como sistematizadora de informações, auxiliando usuários.

Mensagens visuais organizadas formam um sistema de CV que comunica valores institucionais do hospital, mostrando seus serviços e fortalecendo sua marca. O sistema apresenta informações elaboradas e planejadas em um projeto que define peças a serem utilizadas e seu posicionamento. Esse sistema insere-se na ambiência (Esquema 1).

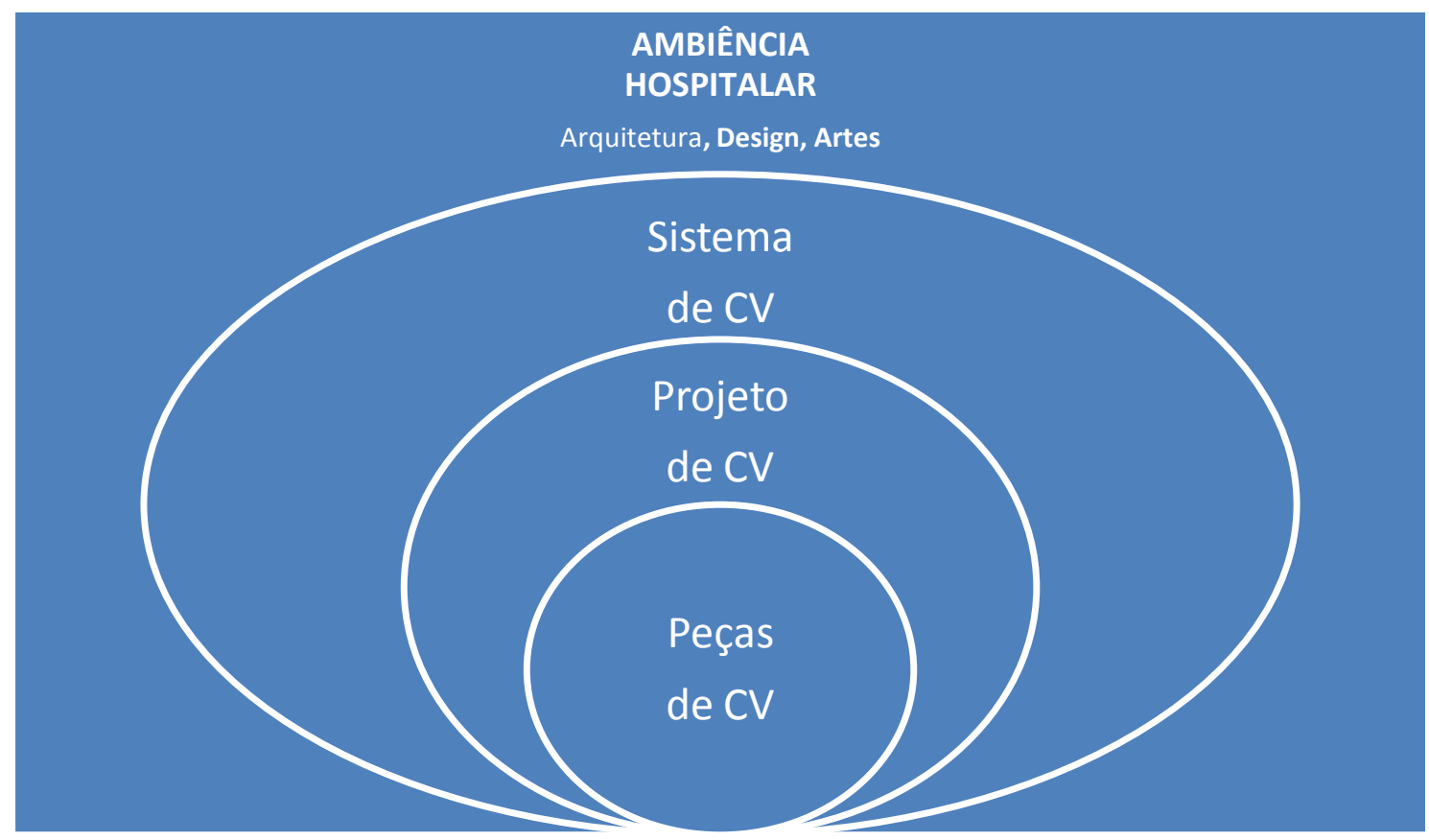

Esquema 1 - CV em hospitais

Fonte: Elaborado pela autora 
Peça de CV é a menor unidade a que se pode reduzir uma informação a ser transmitida e deve estar aplicada em um suporte visual. Este pode ser confeccionado com diversos materiais e se apresentar de diversas formas. São exemplos de peças de CV: placas, fachadas, luminosos, totens (decorativos, informativos e/ou institucionais), banners, displays (incluindo-se aqui os eletrônicos e móveis), painéis (considerando-se inclusive os painéis utilizados para chamada de pacientes), adesivos (em pequenos e grandes formatos), placas de advertência e/ou proibição, adesivos em veículos, uniformes com identificações da instituição, anúncios publicitários e impressos de modo geral (papelaria, folders, catálogos etc.).

Por seu caráter visual, também integram essa lista os pisos diferenciados por cores para orientação de fluxo; pisos diferenciados da sinalização tátil, placas em Braille, batentes de elevador, mapas táteis e alguns elementos de comunicação com o público (como campainhas para comunicação entre pacientes e o setor de enfermagem, caixas de sugestão, totens contendo senhas para atendimento etc.). Já outros formatos, mesmo que considerados como peças de CV (tais como: sites, brindes, embalagens, jornais e revistas), não são aqui relacionados, porque comumente não estão presentes (de forma obrigatória) no espaço físico hospitalar.

Um projeto de CV define e especifica peças a serem aplicadas no ambiente. A partir da organização das informações a serem transmitidas, elabora formatos, integração entre as peças e o melhor posicionamento para cada uma. Nele deve ser considerada a grande possibilidade de estresse psicológico dos usuários (clientes de saúde e/ou staff), bem como os parâmetros relacionados à infecção hospitalar e demais riscos específicos do ambiente hospitalar. Dada a própria circunstância desse ambiente, a CV assume um caráter mais humanizado e hospitaleiro, sendo que cada hospital requer um sistema diferenciado, adequado às suas necessidades e particularidades (público que atende, local em que se situa, tamanho etc.).

A CV é concebida como sistema integrado que auxilia a formação de um contexto mais amplo, chamado aqui de ambiência, criado para propiciar uma experiência sensorial positiva do ambiente aos usuários, dando-Ihes condições de manter maior interação, confortabilidade e espaço próprio para o desenvolvimento do trabalho. Para formar esse conjunto, o sistema de CV 
integra elementos de disciplinas especializadas (Arquitetura, Design, Artes) no ambiente hospitalar, como, por exemplo: sinais de informação, peças de comunicação, decoração (obras de arte; paisagismo); mobiliário e equipamentos (cor, formato, material, disposição); revestimento de pisos, paredes (cores e materiais utilizados); iluminação (natural e/ou artificial); sons; aroma etc.. Toda essa junção cria uma ambiência de natureza multidisciplinar. A CV hospitalar pretende proporcionar ao usuário uma sensação agradável e, ao mesmo tempo, transmitir informações necessárias à sua permanência no local. Nesse sentido, podem ser utilizadas cores em mobiliários, equipamentos e revestimentos para identificar os locais e para reforçar a identidade visual da instituição, por exemplo, assim como pode ser feita aplicação do logotipo em peças que indiquem sinalização ou localização de um setor para reforçar a imagem de marca.

A preocupação com a ambiência relaciona-se a questões de humanização, hospitalidade e acolhimento, principalmente no que diz respeito ao atendimento de clientes de saúde. Atualmente os hospitais, de modo geral, têm como funções tratar pessoas que apresentam problemas de saúde, realizar exames preventivos para evitar certas doenças, realizar pesquisas e divulgá-las para a comunidade. Isso vem provocando, como reação, um hábito de as pessoas irem a hospitais não apenas quando estão doentes. Tem crescido a procura por tratamentos preventivos e por informações sobre como evitar certos problemas de saúde. Alguns hospitais fornecem essas informações por meio de palestras, cursos e eventos, auxiliando usuários a terem uma melhor qualidade de vida.

Com as pessoas que vão a um hospital à procura de uma melhora em sua saúde, consideradas como clientes de saúde, estão seus acompanhantes, visitantes e familiares. O que diferencia esses usuários de frequentadores de outros locais é a maior possibilidade de eles se encontrarem em situações físicas (e/ou emocionais) diferenciadas do normal, devido a problemas de saúde. Mesmo as pessoas relacionadas a um cliente de saúde podem se encontrar em estado diferenciado, sobretudo emocionalmente, por isso é importante que seja dada atenção especial tanto a pacientes quanto às pessoas a eles relacionadas. 
Essa mudança proporcionou um aumento das atividades dessas instituições e das pessoas que realizam trabalhos e/ou estudos em suas dependências (chamadas aqui de forma genérica de staff). Além das pessoas que lidam diretamente com o tratamento dos pacientes (equipes médicas e enfermeiros), há a necessidade de equipes de apoio para realizar funções diversas relacionadas à infraestrutura da instituição. Essas pessoas compõem a lista de usuários de hospitais e podem se encontrar em situação de estresse por causa das características das atividades que desenvolvem. Por isso, tanto a equipe médica e equipe de enfermeiros quanto o pessoal de apoio precisam sentir-se em um local agradável, a fim de realizarem suas funções de modo menos estressante.

O ambiente hospitalar é bastante complexo e requer recursos especiais para atender as necessidades e expectativas de todos esses usuários citados.

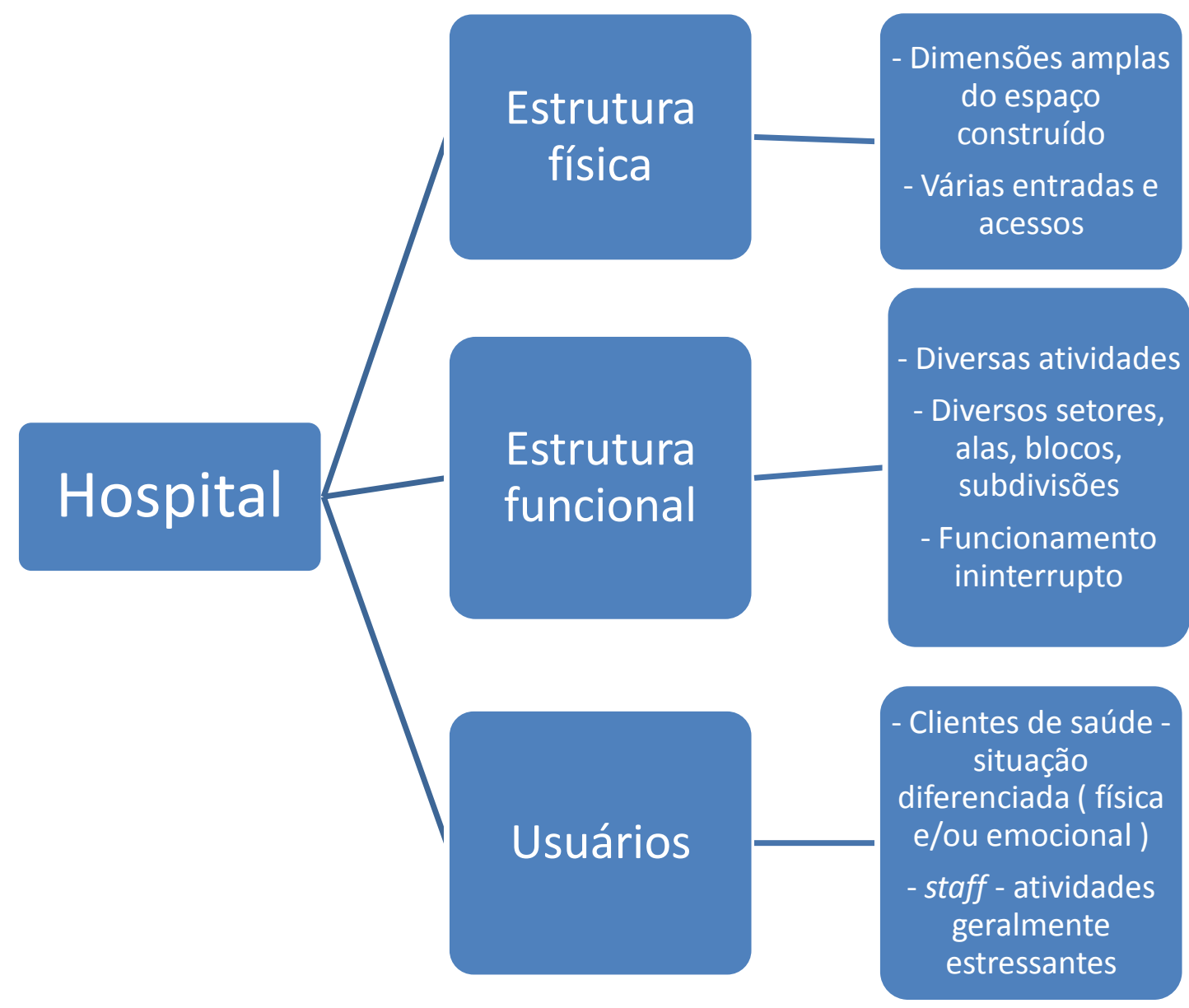

Esquema 2 - Características de um hospital Fonte: Elaborado pela autora

Como resumidamente apresentado no Esquema 2, a estrutura física de um 
hospital (citado aqui de maneira geral, independente de ser público ou privado, de ter uma especialidade ou ser geral) envolve uma área construída com dimensões amplas, com várias entradas e acessos, gerando a necessidade de sinalização para que os usuários possam localizar com eficiência o local de destino. A questão da sinalização envolve tanto o entorno do hospital quanto suas dependências externas e internas. O que se espera da CV nesse sentido é que ela auxilie as pessoas a localizarem os acessos ao seu destino de forma mais rápida e fácil possível, evitando que pessoas com dificuldade de locomoção (temporária ou não) sejam obrigadas a caminhar mais do que o necessário.

Quanto à estrutura funcional, as diversas atividades a serem desempenhadas nesses estabelecimentos, em um funcionamento ininterrupto, geram a necessidade de diferentes setores e subdivisões (influenciando a organização da estrutura física). A necessidade de indicação sobre os locais em que a pessoa se encontra é fundamental para que os usuários identifiquem com clareza onde estão e onde pretendem ir e a CV pode ser muito útil quanto a esse aspecto. É importante lembrar aqui que hospitais têm ambientes com acesso restrito a funcionários, sobretudo os que se relacionam a áreas de risco para a saúde e com problemas de contaminação. Por essa razão, a identificação em hospitais requer maior cuidado e atenção.

O setor hospitalar tem crescido muito nas últimas décadas, inclusive no Brasil. Novos hospitais têm sido criados e muitos já existentes têm passado por processos de expansão de suas estruturas, o que pode causar problemas para que pessoas encontrem o destino desejado (MOLLERUP, 2009, p. 112). Algumas, acostumadas ao "hospital anterior", podem sentir certa dificuldade para adaptar-se à nova estrutura e encontrar os setores aos quais tem que se dirigir para seus tratamentos e procedimentos. Os casos de expansão necessitam de cuidados especiais, tanto em relação à construção (evitando poeira, ruído e demais problemas possíveis) quanto em relação à divulgação das alterações a serem realizadas (evitando que os usuários tenham sensação de desconforto durante o período da construção ou mesmo depois deste para se adequar às novas estruturas).

Quanto maior um hospital, maior sua capacidade de atendimento e maior a circulação de pessoas (gerada pela contratação de mais profissionais e pelo 
aumento de pessoas atendidas). Essa (re)estrutura levou várias áreas a uma especialização para atender necessidades dessas instituições, conforme apresentado no Esquema 3.

À Gestão Hospitalar competem decisões sobre o que será feito no hospital, onde e como será aplicado o orçamento. Essa área determina, por exemplo, se caberá investir em CV ou não, assim como publicidade e propaganda, de acordo com as disponibilidades e conveniências de cada instituição. A Arquitetura Hospitalar é uma área que vem se especializando cada vez mais, procurando propiciar conforto nos ambientes de saúde. Novos hospitais assemelham-se a hotéis, com estrutura predial, tanto externa quanto internamente, no que o Design de Interiores contribui para tornar o ambiente mais agradável. A hotelaria hospitalar auxilia em questões de recepção, acolhimento e infraestrutura, sobretudo para casos de internações em que 0 cliente de saúde precisa de alguns cuidados especiais (semelhantes aos de um hóspede de hotel).

O papel da CV relaciona-se ao Design de informação (sinalizando os ambientes, principalmente dando referências de orientação de fluxo e de segurança), à Identidade Corporativa (auxiliando na identificação e reforçando a imagem de marca da instituição, principalmente nos casos de Publicidade e Propaganda do hospital) e à Arte, que proporciona a criação de um ambiente esteticamente mais humanizado. A sinalização, em termos de orientação de fluxo, exige uma preocupação maior, é um ponto importante da CV. A sinalização de segurança em hospitais requer uma atenção diferenciada, dadas as particularidades do ambiente relacionadas a questões de infecção e contaminação. A Identidade Visual é um instrumento (ou ferramenta) de Marketing, principalmente nos casos de hospitais particulares, dada a concorrência de mercado, que exige fortalecimento da marca e identificação do cliente de saúde com a instituição. A complexidade do hospital gera a necessidade de transmissão de várias informações institucionais (administrativas e funcionais), sem, no entanto, causar poluição visual. 


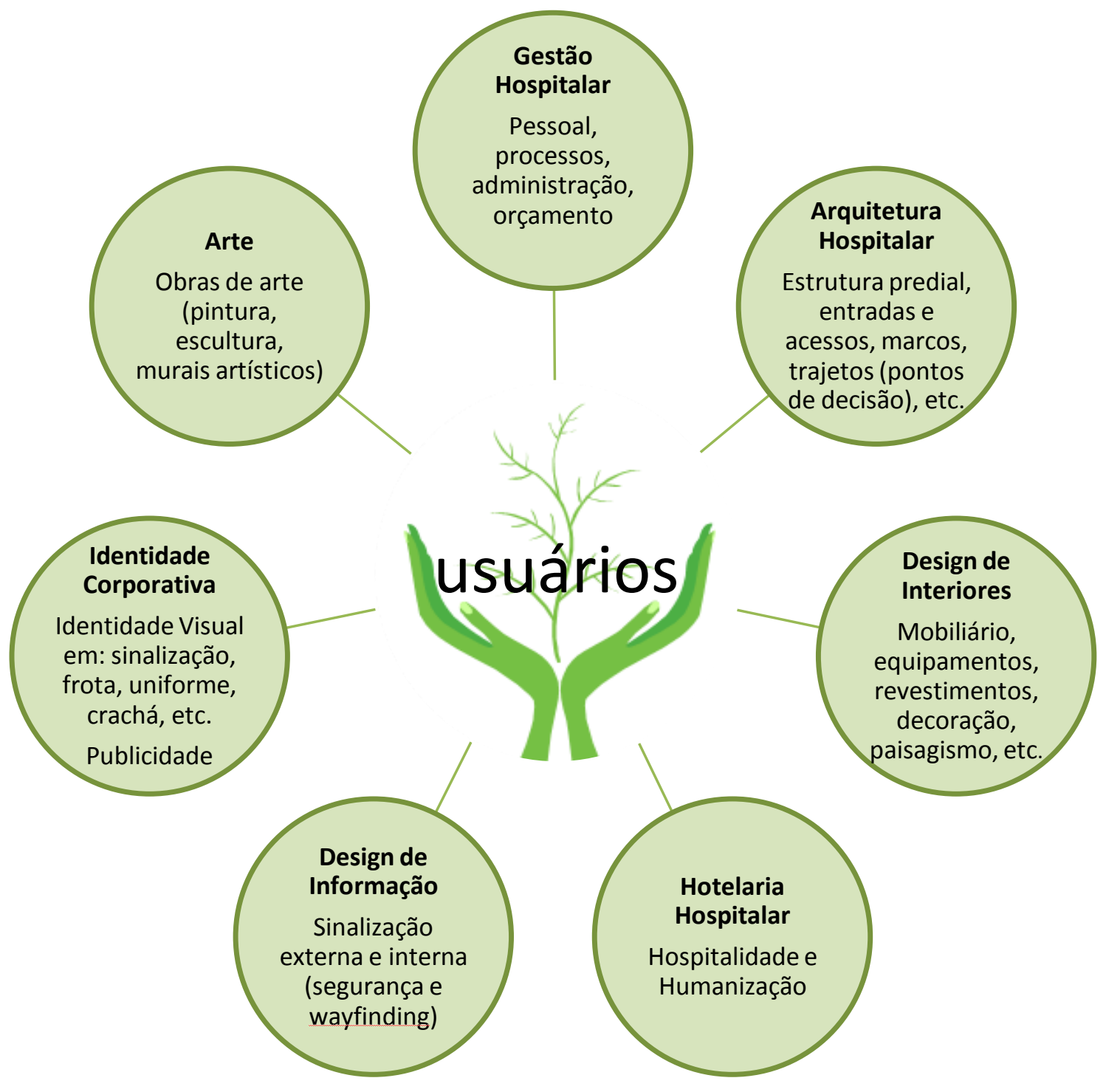

Esquema 3 - Áreas relacionadas à estrutura hospitalar

Fonte: Elaborado pela autora, fundamentado no modelo apresentado por Berger (2009, p.90)

O objetivo geral desta pesquisa foi evidenciar que o ambiente hospitalar, por ser extremamente complexo, necessita de um projeto de CV que tenha um caráter multidisciplinar. Os objetivos específicos foram verificar os elementos que compõem um sistema de CV para hospitais; identificar características específicas em seus ambientes que necessitem de CV; identificar como a CV 
se insere nesse contexto, se tem sido tratada de forma diferenciada e, sobretudo, se há um campo específico (ou uma especialização) da CV para atender as necessidades do setor hospitalar (como vem ocorrendo com outras áreas). Partiu-se da hipótese de que um sistema de CV específico para hospitais tem que ser complexo e diferenciado e envolver conhecimentos de várias áreas.

A metodologia adotada partiu de uma pesquisa bibliográfica abordando áreas que estão se especializando em ambientes hospitalares, tais como Arquitetura, Hotelaria e Gestão. Essas referências possibilitaram uma compreensão das características do hospital, sobretudo quanto à sua estrutura física, organização funcional e infraestrutura. Esses estudos preliminares permitiram observar como outras áreas têm se estruturado para atuar nesse amplo e diferenciado sistema.

Dada a complexidade do tema, não existe uma literatura consolidada quanto a referências específicas sobre $\mathrm{CV}$, como um todo, para esse ambiente. Estudos mais recentes, tanto internacionais quanto nacionais (LEWIS, 2010; MOLLERUP, 2009; GUIMARÃES, 2006; MCLAUGHLIN; MCNEIL; SEBALD, 2005) abordam questões sobre sinalização de orientação de fluxo (wayfinding / wayshowing), mas não mencionam as demais funções e peças de CV. Há estudos sobre a compreensibilidade de símbolos gráficos utilizados em hospitais para uma melhor e mais rápida identificação de seus setores. Esses estudos avaliam a diferença de entendimento de acordo com a cultura dos usuários e quais os pictogramas mais indicados, sobretudo em casos de usuários que tenham dificuldades com o idioma (GAKOPOULOS, 2009; ROJAS ARAYA, 2007; CASTRO; ROSÉ, 2006; COWGILL; BOLEK, 2003; FORMIGA, 2002).

Esta pesquisa teve como fonte de consulta revistas especializadas direcionadas a fornecedores e hospitais (nacionais e internacionais); catálogos de equipamentos e de materiais para construção de hospital; revistas de informação geral (Isto é; Veja; Exame; Revista da Folha de São Paulo; América Saúde); sites de hospitais, de agências envolvidas com a sinalização de algum hospital e da Hospitalar (feira internacional de produtos, equipamentos, serviços e tecnologia para hospitais, laboratórios, farmácias, clínicas e consultórios), realizada anualmente em São Paulo. Neste (www.hospitalar.com) 
são divulgadas, semanalmente, informações sobre o que acontece no setor e, dentre elas, destacam-se, para o âmbito deste trabalho, as que se referem a mudanças de logotipo e de projeto de sinalização; ampliações de espaços e setores; conquistas de selos de acreditação.

É difícil obter informações sobre quem faz CV em hospitais, pois a divulgação é feita, geralmente, pelos fornecedores, mais do que pelos próprios hospitais. Mesmo as ações divulgadas parecem isoladas, pois não apresentam exemplos precisos do trabalho realizado, ficando, portanto, difícil verificar como foi estruturado o projeto e sua sistematização.

As visitas realizadas a alguns hospitais de São Paulo foram úteis para observação e prospecção. Os hospitais visitados, em sua maioria, não apresentavam um sistema de CV estruturado, sobretudo os que tinham passado por reformas para ampliação.

O levantamento de dados foi inviabilizado por causa da dificuldade de acesso às informações de fonte primária, tendo sido necessário recorrer-se a fontes indiretas para obtenção de instrumentos de exemplificação. Isso gerou mudanças de planos e optou-se pelo levantamento iconográfico, utilizando referências disponíveis em meios impressos e digitais, o que levou à elaboração de um banco de dados visuais para caracterizar os elementos da teoria nas imagens obtidas. O resultado foi uma coleção de dados de natureza variada, originados das pesquisas (bibliográfica, de campo e iconográfica).

Em campo, o acesso às informações em ambientes hospitalares está relacionado a aspectos de segurança operacional, o que compromete a divulgação da produção do conhecimento acadêmico. A visualidade disponibilizada pelas instituições hospitalares não apresenta uniformidade, sendo que as informações mais completas são disponibilizadas por fornecedores e produtores de comunicação. A contribuição desta pesquisa, que assumiu um caráter exploratório, está na organização dos estudos na interface de Comunicação Visual aplicada a outras áreas, pois hospitais são organismos complexos, dinâmicos e flexíveis que exigem soluções que acompanhem e respeitem essas características.

Esta tese foi estruturada em quatro capítulos. O primeiro aborda questões específicas sobre hospitais, sempre de modo geral, sem fazer distinções sobre se são públicos ou particulares, nem quanto a suas especialidades. Procurou- 
se levantar características e especificidades desses ambientes (organização físico-funcional e público que circula), que hoje se assemelham a hotéis ou a um lar, procurando dar conforto, segurança e qualidade aos clientes de saúde. A Hotelaria Hospitalar desempenha importante papel nesse setor, pois propicia hospitalidade e humanização e oferece serviços diferenciados que podem fazer com que um hospital seja diferenciado perante os demais concorrentes, sobretudo no caso de hospitais particulares. O hospital pode ser considerado um ambiente terapêutico, principalmente porque seus espaços podem influenciar o estado de saúde (física e emocional) das pessoas que 0 frequentam.

No segundo capítulo foram abordadas questões sobre as especificidades da $\mathrm{CV}$ em ambientes hospitalares, considerando os diferenciais para esse setor (flexibilidade dos espaços para atender as demandas tecnológicas; necessidade de atender normas específicas; uso de materiais que possibilitem fácil manutenção e limpeza; linguagem visual eficiente; posicionamento das peças de CV em locais estratégicos). A CV pode tornar o ambiente hospitalar mais agradável e acolhedor, fazendo com que usuários se sintam bem recebidos, bem como estimular os sentidos e contribuir com o tratamento. Informações bem organizadas e sistematizadas podem dar segurança e autonomia aos usuários, propiciando conforto. Alguns setores (como: salas de raio X; UTI; Pronto Atendimento) necessitam de informações mais detalhadas e específicas sobre procedimentos e atitudes a serem tomadas. No geral, em todos os espaços de um hospital é importante manter certos hábitos (como higienização das mãos, por exemplo), o que pode ser reforçado e lembrado aos usuários por meio da CV. O uso de cores pode auxiliar um usuário a identificar mais facilmente diversos setores ou localizar seu destino.

O terceiro capítulo aborda a questão da ambiência enquanto conjunto de fatores e elementos a serem considerados para transformar o ambiente, tornando-o agradável e acolhedor. Planejar essa ambiência envolve várias áreas: CV, Design de Interiores, Arquitetura, Engenharia, Gestão, Hotelaria etc. Esse trabalho multidisciplinar pode dar mais comodidade aos usuários do ambiente hospitalar.

O quarto capítulo procurou exemplificar como a CV pode auxiliar a construir a ambiência hospitalar, apontando aspectos internos de apresentação de um 
hospital e externos (entorno, fachada, entradas, estacionamento). Os elementos de CV podem se constituir como reveladores de hospitalidade e humanização da instituição.

O resultado desta pesquisa mostrou evidências de que a CV em hospitais pode se constituir como um campo específico, tanto acadêmica quanto profissionalmente. Algumas empresas já estão tomando a frente e especializando-se nesse campo, trabalhando basicamente apenas com hospitais, como é o caso das empresas norte-americanas Aesthetic Inc. e fd2s, que contam com uma equipe multidisciplinar para desenvolver tais projetos. 


\section{CAP. 1 HOSPITAL: CENTRO PROMOTOR DE SAÚDE}

\subsection{Estabelecimentos Assistenciais de Saúde (EAS)}

Sob a denominação geral de Estabelecimentos Assistenciais de Saúde (EAS) encontram-se, no Brasil, todas as "edificações destinadas à prestação de assistência à saúde à população, que demande o acesso de pacientes, em regime de internação ou não, qualquer que seja o seu nível de complexidade" (BRASIL, 1994, p. 6). Os EAS são classificados e hierarquizados por níveis de complexidade (baixa - atenção básica; média; alta) os quais aumentam na medida da aptidão para atender procedimentos e/ou diagnósticos mais complexos.

De acordo com o Ministério da Saúde, as unidades de saúde são distribuídas segundo diferentes níveis de complexidade de serviços da seguinte forma: posto de saúde; centro de saúde; centro regional de especialidades (ambulatório de especialidades); unidade mista; hospital local; hospital regional; hospital especializado; hospital de base ou macrorregional. $\mathrm{O}$ critério para que um EAS seja classificado como hospital, qualquer que seja seu perfil, é, de maneira geral, sua capacidade de "internar" os pacientes, por um curto período, como ocorre nos Serviços de Pronto Atendimento (SPA), ou por longos períodos, nos hospitais de apoio, de crônicos ou em unidades especializadas na recuperação de agravos ao aparelho locomotor (TOLEDO, 2002, p. 60). A palavra "hospital", neste trabalho, é utilizada de modo amplo, abrangendo qualquer tipo acima citado.

O "grau" de gravidade e complexidade do problema que cada enfermo apresenta pode variar de acordo com diversos fatores a ele associados. Os procedimentos a serem realizados dependem justamente desse "grau", pois a instituição hospitalar tem uma dimensão abrangente constituída de vários setores, que podem ser agrupados em duas linhas fundamentais: tratamento (envolvendo diagnose, reabilitação, assistência, prevenção) e educação (envolvendo questões de ensino, pesquisa e divulgação de conhecimentos 
técnicos e científicos), conforme mostra o Esquema 4.

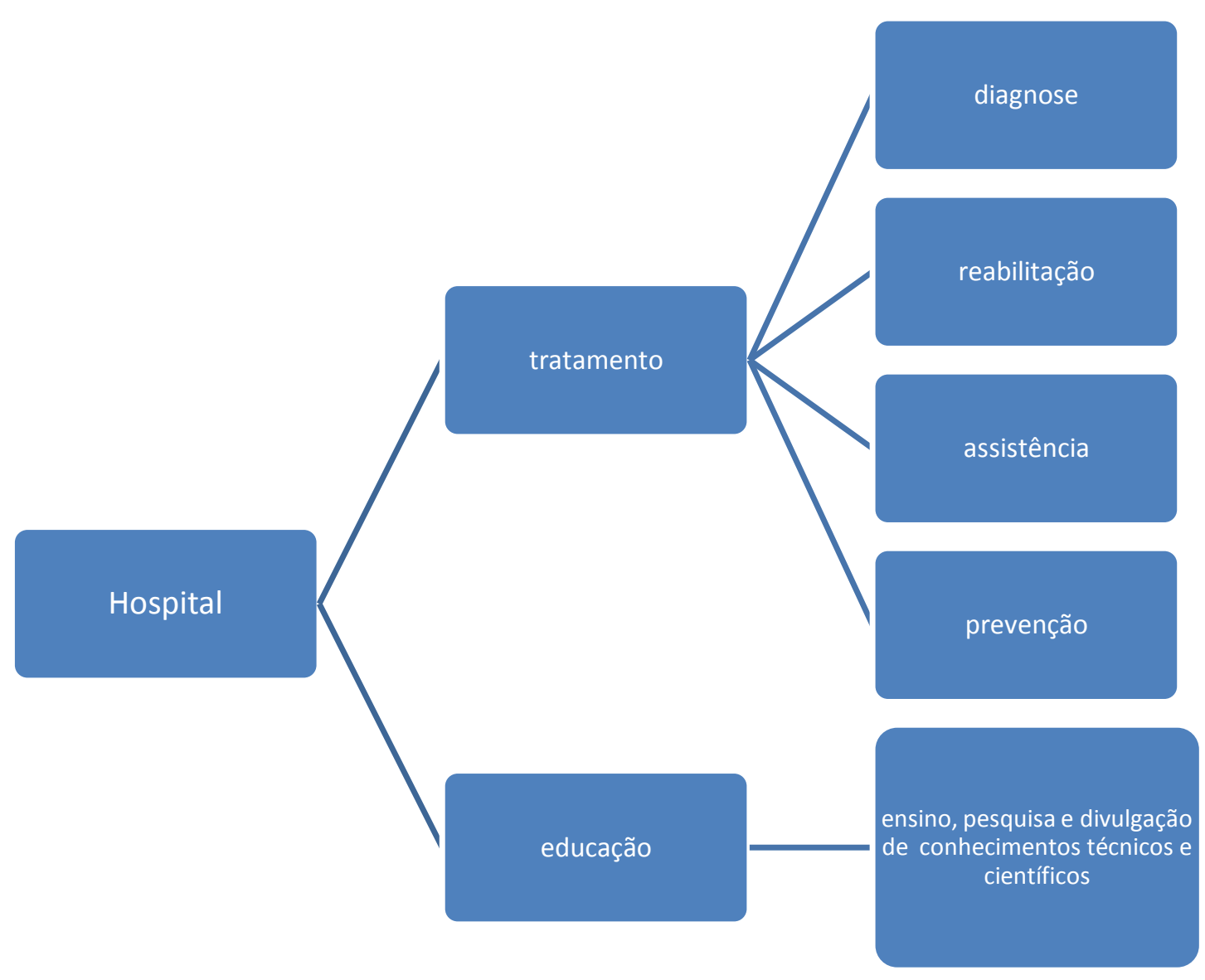

Esquema 4 - Funções do hospital

Fonte: Elaborado pela autora

De acordo com Góes (2004), para o Ministério da Saúde, um hospital é

(...) parte integrante de uma organização médica e social, cuja função básica consiste em proporcionar à população assistência médica integral, curativa e preventiva, sob quaisquer regimes de atendimento, inclusive o domiciliar, constituindo-se também em centro de educação, capacitação de recursos humanos e de pesquisas em saúde, bem como de encaminhamento de pacientes, cabendo-Ihe supervisionar e orientar os estabelecimentos de saúde a ele vinculados tecnicamente. (GÓES, 2004, p. 7)

Percebe-se por essa definição que hoje a pesquisa e a educação ocupam lugar de destaque no setor hospitalar. O conceito de hospital como instituição 
destinada apenas a cuidar da saúde dos pacientes tem origens muito remotas. As primeiras instituições destinadas a receber pessoas doentes foram os templos, conventos e mosteiros; "as organizações especificamente médicas surgem, por motivos de ordem econômica e militar, no Império Romano" (ZOBOLI, 2004, p. 13). Estas se situavam em pontos distantes dos centros mais movimentados dos acampamentos romanos e serviam como abrigo de legionários feridos e para seu socorro.

(...) Eram fortificações que possuíam um formato quadrado dividido em quatro pelo cruzamento de duas vias principais. Na parte direita superior ficava a enfermaria, a Valetudinaria, responsável pelo cuidado das pessoas, afastadas do Veterinarium, local de cuidado dos animais, e das oficinas que ocupavam o canto superior esquerdo. Havia ainda localizado junto à entrada, o espaço que abrigava as funções de administração e serviços gerais. (SAMPAIO, 2005, p. 84)

$\mathrm{Na}$ ldade Média o hospital servia como abrigo de doentes, viajantes e pobres e não existiam as funções de curar e tratar como são entendidas atualmente. A Figura 1 mostra a representação de um hospital medieval da França, construído no séc. $\mathrm{XV}$, destinado a pobres e doentes.

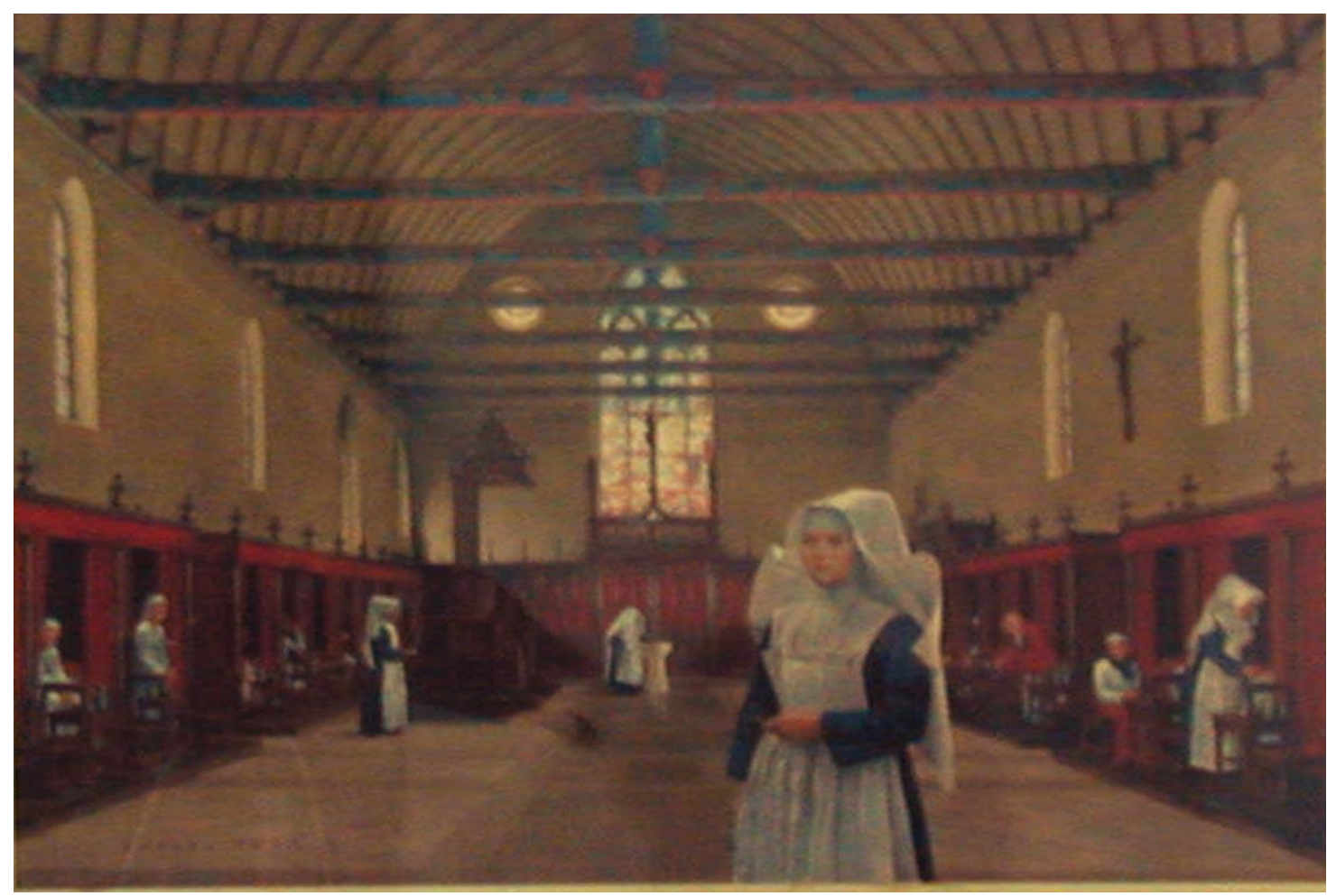

Figura 1 - Representação do Hotel-Dieu de Beaune

Fonte: unw.dodd.cmcvellore.ac.inhom/10\%20-\%20Medieval\%20Hospital.html 
A função dos hospitais era "servir como estrutura de separação e exclusão, isolando os mais pobres e os enfermos da sociedade, de forma a minimizar eventuais riscos sociais e epidemiológicos" (TOLEDO, 2002, p. 13). Os enfermos eram levados para esses locais para que ficassem isolados em virtude de surgimento de moléstias repugnantes e doenças deformantes que atemorizavam a todos (BOERGER, 2005, p. 19), mas não havia técnicas e exigências específicas para a arte de cuidar dos doentes, qualquer pessoa poderia fazer esse serviço (QUINTINO, 2008, p. 21). Os doentes que tinham recursos financeiros eram tratados em suas casas; os hospitais eram destinados aos doentes sem condições financeiras (DIAS, 2005).

(...) O personagem ideal do hospital até o século XVIII, não é o doente que é preciso curar, mas o pobre que está morrendo. $\mathrm{E}$ alguém que deve ser assistido material e espiritualmente, alguém a quem se deve dar os últimos cuidados e o último sacramento. Esta é a função essencial do hospital. Diziase correntemente, nessa época, que o hospital era um morredouro, um lugar onde morrer. (FOUCAULT, 1989, p. 100)

Os hospitais mantiveram um caráter de entidade promotora de assistência social durante quase toda a Idade Moderna.

Durante muito tempo, as instituições hospitalares destinaram-se apenas ao abrigo de peregrinos, viajantes, pobres e, eventualmente, enfermos. O termo hospital era relativo a hóspedes, hospedagem, finalidade à qual a instituição se destinou por vários séculos. As primeiras instituições destinadas ao diagnóstico e tratamento de doenças foram registradas somente no final do século XVIII, quando estas edificações começaram a apresentar condições ambientais adequadas ao restabelecimento dos pacientes. (MATOS, 2008, p. 14)

De acordo com Foucault (1989, p. 99), "o hospital como instrumento terapêutico é uma invenção relativamente nova, que data do final do século XVIII". A partir de uma série de viagens de pesquisa, a França buscou uma padronização para os hospitais existentes.

A presença do médico como profissional da saúde, deslocando-se para atender individualmente os doentes transformou o hospital em "local de sabedoria e de estudos". Durante o séc. XIX, vários acontecimentos na área médica (descobertas de Pasteur e Koch; uso de métodos assépticos e antissépticos para redução de mortes por infecção; surgimento da anestesia, alterando os procedimentos de realização de cirurgias sem dor e com maior possibilidade de 
êxito) contribuíram para "modificar a imagem dos hospitais, que deixaram de ser um lugar onde os pobres e necessitados iam para morrer, tornando-se, ao invés disso, um local de cura" (MORAES; CÂNDIDO; VIERA, 2004, p. 40).

Atualmente, o paciente é encaminhado conforme demanda a gravidade de seu problema de saúde e em função de suas necessidades. Quanto maior a gravidade da doença, mais é possível verificar um aumento das rotinas hospitalares. Nos casos de atendimento de emergência, por exemplo, devido ao alto grau de gravidade, a estrutura operacional básica deve possibilitar que os processos sejam desenvolvidos com rapidez para que as atividades complexas e de alto risco possam ser cumpridas com eficiência.

O objetivo de um hospital não é somente cuidar de doenças, mas sim, do ser humano, seja em termos de tratamento e cura seja em termos de prevenção de doenças. Para prestar atendimento seguro e de qualidade aos pacientes, os hospitais têm investido em reciclagem e modernização, garantindo o aprimoramento constante e a capacitação de seu corpo funcional, com infraestrutura adequada para a prática de atividades médicas. Vários hospitais têm seus próprios institutos de pesquisa para atualizar suas equipes médicas e divulgar conhecimentos para a comunidade por meio de eventos e cursos.

Os hospitais transformaram-se em centros promotores de saúde, que oferecem a seus clientes bem-estar, hospitalidade, conforto, segurança e qualidade, a fim de atender suas expectativas e necessidades. Para isso, várias alterações têm sido feitas em seus espaços que, cada vez mais modernos, aliam à tecnologia de ponta uma relação mais humanizada com os usuários. Sobretudo hospitais particulares procuram ser, hoje, edifícios funcionais refletindo sofisticação e elegância ao mesmo tempo em que cumprem normas e leis específicas.

$\mathrm{O}$ ambiente externo harmoniza-se com a paisagem urbana enquanto $\mathrm{o}$ interno torna-se cada vez mais acolhedor, iluminado, colorido, bem decorado, com mobiliário e equipamentos que asseguram novos padrões de versatilidade e conforto. Nesses hospitais (de uniformes a equipamentos de alta tecnologia), tudo passou a receber um toque mais humano para suavizar sua aparência. Nas figuras abaixo temos como exemplo o Evergreen Hospital Medical Center, em Kiriland, Estados Unidos. Em seus espaços internos, a utilização de vidros (Figura 2) relaciona interior e exterior. Corredores do Departamento de Cirurgia e Emergência são bem amplos e iluminados, com cores suaves (Figura 3). 


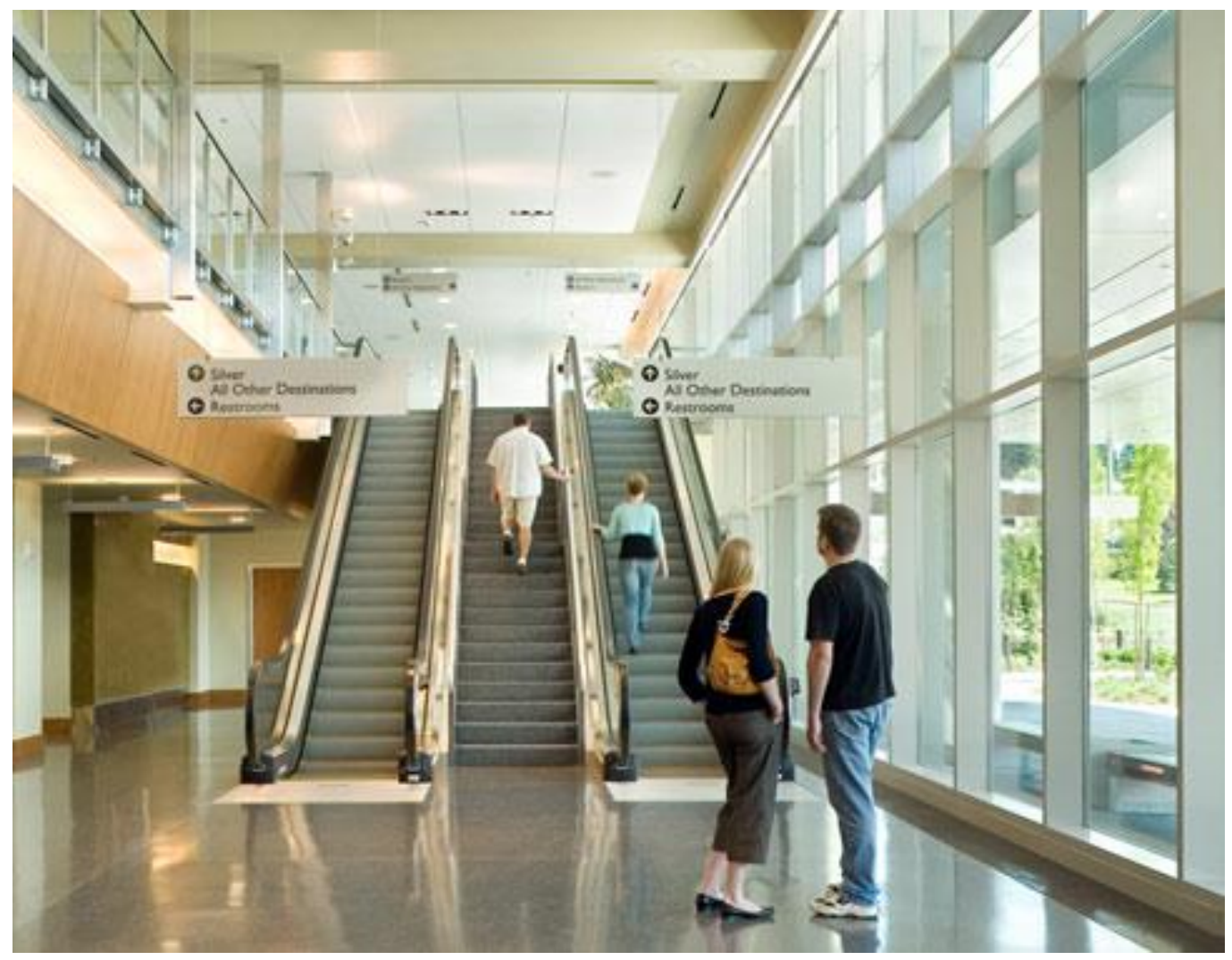

Figura 2 - Evergreen Hospital Medical Center

Fonte: www.mahlum.com/projects/evergreenindex.asp\#

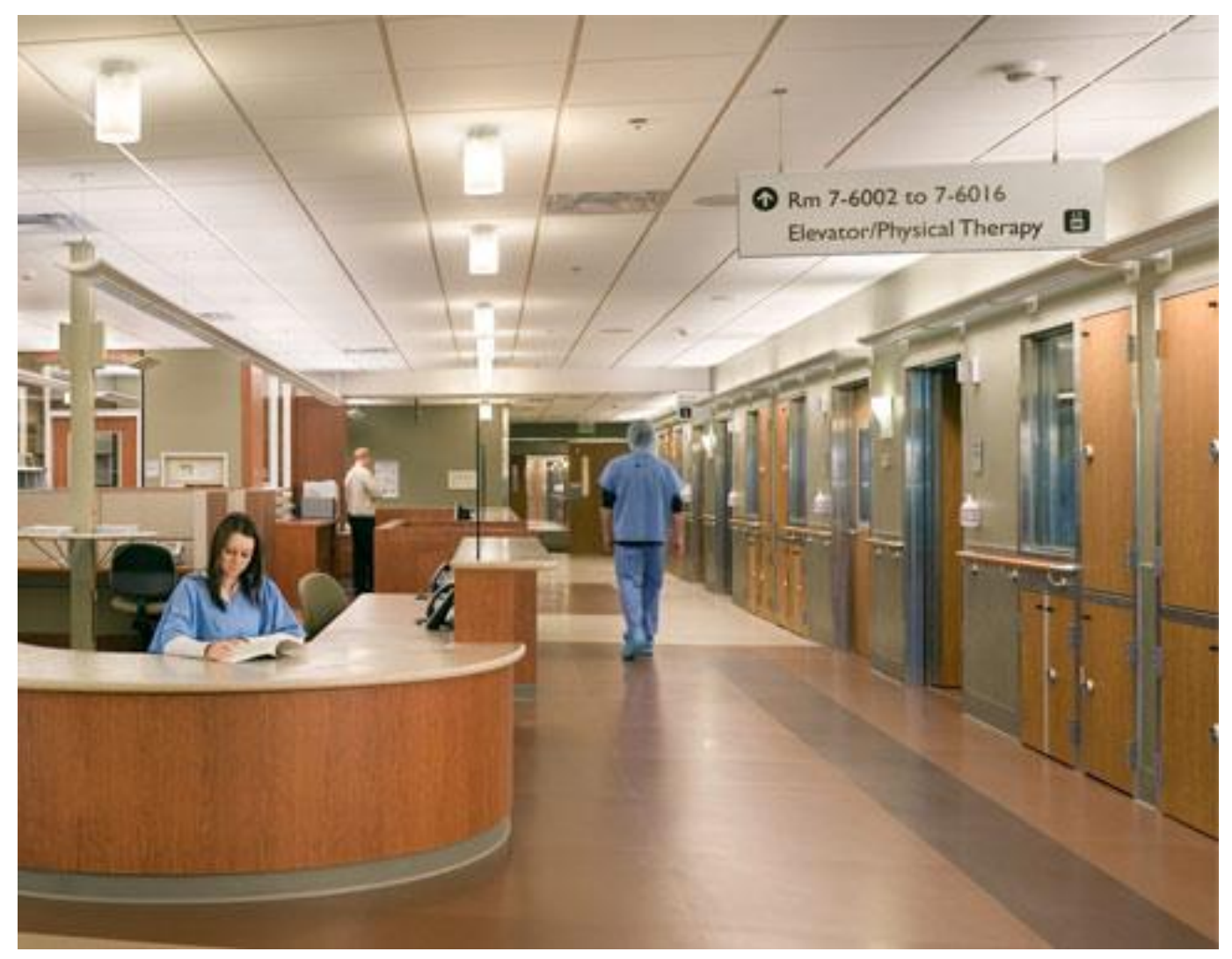

Figura 3 - EHMC: Dep. Cirurgia e Emergência Fonte: unw.mahlum.com/projects/evergreenindex.asp\#

Os edifícios hospitalares são complexos, têm funcionamento intenso e contínuo 
durante as 24 horas de todos os dias do ano. Possuem instalações de grande porte, alto número de pessoas circulando, distintos centros de trabalho que abrigam atividades teperâuticas (consultas, diagnósticos e tratamento, internação, atendimento crítico em Pronto Atendimento, Centro Cirúrgico, Unidade de Terapia Intensiva) além de atividades de áreas administrativas e de serviços de infraestrutura. Todos esses aspectos fazem com que os hospitais representem grandes estruturas edificadas, o que requer grandes áreas de construção, como se pode notar pela Figura 4.

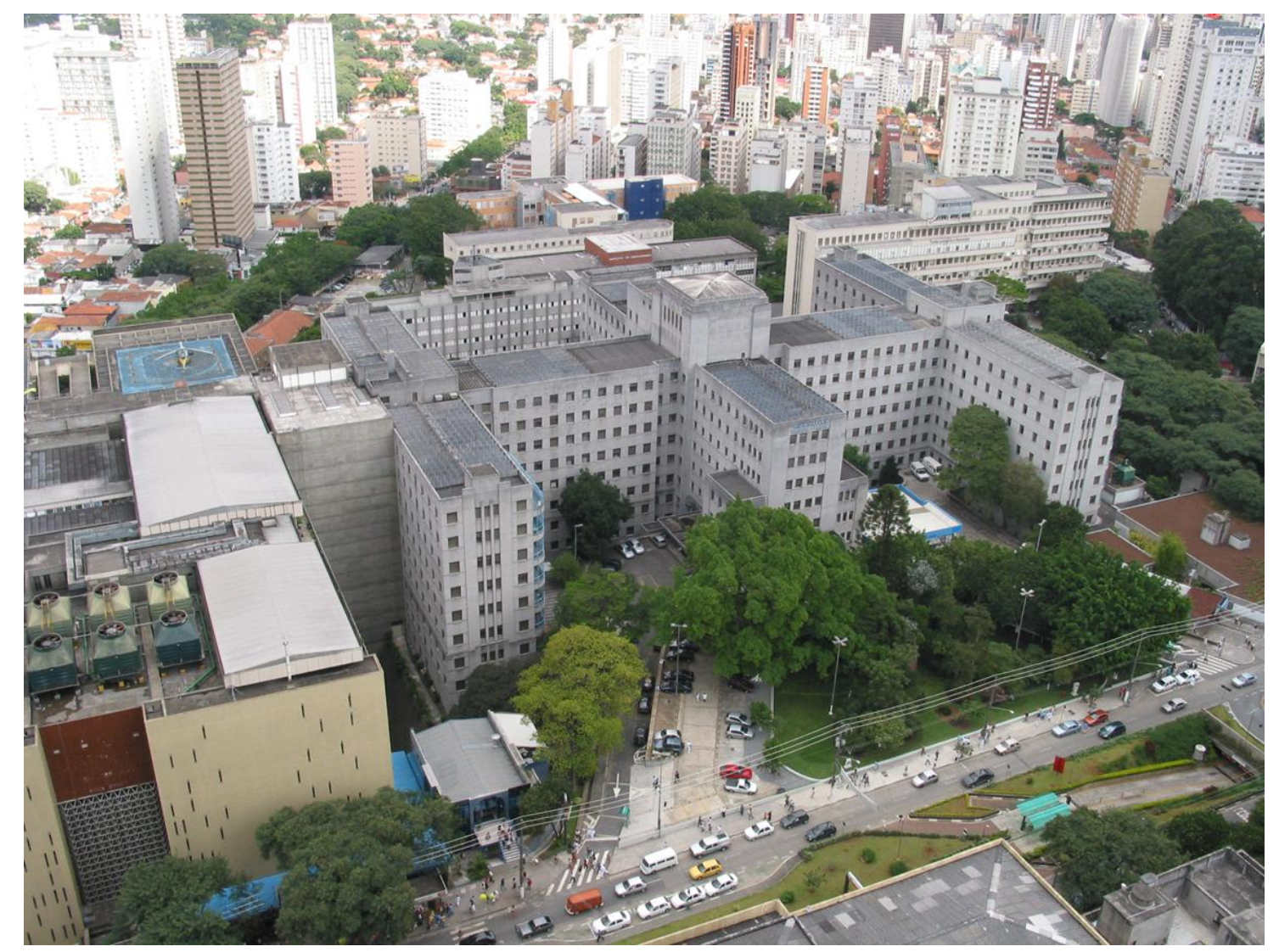

Figura 4 - Vista aérea do Hospital das Clínicas - SP

Fonte: uww.hcnet.usp.br/banco_imagens/pg/aerea_hcimusp.jpg 


\section{2 É hospital, mas não parece}

As fachadas e toda a estrutura de alguns hospitais de ponta muitas vezes enganam quem as vê, pois são semelhantes às de hotéis (como mostra o exemplo na Figura 5). Assim acontece também com os ambientes internos e

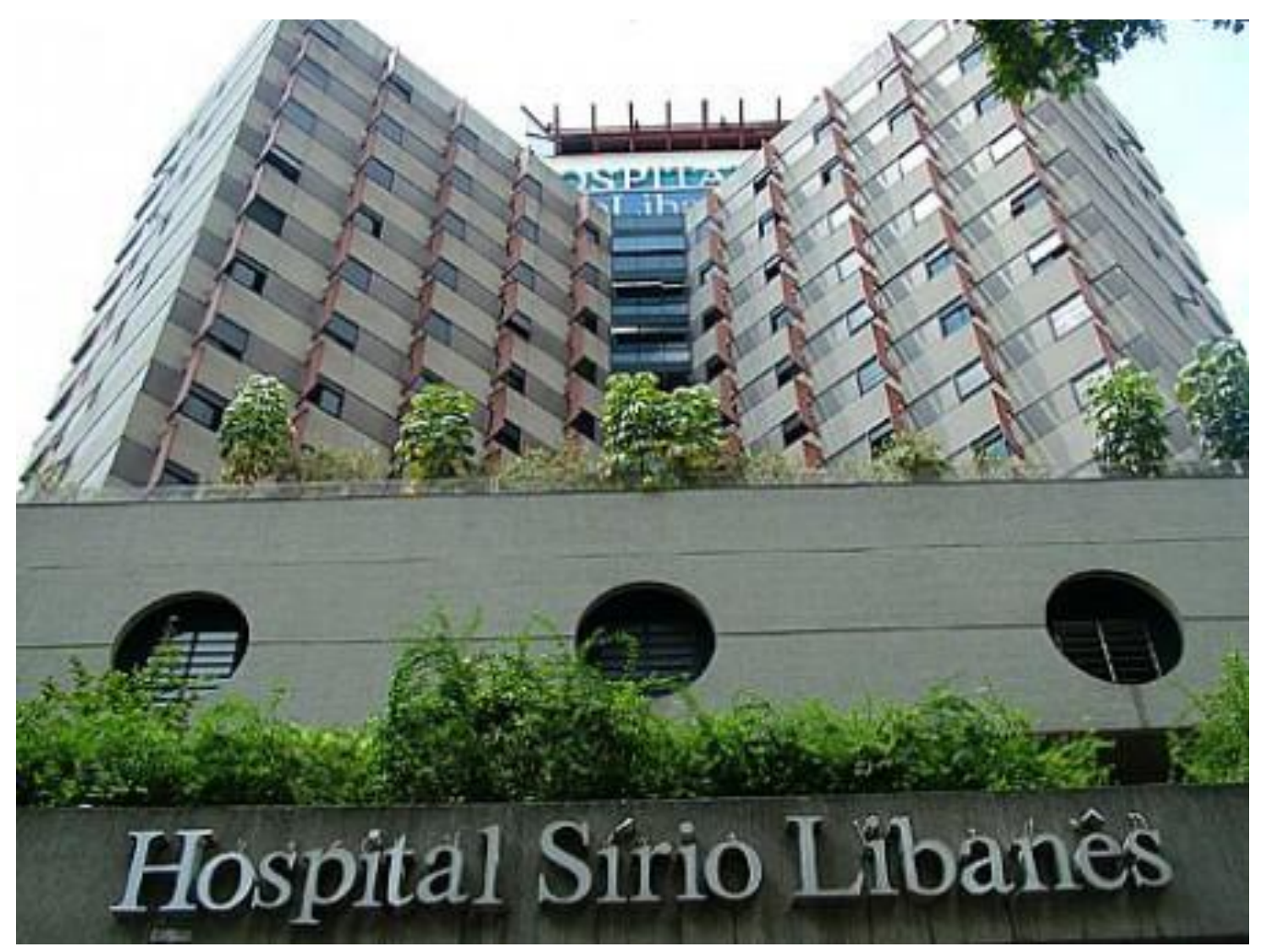

Figura 5 - Fachada do Hospital Sírio-Libanês

Fonte: mtcbrasil.webnode.com.br/album/galeria-de-fotos/hospital-siniolibanes-fachada-jpg/

com o atendimento e com os serviços prestados, baseados nas concepções de hotelaria. Luxo e conforto nas instalações e excelência no atendimento humano estão presentes no novo perfil dos hospitais de ponta (GODOI, 2008, p. 57).

Mudanças arquitetônicas, programação social, serviços de hotelaria com capitão-porteiro e mensageiros devidamente uniformizados e equipados para a recepção do cliente de saúde, quadros em exposição, música ambiente, restaurante, piano-bar e apresentações de músicos (piano e violino) dão a impressão de se ter errado de endereço. Quem entra pelo lobby (saguão) de alguns hospitais particulares tem a sensação de estar num ambiente de hotel de primeira linha. Macas, clientes de saúde aglomerados à espera de atendimento, cadeiras de rodas enfileiradas, ambiente frio e com cheiro de 
éter são cenas do passado. Com essa inovação, alguns hospitais estão deixando de ter a cara de hospital. (TARABOULSI, 2006, p. 25)

Hoje, hospital não é mais sinônimo de doença, é uma unidade de saúde, ensino e pesquisa; lugar de tratamento, cura e recuperação de pessoas que passam por momentos de instabilidade física e/ou emocional. Cada vez mais "o hospital tem deixado de ser aquele ambiente frio e impessoal, buscando uma nova imagem no mercado de serviços de saúde" (GODOI, 2008, p. 119). A preocupação é fazer com que as pessoas se sintam bem nos ambientes hospitalares, não somente as que buscam os serviços do hospital (tanto nos casos de internação quanto nos de diagnóstico, tratamento e prevenção) como também as que trabalham ou circulam em seus espaços.

Essa concepção transparece na arquitetura, na ambiência e no atendimento. A apresentação de um ambiente visualmente organizado e limpo mostra uma concepção de saúde e não de doença (GREVY; GUIMARÃES; VENDRAMINI, 2007). Isso faz com que a "nova cara" dos hospitais expresse a nova mentalidade que permeia essa mudança.

Segundo Bitencourt (2008, p. 33), hospital é uma instituição para "defender a vida e a saúde das pessoas", conforme recomendado pela Organização Mundial da Saúde.

(...) o hospital não existe isoladamente; ao contrário, relaciona-se de maneira integrada em um sistema coordenado de unidades médicas a fim de garantir a assistência à saúde da coletividade. Dentro da estrutura do sistema de saúde, o hospital é a instituição que tem sob sua responsabilidade a recuperação do indivíduo, devolvendo-o à sociedade na melhor condição física e psicológica possível. (ZOBOLI, 2004, p. 28)

Destina-se a clientes de saúde, a fim de proporcionar-lhes prevenção, diagnóstico, tratamento e recuperação. Como menciona Toledo (2002), é um ambiente "feito para curar", que se diferencia dos demais EAS por sua resolubilidade (capacidade de receber, diagnosticar e dar seguimento ao tratamento de pacientes), porte (capacidade de atendimentos e leitos), tipologia (relacionada às atividades desenvolvidas na unidade e públicos a serem beneficiados) e área de influência da unidade (regional, distrital, nacional ou internacional). 
Em termos arquitetônicos, houve uma transformação do edifício hospitalar a partir do surgimento do hospital terapêutico, no século XVIII, e, ainda hoje, muitos arquitetos, inclusive no Brasil, têm dado valiosas contribuições para o avanço do setor com seus projetos inovadores e de alta qualidade (TOLEDO, 2002). Um destaque pode ser feito às obras do arquiteto João Filgueiras Lima, o Lelé. Utilizando recursos naturais de ventilação e iluminação, integrando interior-exterior, colocando obras de arte em locais estratégicos seus projetos são vistos como modelos para a arquitetura hospitalar no país, pois asseguram a qualidade do espaço sem elevar custos (CAVALCANTI; AZEVEDO; DUARTE, 2007, p. 10). Como exemplo (Figura 6), temos o jardim de fisioterapia do Hospital do Aparelho Locomotor (Fortaleza/CE), em que a

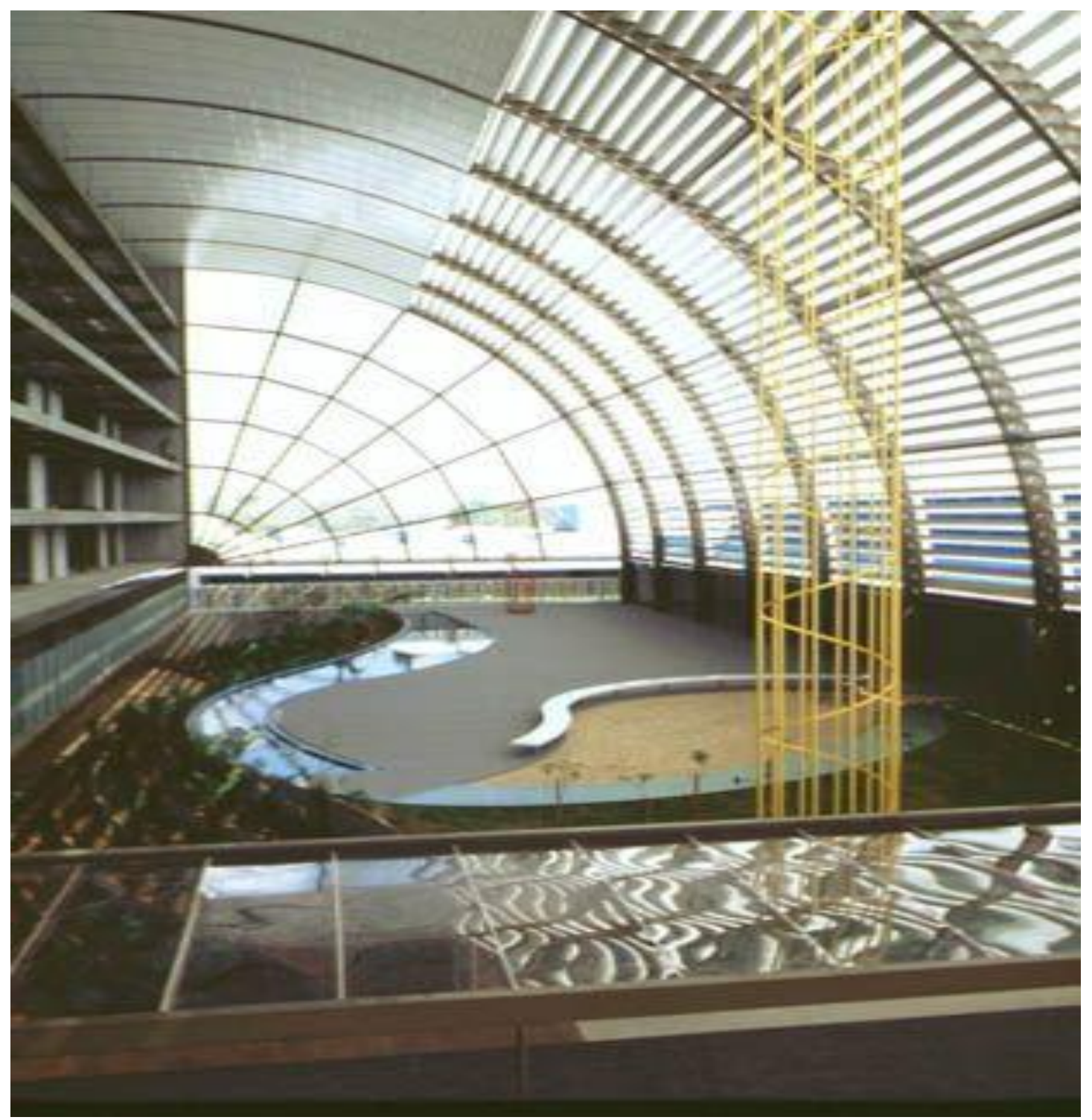

Figura 6 - Hosp. do Aparelho Locomotor

Fonte: www.ponto.org 
cobertura tipo shed possibilita a penetração de raios de luz e de ventilação, tornando o ambiente aprazível e propiciando sensações agradáveis para os usuários (DALLA, 2003, p. 34).

O planejamento de espaços requer novos requisitos de sua arquitetura (SANTOS; BURSZTYN, 2004, p. 13). Medidas estão sendo tomadas para isso, tanto com relação à questão da prevenção de infecções quanto com relação à transformação desses espaços em ambientes mais agradáveis para o público externo (paciente que se recupera e quem o acompanha) e para o público interno (pessoas envolvidas nos trabalhos dentro desses ambientes).

Pelas atividades que um hospital desempenha, não pode ser associado a um ambiente desagradável, ou a um local de medo, insegurança e dor. As interferências arquitetônicas e visuais estão auxiliando nesse requisito, como mostra o exemplo da Figura

7 (Abbotsford Regional Hospital \& Cancer Centre). Uma recepção com espaços amplos, presença de vidros iluminando o ambiente com luz natural, cores em vidros nas paredes, piso também colorido fazem um conjunto para dar um toque mais humanizado.

Independente de seu tamanho, um hospital é um organismo complexo; por isso, além da necessidade de um planejamento para sua estrutura física, é preciso haver cuidado com a forma como são

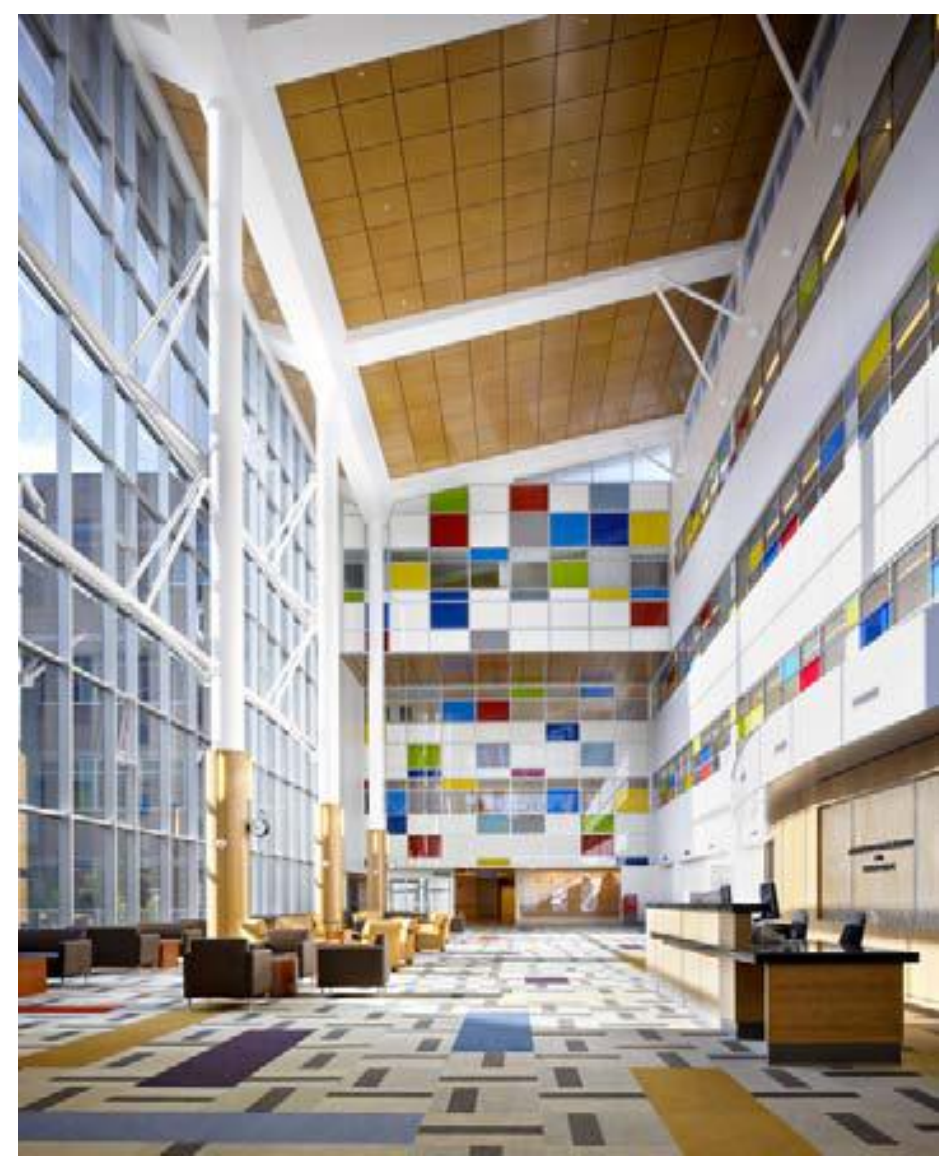

Figura 7 - Abbotsford Regional Hospital \& Cancer Centre Fonte: unw.shawcontractgroup.com/Content/ProjectProfiles/PDFs/project_abbotsf ord.pdf

oferecidos seus serviços, 
os quais passaram a se basear na hotelaria. Com estrutura similar à encontrada em hotéis de luxo, a hotelaria hospitalar oferece uma filosofia de atendimento diferenciado ao cliente de saúde.

Esse novo modelo de hospitalidade em hospitais produziu mudanças nos postos ou unidades de enfermagem com iluminação e decoração diferenciada, fuga do padrão básico de pisos comuns aos hospitais, e a utilização de temas diferentes nos andares ou unidades de internação. Os corredores e áreas de espera criam uma fuga do padrão tradicional de locais fechados com paredes vazias ou apenas televisores para distração. Os espaços procuram ser aconchegantes e reproduzem um clima de acolhimento distante do pesar comum a alguns ambientes hospitalares. Praças internas, esculturas, painéis de arte e exposições temporárias torna a espera menos desgastante e cansativa, e a circulação interna menos tensa. (GODOI, 2009, p. 84-5)

A hotelaria hospitalar ocupa-se dos serviços de apoio direcionados aos clientes de saúde referentes a seu conforto, bem-estar e segurança durante o período de internação (BOERGER, 2005, p. 24). Dessa forma, envolve serviços de recepção, alimentação, acomodação, lavanderia, estacionamento, limpeza etc. Porém, cabe salientar que, independente da internação, todas as pessoas que vão a um hospital devem ser bem acolhidas, respeitadas e bem atendidas.

\subsection{Organização físico-funcional}

Um hospital, na condição de instituição prestadora de serviços, caracteriza-se por ter estrutura dinâmica, com ritmo acelerado, atividades diversificadas, funcionamento ininterrupto todas as horas do dia, todos os dias do ano. Tratase de uma organização complexa que associa "inovações tecnológicas, serviço social, pessoal assalariado e autônomo, financiamento público e privado, missão de caridade e orientação para os negócios" (ZOBOLI, 2004, p. 143). Como cita Quevedo (2006, p. 66), é uma empresa que proporciona bem-estar e saúde fisiológica e psicológica, que tem características fora do comum, do ponto de vista administrativo, com diversas peculiaridades.

O hospital é um dos programas mais complexos a ser atendido pela composição arquitetônica. É um edifício multifacetado, onde interagem 
relações diversas de alta tecnologia e refinados processos de atuação profissional (atendimento médico e serviços complementares) com outras de características industriais (lavanderia, serviço de nutrição, transportes, etc.). (GÓES, 2004, p. 29)

De acordo com a RDC 50, de 21 de fevereiro de 2002 (BRASIL, 2002b, p. 2425), as atividades de um hospital podem ser subdivididas em:

1) atendimento em regime ambulatorial e de hospital-dia - prestação de atendimento eletivo de promoção e assistência à saúde em regime ambulatorial e de hospital-dia, incluindo atividades de promoção, prevenção, vigilância à saúde da comunidade e atendimento a pacientes externos de forma programada e continuada;

2) atendimento imediato - destinado a pacientes externos, em situações de sofrimento, sem risco de vida (urgência) ou com risco de vida (emergência);

3) atendimento em regime de internação - destinado a pacientes internos que necessitam de assistência direta programada por período superior a 24 horas;

4) apoio ao diagnóstico e terapia - prestação de atendimento de apoio contato direto com pacientes internos e externos;

5) apoio técnico - prestação de serviços com contato indireto em funções de apoio;

6) ensino e pesquisa - direta ou indiretamente ligado à atenção e assistência à saúde em funções relacionadas à formação e desenvolvimento de recursos humanos e de pesquisa;

7) apoio administrativo - prestação de serviços de apoio à gestão e execução administrativa;

8) apoio logístico - atendimento ao estabelecimento em funções de suporte operacional.

As quatro primeiras são atribuições fim, constituem funções diretamente ligadas à atenção e assistência à saúde, enquanto as outras são atribuições meio, que contribuem para o desenvolvimento das outras e de si mesmas. Essas atividades, funcionando simultaneamente, de forma harmônica, eficiente e econômica (LIMA-GONÇALVES; ACHÉ, 1999, p. 85) possibilitam a realização da dinâmica hospitalar.

Segundo a classificação do Manual Brasileiro de Acreditação (BRASIL, 2002a), os serviços de apoio técnico e abastecimento envolvem uma ação técnica 
especializada que se relaciona a processos de abastecimento, fornecimento, estocagem, produção e/ou serviços técnicos especializados de apoio e ação assistencial e equipes de profissionais para realizar a terapêutica. As seções são: arquivo médico; controle de infecções; estatísticas; farmácia; nutrição e dietética; central de processamento de roupas (lavanderia); central de processamento de materiais e esterilização; higiene; segurança e saúde ocupacional; serviço social, (idem; p. 73). Os serviços de apoio administrativo e infraestrutura se subdividem em: documentação da planta física; estrutura física; estrutura físico-funcional; sistema elétrico; manutenção geral; controle de resíduos e potabilidade da água; segurança geral (ibidem, p. 93). A seção de ensino e pesquisa tem por finalidade integrar todos os componentes que se relacionem às funções educativas e de pesquisa da instituição, tanto para treinamento funcional quanto para educação permanente, contribuindo no processo de formação de recursos humanos e gerando novos conhecimentos. Subdividem-se em biblioteca e informação científica: organização, controle de informações científicas atualizadas, disponíveis e acessíveis (ibidem, p. 103).

Pode-se extrair dessas classificações que, embora haja variações, estas podem ser consideradas como ajustes organizacionais. Porém, de maneira geral, alguns pontos são comuns em todas, o que demonstra a complexidade da estrutura necessária para o bom funcionamento de um hospital.

Do ponto de vista funcional, além das atividades nitidamente terapêuticas, de apoio ao diagnóstico e tratamento, o hospital desempenha outras funções, entre as quais as de hotelaria, desenvolvidas ao receber, hospedar e alimentar pacientes e acompanhantes, e as industriais, ao produzir, processar e distribuir diversos insumos, tais como roupas, materiais esterilizados, medicamentos e gases. (TOLEDO, 2002, p. 71)

As atividades e serviços desempenhados num ambiente hospitalar devem interagir entre si para que os objetivos organizacionais sejam atingidos (CABRAL, 2007, p. 25). Há um grande contingente de profissionais trabalhando em diversas especialidades e áreas, mas todos são essenciais dentro de um hospital (GODOI, 2008, p. 46).

As equipes de profissionais que atuam em ambientes de saúde, independente do setor, têm um papel vital, pois devem gerar confiança ao paciente e a seus familiares, além de serem tecnicamente competentes (capazes de resolver problemas emergenciais, contribuindo para amenizar as dores físicas e 
emocionais dos enfermos da melhor forma possível). A boa interação entre as equipes de profissionais do hospital e os pacientes (juntamente com as pessoas a eles ligadas) é um dos pontos-chave para transformar esse ambiente em algo mais agradável a quem está passando por momentos difíceis, sobretudo em casos mais graves de internação.

\subsection{Circulação, fluxo e comunicação}

Por ser o hospital um sistema complexo de funções inter-relacionadas, há necessidade de controle constante do movimento de pessoas e bens. Há setores em que deve haver separação ou controle dos fluxos para evitar cruzamentos ou conflitos indesejáveis. A circulação de pacientes internados em estado grave, em macas (como mostra na Figura 8), por exemplo, deve ser

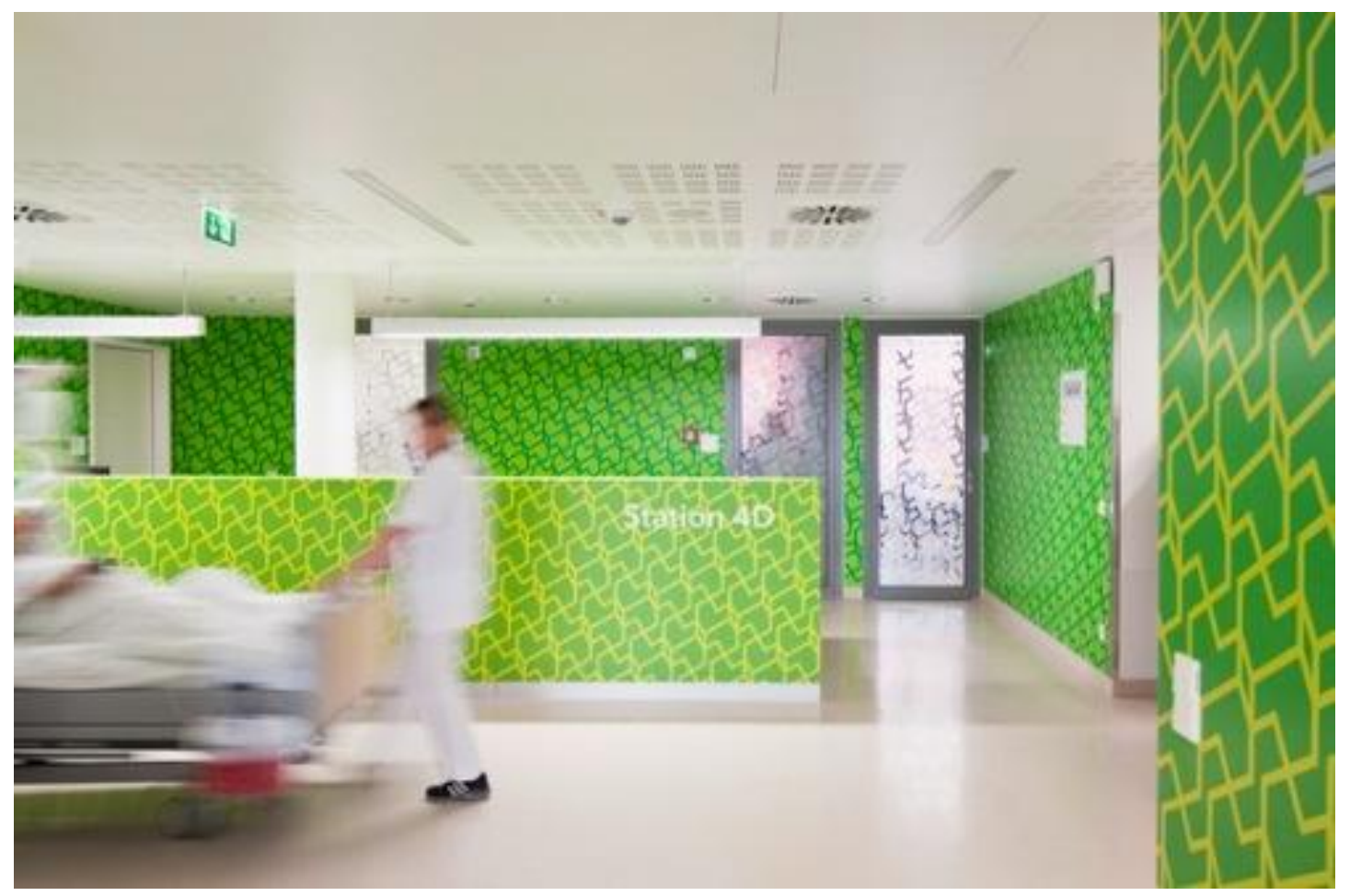

Figura 8 - Hospital Offenbach, Hessen, Alemanha

Fonte: uww.uebele.com/en/projekte/orientienungssystem/kinikum-offenbach.html

feita com cuidado, evitando-se constrangimentos ao passar por espaços em que estejam pacientes externos e acompanhantes, ou mesmo evitando 
problemas ao passar com rapidez nos casos de emergência.

Os hospitais costumam ter vários setores diferenciados, de acordo com especialidades médicas e gravidade de problemas de saúde. Sua estrutura pode ser dividida em áreas específicas (internações - quartos e enfermarias; ambulatórios; centros cirúrgicos; UTIs; análises clínicas; pronto atendimento etc.) e áreas de apoio (cozinha; lavanderia; administração; apoio logístico; recursos humanos; almoxarifado; depósito; estacionamento; farmácia etc.).

Para se determinar as relações entre essas diversas atribuições, é preciso reconhecer quem são as pessoas que circulam nesse tipo de estabelecimento, pois são elas que definem seus fluxos, circulações e acessos. Para o âmbito deste trabalho, a intenção é mostrar quanto é complexo o fluxo de pessoas nesse ambiente.

É difícil referir-se a públicos internos e externos nessa área. Considerando todas as pessoas como usuários, procuramos fazer um rol de setores, sem entrar em aprofundamentos específicos dos profissionais necessários para cada um deles. Para isso, classificamos a população que circula nesse ambiente em três categorias básicas: pacientes; funcionários /colaboradores; demais usuários.

\subsubsection{Pacientes}

Pacientes são as pessoas que estão sob cuidados médicos e podem ser externos ou internos (BRASIL, 1995, p. 40). São considerados externos os pacientes que procuram serviços ambulatoriais, laboratoriais ou mesmo de emergência, mas que não necessitem de internação. Os internos são os admitidos para ocupar um leito hospitalar por 24 horas ou mais. A internação pode ser feita em circunstância de urgência, emergência ou eletiva. Os casos de urgência são os originados por acidentes pessoais ou complicações no processo gestacional; podem ser classificados de acordo com o grau de complexidade em baixa, média (quando não há risco de morte) ou alta (quando não há risco de morte, porém o paciente apresenta um quadro crítico ou agudo). As emergências são decorrentes de risco de morte ou lesões 
irreparáveis para o paciente. O serviço de emergência deve contar com equipe multiprofissional habilitada de plantão ativo, destinada ao atendimento nas 24 horas; deve funcionar em local de uso exclusivo, dispondo de elementos de área física para as diferentes atividades de apoio diagnóstico e terapêutico, contando com equipamentos, medicamentos e materiais compatíveis com a estrutura desse serviço (BRASIL, 2002a, p. 48). As cirurgias eletivas são as programadas, que não ocorrem em razão de eventos considerados de emergência ou urgência.

Entende-se por "cliente de saúde", segundo Taraboulsi (2006, p. 23), "toda e qualquer pessoa que entra em contato com o hospital para adquirir serviço médico-hospitalar, ou simplesmente solicitar uma informação". Assim, juntamente com os pacientes, circulam no hospital seus acompanhantes, familiares e visitantes. Em casos de internação, é necessário que estes sejam identificados, geralmente com uso de crachás diferenciados, para que sua permanência e circulação possam ser controladas de acordo com normas relacionadas aos horários de visita.

\subsubsection{Funcionários / colaboradores}

Os funcionários, chamados hoje de colaboradores, podem ser subdivididos em duas seções: equipes de saúde e equipes de apoio. As primeiras, num conceito bem amplo, englobam todos os profissionais envolvidos no processo terapêutico de forma direta com o paciente (e/ou com seus acompanhantes e familiares). Independente do vínculo empregatício estabelecido com a instituição, esta categoria refere-se a: médicos, anestesistas; residentes; enfermeiros, técnicos e auxiliares de enfermagem; instrumentistas; fisiatras; fisioterapeutas; fonoaudiólogos; terapeutas ocupacionais; psicólogos; assistentes sociais; nutricionistas etc. Consideram-se aqui também os voluntários, ou seja, pessoas que desempenham funções de apoio sem vínculo empregatício com o hospital (ajudantes de forma geral, palhaços, músicos, contadores de histórias, religiosos que visitam pacientes etc.).

$\mathrm{Na}$ categoria que aqui chamamos de "equipes de apoio" encontram-se 
funcionários e/ou colaboradores relacionados aos setores de apoio à atividade hospitalar (administrativo e logístico) e aos novos setores de lazer e bem-estar para os clientes. Também não são considerados aqui os vínculos empregatícios, sobretudo pelo fato de alguns serem realizados por empresas terceirizadas.

O setor administrativo requer profissionais relacionados à administração: financeira, de materiais, de recursos humanos, de sistemas etc. O setor logístico envolve profissionais para os serviços de farmácia, laboratórios de análises e exames etc.

Os novos setores contam com pessoal de informática, marketing, comunicação, relações públicas, ouvidoria etc.. Além disso, há os serviços básicos relacionados à hotelaria hospitalar (recepção e portaria; internação, hospedagem e alta; gastronomia e gerência de alimentos e bebidas; telefonia; lavanderia e rouparia; esterilização de materiais; manutenção e zeladoria; segurança; estacionamento; higiene e limpeza etc.) e os serviços relacionados aos novos espaços e setores gerados (lojas de conveniência; floriculturas; bancas de revistas e jornais; bancos; lanchonetes, bares e/ou restaurantes; fitness centers, galerias de arte etc.).

Os funcionários/colaboradores podem ser identificados por uniformes e/ou crachás, dependendo do setor em que trabalham. Isso facilita visualmente o reconhecimento das funções que desempenham e as eventuais diferenciações de setores aos quais se relacionam.

\subsubsection{Demais usuários}

Há uma circulação a mais de pessoas que não se encaixam como pacientes (ou clientes de saúde) nem como funcionários de um hospital. Nessa categoria encontram-se: doadores (pessoas que doam voluntariamente insumos humanos com fins terapêuticos, como sangue e leite); vendedores e fornecedores (de equipamentos, medicamentos, roupas, móveis etc.); prestadores de serviço; visitantes, conferencistas, instrutores ou convidados; público para palestras etc. 
Cada hospital deve ter uma forma de identificar as pessoas, de modo geral, dependendo do setor a que elas pretendem ir. Essas identificações servem para evitar circulações em áreas de acesso restrito, garantindo a segurança para quem circula e para o próprio hospital.

Todos os envolvidos nesse processo de produção de saúde são valorizados no projeto de concepção do ambiente hospitalar, pois o propósito é dar qualidade de vida às pessoas que circulam por seus espaços, cuidar da vida que se encontra em risco evidente e preservar a vida humana. Assim, não há uma preocupação apenas com os pacientes, seus familiares, acompanhantes e/ou visitantes. Esta se estende também aos provedores da assistência (médicos, demais profissionais de saúde, equipes de apoio administrativo, logístico, técnico e de ensino e pesquisa); doadores (de sangue e de leite); alunos (de graduação e de pós-graduação); fornecedores e vendedores de materiais e de serviços; visitantes (conferencistas, instrutores, convidados). A CV pode auxiliar nesse processo de concepção do ambiente hospitalar, pois sistematiza as informações necessárias a todos os usuários.

\subsection{Turismo de saúde e expansão dos hospitais}

Os hospitais brasileiros de ponta estão atraindo pacientes de várias partes do mundo. O chamado "turismo de saúde" ou "turismo médico" é uma atividade econômica que envolve o setor da saúde e o do turismo e está movimentando o mercado internacional de trocas de serviços de saúde e de bem-estar (GODOI, 2009, p. 14). Além dos custos, as razões para a prosperidade do turismo de saúde são fatores como avanço tecnológico e científico, perspectiva maior de vida, preocupação com a saúde, a estética e a qualidade de vida (TARABOULSI, 2006, p. 174).

O turismo de saúde envolve também movimentação interna no país, uma vez que muitas pessoas procuram tratar-se em grandes centros, o que requer, às vezes, viagens a outros estados ou cidades. Alguns hospitais decidiram investir nesse novo filão em busca de atender o mercado interno e externo; para isso, destinam recursos em pesquisa, capacitação profissional, equipamentos de 
última geração, adequações de seus funcionários para receberem estrangeiros e ampliações de seus espaços e instalações. Procuram adequar-se às exigências de certificações internacionais como o selo da Joint Comission International para dar "garantia a pacientes do mundo inteiro de que o hospital em questão atende aos padrões mais elevados da medicina internacional" (CABRAL; 2009, p. 8).

O cenário desses hospitais está mudando para poder atender esses novos clientes de saúde que vêm, basicamente, dos Estados Unidos, França, Angola, Alemanha, Paraguai e Argentina em busca de especialidades como oncologia, urologia, cardiologia e ortopedia. Para dar atendimento a esses novos clientes, uma das alterações a serem feitas diz respeito à comunicação. $O$ sistema de sinalização passa a ter referências também em inglês (Figura 9).

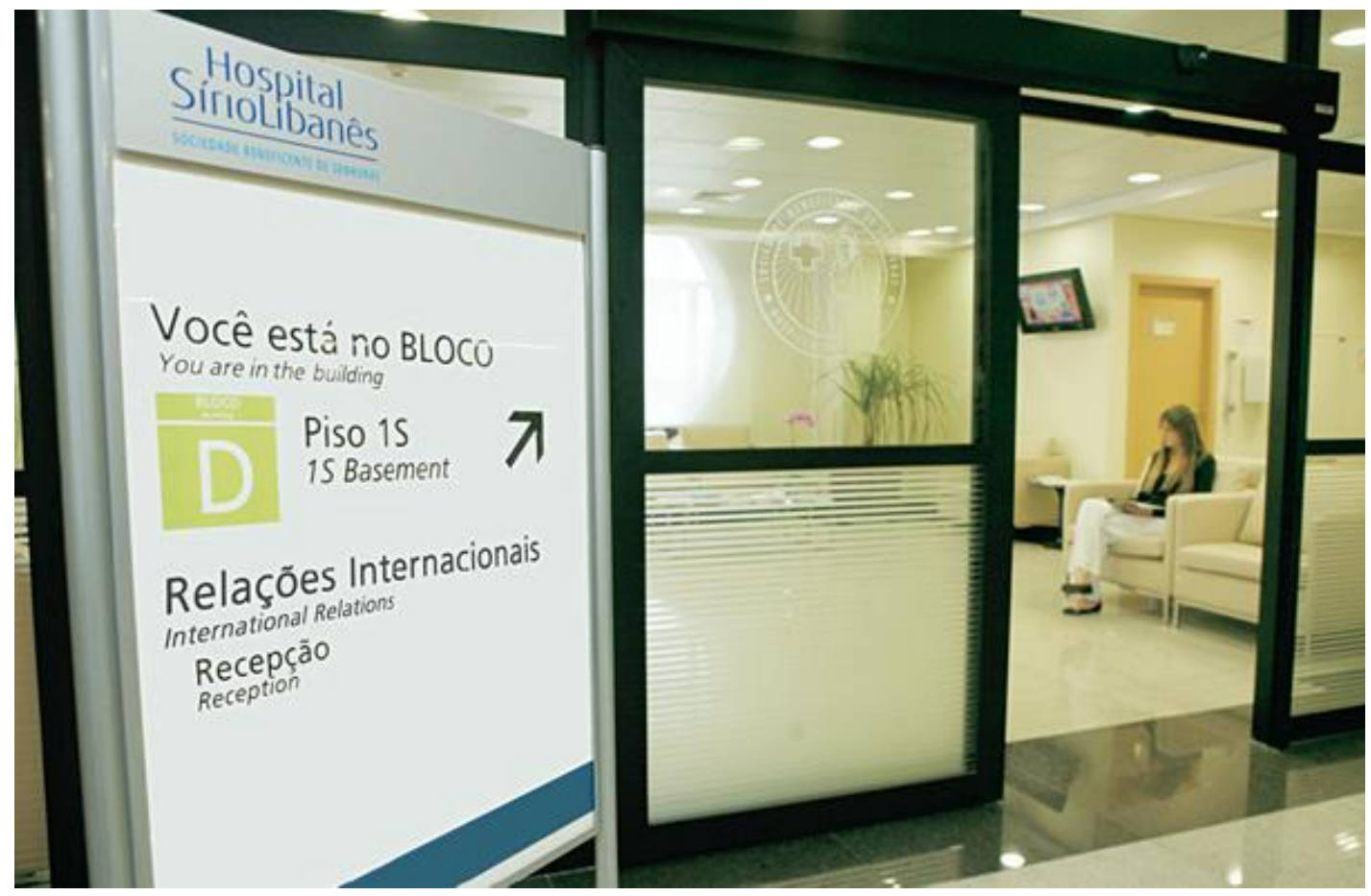

Figura 9 - Comunicação bilíngue - Hosp. Sírio-Libanês Fonte: Vaz (2008)

Outra ação realizada por alguns hospitais de ponta é a inauguração de unidades fora de suas sedes, não só para atender a demanda do turismo de saúde como para atender um público interno (COLLUCCI; 2010, p. 28). O aumento da procura pela rede hospitalar é explicado por fatores como o envelhecimento da população e o crescimento econômico do país (o que faz 
com que mais pessoas tenham acesso à saúde suplementar e a hospitais de primeira linha).

A expansão desses hospitais envolve o planejamento de edifícios que contemplem funcionalidade, otimização de espaços, baixos custos de construção e manutenção e tenham tecnologia de ponta em ambientes modernos e humanizados. Para atender o requisito de ter tecnologia de ponta é preciso que os ambientes possam ser constantemente modificados para receberem os novos equipamentos, o que exige flexibilidade e dinamismo dos espaços.

\subsection{A concorrência}

O atendimento tornou-se um parâmetro de competência para hospitais. Seja um hospital público ou privado, filantrópico ou não, a tendência está sendo ver o paciente como um ente singular, com necessidades e expectativas exclusivas. Como geralmente o paciente não está sozinho, quem o acompanha também merece ser tratado com atenção e respeito.

(...) se a aparência física e a estrutura de serviços oferecida pode influenciar positivamente o conceito do cliente ao entrar em um hospital, maior ainda 0 impacto exercido com um atendimento prestativo e caloroso e com a percepção de serviços rápidos e eficientes. Um bom trabalho desenvolvido desde a chegada facilita a auto-entrega do paciente a toda equipe de profissionais, reduzindo o estresse e o desgaste não apenas do cliente como dos familiares que o acompanham, afinal, é o bem mais precioso que está sendo colocado nas mãos desses profissionais, uma "vida". (GODOI, 2008, p. 20)

Nesse mercado em que clientes de saúde estão cada vez mais exigindo conforto, bem-estar e sofisticação, é importante mostrar que estes são especiais e dar-lhes um atendimento personalizado. É preciso encantar o cliente para assegurar o sucesso no competitivo mercado hospitalar. Esse encantamento requer conhecimento das necessidades de cada cliente e a identificação de seus anseios, aspirações e desejos para oferecer soluções, surpreendendo-o e cativando-o.

Tendo-se em vista que o hospital tem um caráter de prevenção de doenças e 
não apenas de cura, a fidelização é um ponto a ser considerado por gestores e/ou administradores. O cliente deve ser conquistado para que volte ao hospital não apenas para resolver casos nos quais seja necessária internação, mas também para fazer consultas e exames preventivos.

Ainda que a escolha de um hospital esteja vinculada a outros fatores (planos de saúde, especialidades de cada hospital etc.), é possível direcionar esforços para conquistar clientes. Para isso, várias ações devem ser realizadas, relacionadas à qualidade de atendimento; modernizando-se ao construir espaços inovadores, "comprando equipamentos de alta tecnologia e investindo na capacitação de profissionais de todas as áreas", além de contar com equipes médicas que busquem mais conhecimento, "aperfeiçoando suas técnicas e tornando-se profissionais comparáveis aos melhores do mundo" (GODOI, 2008, p. 12).

Com a aprovação do Código de Defesa do Consumidor, em 1990, e dos Direitos dos Usuários dos Serviços de Saúde do Estado de São Paulo, em 1999, houve uma mudança na área da saúde no Brasil. Foram estabelecidas políticas para "atender as expectativas da sociedade, que via surgir um novo tipo de consumidor, mais exigente e mais atento aos seus direitos". Como reflexo disso, "as organizações hospitalares tiveram que criar mecanismos para tornar a sobrevivência possível” (NASSAR, 2003, p. 35).

O paciente passou a ser visto, pelo hospital, como cidadão, cliente e consumidor, tendo o direito de decidir sobre os procedimentos a que vai ser submetido, tendo acesso às informações e esclarecimentos sobre seu estado de saúde antes da realização de qualquer tratamento. Essas alterações fizeram com que os hospitais passassem a oferecer um ambiente mais compatível com as necessidades e desejos dos usuários.

A competitividade na área de saúde aumentou, obrigando os hospitais a se reestruturarem para proporcionarem melhor atendimento. $O$ ambiente hospitalar passou a ser mais familiar, buscando minimizar o impacto que 0 paciente sofre, criando um espaço mais humanizado, mais parecido com um hotel ou com a própria casa do cliente, "modificando a antiga ideia de que o hospital é apenas um local hostil e assustador" (DIAS, 2006, p. 9). 
A matéria de capa publicada na Revista Veja São Paulo, em 8 de julho de 2009 (Figura 10), aponta para o fato que, a partir de 2003, a parcela com 60 anos ou

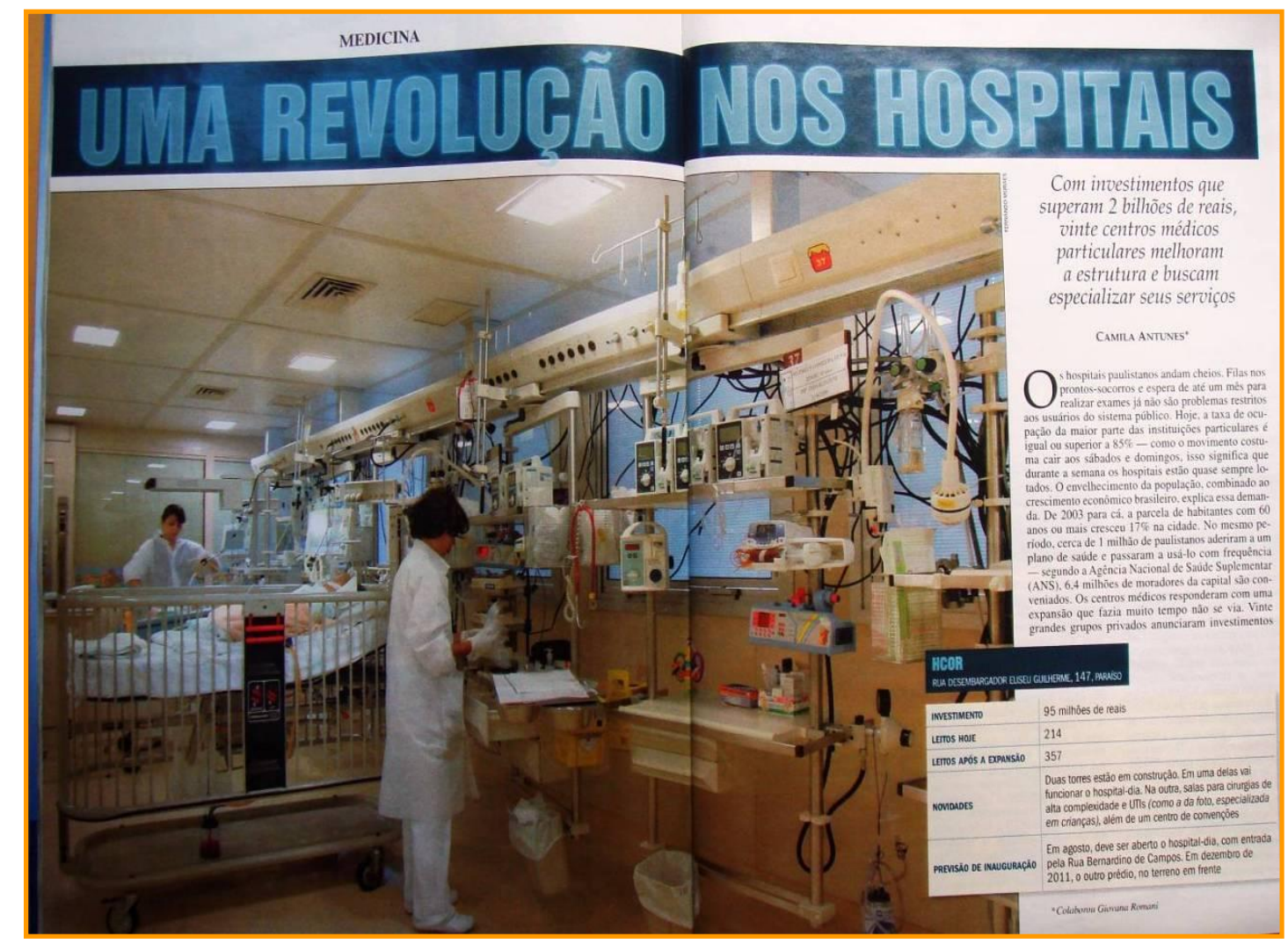

Figura 10 - Revista Veja São Paulo, 08 de julho de 2009 Fonte: Antunes (2009, p. 32-33)

mais cresceu $17 \%$ na cidade de São Paulo e, no mesmo período, cerca de 1 milhão de paulistanos aderiram a um plano de saúde e passaram a usá-lo com frequência, totalizando 6,4 milhões de moradores da capital conveniados. Esses usuários procuram os hospitais para consultas, exames médicos, primeiros socorros e internações. Vinte dos principais hospitais e centros médicos da cidade anunciaram investimentos de 2,2 milhões em novas instalações e equipamentos de ponta e a expectativa é que surjam 1.800 novos leitos a partir dessa expansão (ANTUNES, 2009).

Há uma diferenciação feita com relação aos termos "cliente" e "cidadão". Cecílio (2000) explicita que o termo "cliente" relaciona-se ao "consumidor" de empresas privadas (inclusive as prestadoras de serviços de saúde) e o termo "cidadão" associa-se ao "consumidor" dos serviços públicos governamentais, no campo das políticas sociais. Seja um hospital público ou privado, suas atenções devem estar voltadas para a satisfação do paciente e das pessoas 
que o acompanham, procurando atender suas necessidades não apenas com qualidade, como também com respeito, carinho e dedicação.

Os hospitais particulares, considerados como empresas, para sobreviverem no ambiente competitivo e globalizado, estão tendo que rever suas práticas gerenciais.

A qualidade das instalações e das acomodações que o hospital oferece determina em grande parte o perfil do cliente que o hospital atrairá. Como boa parte do tratamento médico convencional ficou comoditizado, podendo ser encontrado em praticamente qualquer lugar do mundo, o conforto e qualidade da estrutura oferecida pelo hospital assumiu uma nova e maior importância, pois o cliente de saúde não quer mais ser apenas tratado, ele que ser "tratado bem". (GODOI, 2008, p. 69)

A concorrência tem gerado um aumento da excelência no atendimento. $O$ ambiente hospitalar deve estar preparado para receber os clientes de saúde, dando-Ihes suporte terapêutico adequado, acolhendo-os com carinho, atenção, solidariedade, respeito e empenho, para que se sintam atendidos, protegidos e mais confiantes. A hospitalidade nesses ambientes pode ser vista como um fator de diferenciação da prestação de serviços.

A gestão de hospitalidade em hospitais é um tema relativamente novo. Sabese que sempre houve serviços prestados aos pacientes além dos serviços médicos, mas, até pouco tempo atrás, não eram considerados como possibilidade de diferencial de uma instituição para outra. Apenas nas últimas décadas o paciente vem sido tratado como "cliente". Ele tem necessidade e desejos a serem satisfeitos, além da sua saúde, a sua doença ou tratamento. A competitividade futura de hospitais, portanto, depende da gestão integral dos mesmos. Isto corresponde à integração das áreas médica e de hospitalidade, pois, hoje, não há mais apenas pacientes, e sim, "pacientesclientes".

O hospital, hoje, além da necessidade de mudança para paciente-cliente, deve considerar que "ninguém entra sozinho no hospital". Junto com o paciente-cliente chegam familiares, médicos particulares, diferentes convênios, visitas, entre outros. Todo este público precisa ser bem atendido. Assim, a instituição poderá oferecer "serviços de qualidade" no sentido amplo de serviço. (QUEVEDO, 2006, p. 10-11)

É importante que o espaço hospitalar possa ser um local em que as pessoas se sintam bem, sintam-se um pouco mais à vontade, livrando-se o quanto possível de seus receios e medos relacionados ao seu estado de saúde, sobretudo aquelas que, estando em estado grave, têm risco de morrer. Os aspectos físicos devem ser aliados aos humanos, com o intuito de minimizar as condições possivelmente negativas desses ambientes e atender melhor as 
necessidades dos clientes de saúde, que vistos como consumidores, têm seus direitos e buscam qualidade dos serviços. Cada vez mais exigentes, procuram hospitais modernos, com excelência em seus serviços médicos, alta tecnologia, ambientes e atendimentos humanizados.

\subsection{Qualidade}

O fator qualidade no atendimento e no tratamento da doença é considerado hoje como questão básica na escolha de um hospital (MORAES; CÂNDIDO; VIERA, 2004, p. 184). O cliente de saúde espera encontrar um serviço médico ágil, prestado por profissionais capacitados (grau de excelência) e eficientes, em unidades de saúde modernas, com equipamentos de alta tecnologia que contemplem várias especialidades. Associado a tudo isso, espera-se atendimento humanizado e hospitaleiro (Esquema 5).

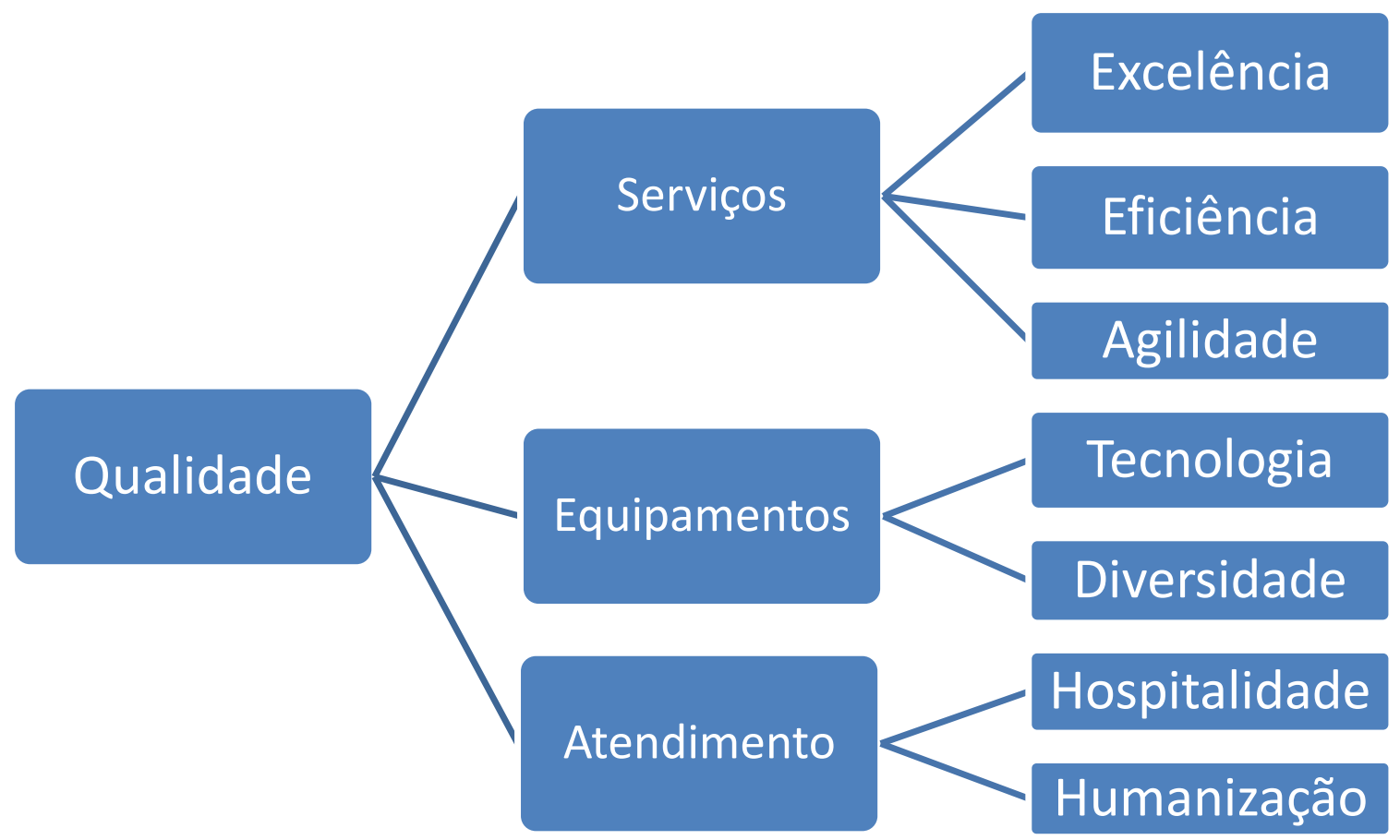

Esquema 5 - Qualidade em hospitais Fonte: Elaborado pela autora

Todas as ações realizadas em um hospital devem ter como enfoque o cliente de saúde, que deve ser visto como um ser que, bem provavelmente, não está 
em situação normal de saúde física e/ou emocional. O ambiente hospitalar deve estar cada vez mais preparado tecnologicamente para recebê-lo, de forma digna e respeitosa, dando-lhe suporte terapêutico adequado para que suas dores e sofrimentos (assim como os das pessoas que o cercam) sejam minimizados quanto possível.

A qualidade de serviços em hospitais está relacionada ao grau de satisfação do cliente de saúde, dado pela "relação entre o que ele viu (percebeu) e o que ele esperava ver (expectativa). Nesta relação, o controle de Qualidade é feito pelo usuário, comparando a expectativa com a experiência efetiva" (CABRAL, 2007, p. 3). Para se manter nesse mercado extremamente competitivo, as organizações hospitalares têm procurado corresponder à satisfação das necessidades de seus clientes.

Hospitais privados passaram a atender pacientes do Sistema Único de Saúde (SUS) e isso fez com que os hospitais públicos também passassem a ter maior preocupação com a qualidade de seus serviços. É preciso prestar contas, planejar e medir o grau de satisfação dos usuários. A formação médica deve ter atualização constante, acompanhando as evoluções tecnológicas (ARTMANN; RIVERA, 2006, p. 216).

\begin{abstract}
Algumas instituições hospitalares privadas têm buscado certificações de qualidade auferidas por empresas avaliadoras reconhecidas internacionalmente, com a finalidade de diferenciar seus serviços e utilizar essa diferenciação em relação aos demais como forma de estabelecer padrões de reconhecimento entre seus clientes e a competição mercadológica.

O Sistema Único de Saúde (SUS) elegeu alguns critérios (...), baseados em conceitos e técnicas oriundas da qualidade total praticadas em outras empresas, principalmente em hotéis que adotaram o sistema de qualidade em sua gestão. (MORAES; CÂNDIDO; VIERA, 2004, p. 198-199)
\end{abstract}

Por ser algo intangível, é difícil mensurar o grau de satisfação ligado à qualidade dos serviços prestados a uma pessoa. Por essa razão, "alguns padrões básicos foram estabelecidos por organismos normalizadores para garantir produtos e serviços que atendam a padrões nacionais ou internacionais de qualidade" (GODOI, 2008, p. 103). A necessidade de adotar medidas para melhorar a qualidade no setor de saúde fez surgirem organizações para avaliar o desempenho desses serviços.

A missão essencial das instituições hospitalares é atender seus pacientes de 
forma adequada. Por isso, todo hospital deve preocupar-se com a melhoria permanente da qualidade de sua gestão e assistência, buscando uma integração harmônica das áreas médica, tecnológica, administrativa, econômica, assistencial e, se for o caso, de docência e pesquisa. (BRASIL, 2002a, p. 11)

De acordo com Rooney e Ostenberg (1999, p. 2), "o licenciamento, a acreditação e a certificação são abordagens de avaliação da qualidade para atender às necessidades de informação sobre qualidade". O licenciamento é dado por uma autoridade governamental a um profissional ou a uma instituição de saúde para funcionar; a acreditação é realizada por uma organização que avalia e reconhece que a instituição de saúde atende os padrões predeterminados; a certificação é dada geralmente a profissionais individuais e implica que estes receberam instrução e treinamento adicionais e demonstraram competência em uma especialidade além dos requisitos mínimos para seu licenciamento.

Das normas certificadoras utilizadas por hospitais brasileiros destacam-se: CQH - Compromisso com a Qualidade Hospitalar; ONA - Organização Nacional de Acreditação; ISO - International Organization for Standartization; $\mathrm{JCI}$ - Joint Comission Internacional (PINHEIRO; GIACOMINI FILHO; SILVA, 2007). A certificação é procurada pelos hospitais voluntariamente e trata-se de um "reconhecimento público da produção de serviços de qualidade de uma organização de saúde, não sendo necessariamente um processo que se completa ou finaliza no momento da certificação" (GODOI, 2008, p. 104). Espera-se que a instituição procure uma melhora constante da qualidade de seus serviços prestados.

Essas certificações são utilizadas pela publicidade como item diferencial na divulgação dos hospitais, que menciona quais os selos (tipo de certificação e nível conquistado) a instituição recebeu. Algumas instituições procuram obter várias certificações, inclusive selos internacionais, sobretudo as que têm direcionado esforços investindo no turismo de saúde (tanto nacional quanto estrangeiro).

Para atender os pacientes de forma adequada é preciso haver uma constante preocupação com a melhoria da qualidade da gestão e da assistência, buscando a integração das áreas médica, tecnológica, administrativa, econômica, assistencial e de docência e pesquisa (quando for o caso). 
De acordo com o Manual Brasileiro de Acreditação Hospitalar (BRASIL, 2002a), o Programa Brasileiro de Acreditação da ONA reconhece que o hospital é um sistema complexo, no qual as estruturas e os processos são interligados de tal forma que o funcionamento de um componente interfere em todo o conjunto e no resultado final. Esse instrumento de avaliação, referência em todo o território nacional, define os padrões a serem cumpridos pelas organizações de saúde em três níveis de complexidade crescente, com princípios específicos. É composto de sete seções, que interagem entre si, permitindo uma avaliação com consistência sistêmica.

As seções são:

1) lideranças e administração;

2) serviços profissionais e organização da assistência;

3) serviço de atenção ao paciente/cliente;

4) serviço de apoio ao diagnóstico;

5) serviços de apoio técnico e abastecimento;

6) serviços de apoio administrativo e infraestrutura;

7) ensino e pesquisa.

Essas seções, por sua vez, são divididas em subseções, que tratam do escopo específico de cada serviço, setor ou unidade. Destas, destacam-se, para o âmbito deste trabalho, as subdivisões do item 6 (serviços de apoio administrativo e infraestrutura):

a) documentação da planta física;

b) estrutura físico-funcional;

c) sistema elétrico;

d) manutenção geral, controle de resíduos e portabilidade da água;

e) segurança geral.

Cada subseção contém padrões interdependentes a serem atendidos integralmente para a obtenção da certificação. Esses padrões apresentam suas definições e uma lista de itens de orientação, alinhados com os itens considerados pertinentes aos princípios, para avaliar a estrutura, o processo e o resultado do serviço, setor ou unidade. Os itens norteiam o processo de visita, pois apontam as fontes para os avaliadores procurarem evidências e servem como referência para as instituições se prepararem para receber a equipe avaliadora. Percebe-se, em todo o Manual (BRASIL, 2002a), que 
apenas duas subdivisões fazem menção a questões de sinalização ("c" e "e"), as quais se encaixam nas contribuições da CV.

A subdivisão "c" (estrutura físico-funcional) avalia as vias de acesso à instituição, circulação interna e externa, sinalização e fluxos. No nível 1 , espera-se que a instituição tenha sinalização externa para orientar o acesso e sinalização de fácil entendimento e visualização em todas as áreas de circulação; no nível 2, que tenha um sistema de planejamento, organização e manutenção dos acessos e da circulação e um sistema de padronização de sinais, símbolos e sinalização (externa e interna); no nível 3, que apresente um sistema de acesso, fluxo e circulação com evidências de vários ciclos de melhoria.

A subdivisão "e" (segurança geral) avalia se os serviços garantem a integridade dos usuários por meio de infraestrutura adequada e se há procedimentos de prevenção de acidentes, sinistros, violência e riscos. No nível 1 , requer sinalização clara e de fácil compreensão para saídas de emergência; extintores de incêndio; obras, atividades de manutenção e situações de emergência. Nos níveis 2 e 3 os itens de orientação apenas indicam que devem ser observadas evidências de ciclos de melhoria sem, no entanto, fazer especificações maiores sobre suas possibilidades.

Esperamos que, no futuro, essas indicações relacionadas à CV possam ser ampliadas e melhoradas. É provável que, com a implantação do sistema de humanização, os selos de qualidade passem a considerar os demais elementos de $\mathrm{CV}$ relacionados à construção da ambiência.

\subsection{Conforto}

Os projetos dos ambientes hospitalares, por estarem diretamente ligados à saúde do ser humano, mais do que outros ambientes, requerem conforto e qualidade e devem ser desenvolvidos de forma a satisfazer mais plenamente seus usuários. O projeto arquitetônico de um hospital deve atender demandas da tecnologia médica, ter flexibilidade dos espaços (determinada por variáveis epidemiológicas) e satisfazer o usuário por meio do conforto. (BITENCOURT, 
2008, p. 63).

Para o âmbito deste trabalho, destacam-se os seguintes aspectos relacionados a conforto em hospitais: ambiental (conforto visual, acústico, olfativo e térmico); ergonômico (relativo ao layout de móveis e equipamentos); estético (presença de obras de arte e de elementos de decoração); emocional (relacionado à hospitalidade e humanização), como resume o Esquema 6.

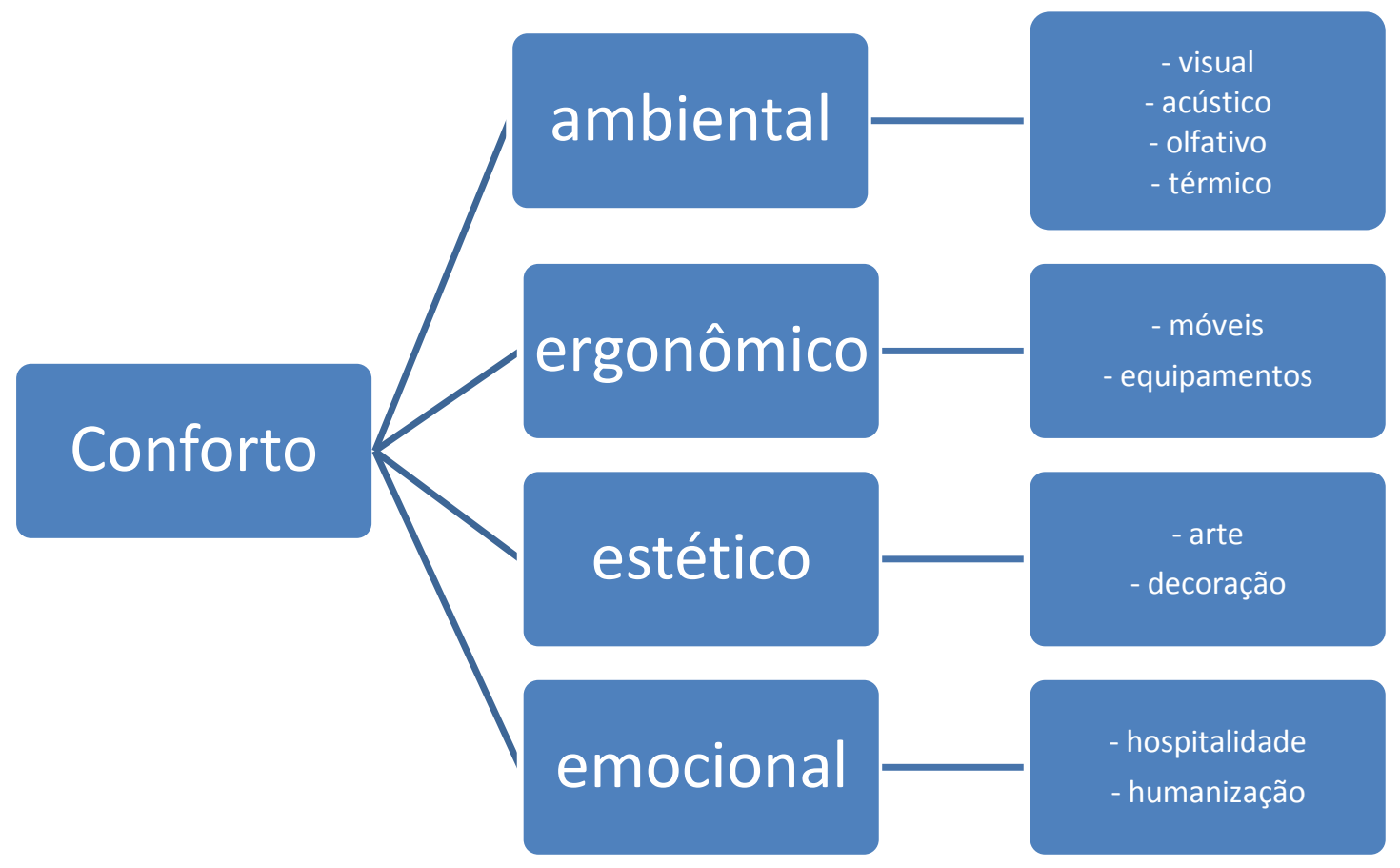

Esquema 6 - Conforto em hospitais

Fonte: Elaborado pela autora

Considerando-se as características específicas de um hospital, seu projeto arquitetônico requer uma série de preocupações com a satisfação e o bemestar tanto de seus clientes de saúde quanto da equipe de trabalho em geral e dos administradores (SAMPAIO, 2005, p. 79).

O conforto ambiental quando abrange as sensações de bem-estar com relação à temperatura, umidade relativa e movimento do ar, radiação solar e radiação infravermelha - emitida pelo entorno -, é denominado conforto térmico; quando se refere ao bem-estar com relação a ver bem, a ter uma quantidade de luz satisfatória e que possibilite a realização de uma tarefa visual confortavelmente, é denominado conforto visual, lumínico ou luminoso e quando não existir no ambiente, nada que interfira na capacidade de ouvir satisfatoriamente o som desejado, quando a sensação de bem-estar estiver relacionada a ouvir bem, o conforto é denominado acústico. Devemos considerar ainda o conforto olfativo, sensação de bem-estar com relação aos odores existentes no ambiente. (SAMPAIO, 2005, p. 156)

A sensação de conforto não é tão facilmente mensurável, pois ela é o resultado 
da harmonia de vários condicionantes (visuais, acústicos, térmicos etc.) que propicia a integração do usuário ao seu meio (BITENCOURT, 2008, p. 65).

$O$ conforto ergonômico relaciona-se à adequação de equipamentos e móveis aos usuários (sejam eles clientes de saúde ou funcionários/colaboradores). A tecnologia tem exigido constantes mudanças dos espaços para adequar equipamentos de ponta. Por isso, os espaços hospitalares devem ser flexíveis para acomodar novos modelos de equipamentos, redesenhados $\mathrm{e}$ modernizados.

O conforto estético combina elementos e informações de caráter técnico com a sensibilidade estética da organização espacial do conjunto de seus diferentes setores. A Figura 12 apresenta uma possibilidade de humanização do

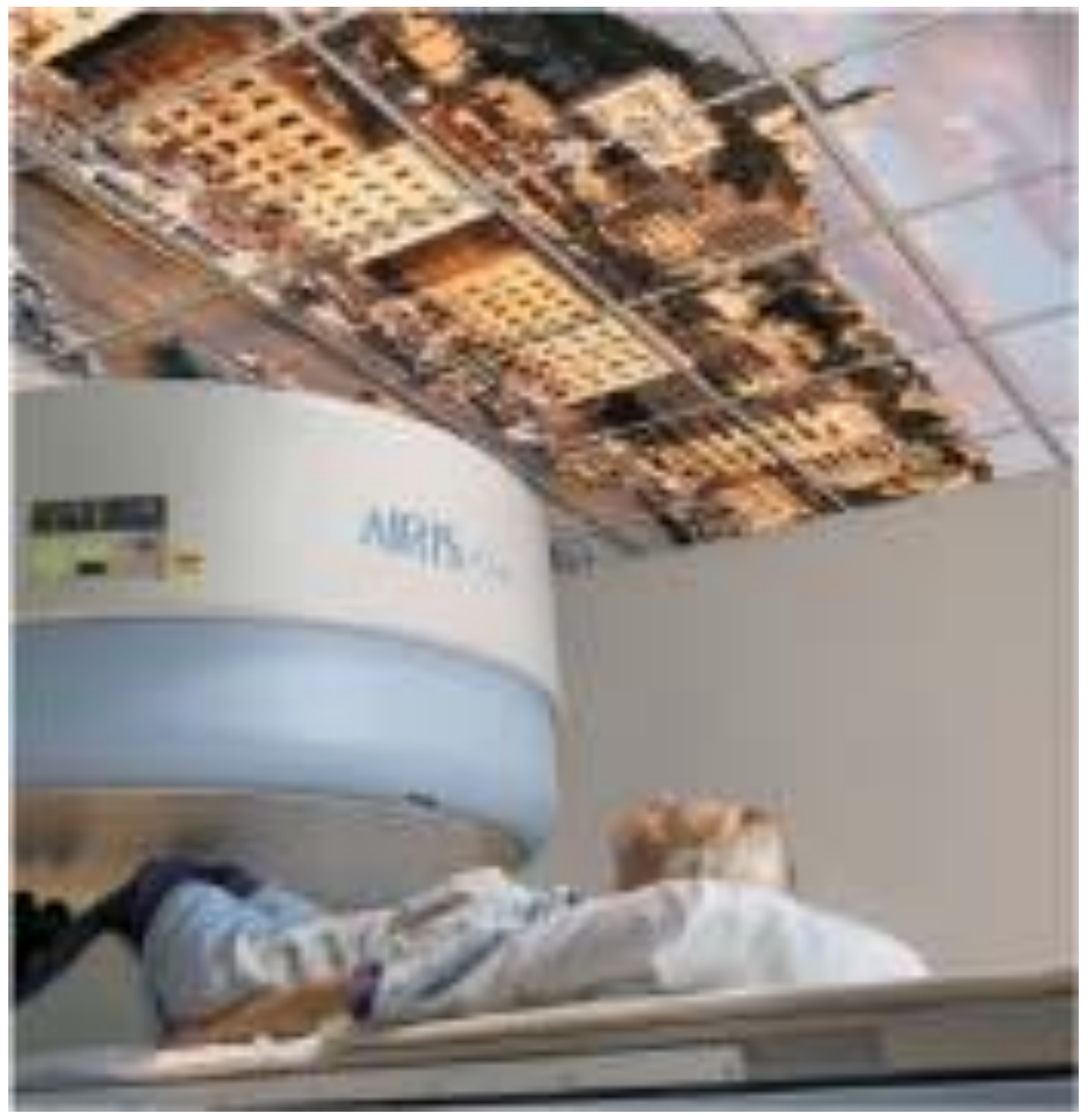

Figura 12 - Painel luminoso

Fonte: uww.heathcaredesignmagazine.com/artide/artwork-comer-wall-protection-lighting-wayfinding?page=2

ambiente, com instalação de painéis luminosos no teto para o paciente ter uma visão mais agradável enquanto realiza seus exames. Assim como esses 
painéis, obras de arte, elementos de decoração, iluminação e esquema de cores não devem ser vistos apenas como um componente de acréscimo secundário, mas como possibilidade de exercer uma função terapêutica (BITENCOURT, 2008, p. 96; LIMEIRA, 2006, p. 88).

Quanto ao conforto emocional, as ações realizadas dentro de hospitais estão tendo como objetivo transformar a presença em seus ambientes em algo um pouco mais ameno, já que esta é indispensável para os clientes de saúde. Para atender essa nova tendência, é fundamental que a recepção dos pacientes (seus acompanhantes, familiares e visitas) seja bem feita.

\subsection{Hotelaria Hospitalar}

Todos os envolvidos no atendimento devem se empenhar em melhorar a qualidade de seus serviços, para tornar a estada dos clientes de saúde (seus acompanhantes, visitantes e familiares) em algo o mais agradável possível. Em especial nos casos de internações, durante o período em que o paciente permanece no hospital, encontra-se em um local com o qual não tem identidade nem nenhuma relação. Ao se internar, a pessoa tem uma interrupção do curso normal de sua vida, deixa seu espaço próprio, habitual. Afasta-se de sua casa, do convívio com seus familiares e de seu trabalho, tendo que conviver temporariamente com pessoas entranhas, o que, muitas vezes, representa a perda da privacidade, sensação de insegurança, medo e abandono.

Além disso, o paciente internado torna-se "hóspede" em um hospital, local provisório, comparado com hotéis, daí a importância de sentir-se em um local confortável e seguro. O serviço de hotelaria hospitalar contribui com os três aspectos acima abordados: qualidade, conforto e segurança. Este passou a ser o setor responsável por ajudar a tornar o ambiente terapêutico mais hospitaleiro, contribuindo para a recuperação do paciente, fazendo a interação entre este e a equipe de saúde e dando suporte para a família. Para isso,

É necessário modernizar as organizações de saúde, preocupando-se com a 
estrutura física, o aspecto visual, identificando toda a parte externa e interna sobre a localização dos espaços, com cores suaves e alegres, com limpeza constante, revistas atualizadas, disponibilizar água e café, proporcionar treinamento para os funcionários, objetivando auxiliá-los no atendimento para que desempenhem um trabalho de equipe e transmitam a imagem da organização. (...)

Poucas organizações de saúde desenvolvem posturas básicas e elementares para resolver o problema. Uma recepção bem organizada, com identidade visual, com funcionários treinados para a função contribui significativamente para a construção da imagem. (NASSAR, 2003, p. 13)

A hotelaria hospitalar procura criar e organizar um espaço em que o ser humano que precisa de cuidados especiais sinta-se bem, atendendo um conjunto de necessidades humanas específicas, dando suporte para supri-las para que o paciente sinta conforto e segurança. O objetivo é criar condições agradáveis para facilitar o processo terapêutico, uma vez que este requer procedimentos que são, geralmente, incômodos e desagradáveis para o paciente.

(...) a hotelaria hospitalar é o conjunto de serviços disponibilizados aos clientes internos (funcionários) e aos clientes externos (pacientes e acompanhantes). São os cuidados com o paciente e seu(s) acompanhante(s), desde a sua chegada ao hospital até a sua saída, com repasse de informações administrativas e serviços aos colaboradores. A hotelaria hospitalar tem por objetivo oferecer condições de conforto, bem-estar, assistência, segurança e qualidade no atendimento, através de cortesia, segurança, acompanhamento do cliente, responsabilidade com acomodação, roupas, ambiente, higiene, manutenção e alimentação. É a reunião de todas as atividades oferecidas nos hotéis, agregadas a todas as práticas profissionais existentes nas instituições de saúde. (QUEVEDO, 2006, p. 3132)

As contribuições do serviço de hotelaria hospitalar relacionam-se com a melhoria da infraestrutura do hospital, o que envolve modernização de equipamentos. A gastronomia também tem recebido uma atenção especial, contando com várias opções, "trazendo um pouco mais de sabor à insossa comida hospitalar" (GODOI, 2008, p. 48-51). Boerger (2005, p. 29) menciona que muitos serviços refletem seu conforto na infraestrutura, tais como: "banco 24 horas; telefones públicos; máquinas de refrigerantes; achados e perdidos; restaurantes e lanchonetes; lojas de conveniências; floricultura; fraldário; espaço ecumênico; fitness center".

Em termos gerais, hospitalidade associa-se à ideia de tratar bem quem está em deslocamento, ou seja, quem se encontra em lugares diferentes de seu entorno 
habitual e necessita da prestação de serviços de hospedagem e de alimentação. Pode ser definida como "o ato de receber ou acolher bem o visitante, familiar, amigo ou desconhecido" (GODOI, 2008, p. 18). Relaciona-se com a "vontade e o hábito de tratar bem o próximo sem que isso implique retorno ou expectativa de reciprocidade" (TARABOULSI, 2006, p. 175); com "bom acolhimento, liberalidade, amabilidade e afabilidade no modo de receber os outros" (BOERGER, 2005, p. 54).

Nos ambientes hospitalares, a hospitalidade agrega valor ao tratamento dispensado às pessoas, uma vez que envolve o modo como estas podem ser recebidas. O implemento da hotelaria hospitalar tem como objetivo proporcionar mais conforto para as pessoas internadas e seus acompanhantes. $O$ acolhimento é essencial, sobretudo em ambientes em que o ser humano não esteja em sua situação habitual. Acolher envolve ideias de apoio, comodidade, conforto e satisfação das necessidades humanas.

O diferencial de um hospital pode ser dado ao se oferecer um serviço de

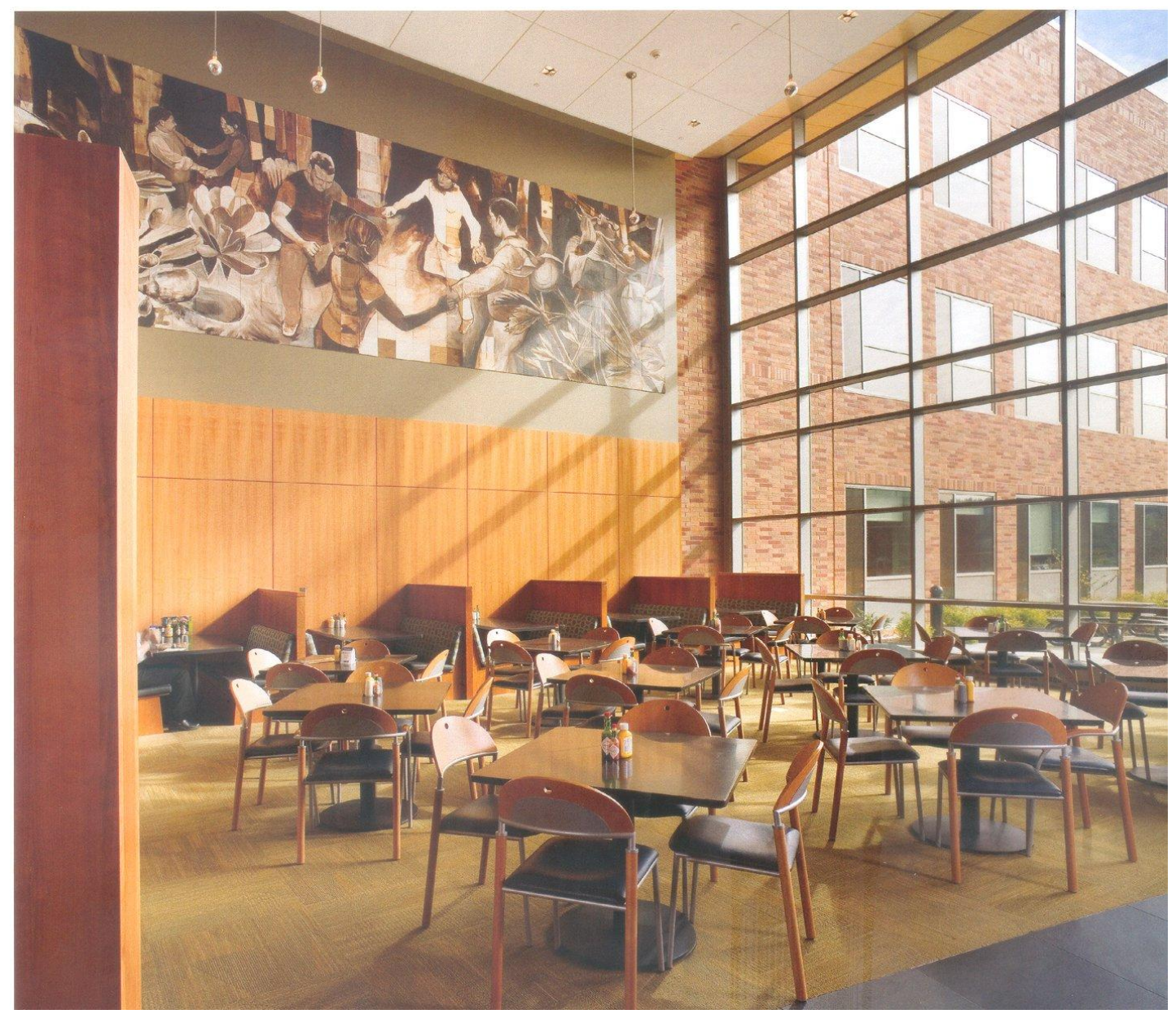

Figura 13 - Cafeteria do Providence Newberg Medical Center (Oregon)

Fonte: Boekel (2008, p. 219) 
qualidade, com atendimento técnico específico associado a respeito, atenção, bem-estar, apoio, aconchego, conforto, segurança, afeto. A Figura 13 mostra a Cafeteria do Providence Newberg Medical Center, em Oregon. É um espaço amplo, bastante iluminado naturalmente, com um quadro em toda a extensão de uma das paredes. Esse ambiente pode servir como lugar de descontração, além de alimentação, principalmente para acompanhantes e visitantes de pacientes internados.

De acordo com Dencker (2007, p. 89), "os grupos compartilham uma preocupação de ordem moral sobre como receber o outro em seu espaço simbólico, como conviver com o diferente, como adentrar no espaço simbólico do outro". Disso se depreende que o conceito de hospitalidade, por envolver o encontro de duas partes diferentes (quem recebe e quem é recebido), associase à ideia de interação e, consequentemente, de comunicação.

(...) A hospitalidade se dá no momento do encontro e por meio da comunicação, quando aquele que recebe, o anfitrião, emite a mensagem, que tanto pode ser de boas vindas quanto um grito de guerra, o receptor decodifica a mensagem e emite a resposta, pacífica ou hostil, estabelecendo a interação, a comunicação inicial.

O encontro, que caracteriza a relação de hospitalidade, tanto pode resultar na dominação dos que chegam pelos que recebem quanto pela submissão desses ao estrangeiro.

O encontro pode resultar na hostilidade ou no conflito, quando as duas partes não se reconhecem, resultando na dominação que tem origem na disputa entre as partes. Por outro lado, a disputa pode permanecer latente e o contato se estabelecer por meio da observação de códigos que regulam a interação. A hospitalidade, nesses termos específicos, implica em uma abertura, na aceitação do outro, no reconhecimento, a priori, do outro como alguém em quem se pode confiar. É uma aposta que dá inicio ao processo de acolhimento e ao estabelecimento da comunicação com o outro, trata-se do reconhecimento do outro enquanto estranho, porém digno de respeito. (DENCKER, 2007, p. 97)

Nos hospitais, a hospitalidade assume um caráter mais específico vinculado a regras de convivência e de interação. De acordo com Imamura e Bueno (2007, p. 1), "a hospitalidade é um fenômeno complexo e a reflexão sobre sua natureza, sua função e sobre o papel que ele exerce nas relações sociais se multiplicam, ampliando suas interfaces e suas articulações em diferentes segmentos da sociedade".

A comunicação, nesse cenário, assume um importante papel, pois permeia as relações de acolhimento e o estabelecimento de redes de interação, 
notadamente nas recepções e seu entorno. Assim, é importante inserir esse conceito no foco de preocupações da comunicação organizacional de instituições ligadas ao setor da saúde. Suas ações, principalmente por meio da $\mathrm{CV}$, devem dar uma atenção especial às questões relacionadas à hospitalidade, procurando aprimorar e melhorar a qualidade de seus serviços. A Figura 14 mostra a recepção do Centro Pediátrico da Lagoa. A programação

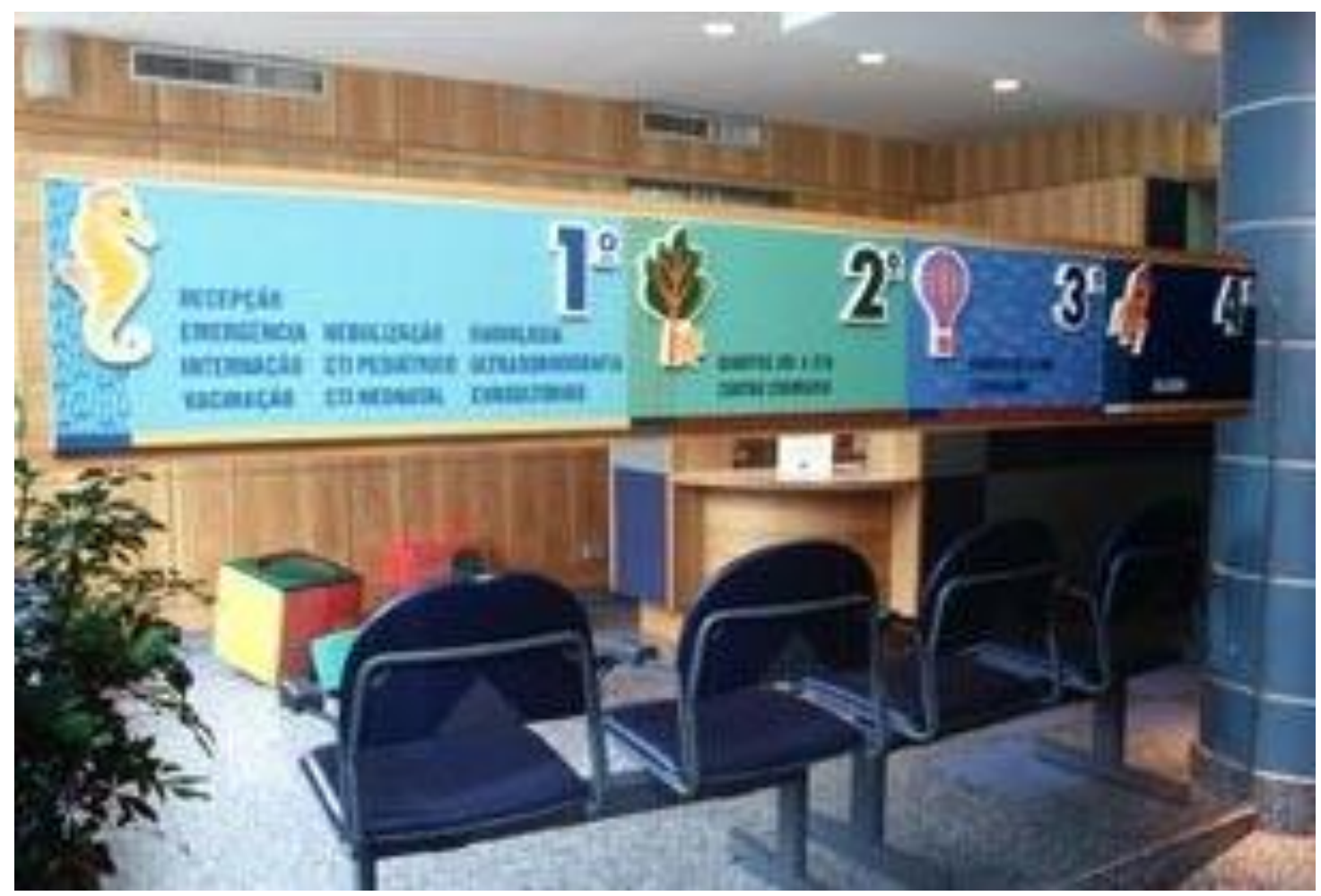

Figura 14 - Recepção do Centro Pediátrico da Lagoa Fonte: www.videsign.com.brfllashbase.htm

visual, feita por Valéria London Design, adequou a sinalização com foco no público infantil. Receber bem implica em considerar o usuário, verificando suas necessidades e adaptando o espaço a elas. Com isso, os hospitais estarão se adequando cada vez mais à realidade de mercado que hoje, com a competitividade, têm clientes mais exigentes e conscientes de seus direitos. 


\subsection{Ambiente hospitalar: ambiente terapêutico}

Num entendimento mais amplo e abrangente, o espaço físico de um hospital faz parte do processo de cura, ou seja, o ambiente também pode ser terapêutico e auxiliar na recuperação do paciente, interferir em seu tratamento ao proporcionar sensação de bem-estar, conforto e acolhimento. No caso de um hospital infantil, essa preocupação é ainda um pouco maior. O Edinburg Children's Hospital, no Texas, EUA (Figura 15), tem uma fachada semelhante a uma caixa de brinquedos, colorida e enfeitada, procurando reduzir a ansiedade

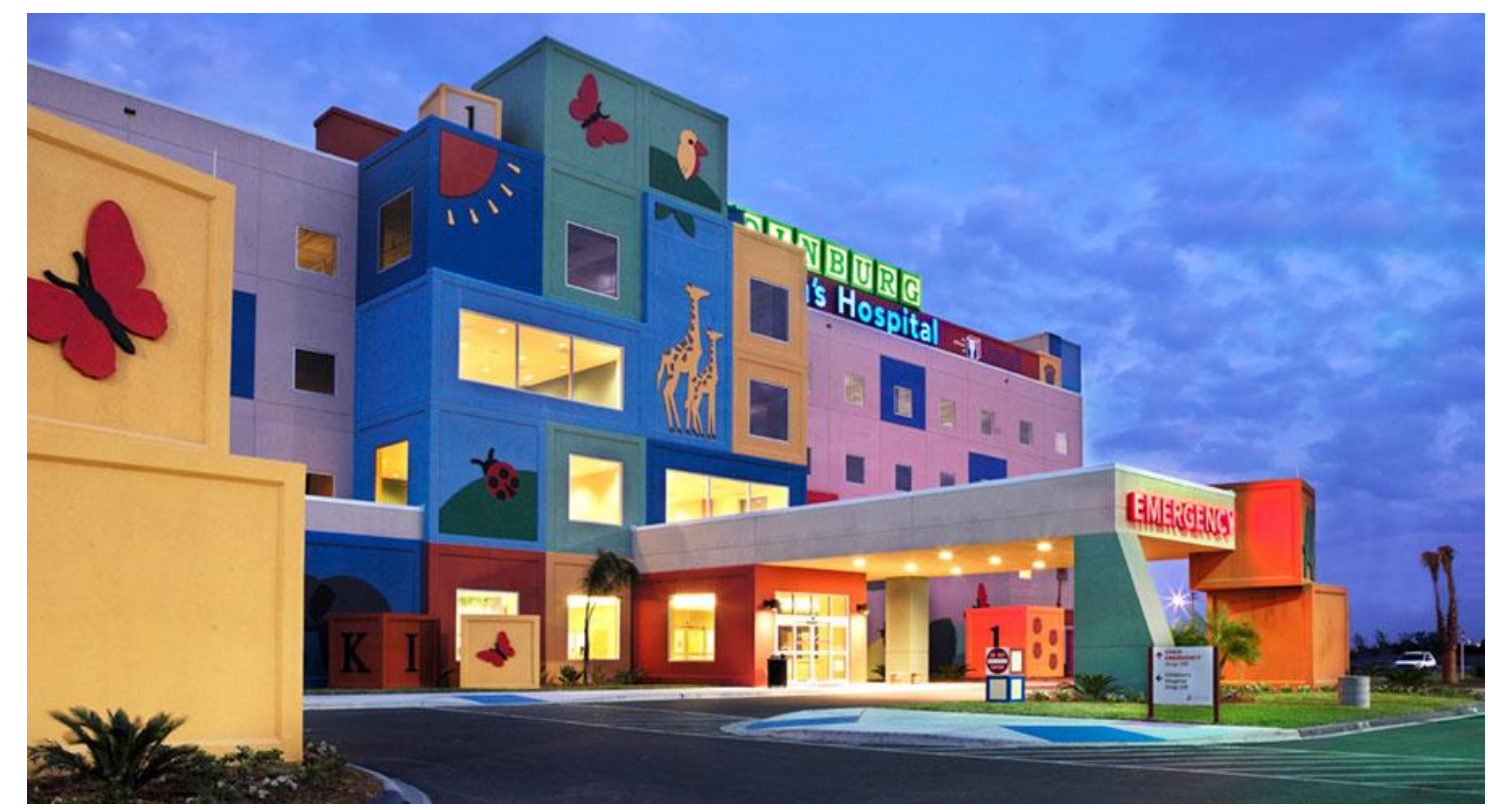

Figura 15 - Edinburg Children's Hospital

Fonte: www.window.state.tx.us/specialrpt/tif/southtexas/healthcare.html

e a tensão da criança que precisa ir a um hospital para receber cuidados médicos.

De acordo com Matarazzo (2010, p. 138), vários estudos demonstram que o ambiente influencia o comportamento dos usuários do espaço físico e, em especial para a área de saúde, pode influenciar no processo terapêutico do paciente.

Os especialistas têm sugerido recentemente, que a arquitetura hospitalar deve não apenas evitar o stress ambiental, como pode efetivamente contribuir para a recuperação do paciente (BAIER, 1995; HERMAN MILLER, 2007; ULRICH E ZIMRING, 2007). Passou-se então a entender o hospital como um 
ambiente de suporte total ao tratamento, isto é, como um instrumento terapêutico em si, sendo a humanização uma característica indispensável.

O ambiente físico também influi na atuação do corpo médico e de enfermagem, devendo favorecer o desenvolvimento de suas atividades. Ao colaborar para a saúde mental e psicológica dos funcionários, o espaço contribui para a sua satisfação e potencializa uma maior produtividade, o que se reflete no atendimento aos pacientes.

Além disso, a qualidade da arquitetura hospitalar é fator fundamental para que a instituição assegure uma posição estratégica no mercado. Com o crescimento do número de clínicas e pequenos hospitais, aumentam as possibilidades de escolha do paciente. Embora o nível do atendimento médico seja o principal critério que determina esta escolha, as características do ambiente físico também influem. (CAVALCANTI; AZEVEDO; DUARTE, 2007, p. 8)

Certamente que este ponto de vista não tem como intenção considerar que o ambiente é o único responsável pelo processo de cura. Concordamos com Toledo (2005, p. 3) que "o ambiente hospitalar pode ser facilitador e, até mesmo um estimulador, de práticas que considerem a autoestima dos pacientes como fator de cura".

Mudanças físicas podem fortalecer as concepções de humanização dos ambientes hospitalares, tanto para os clientes de saúde quanto para as equipes que trabalham no local (profissionais de saúde e demais equipes). Esses edifícios têm características específicas que devem satisfazer necessidades técnicas e funcionais envolvidas no processo terapêutico. Levar a atenção para essas necessidades implica em ter uma maior preocupação com a percepção dos usuários e com as possíveis interferências que 0 ambiente pode gerar neles.

Procurando amenizar a dor e o sofrimento comuns aos ambientes de saúde, a tendência tem sido proporcionar aos usuários condições mais favoráveis em termos de luz, cor, som, temperatura e ergonomia. A Figura 16 apresenta um ambiente iluminado, proporcionando maior conforto aos usuários, sobretudo visual. Alguns pontos a serem considerados são: iluminação adequada, diminuição dos níveis de ruído, comodidades térmicas, privacidade visual e acústica, conforto e controle do espaço pelos ocupantes, uso adequado de cores em paredes e pisos, painéis com imagens de natureza, visão para 0 exterior, mobiliário adequado etc. (MACHADO, 2010, p. 17). 


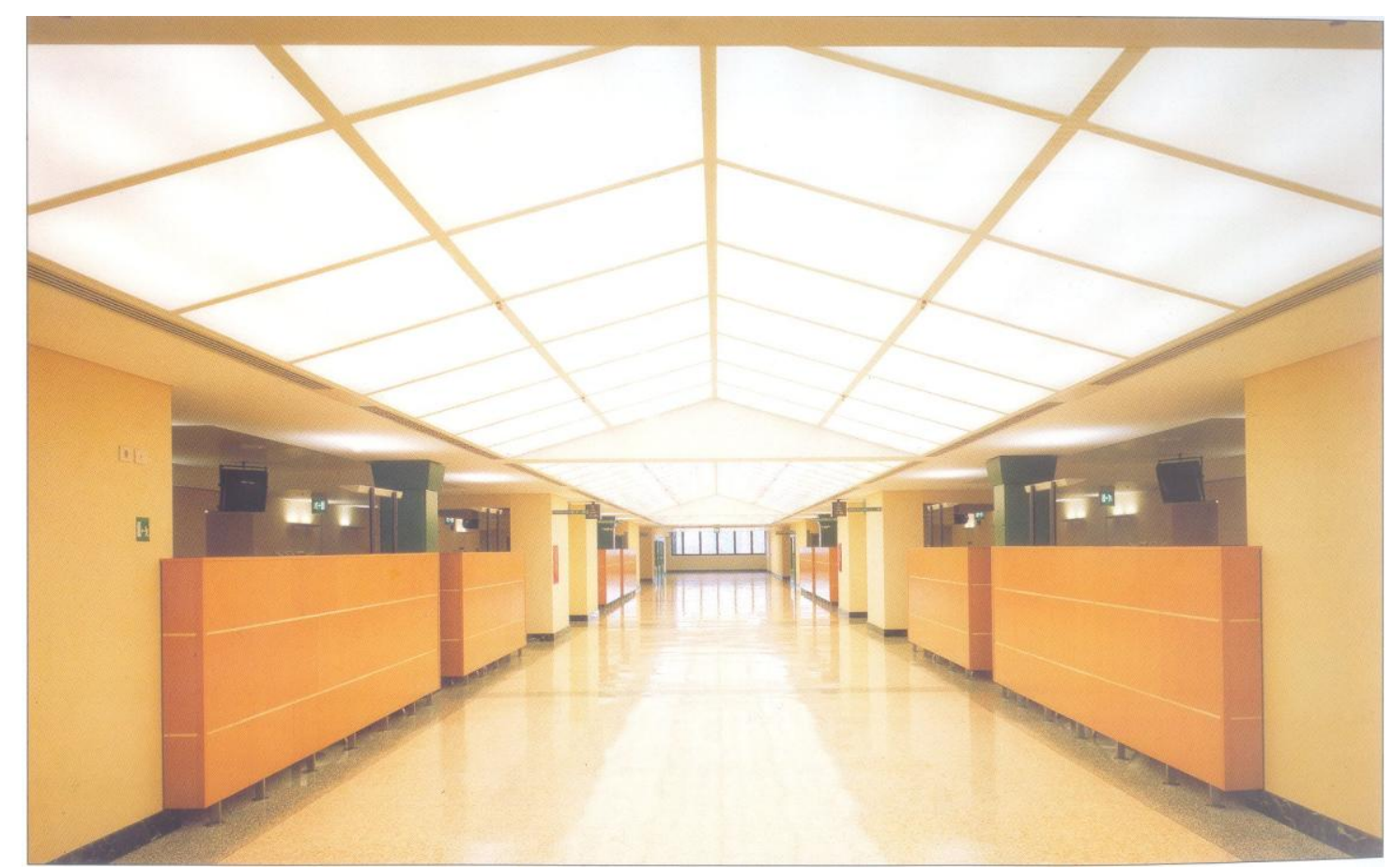

Figura 16 - Instituto Clínico Humanitas (Itália)

Fonte: Broto (2009, p. 298)

Um projeto de CV para ambiências hospitalares deve considerar cada setor do hospital em particular e no todo, ao mesmo tempo, procurando aliar as informações relativas a onde a pessoa está (ou deseja ir) às relativas ao seu bem-estar. A CV deve ser vista e planejada como um sistema integrado e complexo capaz de auxiliar os usuários.

A imagem visual pressupõe um projeto de comunicação visual que contemple desde uma logomarca que identifique de imediato a instituição até a padronização de uma sinalização externa/interna, identificação de veículos, impressos, uniforme do staff, entre outros equipamentos da instituição. (GÓES, 2004, p. 107)

Um sistema de informações para um ambiente de saúde deve ser bem estruturado e planejado para poder atingir o máximo possível de usuários, com informações sistematizadas para atender a todos que circulam em suas dependências, independente do motivo de sua presença no local. 


\section{CAP. 2 COMUNICAÇÃO VISUAL EM HOSPITAIS}

\subsection{Especificidades da Comunicação Visual em hospitais}

No campo da CV encontram-se reunidas as mais diversas formas de transmitir informações utilizando recursos visuais (imagens, sinais, signos, desenhos, gráficos, mapas, pictogramas, cores etc.). Dentro de uma instituição, a CV desempenha um importante papel, é um fator de contato entre esta e seu público.

Muitas vezes a quantidade de estímulos visuais atrapalha a qualidade dos mesmos, por isso, a variedade de materiais e técnicas disponíveis deve contribuir para que a informação visual seja o mais legível e clara possível. 0 uso excessivo de recursos dispostos de forma aleatória pode tornar as mensagens mais complexas e confusas.

Vários hospitais têm investido em mudanças, dentre elas a reestruturação e modernização de sua identidade visual e de sua sinalização. O intuito é acompanhar as tendências mundiais de comunicação com seus públicos estratégicos, fazendo-os perceberem e se identificarem com os valores da instituição.

O turismo de saúde impulsionou ainda mais a concorrência entre hospitais, fazendo com que estes busquem maior inscrição no cumprimento das necessidades e desejos de seus clientes. Permanecer competitivo mundialmente exige melhores cuidados e a CV como um todo passou a ser um elemento de diferenciação entre os concorrentes (MCLAUGHLIN; NCNEIL; SEBALD, 2005, p. 1).

A CV deve ser encarada como elemento fundamental e não apenas como algo estético. A crescente expansão dos hospitais, que geralmente envolve a criação de novos complexos, torna evidente a necessidade de uma comunicação eficiente que informe (de modo claro e prático) a localização dos diversos ambientes a todos os seus públicos. 
A CV disponibiliza as informações institucionais e, em especial em ambientes de saúde, reflete seus valores, sua missão e visão. Até o fato de móveis hospitalares, equipamentos e aparelhagem médica adquirirem formas e cores para amenizar seu tamanho vultoso, por exemplo, pode ser visto como fator de $\mathrm{CV}$ no caso de um hospital que queira transmitir conceitos de hospitalidade e

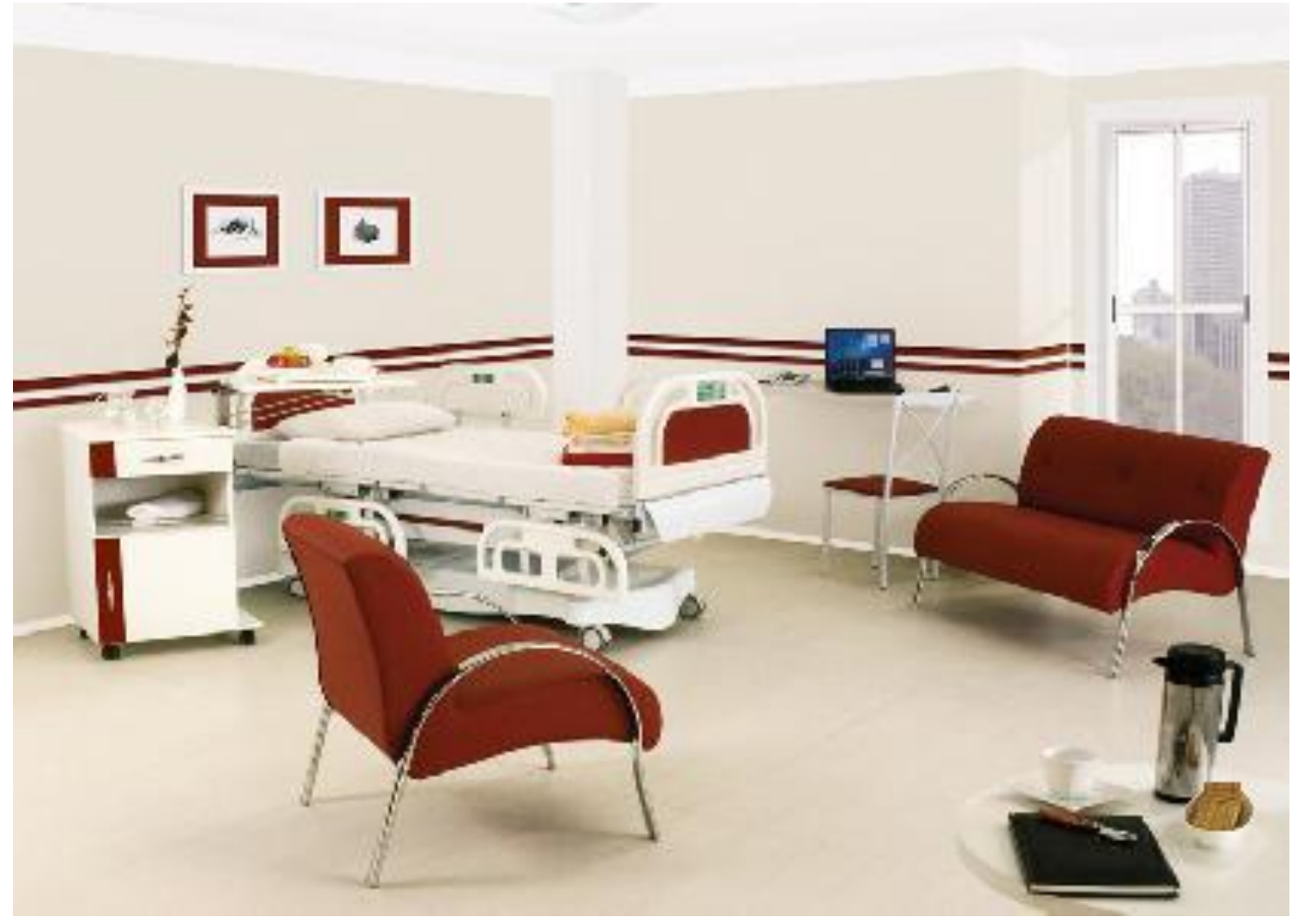

Figura 17 - Móveis hospitalares

Fonte: uww.removeis.com.br/new_site/produto.php?index=199

humanização. Exemplo disso está na Figura 17, que mostra móveis de um quarto de hospital coloridos (cama, sofá, poltrona, mesa formam um conjunto harmônico).

\subsubsection{Flexibilidade e possibilidades de alterações dos espaços}

As transformações ocasionadas pelo avanço tecnológico e pela indústria de equipamentos hospitalares exigem que esses espaços sejam passíveis de alterações, buscando-se adaptações para cada nova situação. São utilizados 
recursos como: paredes leves, divisórias, estruturas com modulação para facilitar o arranjo interno dos ambientes hospitalares (MATOS, 2008, p. 58).

(...) o novo hospital deve ser capaz de resolver plenamente os problemas de saúde para o qual foi procurado, valorizando a intimidade de seus pacientes, através da incorporação e da utilização da tecnologia de modo eficaz e discreto, considerando valores culturais e regionais, permitindo uma maior identificação de seus usuários com o ambiente em que o atendimento é prestado.

A rapidez no desenvolvimento tecnológico e nas formas de atendimento aos pacientes exige dos arquitetos o estudo contínuo sobre novas técnicas de tratamento e diagnóstico, sobre os novos materiais e sistemas construtivos. Além de oferecer ambientes funcionais e seguros para os profissionais de saúde, os arquitetos devem possibilitar que o ambiente hospitalar seja agradável, reconhecível e seguro para o paciente, tanto quanto a sua própria casa, integrando e facilitando a participação de sua família no seu tratamento. (GOMEZ, 2007)

Projetar um hospital é uma tarefa complexa, que exige noções dos objetivos e funcionamento de cada setor desse ambiente que se caracteriza por suas especificidades.

Una vez comprendido que la vida empieza y acaba generalmente en los hospitales, y que son precisamente los centros de salud y sus profesionales los que tratan de hacer que el paso por este mundo sea más llevadero y saludable, la nueva arquitectura hospitalaria está empezando a mostrar también el lado más humano. (...) el trabajo arquitectónico de las clínicas y hospitales debe ser entendido como un arte y una técnica capaz de acercar al hombre al estado de bienestar deseado, procurando a su vez que la estancia en un centro sanitario deje de ser algo que para muchos todavía es algo incómodo. (BROTO, 2009, p. 7)

Implantar uma unidade hospitalar é um desafio arquitetônico, pois deve prever o equacionamento correto de suas principais circulações e a flexibilidade relacionada à ampliação e adaptação que o edifício enfrentará por causa das constantes atualizações impostas pela evolução da ciência da saúde. Os projetos devem considerar a distribuição das áreas, estabelecendo relações de proximidade entre especialidades afins. 
$\mathrm{Na}$ Figura 18 vemos um exemplo bem atual de arquitetura do edifício hospitalar, um projeto de Frank Gehry. A Cleveland Clinic Lou Ruvo Center for Brain Health, em Las Vegas (Nevada, EUA), destinada ao tratamento, pesquisa e ensino de saúde mental, tem uma construção inusitada que apresenta novas formas de linguagem em termos de design arquitetônico, com uma construção surreal que tem o cérebro como inspiração.

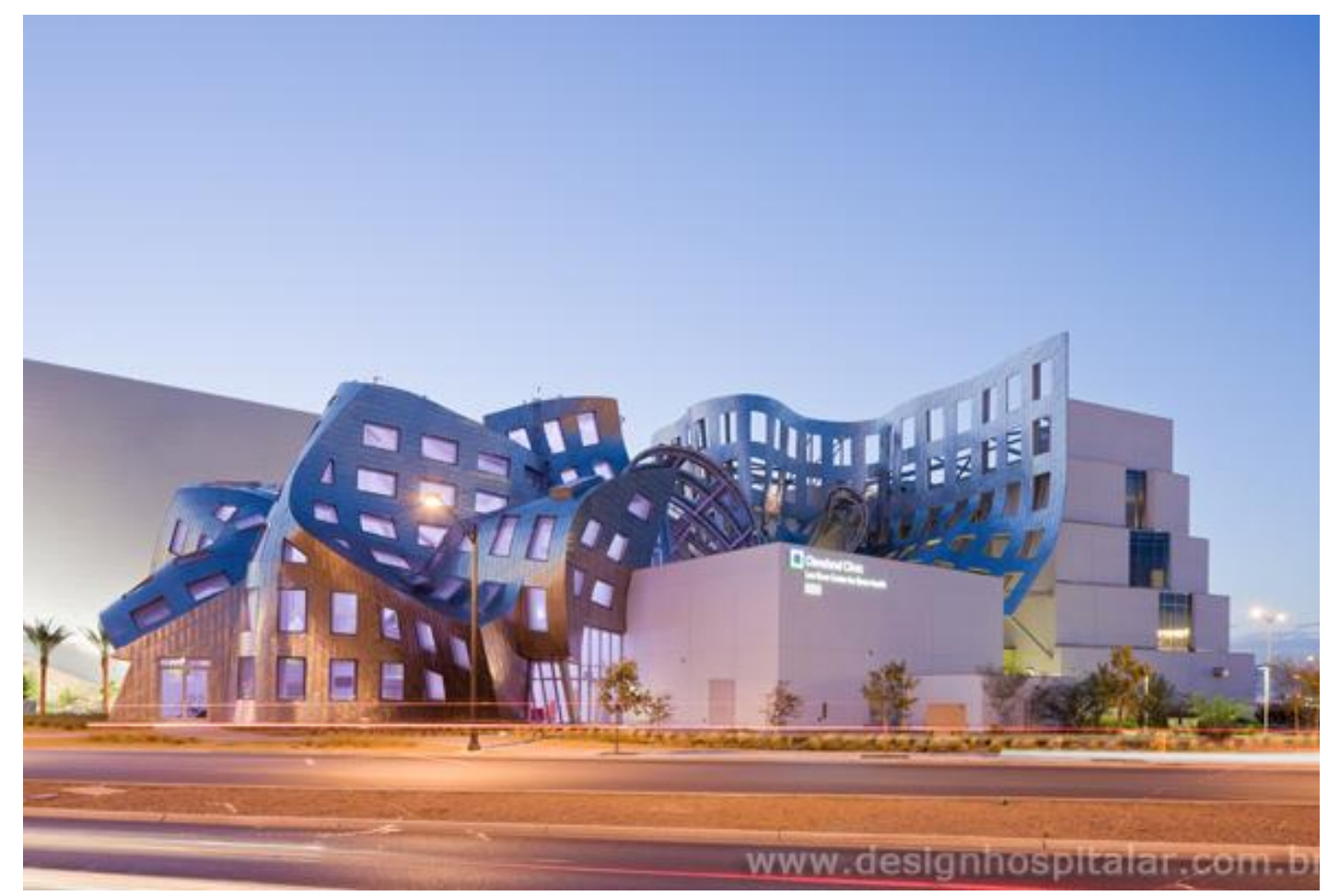

Figura 18 - Cleveland Clinic Lou Ruvo Center for Brain Health Fonte: unw.saudebest.com.brhome/saude-best-2010/

A arquitetura hospitalar requer uma série de preocupações com a satisfação e bem-estar tanto para o público interno (equipe médica, funcionários, setores administrativos, logísticos e técnicos) quanto do externo (paciente, acompanhantes, visitantes).

A elaboração do projeto arquitetônico para construção de estabelecimentos assistenciais de saúde é um processo complexo que deve buscar, invariavelmente, satisfazer uma significativa diversidade de critérios técnicos e de compatibilidades físico-funcionais. A concepção da solução projetual, além de atender às demandas da tecnologia médica, às características geográficas regionais, à flexibilidade dos espaços determinada pelas variáveis epidemiológicas, deve contemplar, com fundamental relevância, a satisfação do usuário através do conforto ambiental em seus diversos aspectos (BITENCOURT, 2008, p. 63) 
O arquiteto hospitalar deve estudar as soluções de implantação dos edifícios, considerando prioritariamente suas características funcionais, proporcionando, com estética e criatividade, uma utilização econômica e confortável. Exemplo dessa aplicação arquitetônica é procurar diminuir os percursos e cruzamentos entre os diversos trajetos da unidade (CARVALHO, 2004), facilitando o acesso e a circulação dos usuários. A CV pode auxiliar essa circulação com sinalizações de orientação de fluxo, que devem, já em seu planejamento, prever possíveis alterações futuras acompanhando as mudanças que se fizerem necessárias no ambiente hospitalar.

\subsubsection{Necessidades de normas específicas}

Os projetos de hospitais físicos de Estabelecimentos Assistenciais de Saúde (novas construções, áreas a serem ampliadas ou reformas) exigem atenção especial, dada sua complexidade e seguem as normatizações da Agência Nacional de Vigilância Sanitária - ANVISA (Resolução - RDC no. 50, de 21 de fevereiro de 2002), feitas com o intuito de dimensionar e organizar, de forma efetiva e eficiente, os estabelecimentos públicos ou privados. Cada EAS tem um programa arquitetônico que varia de acordo com as atividades que nele ocorrem e com os ambientes necessários para a realização dessas atividades. São considerados ambientes os espaços fisicamente determinados e especializados para o desenvolvimento de determinada(s) atividade(s), caracterizados por dimensões e instalações diferenciadas, podendo se constituir de uma sala ou de uma área (ex.: sala de atendimento individualizado, de demonstração e educação em saúde, de imunização, de preparo de paciente, de serviços, de curativo; consultórios diferenciados, de serviço social, odontológico; posto de enfermagem e serviços; quarto etc.).

$\mathrm{Na}$ atualidade, as normas vigentes para a arquitetura hospitalar destacam como aspectos mais importantes aqueles que privilegiam a humanização dos ambientes e a flexibilidade para atender à constante necessidade de reformulação e expansão. As disciplinas que se dedicam a focar os EAS os compreendem como ambiente de organizações mais complexas, que envolve um elevado nível de planejamento e muitos elementos, que no tocante à 
arquitetura exige a necessidade de compreender o funcionamento hospitalar para poder desenvolver bons projetos de acordo com os recursos disponibilizados pela instituição. (RODRIGUES, 2008, p. 17)

É preciso elaborar fluxogramas e funcionagramas para que se tenha um bom projeto arquitetônico de um Estabelecimento de Saúde, com o intuito de solucionar corretamente seus fluxos internos, externos e acessos. Isso refletirá em toda a vida útil do edifício. Deve ser feito também um estudo das interrelações entre os diversos serviços, estacionamentos, urbanização de vias, paisagismo e outros cuidados variáveis, de acordo com o porte da unidade (CARVALHO, 2002, p. 23). Esse estudo também é necessário ao se planejar um sistema de CV. Em um hospital, o fluxo de pessoas varia de acordo com seus usuários.

Há os [usuários] que possuem maior tempo de contato com o edifício de saúde e que, por isso, têm menos necessidade de chaves exteriores de informação visual; geralmente, trabalham ali como auxiliares, pessoal administrativo, paramédico ou médico. E, por outro lado, há os que demandam do sistema de comunicação visual informação precisa e imediata, pois ou são estranhos ao estabelecimento, ou seus usuários esporádicos; são os pacientes (externos e internos) e as visitas. Pode-se, porém, examinar tal desempenho em sua validade para qualquer indivíduo, trabalhando-se com características de aprendizado comuns à espécie humana (universais no desenvolvimento cognitivo). (BRASIL, 1995, p. 13)

De acordo com Bitencourt (2008, p. 72), diferente de outras instalações, os hospitais devem ser mantidos em condições higiênicas que impeçam a difusão de bactérias e vírus patogênicos. Para isso, esses ambientes devem "ser divididos em setores específicos e isolados para impedir a contaminação cruzada das áreas por efeito da difusão do ar".

Além das normas relacionadas a controle de infecção, hospitais devem dar atenção especial a pessoas com deficiências, sobretudo as visuais ou de locomoção, porque nesse ambiente há grande possibilidade de usuários terem problemas (temporários ou não) que os impeçam de caminhar com destreza. Cadeiras de rodas devem estar sempre disponíveis, assim como sinalização específica para deficientes visuais. 
As diretrizes relativas à acessibilidade garantem que o acesso dos portadores de deficiência seja facilitado e que estes também possam ter autonomia em sua locomoção pelo hospital. A Norma NBR 9050 (Decreto Federal 5296)

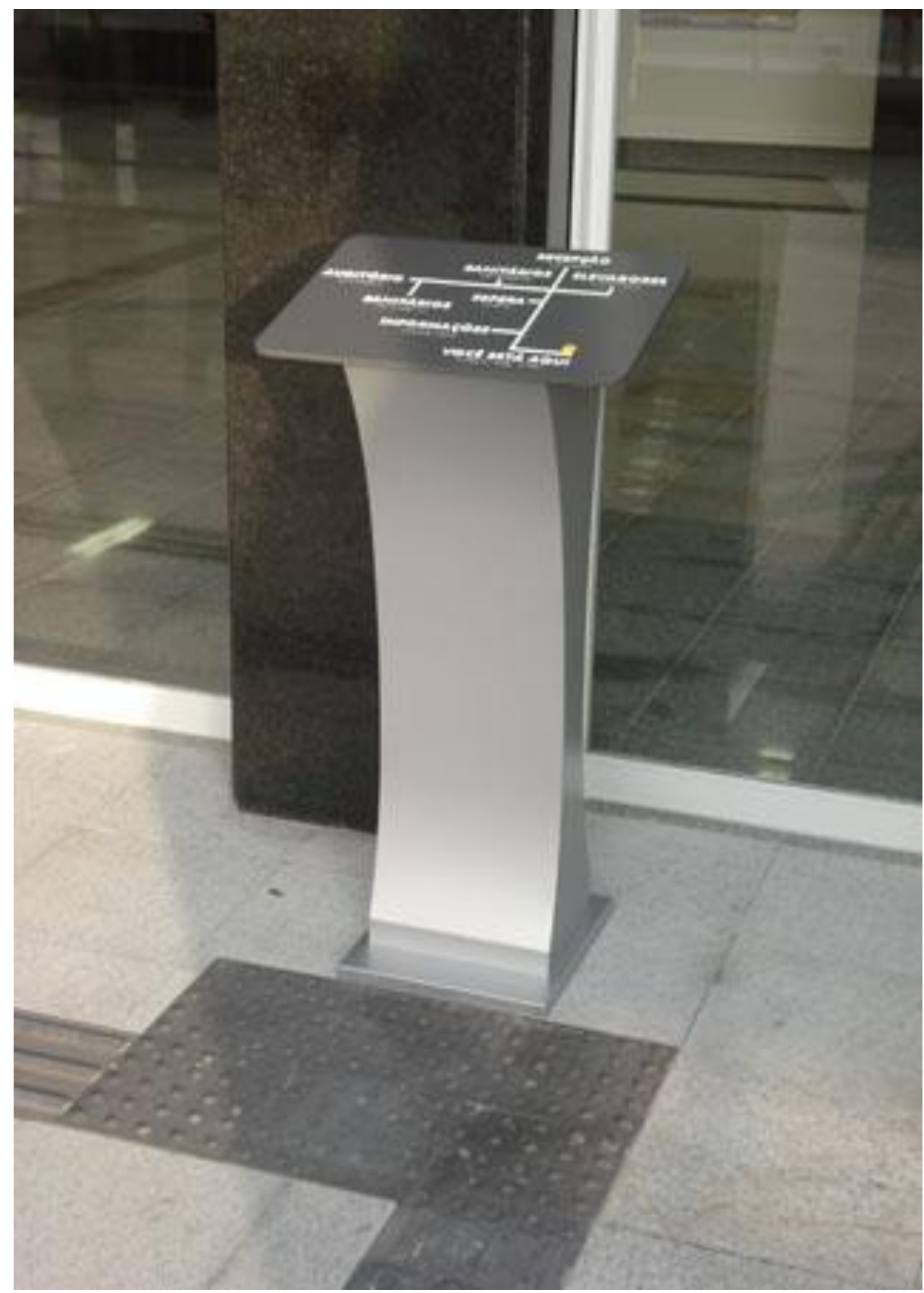

Figura 19 - Mapa tátil

Fonte: www.arcomodular.com.br

orienta como a sinalização deve ser feita para atender as necessidades desses usuários. A Figura 19 mostra, como exemplo de acessibilidade, um mapa tátil do Hospital M'Boi Mirim, hospital da rede municipal de São Paulo, para atender os preceitos de acessibilidade, inclusive com as referências de chegada a ela viabilizadas pelo piso diferenciado. 


\subsubsection{Materiais}

Um ambiente hospitalar, por sua natureza, exige maior cuidado e atenção com os materiais empregados em todos os objetos colocados em seu interior, sobretudo para evitar riscos de infecção e contaminação. Nesse sentido, os materiais utilizados para a confecção das peças de CV a serem colocadas nesses espaços devem obedecer às regras estabelecidas por órgãos competentes.

Alguns materiais (alumínio, bronze, latão altamente polido, vidro, madeira etc.) podem servir também como decoração, mas é preciso considerar questões relativas aos processos de fabricação para evitar acúmulo de elementos patogênicos. O uso de materiais contemporâneos (inox, gesso, granito, alumínio composto, vidro etc.) pode dar um ar de modernidade, remetendo a conceitos de inovação e tecnologia.

Preocupado com a ideia de criar uma atmosfera agradável que revelasse a hospitalidade em dois hospitais japoneses (Hospital Umeda, em 1998 e Hospital Katta, em 2002), o designer Kenya Hara criou uma sinalização feita em algodão lavável, conceito derivado das toalhas brancas de restaurantes, dando noção de limpeza e de hospitalidade, como mostram os exemplos (Figura 20 e Figura 21).

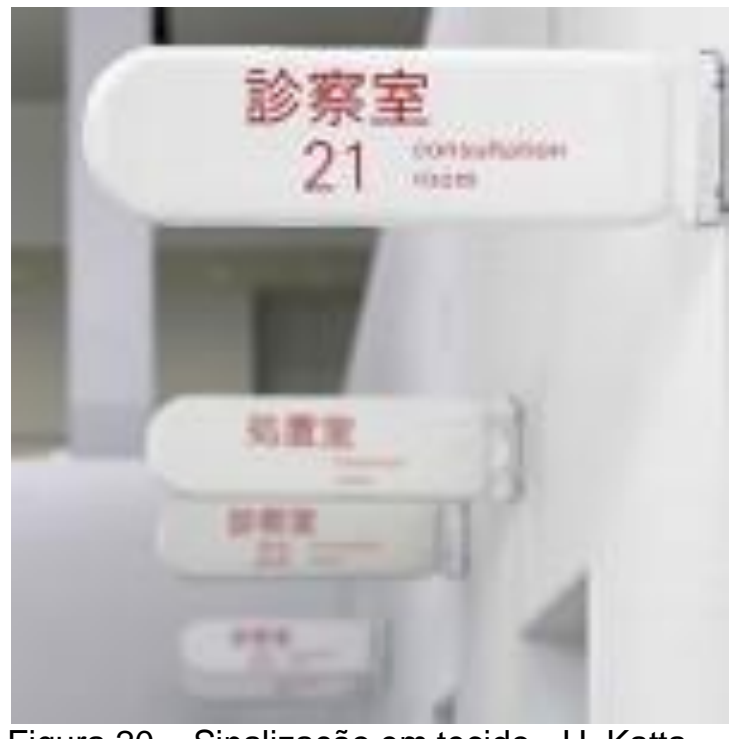

Figura 20 - Sinalização em tecido - H. Katta Fonte: uww.spoon-tamago.com/2008/09/17/kenya-hararetrospective-part-2/

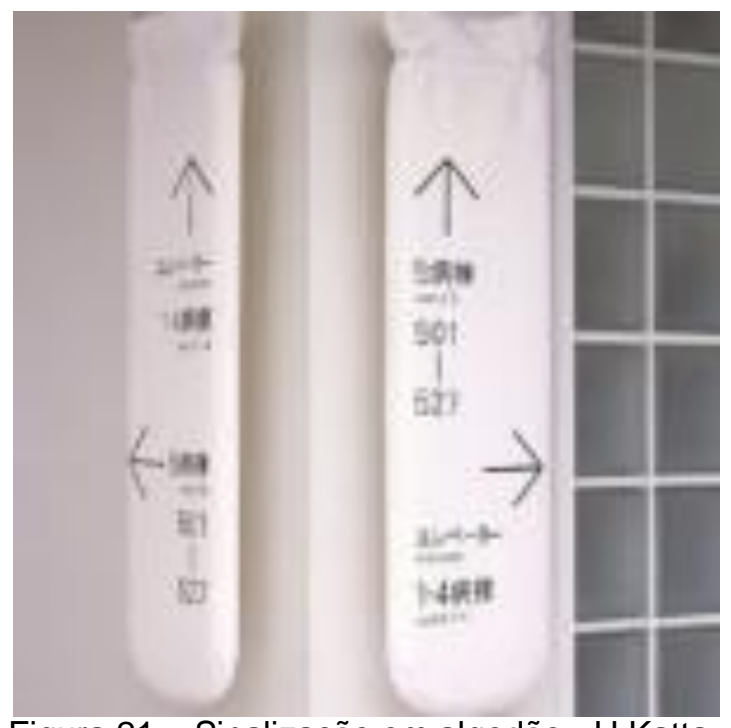

Figura 21 - Sinalização em algodão - H.Katta Fonte: unw.spoon-tamago.com/2008/09/17/kenyahara-retrospective-part-2/ 
Uma questão a ser considerada é quanto a casos diferenciados, nos quais pacientes precisem de cuidados específicos. Um exemplo é o Hospital Vera Cruz, clínica de tratamento psiquiátrico, localizado no bairro Jaçanã (em São Paulo). As peças de CV, além de seguirem regras de segurança específicas, "foram desenvolvidas totalmente em adesivos recortados e aplicados sobre as superfícies: portas, paredes, etc.”, sem arestas, sem superfícies rígidas, sem componentes em acrílico ou vidro nem outros elementos que possibilitem que um paciente, em surto, utilize-as para se ferir ou ferir outras pessoas (GREVY; GUIMARÃES; VENDRAMINI, 2007).

\subsubsection{Linguagem visual}

A eficácia de um sistema de CV é, em grande parte, resultado da linguagem utilizada para transmitir a identidade, indicar direções, orientar fluxos e transmitir mensagens de segurança, de alertas ou mensagens com avisos gerais. A linguagem pode representar e comunicar os objetos, ações e sentimentos em nossas vidas por palavras e/ou imagens. Palavras são formadas a partir de uma ou mais línguas e podem ser representadas por uma grande variedade de tipos de fontes e são um método eficaz de comunicar ideias complexas inter-relacionadas.

Podemos definir projetos de sinalização como uma associação de formas escultóricas informativas distribuídas num determinado espaço físico, aberto ou fechado. Suas características mais importantes são a legibilidade e a veiculação de informações compreensíveis e fidedignas que antecipem as necessidades de esclarecimento dos usuários. (...)

Existem basicamente dois tipos de projetos de sinalização. O primeiro é aquele elaborado para novos edifícios (...). O segundo envolve projetos de sinalização de edifícios já em uso, portanto, com uma dinâmica de ocupação consolidada. (CHAMMA; PASTORELO, 2007, p. 151)

Por meio de um código lógico que utiliza recursos visuais (alfabeto, cor, pictogramas), as mensagens são emitidas com facilidade, rapidez e de forma instantânea, evitando ambiguidade na tomada de decisões.

(...) Os códigos dos quais a ergonomia pode se valer em relação a percepção visual são (a) cromático: seu uso é vital para reforçar a informação, em 
função de diversos objetivos; (b) tipológico: refere-se as letras, números, e outros caracteres e sinais com os quais a informação é produzida; (c) morfológico: vale-se das leis da gestalt, deve visar a melhor organização visual possível em termos de harmonia, equilíbrio, suporte e informação; é de fundamental importância para facilitar a percepção e a rapidez da leitura da mensagem veiculada; (d) tecnológica: diz respeito aos materiais, às técnicas e aos processos de produção, reprodução e transmissão da informação visual e no que se refere aos elementos estruturais de configuração e sustentação física do signo. (EVERLING et al., 1999, p. 4)

Os textos utilizados para compor a sinalização devem ser claros e diretos e, para isso, o melhor é usar o modo imperativo, pois "o usuário não pode parar para pensar", "deve obedecer instintivamente". As palavras utilizadas devem ser simples, curtas, sobretudo porque o espaço geralmente é escasso. Além disso, os termos utilizados devem ser reconhecidos por todos os usuários, não apenas pela equipe médica. $O$ uso de palavras longas pode implicar em redução da dimensão da letra e isso diminui a legibilidade (CHAMMA; PASTORELO, 2007, p. 156).

A Figura 22 é uma ilustração de organização de sistema de CV para um

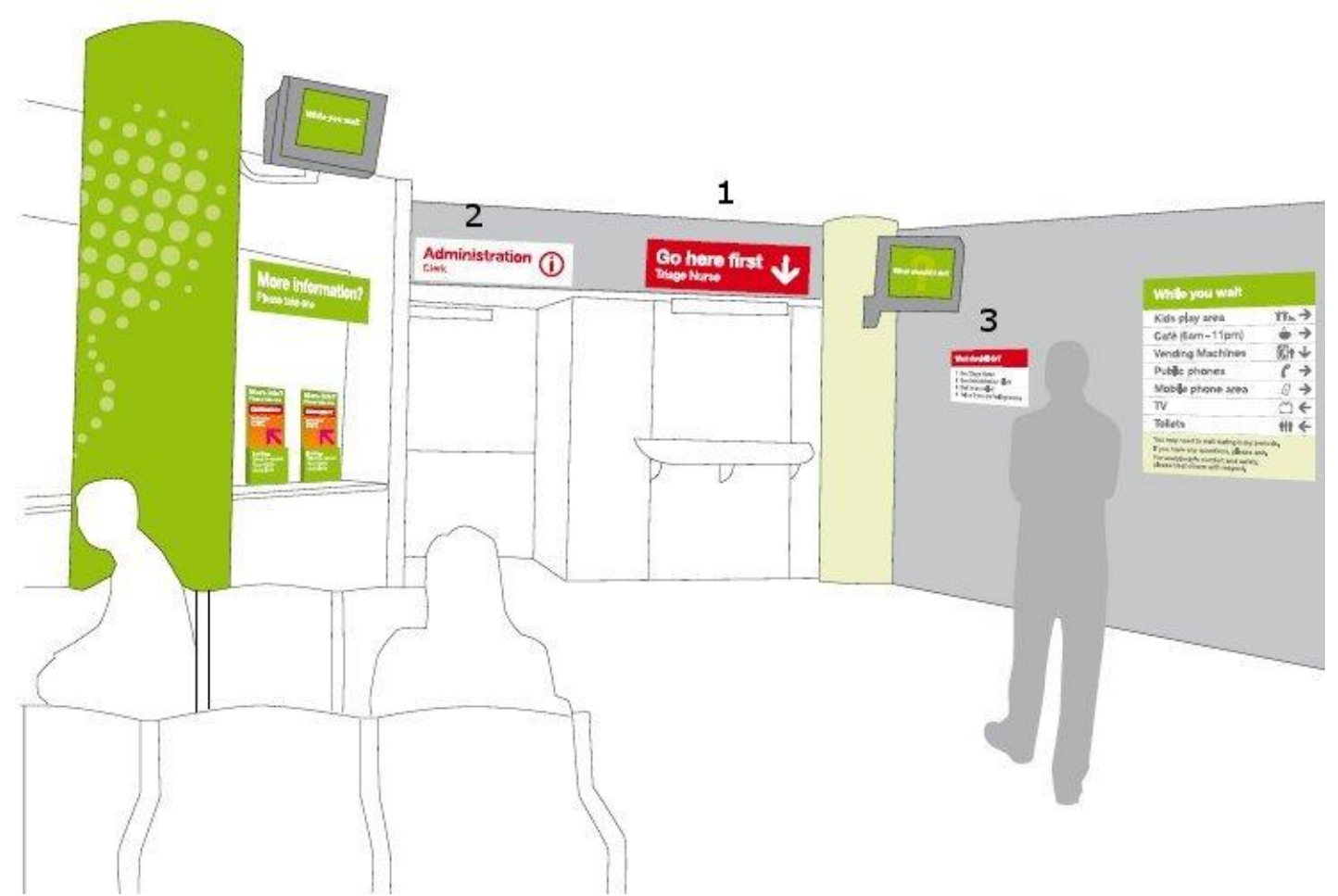

Figura 22 - llustração de CV em emergência

Fonte: Victorian (2009, p. 27)

Departamento de Emergência, apresentando possibilidades de posicionamento para as peças de comunicação (VICTORIAN, 2009, p. 27). Informações bem posicionadas, possíveis de serem vistas e lidas com facilidade ajudam a tornar 
o ambiente não poluído visualmente. Em destaque, há uma placa (1) indicando claramente o que deve ser feito assim que o usuário chega (Go here first). À esquerda há uma placa (2) indicando o local para onde o paciente será encaminhado posteriormente (Administration). Na parede lateral há uma placa (3) com indicações de procedimentos a serem realizados. Em especial em um Departamento de Emergência, é preciso que as informações sejam rapidamente identificadas, evitando atrasos por problemas de comunicação.

A sinalização visual (enquanto parte de um sistema de CV) auxilia na construção de uma ambiência ao proporcionar autonomia e segurança aos usuários. Isso é possível quando esse conjunto tem uma linguagem visual que seja adequada ao hospital (possibilitando que este reflita sua identidade) e, ao mesmo tempo, seja clara e eficiente (possibilitando que os usuários se locomovam com mais facilidade).

\section{Go here first Triage Nurse}

\section{Administration Clerk

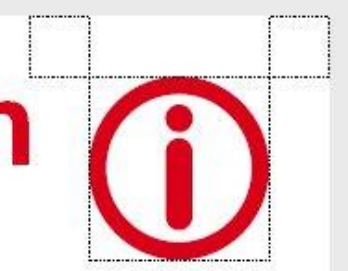

EOS(a)

\section{Administration} Clerk

\section{What should I do?}

1 See Triage Nurse

2 See Administration Clerk

3 Wait to be called

4 Tell us if you are feeling worse

Max $400 \mathrm{~mm}$

Figura 23 - Exemplo de placas de sinalização

Fonte: Victorian (2009, p. 20)

Retomando o exemplo dado no item anterior (Figura 22), referindo-se ao guia para sinalização de um Departamento de Emergência, a Figura 23 apresenta 
em destaque as placas mencionadas (1, 2 e 3). A mensagem principal de orientação (bem simples e clara: Go here first - Triage Nurse) ganha destaque pela cor vermelha no fundo, contrastando com as letras brancas. A mensagem indicando onde fica o setor "Administração" tem duas versões possíveis, com ou sem o símbolo de informação, mas ambas com fundo branco em contraste com as letras em vermelho. A placa 3 fornece informações sobre procedimentos a serem realizados, dando indicações em etapas básicas, passo a passo (1 See Triage Nurse; 2 See Administration Clerk; 3 Wait to be called; 4 Tell us if you are feeling worse).

Quanto aos caracteres (alfabeto e números), há que se considerar que as placas de sinalização devem possibilitar a legibilidade. As recomendações feitas por Dul (2004, p. 43-47) são:

- evite textos com todas as letras maiúsculas - os textos que usam só letras maiúsculas não são muito legíveis;

- os alinhamentos à direita não devem deixar espaços em branco - prejudicam a legibilidade, quebrando a continuidade da linha;

- use tipos de letras simples - caracteres mais simples são mais legíveis;

- evite confusão entre letras - há confusões causadas pelo formato semelhante entre certas letras e números (ex.: entre $\mathbf{O}$ e Q; T e Y; S e 5; I e L; I e 1);

- as letras devem ter tamanho adequado - usar letras com formas e proporções adequadas à distância de leitura. Em cartazes, para uma distância de 100 cm, a letra deve ter pelo menos $5 \mathrm{~mm}$ de altura;

- as linhas longas exigem maior espaçamento entre elas - quanto maior o comprimento da linha, maior deverá ser o espaçamento;

- um bom contraste ajuda na legibilidade - o contraste é a diferença de brilho entre a figura e o fundo. Aumentando-se o contraste, há melhoria da legibilidade;

- use símbolos com cuidado - são recomendáveis para avisos em locais públicos, onde circulam muitas pessoas. Seu uso requer cuidados (considerar diferenças culturais e a imagem mental que as pessoas possam ter sobre 0 significado de um símbolo; transmitir apenas um conceito em cada imagem; não utilizar símbolos muito estilizados, que se afastam da realidade por serem mais difíceis de serem entendidos). 
As cores podem ser utilizadas tanto para influenciar no processo terapêutico quanto para orientar o fluxo, colaborar para diferenciar setores (tipos de atendimentos, especialidades, tipos de serviços etc.) ou ainda reforçar a identidade visual da instituição. O emprego de cores em geral é bem diversificado, mas há que se considerar, em especial que

As cores ou composições cromáticas, em um hospital, estão presentes em todo o espaço visual; desde os uniformes, equipamentos, até obras de arte e mobiliário, e juntamente a outros elementos arquitetônicos, compõem o espaço. Ela [a cor], no entanto, não serve somente como um elemento estético ou decorativo em um ambiente; pode desempenhar outras funções, como a de prover informação como, por exemplo, a orientação das circulações e a setorização das áreas de um hospital. (MATARAZZO, 2010, p. 148)

As cores utilizadas nas peças de sistemas de sinalização podem servir como relação de contraste entre figura e fundo ou como fator relevante da relação das cores para a pertinência corporativa (GUIMARÃES, 2006, p. 84). O logotipo pode ser colocado em cada sinalização, além do uso da cor da instituição, como é o caso da sinalização do Hospital São Camilo (Figura 24).

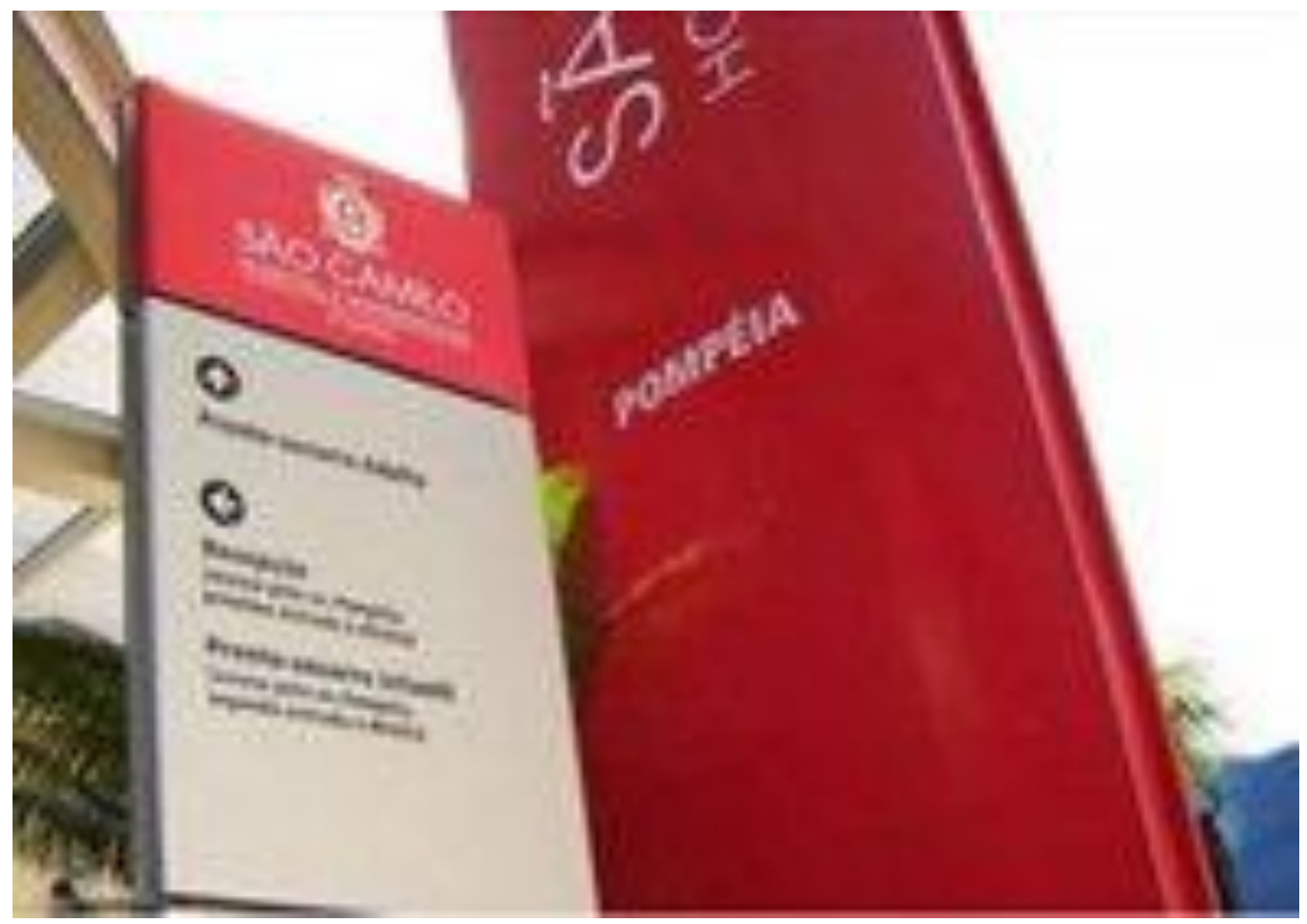

Figura 24 - Sinalização com logotipo do hospital

Fonte: uww.kojima.com.br/?gclid=CL-53uSp0KcCFUHr7QodoSByqw

As cores também podem ser utilizadas para diferenciar setores, 
departamentos, alas, serviços etc. Um exemplo é o projeto desenvolvido pelo Laboratório de Imagem (Labim) da Faculdade de Arquitetura e Urbanismo da USP para o Instituto de Psiquiatria do Hospital das Clínicas da Faculdade de Medicina da Universidade de São Paulo. O código cromático foi utilizado para identificar os três blocos da instituição (verde para o Bloco Sul; laranja para o Bloco Central e lilás para o Bloco Norte).

A Figura 25 apresenta o mapa esquematizado com a aplicação do código cromático. Esse mapa de localização, colocado em corredores em painéis de

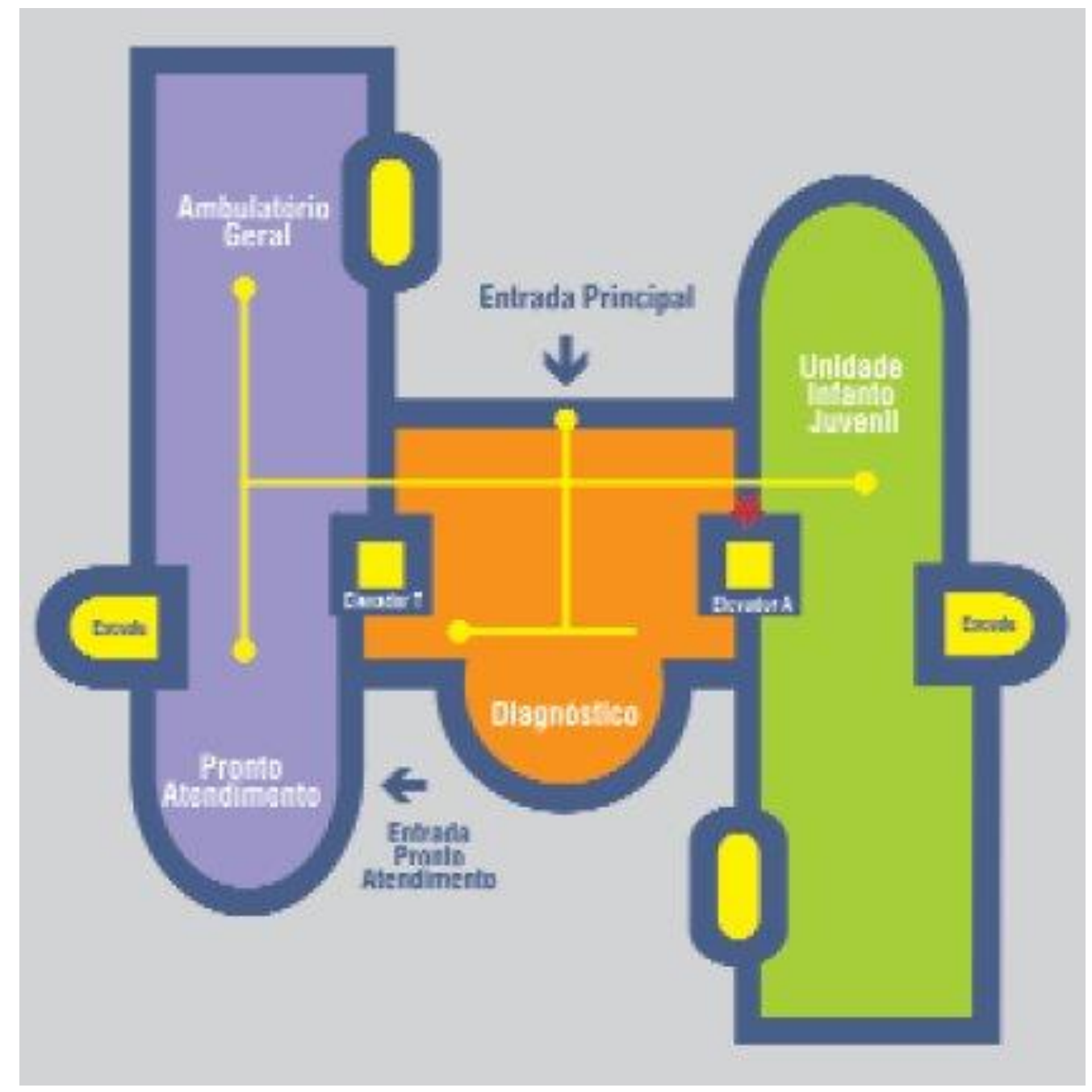

Figura 25 - Projeto de sinalização do IPQ-HC

Fonte: Romão (2006, p. II)

identificação que indicam os serviços em cada bloco e andar, serve como facilitador para o usuário. De forma rápida este pode localizar as informações necessárias para sua locomoção dentro da instituição (Figura 26). Os grafismos e a sinalização acompanham o código morfológico (Figura 27). 


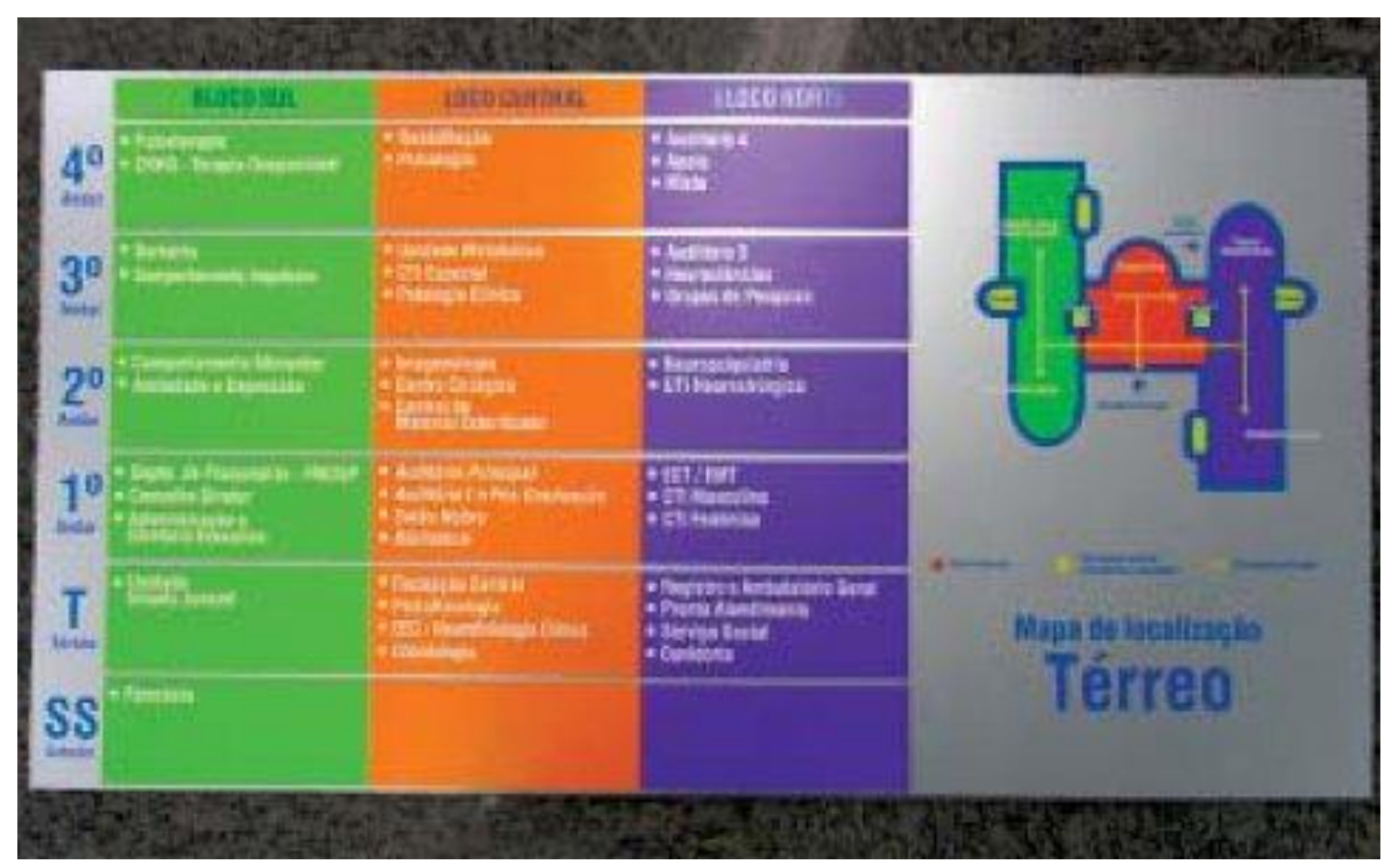

Figura 26 - Painel de identificação do IPQ-HC

Fonte: Romão (2006, p. II)

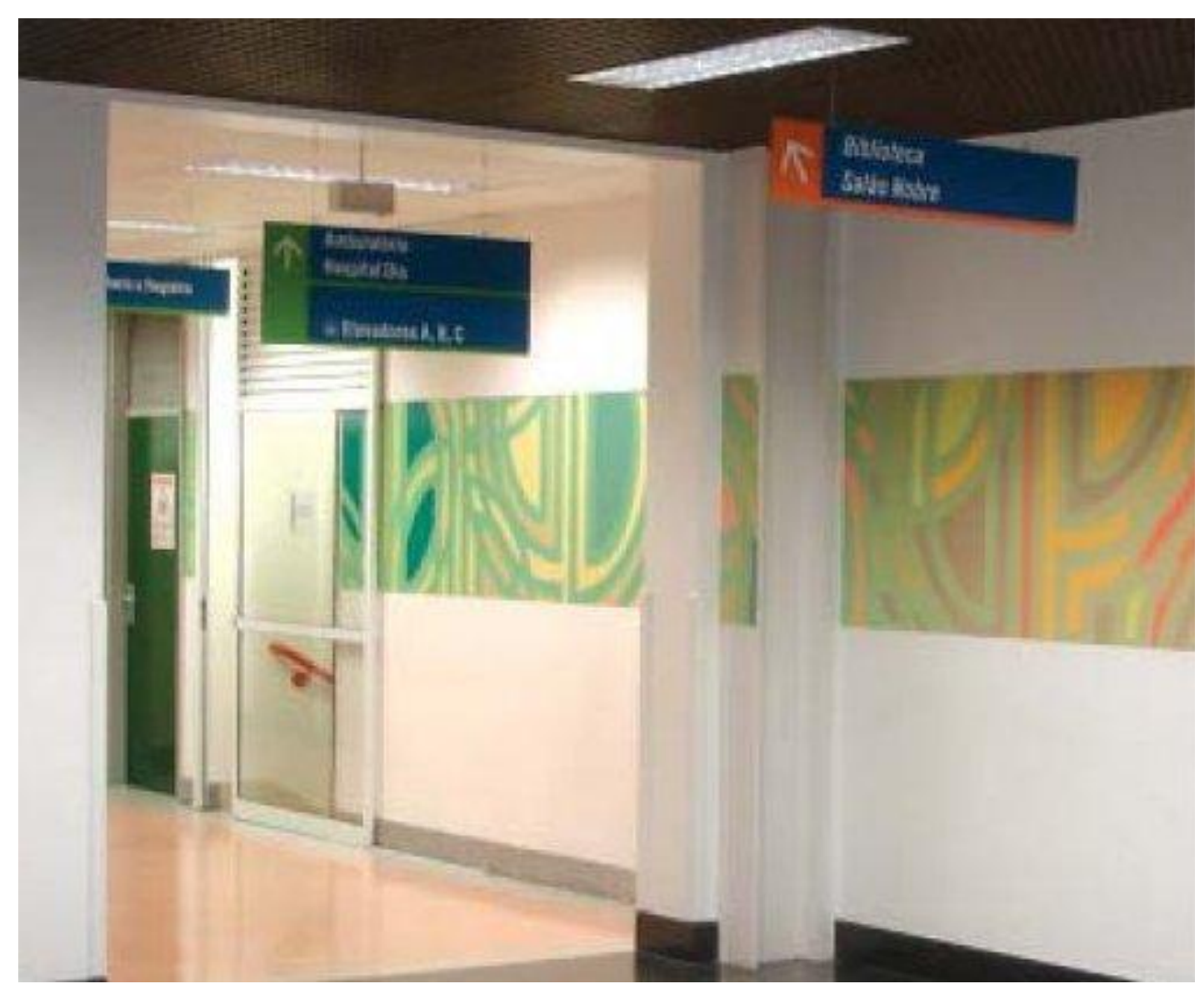

Figura 27 - Sinalização do IPQ-HC

Fonte: Romão (2006, p. 17) 
Em alguns casos, são utilizadas cores no piso para orientar o fluxo, como mostra a Figura 28. O Denver Children's Hospital, EUA, adotou o sistema de orientação de fluxo com faixas no piso e nas paredes, facilitando a circulação de usuários. Esse sistema facilita a identificação de caminhos a serem realizados e, ao mesmo tempo, podem servir como elemento decorativo, sobretudo em casos de hospitais infantis. Um ambiente colorido pode chamar mais a atenção de crianças, servindo como distração.

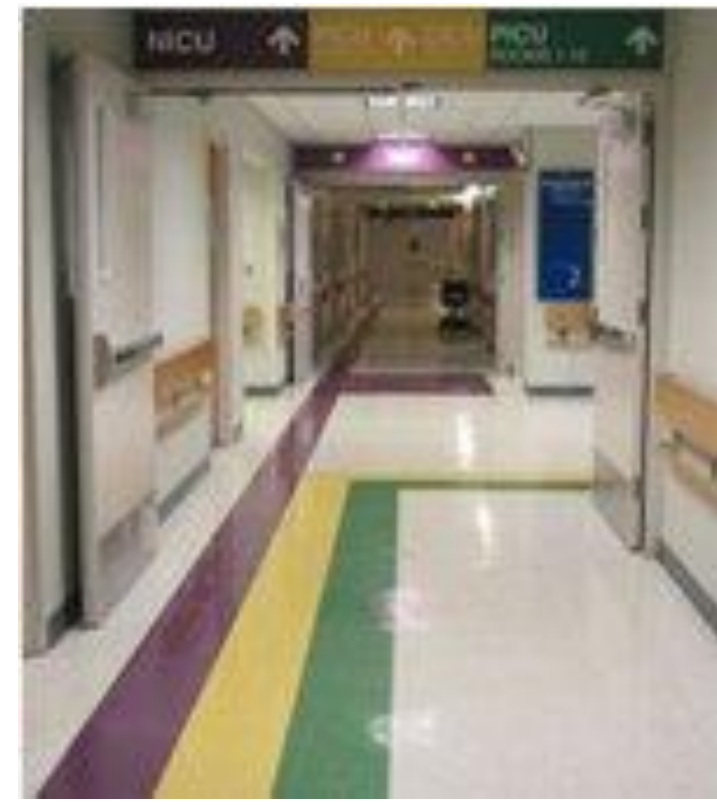

Figura 28 - Piso para orientar fluxo Fonte:

unw.inktankdesign.com/porttolio.php?cat=environment\&i $\mathrm{d}=$ enviro2CROOKED

Metodologias de imagem podem variar de uma codificação mais elaborada (ilustrações pictóricas e fotografia) para uma mais simples (cores e símbolos).

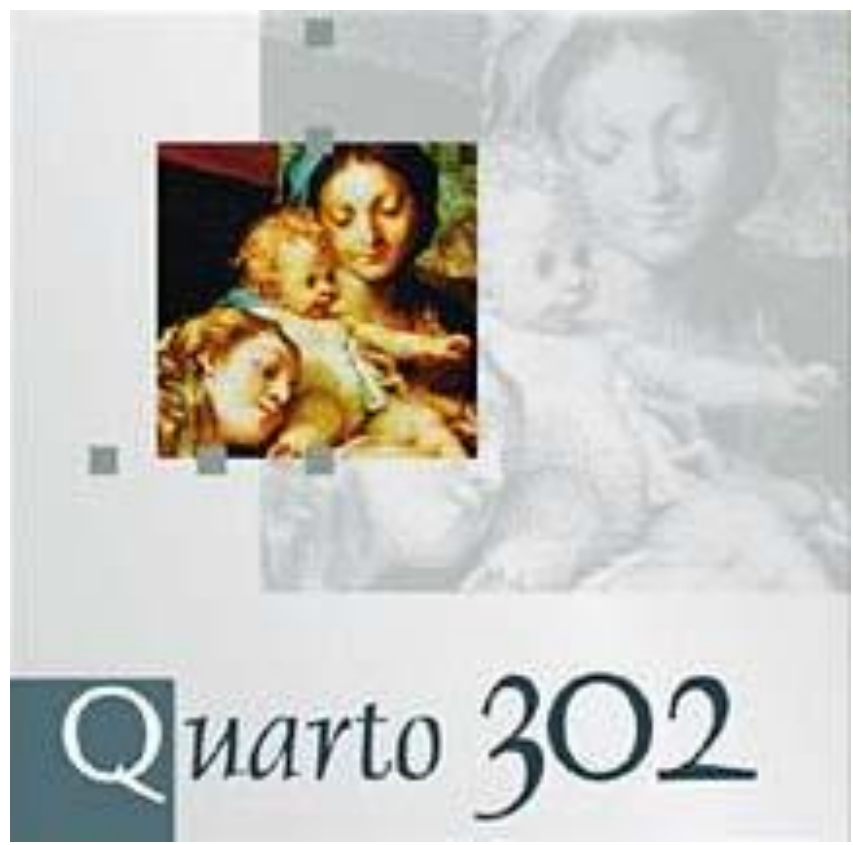

Figura 29 - Exemplo de ilustração pictórica em sinalização Fonte:uww.videsign.com.brfllashbase.htm

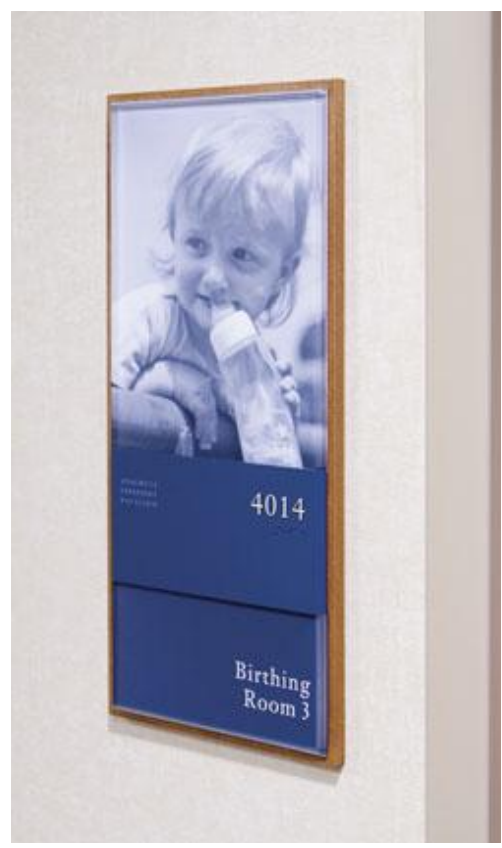

Figura 30 - Exemplo de fotografia em sinalização Fonte:www.fd2s.com/work/ 
Em um hospital não é muito comum o uso de ilustrações pictóricas e fotografias na sinalização, mas temos como exemplo a Figura 29, que mostra sinalizações feitas pelo escritório Vera London Design para a Clínica Perinatal Laranjeiras, no Rio de Janeiro e a Figura $30 \mathrm{com}$ exemplo de fotografia em sinalização feita pelo escritório fd2s para o hospital da Universidade de Colorado, EUA.

Símbolos podem contribuir para a simplicidade, clareza e personalidade de um sistema de sinalização. Devem ser o mais simples e diretos possível, sem perder a mensagem pretendida.

Os pictogramas, também conhecidos pelo nome de símbolos de sinalização, são signos de comunicação visual que têm por função transmitir mensagens de natureza informativa, prescritiva ou operativa ao maior número possível de pessoas, independentemente das diferenças de sexo, idade, instrução ou nacionalidade que elas possam apresentar. (SOUZA, 1995, p. 171)

Os sistemas de símbolos seguem regras para sua codificação e decodificação. Aprendemos a ler as informações codificadas e passamos a compreender as mensagens a partir de sua decodificação, ou seja, temos que aprender a convenção. No caso da leitura de pictogramas, sinais destinados a fornecer informações essenciais para serem compreendidos por pessoas de diferentes línguas, há que se considerar que estes são mais úteis quanto menos necessitem de aprendizagem de regras de decodificação. Para isso, a imagem utilizada para formar um pictograma "tende a assumir as características e a transmitir o sentido da total categoria dos objetos a que pertence o objeto em exame" (MASSIRONI, 1996, p. 118).

Quando se planeja um ícone, símbolo ou pictograma para expressar determinada informação, é necessário considerar o receptor, procurando evitar falha na transmissão de mensagens e, para isso, a simplificação é um ponto que tem sido destacado. $O$ excesso de informações pode causar ruídos na comunicação, a quantidade de estímulos visuais atrapalha a qualidade dos mesmos, portanto, a simplificação pode facilitar a descodificação da mensagem. A variedade de materiais e técnicas disponíveis deve contribuir para uma informação visual o mais legível e clara possível. O uso excessivo de recursos dispostos de forma aleatória pode tornar as mensagens mais complexas e confusas.

Para ilustrar o quanto pode ser diferenciado o sistema de sinalização, 
apresentamos três exemplos internacionais de projetos realizados para hospitais. Diversos fatores (barreiras linguísticas, diversidade cultural, humanização etc.) levaram alguns designers a desenvolver esses projetos.

Em 1978, foi realizado pelo escritório de Ronald Shakespear um sistema de sinalização para humanizar a ala de obstetrícia do Hospital Durand, em Buenos Aires utilizando uma cegonha como símbolo (Figura 31).

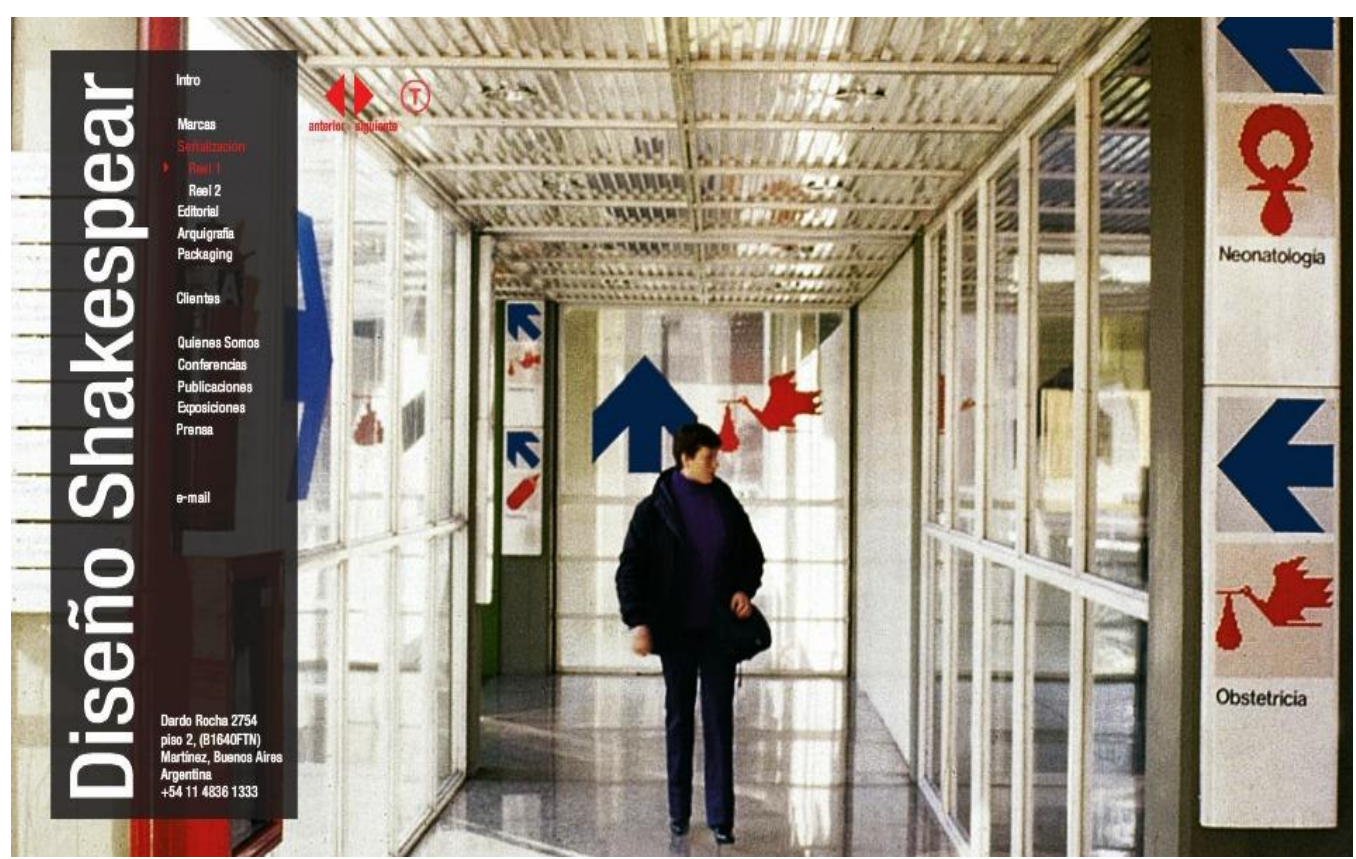

Figura 31 - Aplicação do sistema de sinalização

Fonte: www.webshakespear.com.br

Esse sistema acabou sendo mais tarde adotado em todos os hospitais da rede municipal (SHAKESPEAR, 2003, p. 113).

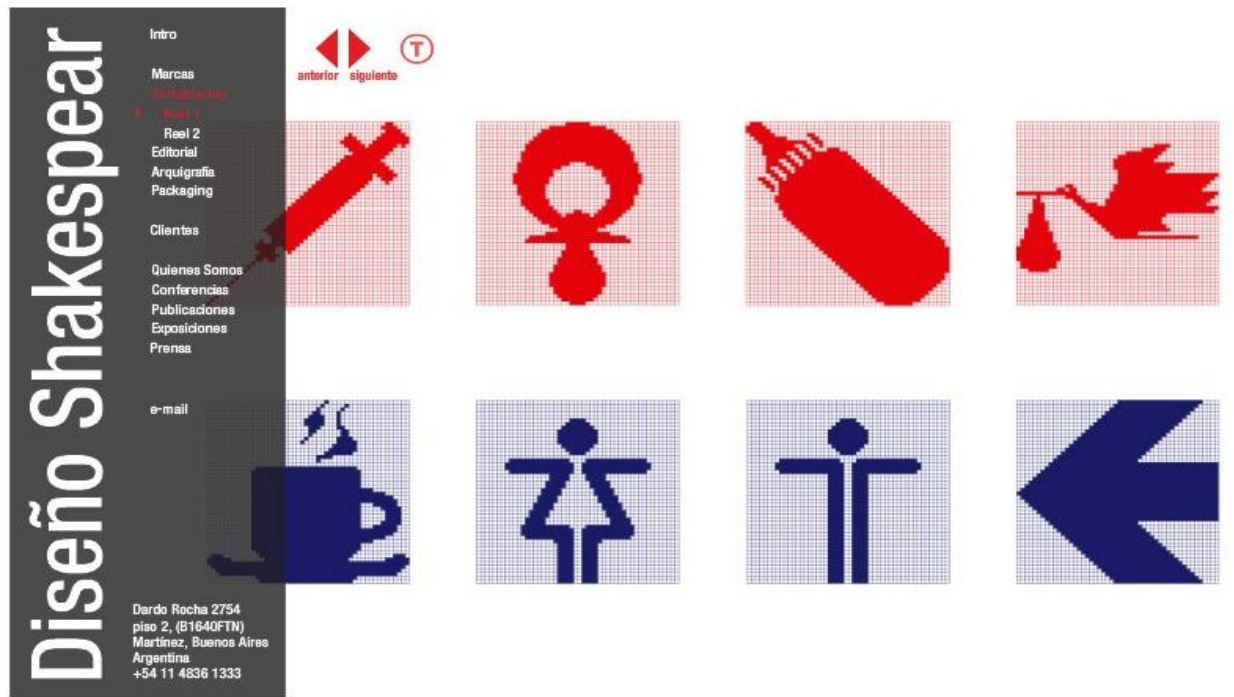

Figura 32 - Sistema de ponto cruz

Fonte: www.webshakespear.com.br 
A partir da cegonha, o repertório de símbolos de sinalização do hospital pioneiro foi desenvolvido como o mesmo caráter gráfico e conceitual, utilizando um sistema de ponto cruz (Figura 32): formas sensíveis; padrão de cor; temas afáveis para traduzir as disciplinas médicas e os serviços hospitalares relacionados a maternidades. Cegonha, mamadeira, injeção, chupeta foram símbolos utilizados para remeter à ideia de bebês

Em 1985, Ravi Poovaiah desenvolveu um estudo em cinco hospitais da Índia, dentro dos limites da cidade de Bombaim. A Índia tem uma diversidade linguística e cultural grande (14 línguas principais e cerca de 1.600 dialetos), além de ter muitos adultos literalmente analfabetos e uma limitação determinada pela cultura tradicional que faz distinções entre gênero e castas ou comunidades religiosas (GAKOPOULOS, 2009, p. 6).

A ausência de um sistema de signos acarretava vários problemas, tais como: não identificação dos serviços; usuários ficavam em filas erradas (sobretudo os que iam aos hospitais pela primeira vez), o que ocasionava perda de tempo, atrasos em consultas e filas longas.

O projeto envolveu a criação de um conjunto de possíveis soluções a serem testadas e avaliadas por usuários (pacientes, visitantes e funcionários do hospital). A partir dos resultados das avaliações, foi definido o conjunto mais apropriado para ser utilizado como linguagem alternativa, comum a pessoas com diferentes linguagens, letradas ou não (INDIA, 1985, p. 74).

A Figura 33 apresenta exemplos dos símbolos gráficos relacionados à identificação de pessoas (homem, mulher) e profissionais (médico, enfermeira), que revelam elementos culturais. Notamos que há uma diferenciação nas roupas (ícone "Homem 2", "Senhora 2, "Lady 2"). 

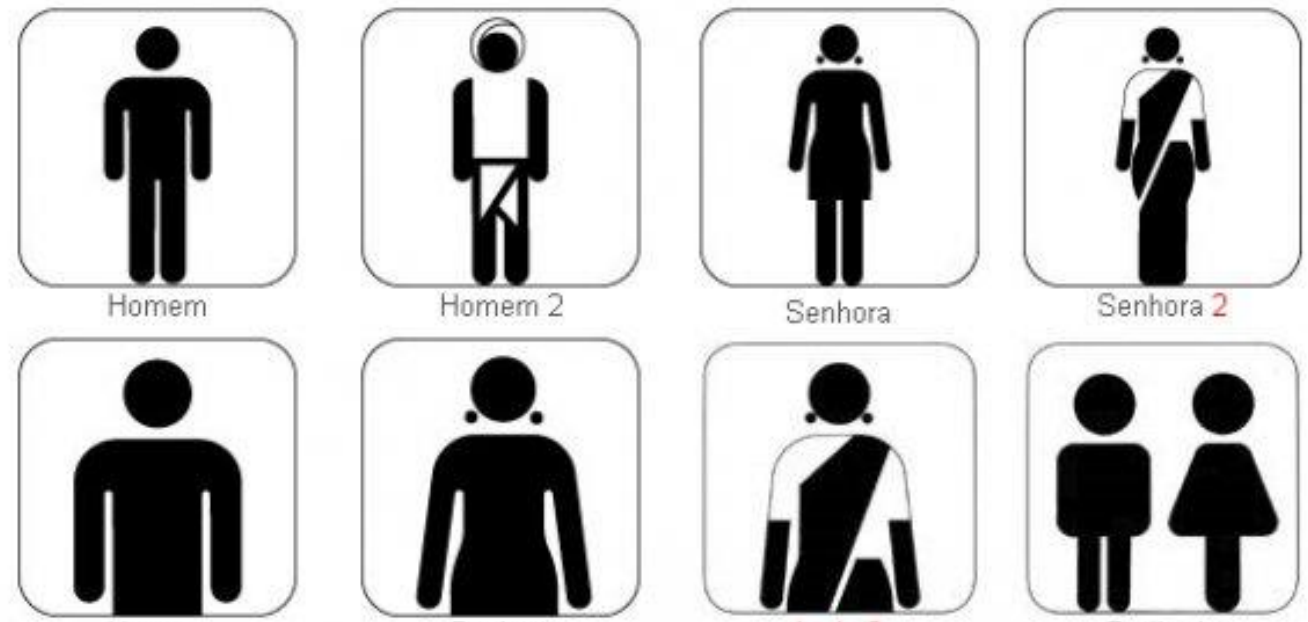

Homem

Senhora

Lady 2

Pediatria

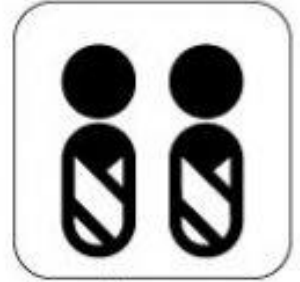

Nursary

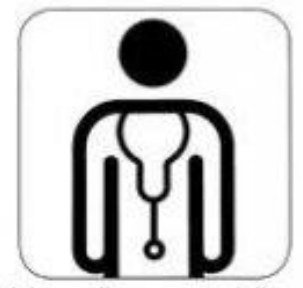

Masculino médico
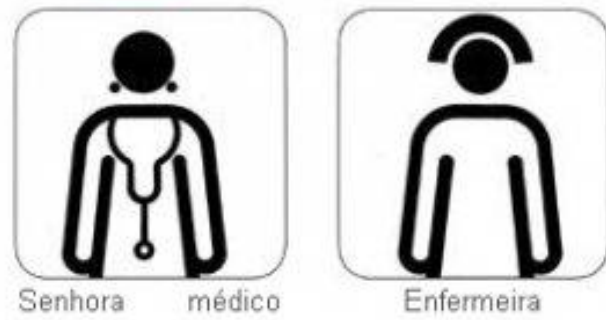

Enfermeira

Figura 33 - Símbolos gráficos 1 - Bombai

Fonte: desenhantes.wordepress.com/2010/04/30/estudo-de-caso-sinalizacao-hospital

A Figura 34 apresenta símbolos relacionados a algumas especialidades.

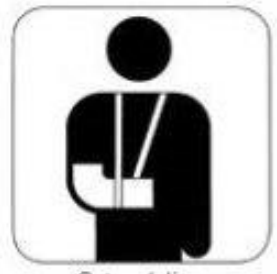

Ortopédico

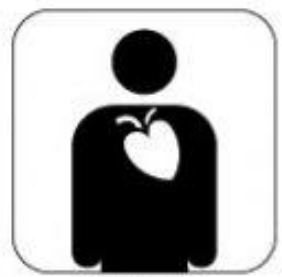

Cardiologia

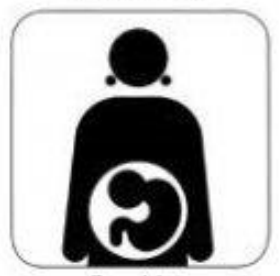

Gravidez

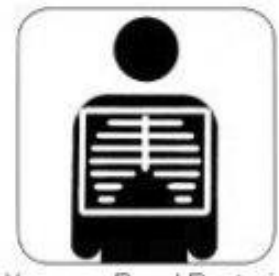

- Ray / Rastreio

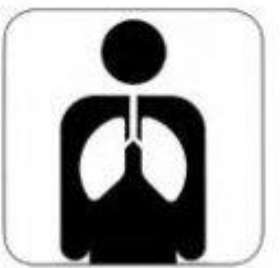

Respiratório

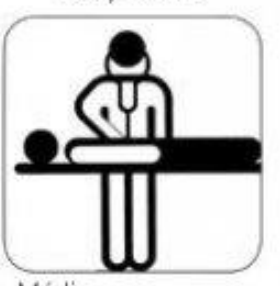

Médico

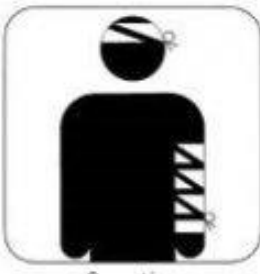

Curativo

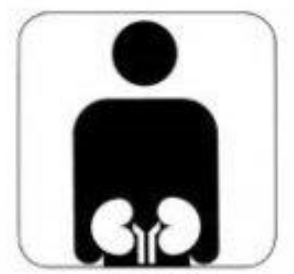

Urologia

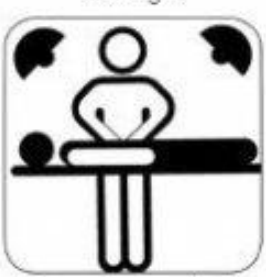

Operaçăo teatro

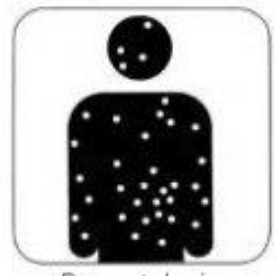

Dermatologia

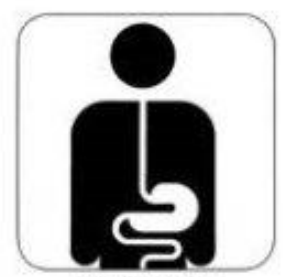

Gastrology

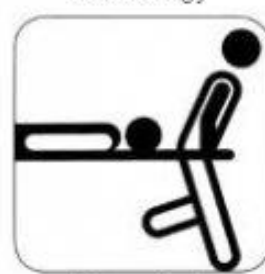

Emergência

Figura 34 - Símbolos gráficos 2 - Bombai Fonte: India (1985, p. 74) 
Em 2003, foi desenvolvido pela Society for Environmental Graphic Design (SEGD), com a JRC Design o projeto chamado Hablamos Juntos, que teve como objetivo melhorar a hospitalidade e permanência de pacientes latinos em quatro hospitais dos EUA: Sommerville Hospital, em Massachusetts, Saint Francis Medical Center, em Nebraska; Grady Memorial Hospital, em Atlanta e o Hospital Kaiser Permanente, em São Francisco. O desenvolvimento de pictogramas para a sinalização dos ambientes hospitalares baseou-se em evidências de que eles podem auxiliar não somente a comunicação dos indivíduos que não falam a língua inglesa, mas também daqueles que dominam o idioma. Sua aplicação nos espaços deve estar relacionada com um conjunto de normas suplementares que tenham por objetivo tornar a relação dos pacientes com os ambientes de saúde mais tranquila e confortável.

Usando métodos ilustrados por Wendy Olmstead, foi feita uma revisão dos símbolos e selecionados os mais representativos (Figura 35).

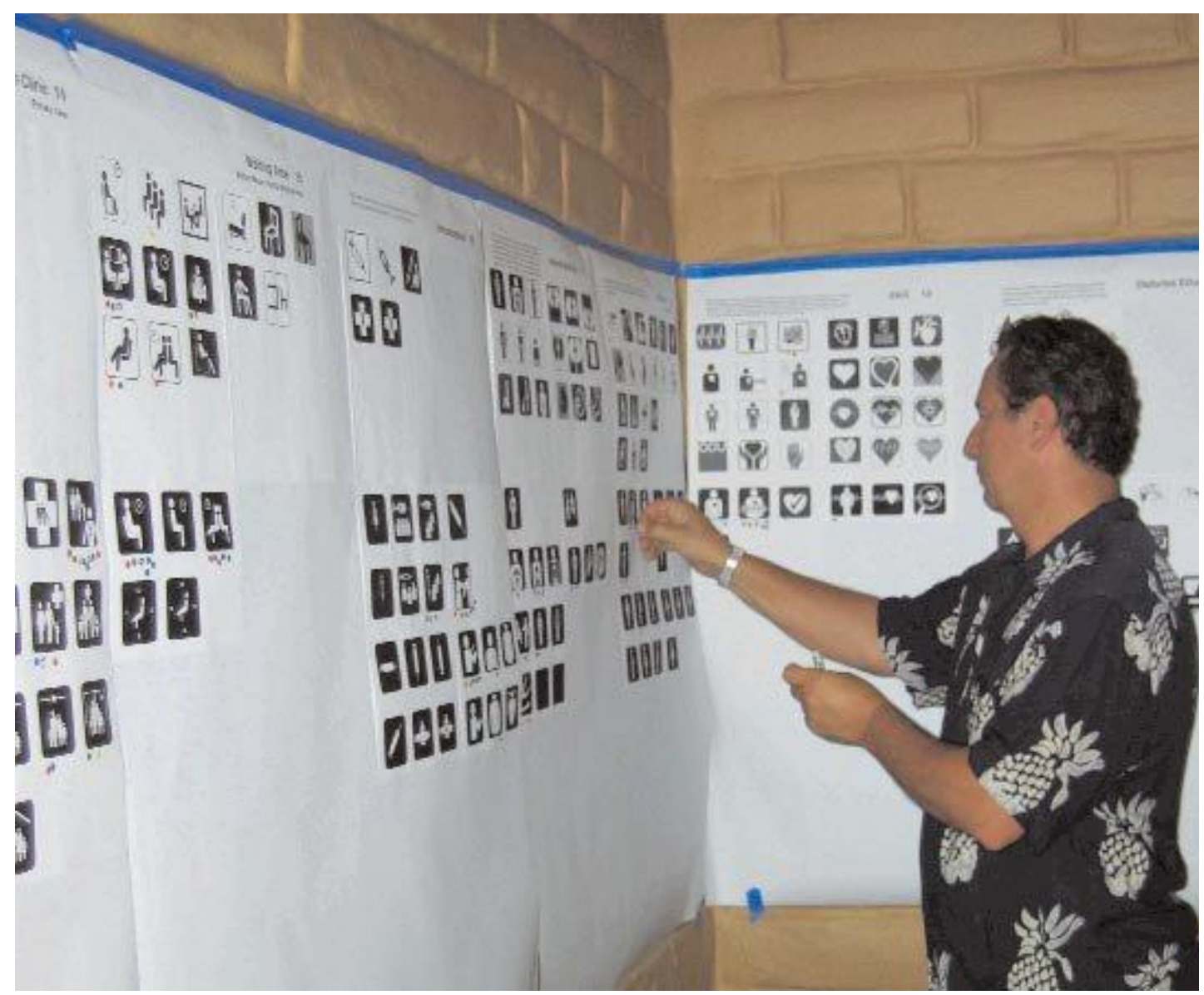

Figura 35 - Símbolos para teste - Hablamos Juntos Fonte: Berger (2009, p. 62) 
A partir dessa revisão foi criada uma linguagem de símbolos para uso específico no ambiente de saúde. A Figura 36 mostra alguns exemplos.

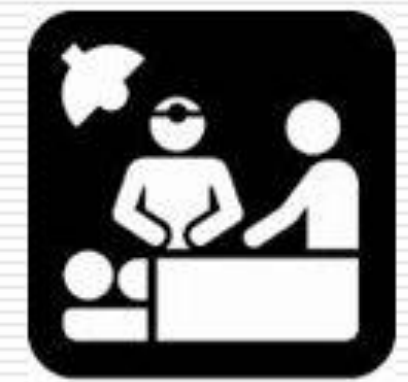

Surgery

Cirugía

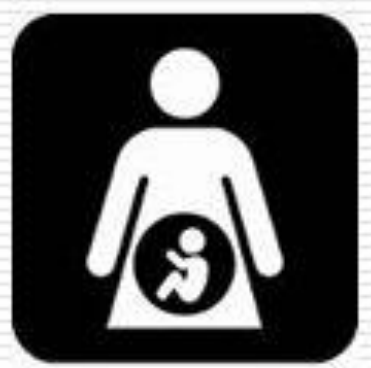

OB Clinic

Clinica de Obstetricia

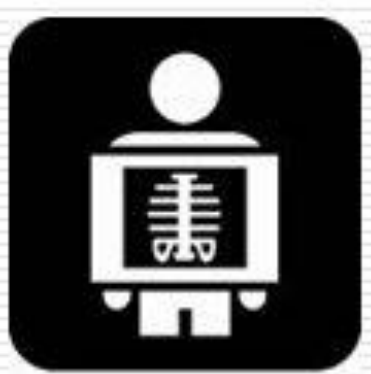

Radiology Radiología

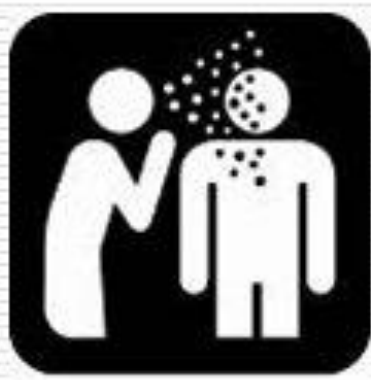

Infectious Disease Enfermedades Infecciosas

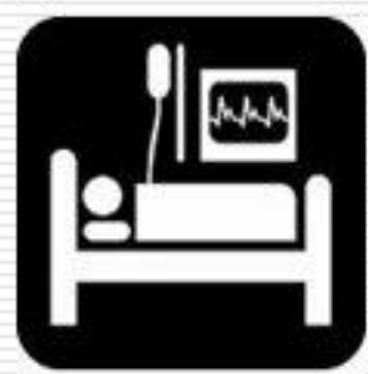

Intensive Care Cuidado Intensivo

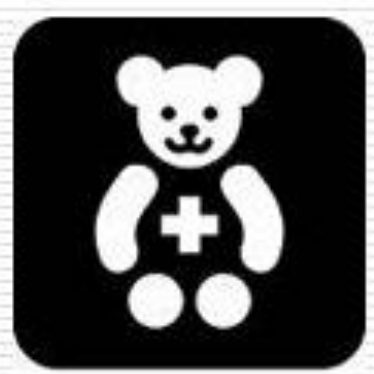

Pediatrics Pediatría

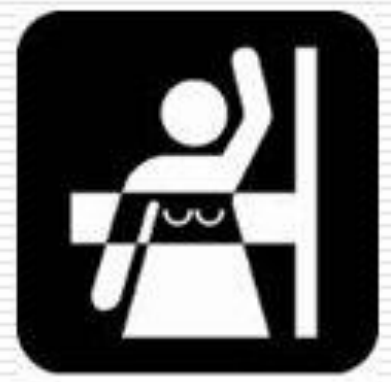

Mammography Mamografia

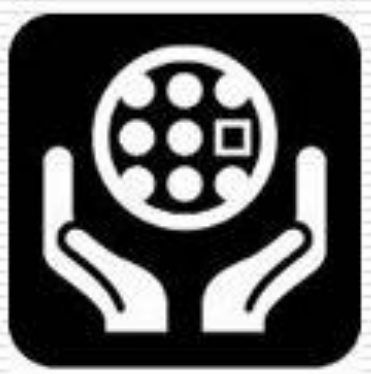

Oncology Oncologia

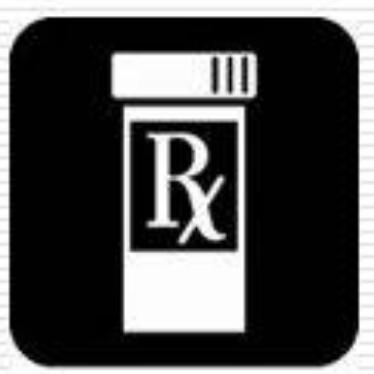

Pharmacy Farmacia

Figura 36 - Símbolos gráficos - Hablamos Juntos

Fonte: www.hablamosjuntos.org/signage/symbols/default.symbols.asp

Esses exemplos apontam para o fato de que cada sistema de comunicação deve ser analisado e estudado para melhor se adequar ao local para onde for desenvolvido. É importante considerar a opinião dos usuários ao elaborar o projeto, verificando se as informações são bem compreendidas. 


\subsubsection{Pontos de decisão}

São chamados pontos de decisão os locais em que um usuário pode ter dúvidas sobre qual caminho seguir para chegar a seu destino final

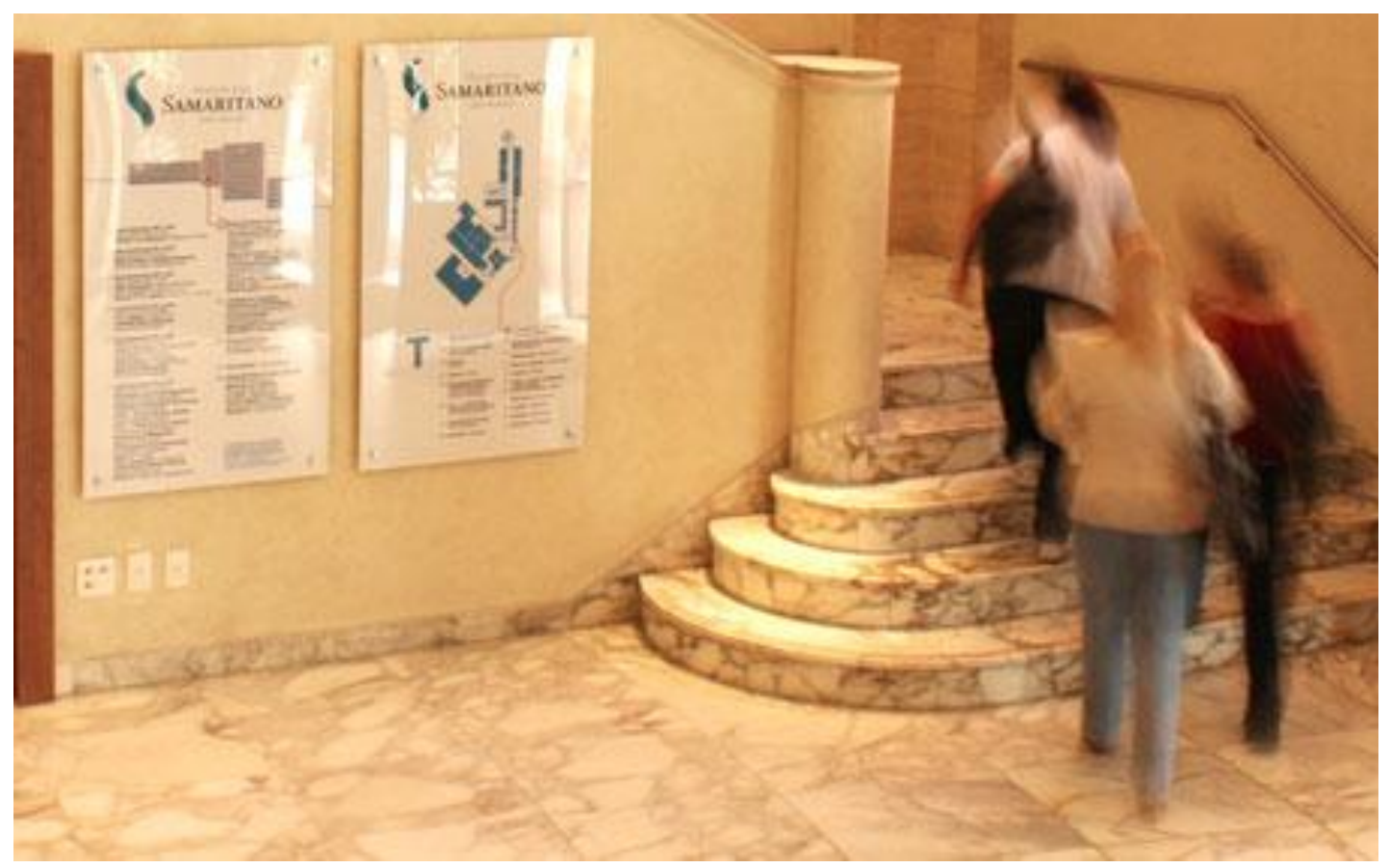

Figura 37 - Exemplo de ponto de decisão

Fonte: uww.casodesign.com.briindex.asp?c=f6331bfd4501bd20e461e4eaf0709364

(MCLAUGHLIN; MCNEIL; SEBALD, 2005, p. viii). Esses pontos devem ser identificados por quem planeja o sistema de comunicação e devem conter informações suficientes para que os usuários possam se locomover com autonomia e segurança (Figura 37). Esses autores apontam oito critérios para avaliar sistemas de sinalização com o objetivo de eliminar, o quanto possível, a confusão e a desorientação dos usuários em um hospital (idem, p. 33-51). Esses critérios foram desenvolvidos comparando-se os pontos de decisão (áreas nas quais as pessoas têm que decidir qual direção seguir) no Bumrungrad Hospital; Bangkok Hospital; Conrad Hotel e Sangri-La Hotel (todos na Tailândia). Os critérios, estabelecidos pelos autores, em ordem de importância para a análise específica do Bumrungrad Hospital foram:

1. visibilidade - a sinalização deve ser livre de obstrução física e concebida para ser lida (ter bom contraste, tamanho grande de fonte 
etc.), tanto a sinalização de trânsito das ruas próximas ao hospital quanto à relacionada às suas dependências propriamente ditas;

2. flexibilidade - a sinalização deve ser capaz de acomodar as alterações ao layout do hospital em toda sua extensão, ou seja, o sistema tem que ser facilmente atualizável (a sinalização deve acompanhar as possíveis reorganizações e reestruturações de um hospital). Atualmente, para facilitar esse processo, há uma tendência em outros países a optarem pelo uso de sistemas digitais em vez sistemas estáticos;

3. facilidade de uso - a sinalização deve ser fácil de usar e acessível a todos os usuários, independentemente da capacidade de linguagem e experiência técnica. $O$ sistema de orientação não será útil se a informação não for facilmente acessível e fácil de entender. Displays com grandes dimensões e frases simples e curtas são mais eficazes para comportar as informações necessárias. No caso de hospitais que recebem clientes de países estrangeiros, é preciso verificar a quantidade de línguas a serem utilizadas no sistema de sinalização;

4. quantidade adequada de informação - isso significa que, uma vez que o usuário entre em um ponto de decisão, ele terá todas as informações necessárias, nada mais e nada menos, para tomar a decisão correta. Mostrar a quantidade adequada de informações não significa que o sistema será fácil de usar (critério anterior). Toda informação fornecida deverá facilitar o fluxo de tráfego ao levar os usuários a seus destinos rápida e facilmente, ou seja, a informação adequada refere-se àquela que o usuário necessita para escolher a direção certa. Este é um critério complicado em hospitais, que depende do ponto de vista de vários tipos diferentes de usuários (clientes de saúde; equipes de trabalho; demais visitantes) para ser estabelecido;

5. adequação de localização - as placas de sinalização devem servir às necessidades dos usuários em locais específicos e se adequar ao ambiente. Este critério não se preocupa com os aspectos reais de orientação de fluxo, pois o enfoque maior é dado à aparência geral do hospital, ou seja, a preocupação é verificar se há uma combinação estética de cores, design do hospital, decoração e sinalização (obs.: este critério é o que mais se aproxima dos propósitos deste trabalho no que 
se refere à ambiência hospitalar);

6. confiabilidade - um projeto confiável deve ser seguido ao longo de um sistema de sinalização, reforçando a marca e permitindo que os usuários encontrem o caminho com maior facilidade;

7. consistência - a sinalização deve ter uma coerência entre seus elementos, tornando-os não partes isoladas, mas sim um sistema. Todos os elementos que compõem as sinalizações devem ter características unificadoras semelhantes (mesmo tipo de tecnologia, cor, fonte etc.). Também o posicionamento (localização) das placas de sinalização deve refletir uma uniformidade. A consistência auxilia os usuários a seguirem um sistema de sinalização global, proporcionando a garantia de que estão fazendo o que precisam para se locomoverem com segurança e autonomia no espaço hospitalar;

8. viabilidade - refere-se à disponibilidade total de um sistema para o local em que se encontra o hospital. No caso do Bumrungrad Hospital, por exemplo, foi preciso verificar se as recomendações para alterações do sistema de sinalização poderiam ser executadas, sobretudo considerando-se o fator custo.

O trabalho desses autores fornece um exemplo internacional de análise de sistemas de sinalização de um hospital de grande porte, considerado o maior hospital privado do Sudeste Asiático, que atende pacientes de mais de 140 países para cuidados médicos de rotina. Os critérios apontados complementam as recomendações para melhorar o sistema de sinalização (GSG, 2008), pois servem como modelo de análise pós-implementação do sistema.

Noções a respeito do campo de visão normal apresentam informações importantes a serem considerados nos projetos de sinalização. Questões sobre ângulos de convergência, cone de visão e distâncias próprias para uma melhor leitura de placas de sinalização e campo visual fornecem parâmetros principalmente para se determinar onde devem ser os melhores locais para posicionar as sinalizações. De acordo com Jan Dul (2004, p. 43), "o olho humano é capaz de perceber simultaneamente uma grande quantidade de informações", portanto, a forma de apresentação destas deve ser adequada à capacidade de percepção dos olhos. 


\subsection{Identidade Visual}

A Identidade Visual define um conjunto de elementos visuais ou gráficos, formando um sistema para identificar um nome, uma ideia, um produto, uma empresa, uma instituição ou serviço. Considera-se como Identidade Visual o "componente de singularização visual que é formado por um sistema expressamente enunciado, realizado voluntariamente, planejado e integrado por elementos visuais de aplicação coordenada" (PEÓN, 2009, p. 10). Os elementos da Identidade Visual são: logotipo; assinatura; símbolo; versões da marca; tipografia e cores institucionais; grafismos; normas para layouts etc. Uma Identidade Visual bem planejada e sistematizada transmite a imagem que a instituição pretende assumir, pois a representação gráfica reflete sua seriedade, comprometimento, solidez, pretensões, objetivos, atitudes, valores e missão.

O Hospital Sírio-Libanês, por exemplo, mudou sua Identidade Visual primeiramente pela agência Und. O logotipo tinha sido desenhado a partir do selo (uma enfermeira) da sociedade mantenedora, com o intuito de comunicar os atributos do hospital: excelência médica, atendimento humano, tradição associada com modernidade e pesquisa avançada, atenção, calor humano (CHAMMA; PASTORELO, 2007, p. 223). Em 2009, com o objetivo de traduzir os valores da instituição: humanismo, identidade cultural de origem, excelência e cuidado/proximidade, a agência OZ Design atualizou o logotipo. De acordo com as informações obtidas no site da OZ Design (www.ozdesign.com.br), o novo símbolo foi desenhado na forma de uma mandala, composta por pessoas de mãos dadas, traduzindo a integração entre Filantropia e Ciência, "matizes da identidade que são expressas pela geometria da forma que desenha indivíduos reunidos em torno de um ideal, como a marca de uma cultura em que as relações interpessoais são o maior valor humano". A Figura 38 apresenta os dois logotipos, o da Und à esquerda e o da OZ Design à direita. 


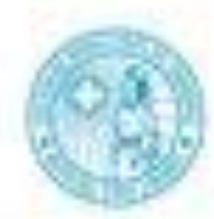

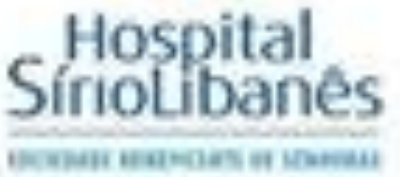

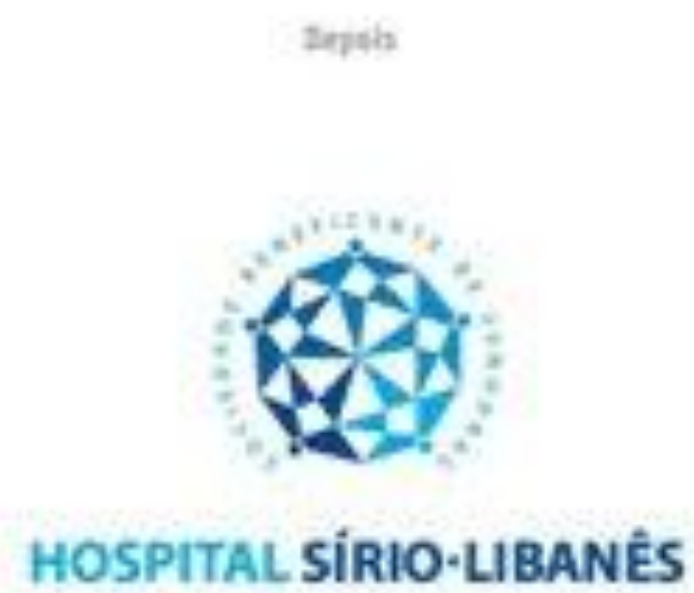

Figura 38 - Logotipos do H. Sírio-Libanês

Fonte: www.ozdesign.com.br

O novo logotipo foi aplicado em papelaria (Figura 39 e Figura 40); uniformes

(Figura 41 e Figura 42); frota (Figura 43); sinalização (Figura 44, Figura 45 e Figura 46).

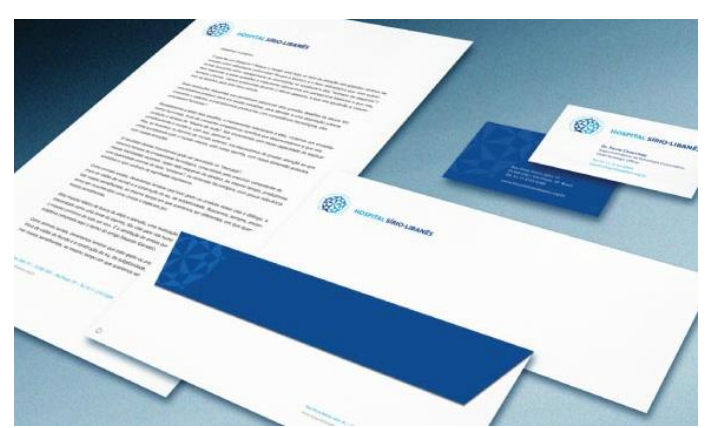

Figura 39 - Papelaria (cartas e envelopes) Fonte: www.ozdesign.com.br

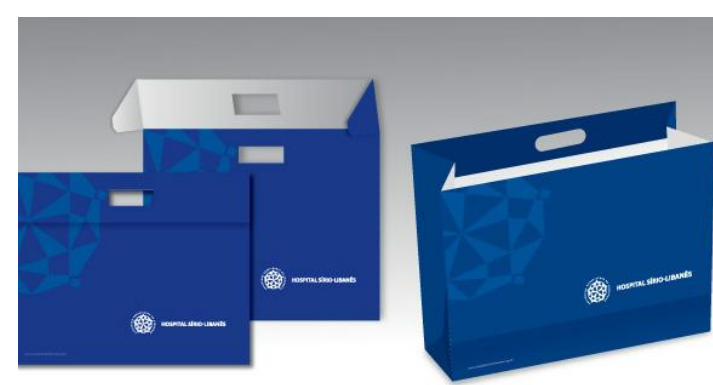

Figura 40 - Papelaria (embalagens) Fonte: www.ozdesign.com.br 

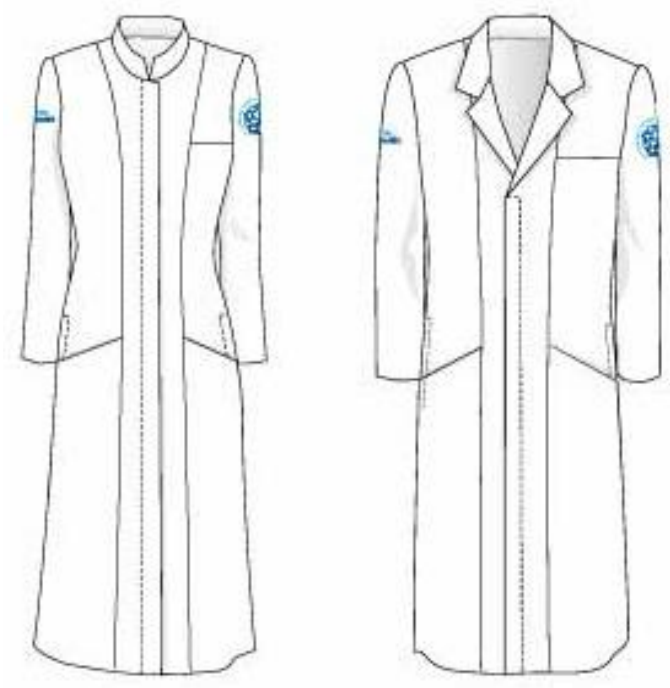

Figura 41 - Uniformes

Fonte: www.ozdesign.com.br

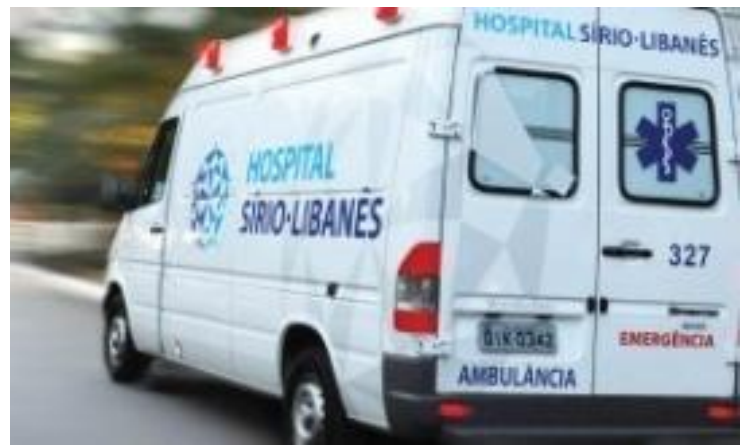

Figura 43 - Frota

Fonte: www.ozdesign.com.br

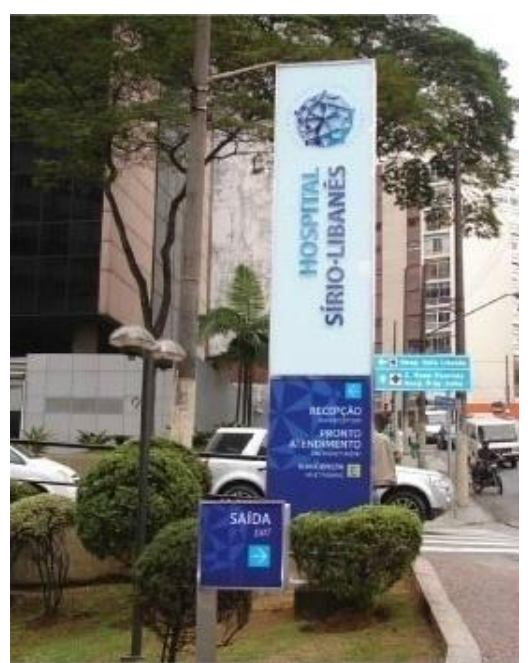

Figura 45 - Totem de entrada Fonte: www.ozdesign.com.br

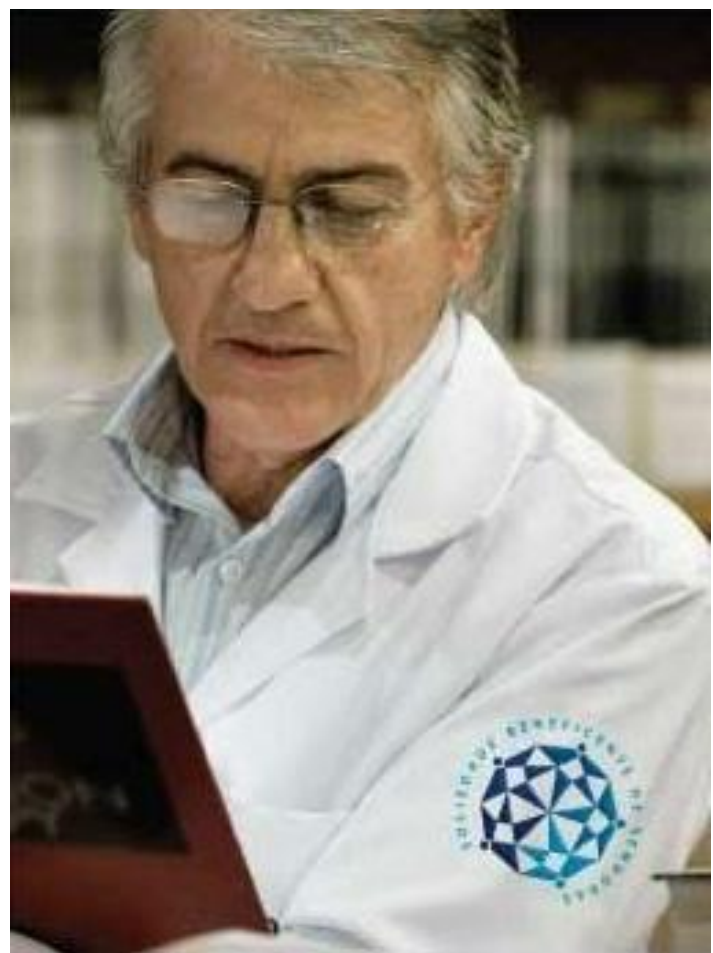

Figura 42 - Uniforme (detalhe)

Fonte: www.ozdesign.com.br

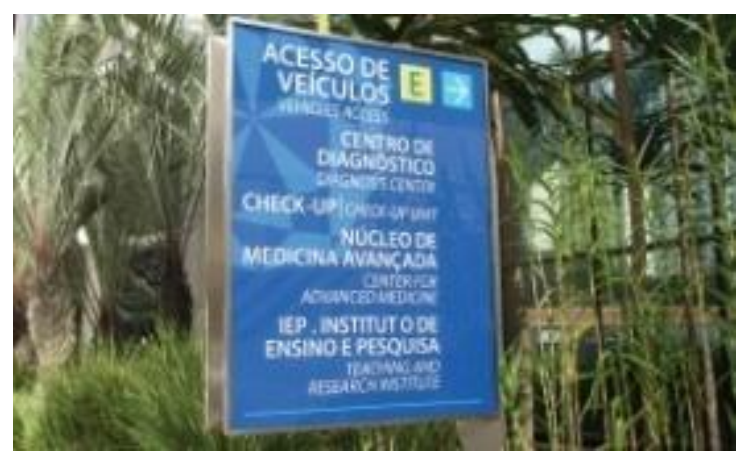

Figura 44 - Sinalização externa Fonte: www.ozdesign.com.br

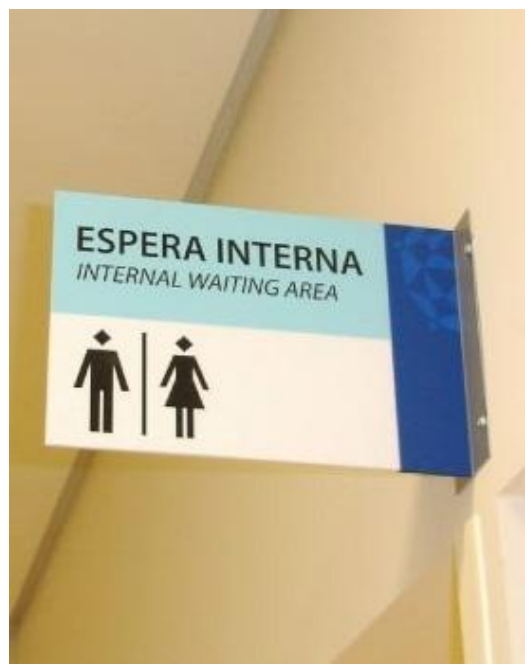

Figura 46 - Sinalização interna Fonte: www.ozdesign.com.br 
Outro ponto a destacar quanto à presença do logotipo é que este pode ser utilizado como decoração, o que ajuda a reforçar a imagem da instituição. Um exemplo é o Hospital A. C. Camargo (Figura 47), cujo logotipo é um círculo

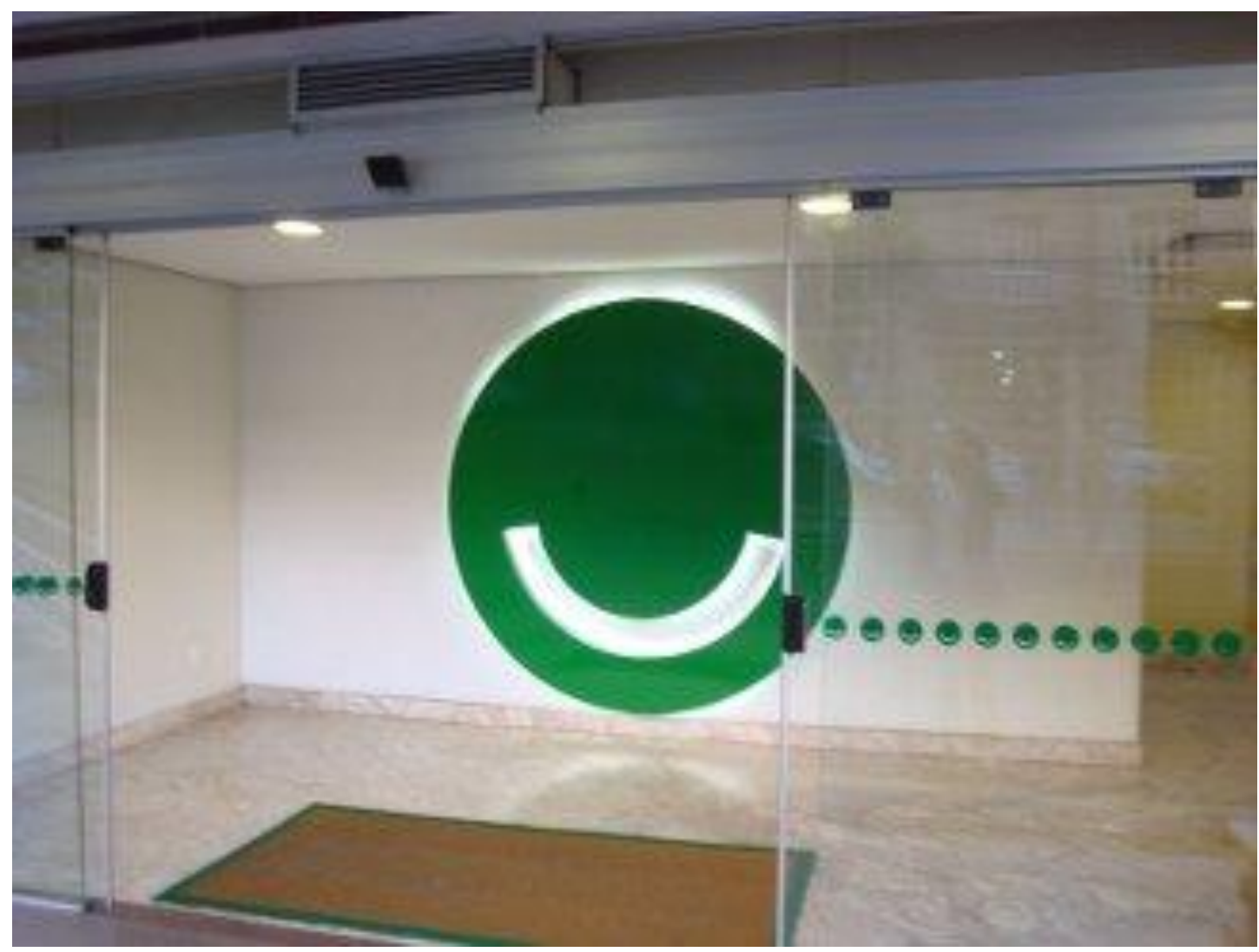

Figura 47 - Entrada H. A.C. Camargo

Fonte: Foto da autora

verde com um "sorriso". Colocado na entrada do hospital, parece que a pessoa está sendo recebida com alegria. A aplicação no vidro reforça essa ideia, além de servir como alerta para evitar acidentes.

Para se estabelecer e ser facilmente reconhecida e diferenciada das demais, uma marca precisa ter consistência e uniformidade em suas aplicações. Esta e suas aplicações "são reflexos da cultura corporativa da empresa e devem expressar tanto atributos de gestão, recursos humanos, produtos, entre outros, como atributos comerciais, sociais, éticos e estéticos da organização" (CHAMMA; PASTORELO, 2007, p. 85).

Um Manual de Identidade Visual estabelece e normatiza os critérios de uso da imagem corporativa de uma instituição, sistematizando o uso de seus elementos básicos (símbolo, cor, tipologia da fonte e proporções) e sua forma de aplicação (fachada; placas de sinalização; papelaria; uniformes; frota; 
banner; internet; publicidade etc.). Esses manuais "são concebidos para servir como instrumento de divulgação da política de imagem da instituição, e são utilizáveis durante um longo período" (idem, p. 119).

A CV em hospitais pode auxiliar indiretamente a recuperação dos pacientes, ao trazer mais conforto a eles e a quem os cerca. Um ambiente bem sinalizado, por exemplo, pode demonstrar que o conhecimento técnico-científico e o atendimento médico-hospitalar também estão bem organizados, pois, para se fazer um projeto de sinalização é preciso que representantes de todos os usuários explicitem seus pontos de vista e necessidades. $\mathrm{O}$ design gráfico de um projeto deve ser agradável, objetivo e eficiente. Desenhos podem ser utilizados como estímulos necessários ao paciente, sobretudo no caso de atendimento a crianças.

\subsection{Orientação de fluxo}

Em ambientes internos, a sinalização visual é um elemento que pode servir para cumprir funções de orientação de seus espaços para uma melhor e mais rápida acessibilidade aos serviços requeridos e para maior segurança em deslocamentos e ações. Constitui-se uma forma de guia para o indivíduo posicionar-se, chamando sua atenção para as informações sobre o local.

Em um hospital, a sinalização se diferencia de outros ambientes internos (como shopping centers, aeroportos, parques, restaurantes etc.) por atender a um público que se encontra em uma situação diferenciada de seu estado normal de saúde. A área de sinalização tem a função básica de organizar o fluxo de pessoas no espaço e identificar os lugares, evitando entradas em locais indesejados. Tanto para os pacientes (externos e internos), seus acompanhantes e visitantes quanto para quem trabalha em um hospital, a questão primordial é a orientação, principalmente porque várias pessoas aproveitam a ida ao hospital para fazer consultas, realizar exames ou outros procedimentos, o que as leva a circularem por setores diferenciados (BERGER, 2009, p. 86).

Pela estrutura complexa, alguns hospitais se parecem com labirintos, o que se 
transforma em uma maior dificuldade de reconhecimento de padrões e sinais para algumas pessoas, devido à doença ou ao estado emocional alterado. Esses aspectos, juntamente com a falta de familiarização com o edifício, podem gerar inquietação do usuário no que diz respeito a sua segurança. A sinalização pode aliviar essa sensação e facilitar os deslocamentos por meio de informações claras e legíveis (MATOS, 2008, p. 64-5).

Para que um sistema de sinalização seja eficiente, é importante que seja feito um projeto que compreenda o funcionamento de cada espaço por onde os usuários circulam, incluindo áreas de acesso restrito. Para planejar esse sistema a ser aplicado em ambientes tão específicos, é necessário elaborar um plano minucioso, com uso de mapas de localização, considerando e compreendendo as necessidades dos usuários e do local.

Estudos ergonômicos sobre apresentação das informações consideram o tempo de reação entre um estímulo e sua resposta.

Em Shopping Centers encontram-se os mapas de orientação, do tipo "você está aqui". Entretanto, esses mapas geralmente estão colocados em expositores verticais. Para orientar-se é necessário fazer o rebatimento mental desse mapa para o piso e, muitas vezes, uma rotação. Muitas pessoas têm dificuldade de raciocínio espacial para realizar essas operações mentais. A indicação seria melhor se o mapa estivesse no chão, coincidindo com a orientação do edifício (norte do mapa coincidindo com o norte do edifício). (IIDA, 2005, p. 289)

Por isso é importante que um projetista do sistema de CV em ambiências hospitalares considere os aspectos ergonômicos, a fim de abreviar o tempo de reação dos usuários de cada ambiente do hospital, simplificando suas decisões e aumentando a compatibilidade entre o sistema real e sua representação.

\subsubsection{Mapas e diretórios}

Os hospitais, por serem ambientes internos diferenciados, requerem projetos mais difíceis de produzir, principalmente para atender o cumprimento de normas sanitárias.

Hospitais são os casos de sinalização mais desafiadores, simplesmente porque a quantidade de informações a ser distribuída é enorme. Indicações 
de toda natureza, como: onde deve ser disposto o material descartável utilizado, as especificações das dietas dos pacientes e até a sempre penosa sinalização do velório. Temos de nos antecipar a tais demandas por informação do usuário a cada ponto. E confirmá-las mais à frente. (CHAMMA; PASTORELO, 2007, p. 155-156)

O estudo dos fluxos de um hospital tem como objetivo reconhecer as diferenciações necessárias entre fluxos de usuários externos e do pessoal interno. A circulação da equipe interna deve contar com áreas de acesso restrito para que possa ocorrer a circulação de macas, cadeiras de roda, carrinhos (de limpeza e de roupas sujas), por isso é importante que sejam previstos fluxos diferenciados, evitando constrangimentos e situações desagradáveis.

A Figura 48 apresenta o mapa localizado na entrada do UCSF Medical Center, EUA. O suporte multifacetado permite a visualização das informações de vários

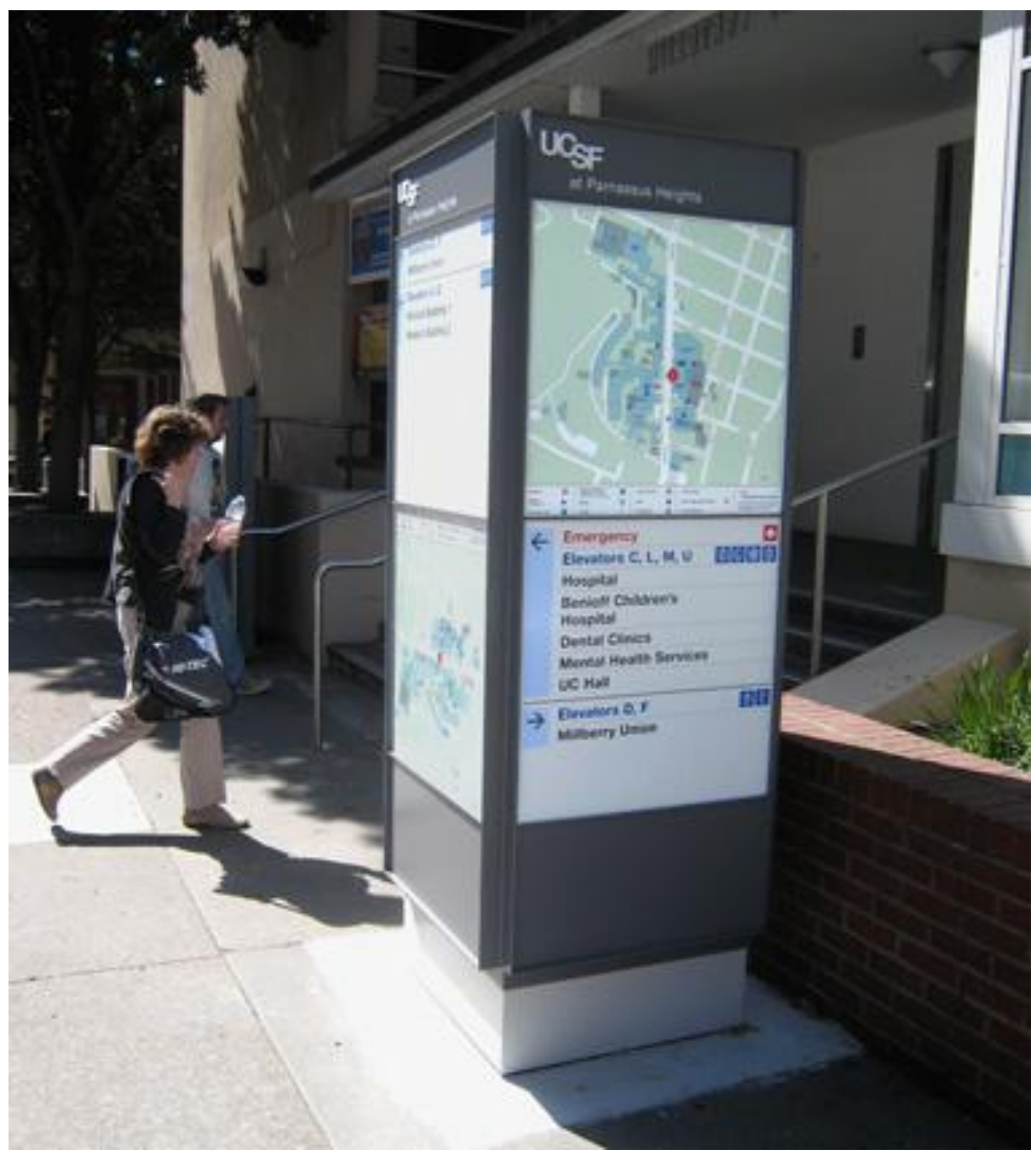

Figura 48 - Mapa na entrada do hospital Fonte: www.fd2s.com/work/ 
ângulos, permitindo que os usuários possam localizar o que está nesse prédio e onde se encontram outros departamentos. Por ser um mapa externo, apresenta informações mais gerais do hospital em relação ao seu entorno.

A Figura 49 mostra um mapa no interior do mesmo hospital, fornecendo informações mais específicas referentes ao piso em que a pessoa se encontra.

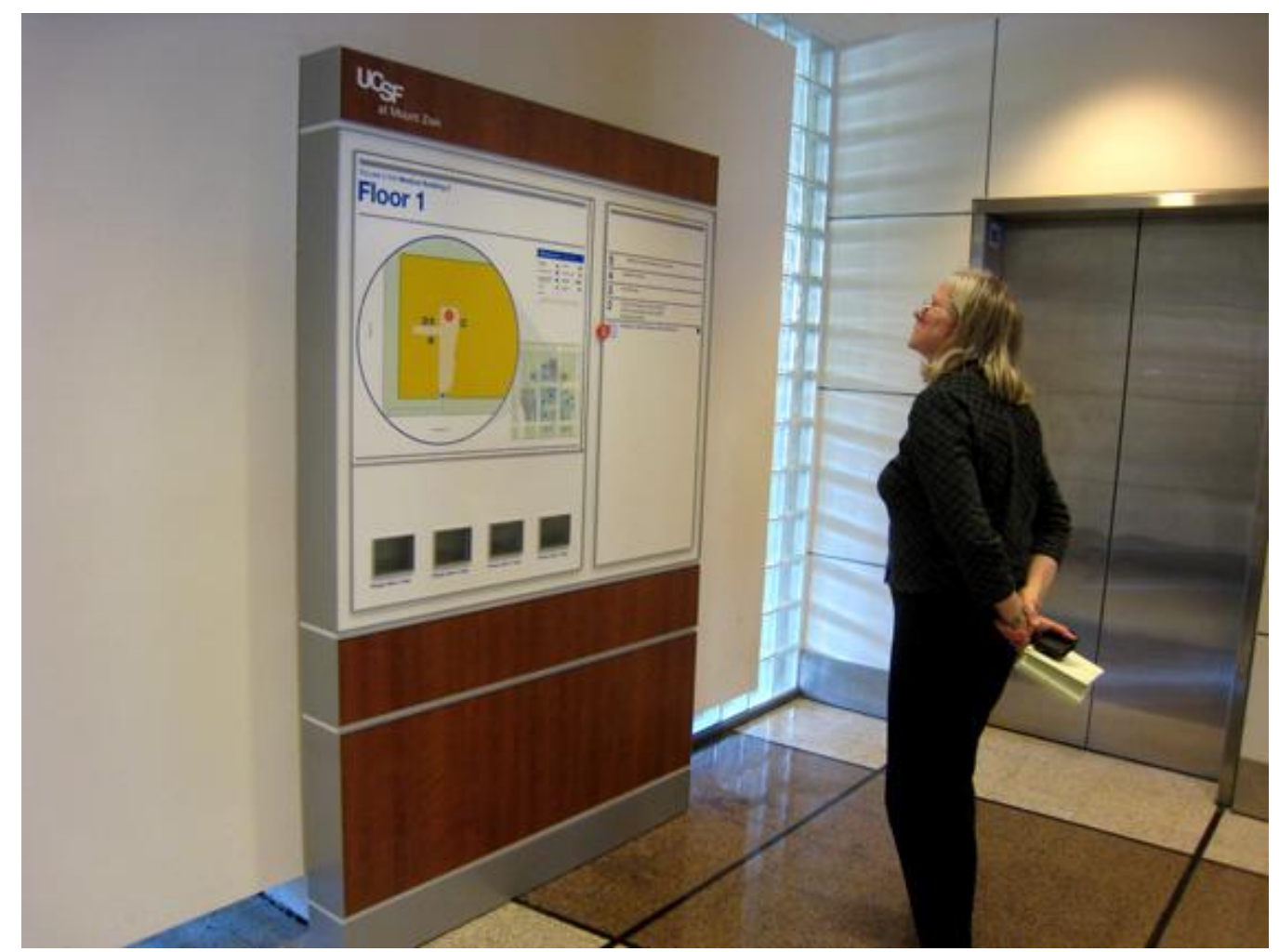

Figura 49 - Mapa no interior do hospital Fonte: www.fd2s.com/work/

Elaborar um sistema de sinalização é tão complexo e amplo quanto a estrutura de um hospital. Quanto maior for um hospital (número de prédios, andares, setores etc.), mais complexo será seu sistema de sinalização. É preciso verificar quais são os possíveis trajetos a serem percorridos pelos usuários, desde a entrada até as dependências mais acessadas. Setores relacionados a emergências exigem cuidado ainda maior com sinalização.

Essa hierarquia das informações é definida com auxílio de usuários (geralmente quem trabalha no hospital), procurando saber quais devem ser transmitidas e como podem ser mais bem compreendidas e onde podem ser colocadas. Informações em excesso podem causar confusão, gerar um ambiente mais poluído e desagradável visualmente. 
O Growth Solutions Group (GSG, 2008) elaborou um guia para melhorar o sistema de sinalização de hospitais, no qual faz as seguintes recomendações: hierarquia das informações, colocadas em uma sequência lógica, de acordo com a relevância dos setores e destinos; incorporação da identidade visual do hospital (logotipo, cores, símbolos); cuidado ao usar setas, evitando que estas sejam muito estilizadas, garantindo a legibilidade; uso de código cromático para identificação de áreas, facilitando o reconhecimento e memorização; cores utilizadas para orientação devem ser diferenciadas das demais (segurança, avisos, advertências, proibições etc.); possibilidade de uso de linhas coloridas no piso para auxiliar a locomoção dos usuários.

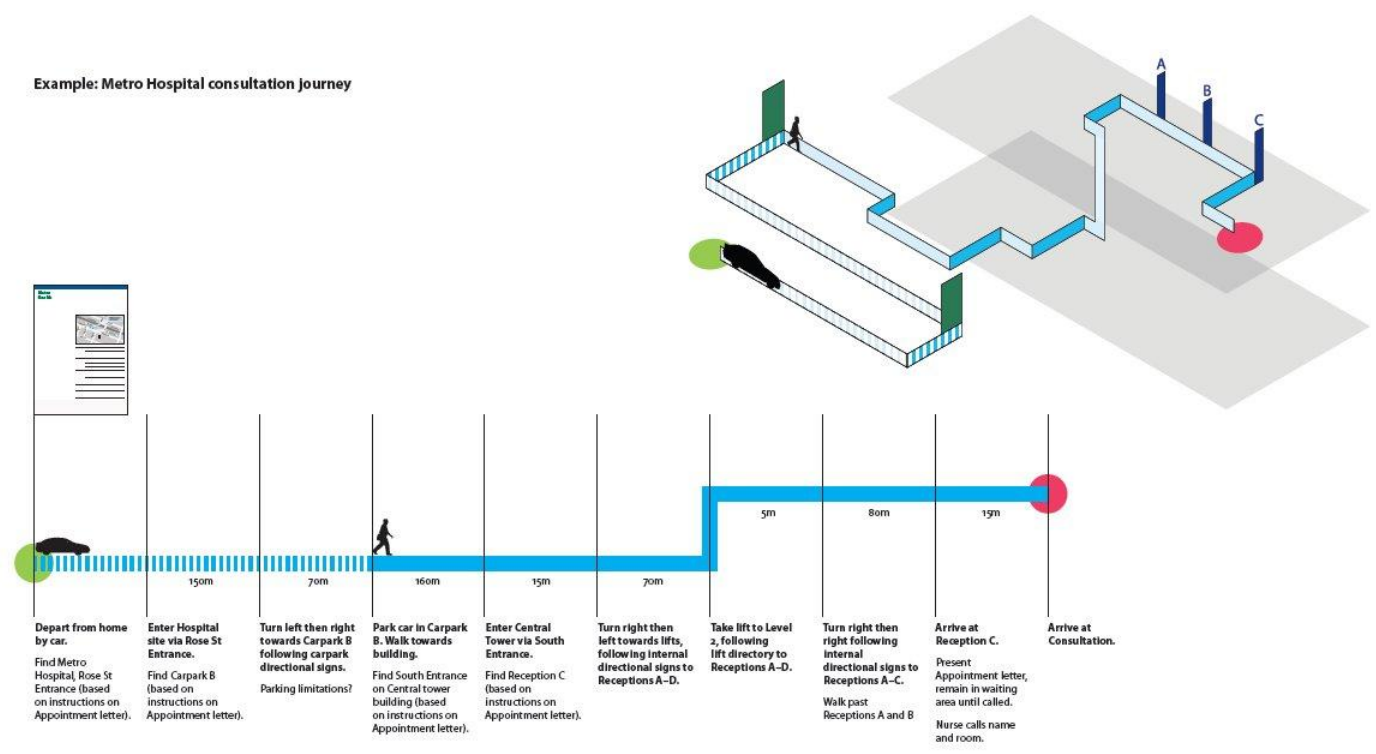

Figura 50 - Exemplo de trajeto de um hospital Fonte: GSG (2008, p. 12)

A Figura 50 apresenta um exemplo de mapa com trajeto a ser realizado por um usuário em um hospital (utilizado apenas como ilustração para o referido guia). A proposta é mostrar que um projeto de orientação de fluxo deve considerar as formas de chegada (de carro ou a pé); as respectivas entradas e todos os percursos possíveis de serem usados por uma pessoa para chegar a determinado local dentro de um hospital. Esse mapa possibilita que se tenha a noção de quantos metros o usuário tem que percorrer e aponta possibilidades de verificação de pontos de decisão (locais em que devem ser colocadas sinalizações para evitar dúvidas ou escolha de trajeto errado).

Um sistema de sinalização visual incorpora marcas, sinais, mapas e 
dispositivos direcionais que indicam onde uma pessoa está, para onde quer ir e como chegar. Um projeto bem sucedido de sinalização interna permite que as pessoas: determinem sua localização dentro de um cenário; determinem seu destino; desenvolvam um plano que as leve de sua posição a um destino. Pode ser concebido como um auxiliar que oferece informação e orientação às pessoas de forma clara, conveniente, amigável, para ajudar usuários a encontrarem o trajeto a ser feito em um ambiente.

A sinalização visual é um conjunto coerente de signos cuja função é transmitir informações breves e precisas, destinadas a advertir, orientar e instruir um indivíduo em determinado espaço (BRAN, 1971, p. 55). Segundo Frutiger (2001, p. 315), os sinais que fazem parte da sinalização têm como objetivo não apenas comunicar, "mas sobretudo produzir uma reação imediata no observador".

Tanto quando estamos em ambientes de circulação pública ou restrita como quando estamos diante de um objeto do qual desconhecemos o uso, a sinalização nos ajuda a solucionar mais rapidamente possíveis problemas. Para que isso seja possível, o excesso de informação deve ser contido, evitando confusões e facilitando uma percepção mais rápida. Esses sinais têm diversas funções, relacionadas, fundamentalmente, à orientação de fluxo; identificação ou identidade corporativa; interdição ou proibição de ações; advertência para prevenção de acidentes; prescrição e instrução.

Além do aspecto funcional, a sinalização serve para identificar setores diferenciados e para reforçar a identidade visual de um hospital. Participa da construção do ambiente, atribuindo um significado ao espaço, desempenhando um importante papel como ferramenta de marketing e de divulgação e transmitindo alguma mensagem ou valor da instituição.

Uma boa sinalização busca a funcionalidade da informação. Seu objetivo é atingido quando atende satisfatoriamente as necessidades das pessoas, facilitando sua circulação em ambientes internos e externos, conhecidos ou não; dando informações sobre precauções a serem tomadas e sobre regras para melhorar a vida em comunidade (principalmente nos grandes centros urbanos, nos quais as placas de sinalização de trânsito, por exemplo, têm grande importância para ordenar e organizar o tráfego de pessoas e de veículos). Nos arredores de um hospital, as placas de sinalização indicando a 
localização de hospitais devem ser posicionadas de forma a facilitar sua visualização, garantindo acesso mais rápido e eficiente. Placas cobertas por galhos de árvores ou com problemas de conservação e manutenção podem dificultar o processo de decodificação por parte dos usuários.

O avanço tecnológico tem possibilitado a criação e ampliação de novos meios de acesso a informações, facilitando a obtenção destas aos usuários e procurando reduzir tempos de espera gastos. De maneira ágil e instantânea um usuário pode verificar em displays eletrônicos com telas touchscreen onde
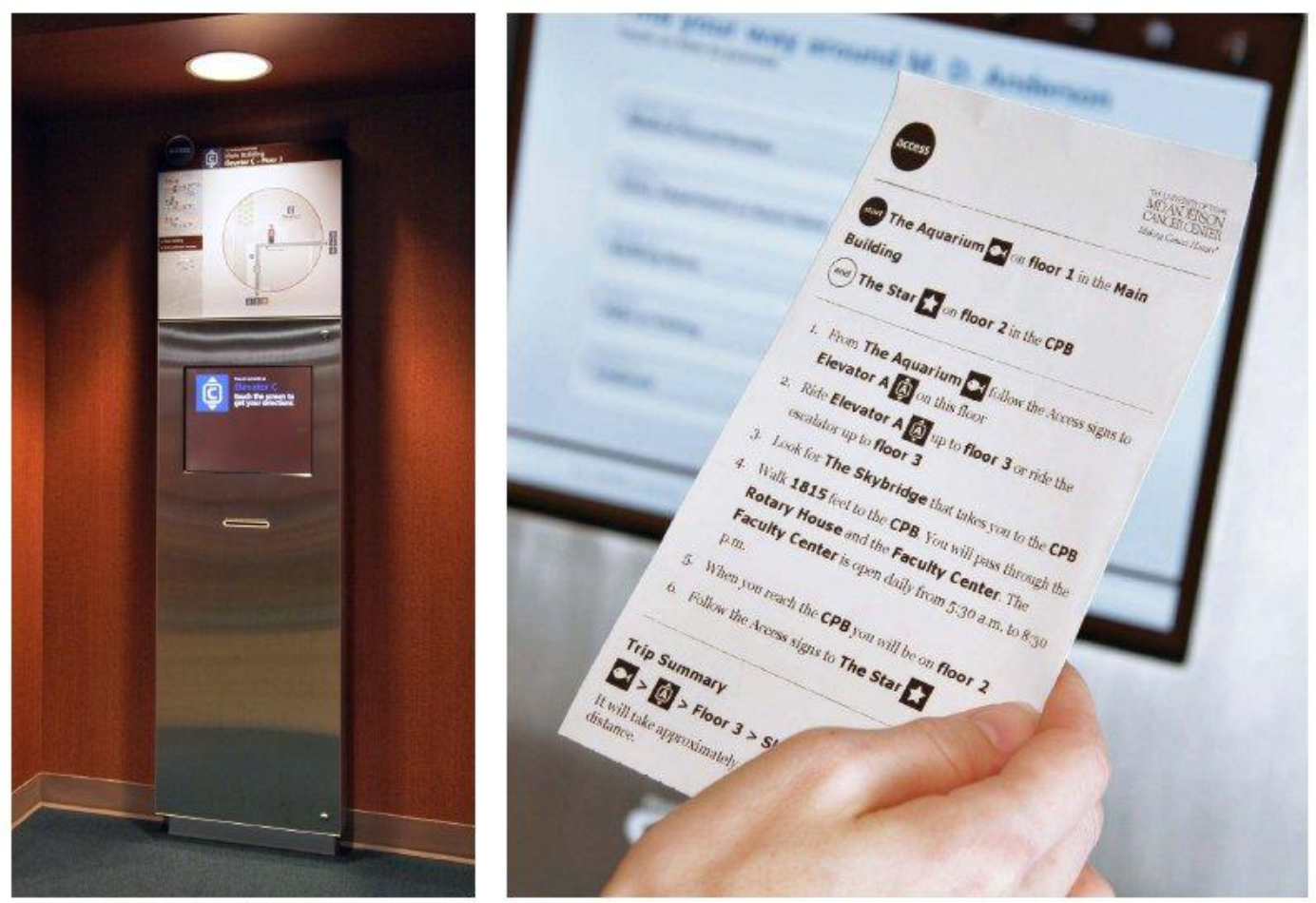

Figura 51 - Display touchscreen - M.D. Anderson Cancer Center (EUA) Fonte: access.fd2s.com/

deseja ir e receber as informações detalhadas em um material impresso (Figura 51).

O projeto de sinalização do M. D. Anderson Cancer Center (EUA) foi realizado pela empresa fd2s (Austin, TX), especializada em desenvolvimento de projetos de sistemas de wayfinding e programas de gráficos ambientais. Além da possibilidade de utilizar 27 displays eletrônicos colocados no campus do hospital, o usuário pode acessar as informações pela internet, antes mesmo de sair de casa, verificando os destinos e caminhos a serem percorridos, graças a um programa de software. 
A sinalização em um ambiente hospitalar pode servir não apenas para cumprir suas funções de comunicação como também para contribuir com a formação de um ambiente mais agradável, tranquilo. Espera-se que a CV possa ajudar a reduzir ao máximo possíveis conflitos gerados por falta de informação organizada. Ao colocar no site informações sobre os trajetos a serem feitos, a instituição mostra que tem uma preocupação com o cliente de saúde e uma organização estruturada.

\subsubsection{Sinais de localização e identificação}

Hospitais habitualmente têm vários setores, alas e outras subdivisões que podem confundir os usuários. Para que estes possam se localizar com rapidez e eficiência, é importante que cada local tenha características que facilitem sua identificação e reconhecimento. Numa ala de internação, por exemplo, local em que há muita semelhança entre os quartos, é importante que estes tenham uma identificação clara para evitar que visitantes entrem em local indesejado, o que pode causar inconvenientes e/ou constrangimentos (tanto para visitantes quanto para pacientes internados).

Quando o hospital tem várias torres ou blocos, devem ser feitas identificações para cada uma dessas subdivisões. Muitas vezes o melhor é nomear essas estruturas ou usar cores diferentes para diferenciá-las. Os acessos ao setor de emergência ou pronto atendimento também devem estar bem sinalizados A empresa $f d 2 s$ desenvolveu o sistema de sinalização e gráficos ambientais para o M. D. Anderson Cancer Center (EUA), a fim de reforçar a comunicação com os usuários do hospital. Utilizando a denominação "Access" (Figura 52), criou um sistema de identidade gráfica que integra tecnologia e procedimentos. Foram criados nomes e símbolos para distinguir locais de referência (Figura 53) no interior do prédio. 

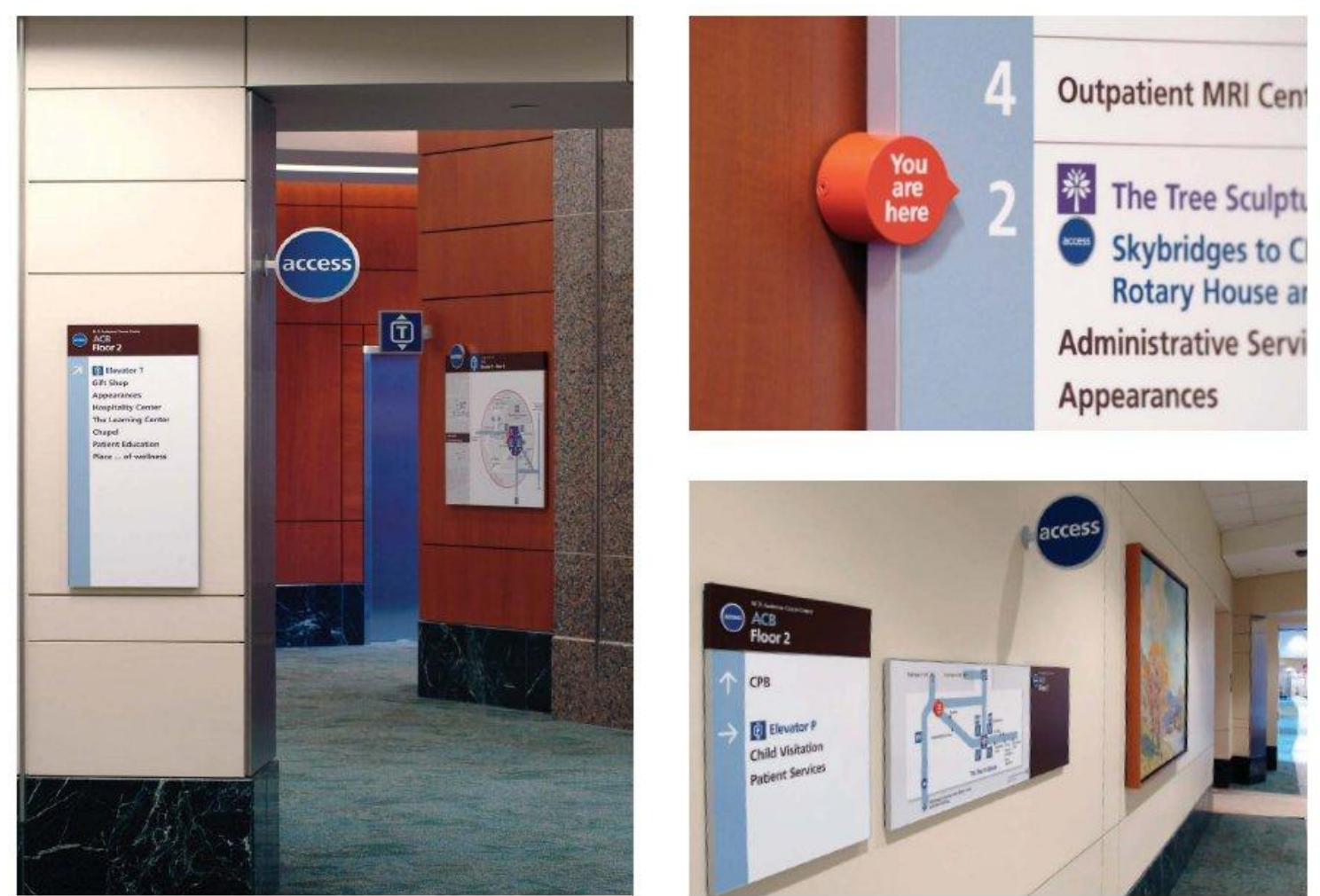

Figura 52 - Sistema "Access" - M.D.A. Cancer Center (EUA) Fonte: access.fd2s.com/

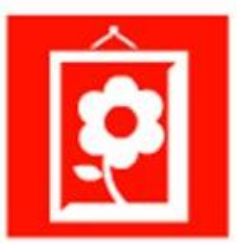

The Art Gallery

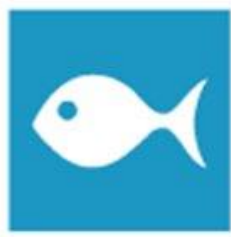

The Aquarium

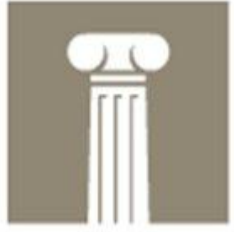

The Forum

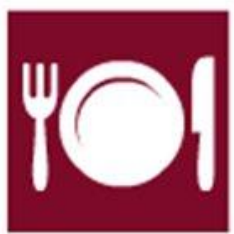

The Cafe Corner

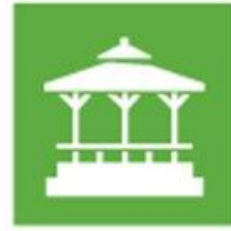

The Gazebo

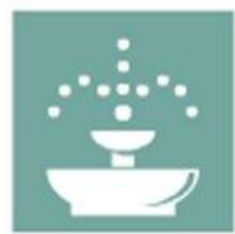

The Fountain

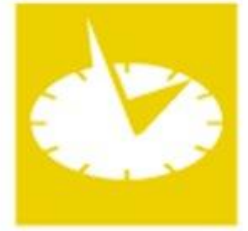

The Sundial

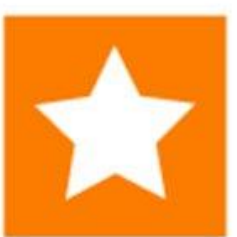

The Star

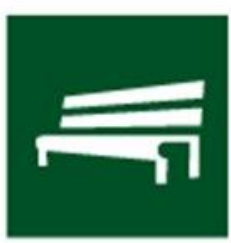

The Park

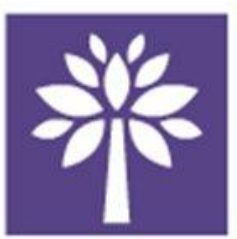

The Tree Sculpture

Figura 53 - Símbolos e locais de referência do M.D.A. Cancer Center Fonte: access.fd2s.com/ 
Outro exemplo é o elaborado pela Aesthetic Inc. para o MultiCare Tacoma General Hospital (Tacoma, Washington). Foram utilizados quatro ícones para identificar os pavilhões do hospital e a paleta de cores foi aplicada em cada pavilhão em particular. Gráficos, ícones e cores ajudam a estabelecer unidades e setores reforçando a identidade da instituição (Figura 54).

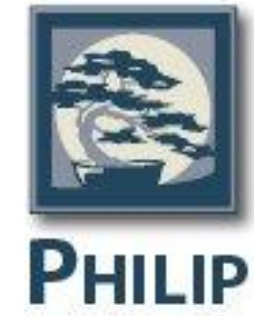

PAVILION
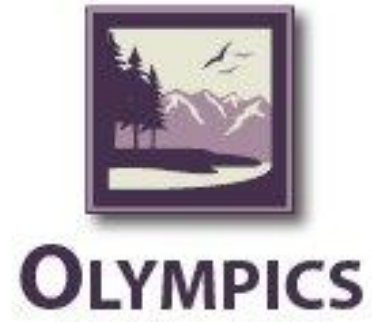

PAVILION

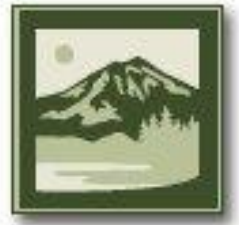

RAINIER

P A VILION

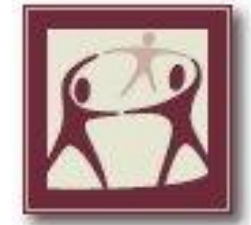

MiLgARD

P A V I L I O N
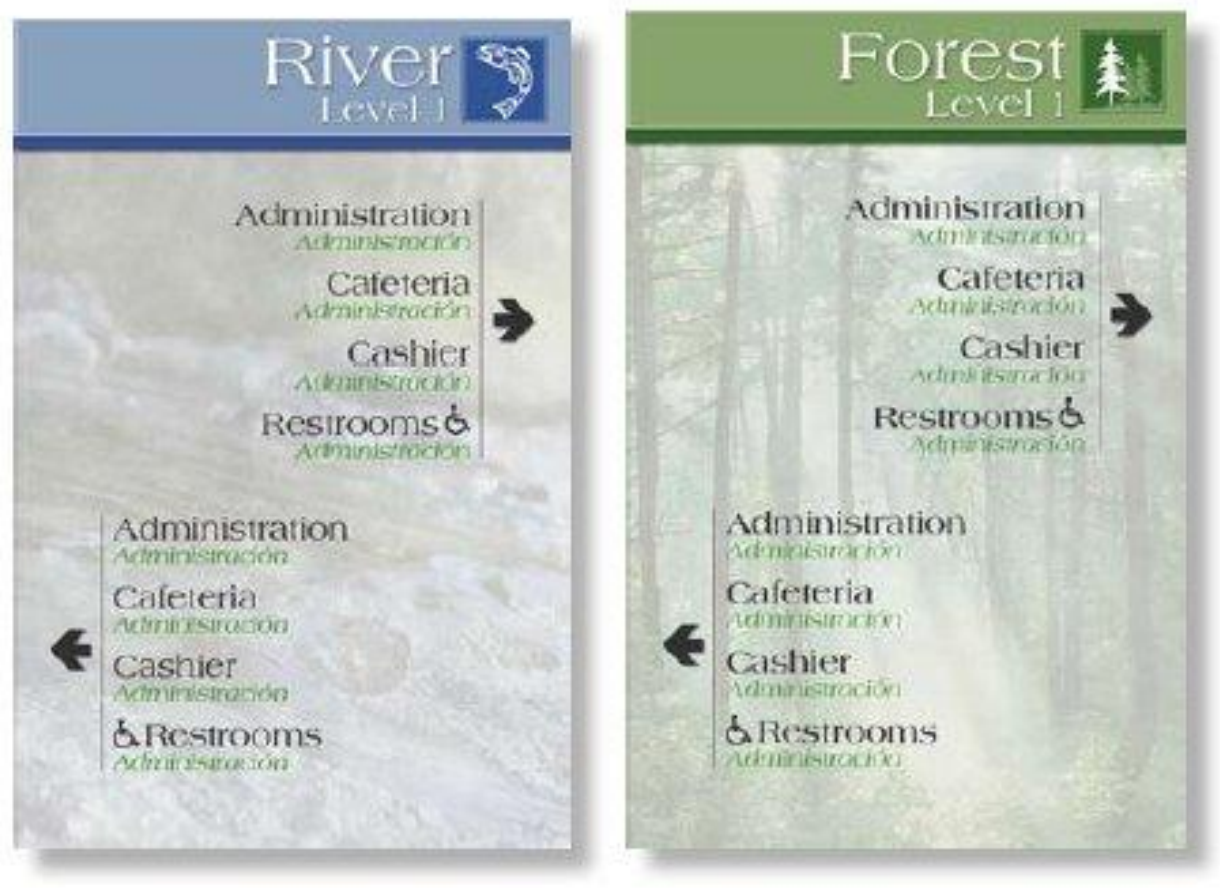

Figura 54 - Identificação de pavilhões: MultiCare Tacoma General Hospital Fonte: www.aesthetic.net 


\subsection{Sinalização de segurança}

A questão da segurança em hospitais é mais ampla do que se imagina inicialmente. Geralmente é associada apenas a questões de riscos de infecção e de contaminação, mas há também a necessidade de o hospital manter uma vigilância patrimonial e preocupar-se com a segurança estrutural, relacionada à qualidade de seus serviços (Esquema 7). Apesar de essa questão ser extremamente abrangente, salientamos neste trabalho apenas alguns aspectos relacionados com a sinalização de segurança.

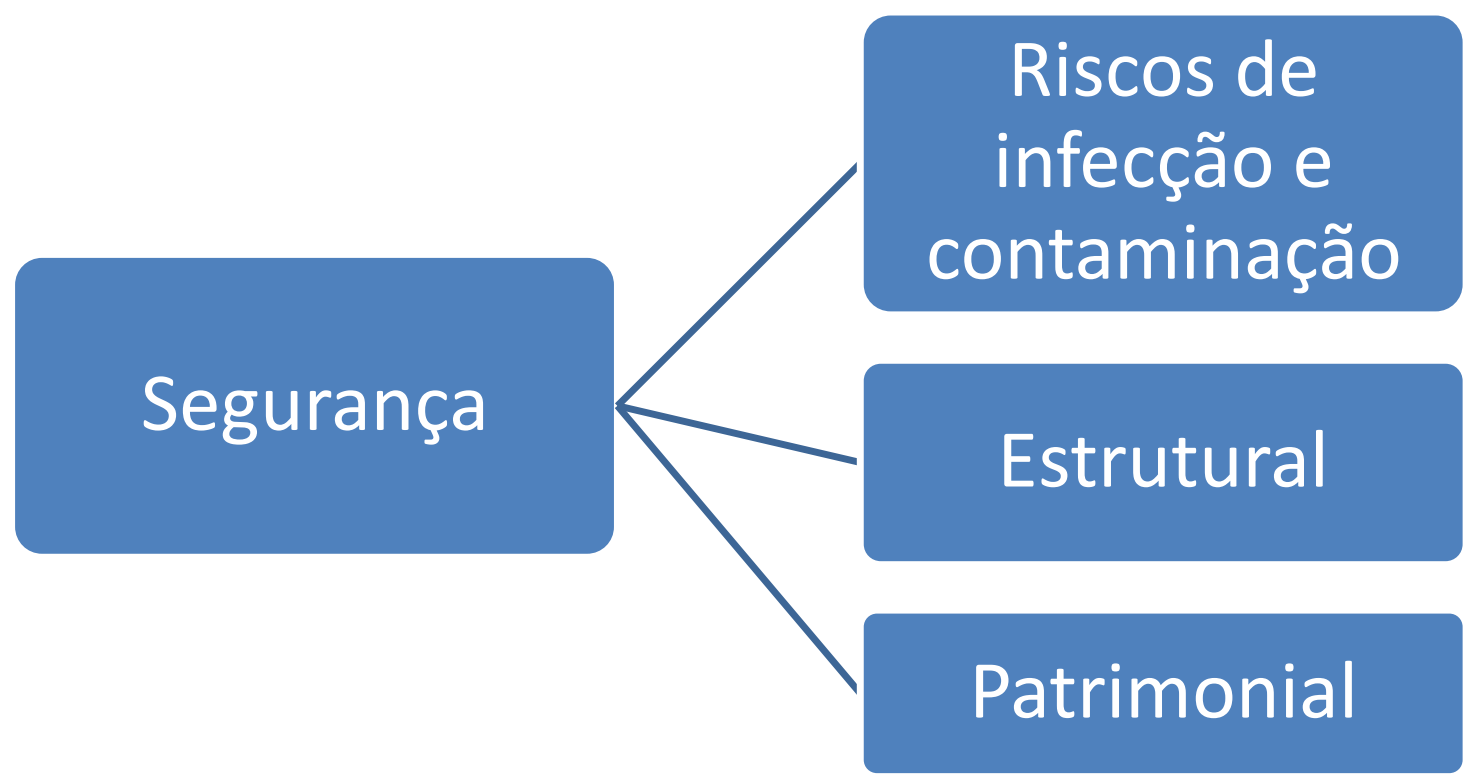

Esquema 7 - Segurança em hospitais

Fonte: Elaborado pela autora

Os riscos de infecção e contaminação requerem uma sinalização especial e cuidadosa em um ambiente hospitalar, evitando que pessoas tenham seu estado de saúde piorado. A segurança estrutural relaciona-se a precauções em casos de incêndio, terremoto ou problemas semelhantes. Requer sinalizações indicando extintores de incêndio, rota de fuga, mapa de risco e baseia-se em normas estabelecidas por órgãos de inspeção. A segurança patrimonial assegura que os usuários possam transitar pelos ambientes hospitalares sem problemas relacionados a furtos, assaltos ou até problemas mais graves (como evitar que alguém entre em um hospital para matar um paciente, por exemplo). 


\subsubsection{Segurança estrutural}

A segurança estrutural diz respeito, por um lado, às expectativas de diagnóstico, tratamento e cura por parte dos clientes de saúde e, por outro, à própria estrutura física do hospital (comuns a qualquer tipo de estabelecimento). Com relação ao primeiro aspecto, espera-se agilidade e excelência no atendimento médico, cordialidade no atendimento geral, eficiência de exames e avaliações.

A sinalização de enfermagem é um sistema relacionado à CV que pode aqui ser enquadrado como auxiliar em termos de segurança estrutural. O cliente de saúde tem, com esse sistema, segurança de que será atendido, caso precise se comunicar com alguém do posto de enfermagem fora dos horários comuns de atendimento $\mathrm{O}$ sistema interliga cada leito, sanitário e banheiro das diversas unidades e ambientes em que o paciente interno pode estar com o posto de enfermagem que the dá assistência (BRASIL, 2002b, p. 116-117). A Figura 55 mostra a sinalização em um banheiro de hospital para contato com a Enfermaria. A corda, com bolas vermelhas, pode até servir de apoio caso - paciente se desequilibre.

Com relação à estrutura física do

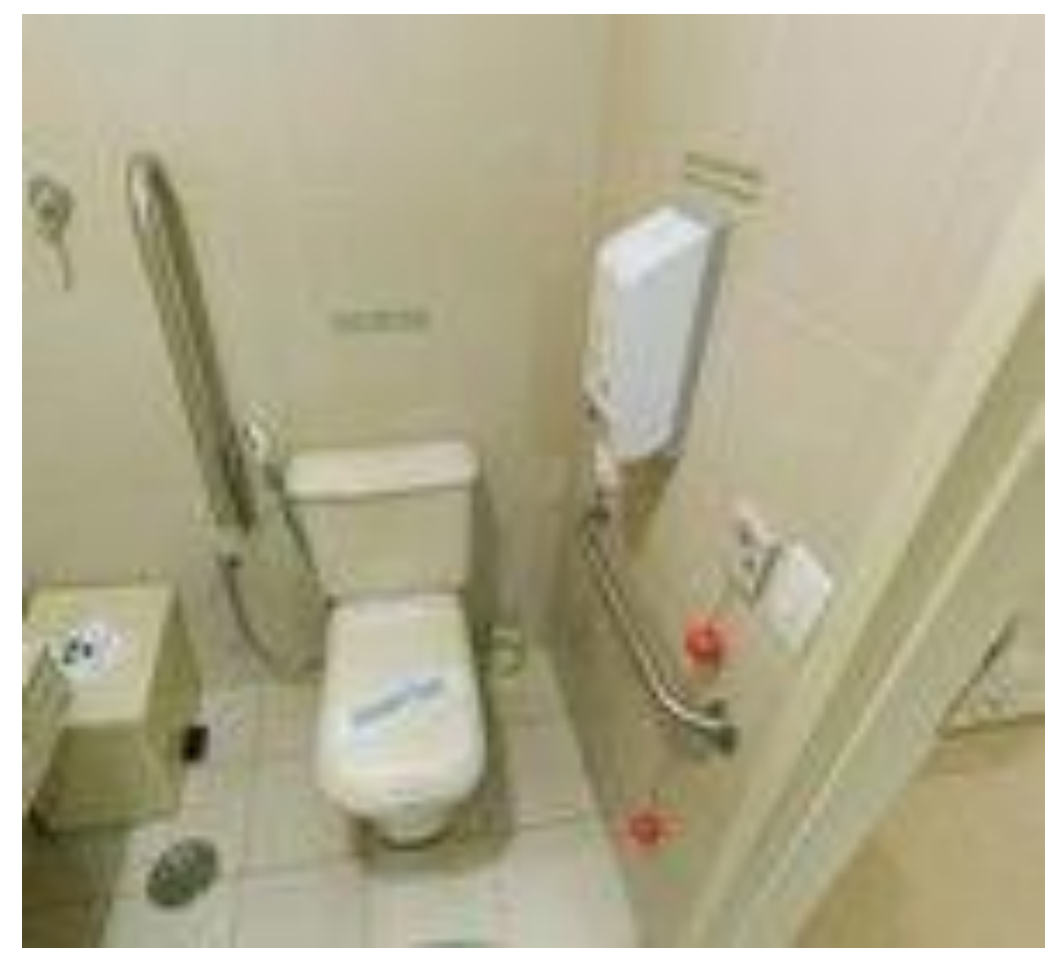

Figura 55 - Sinalização de enfermagem no banheiro Fonte: unw.hospitalalemao.org.brhaoc/Defaultaspx?idPagina=35613 hospital, há normas para garantir a 
segurança, com sinalização prevista nos projetos físicos de Estabelecimentos Assistenciais de Saúde (RDC no. 50, de 21 de fevereiro de 2002, códigos, leis, decretos, portarias e normas federais, estaduais e municipais).

A sinalização de segurança contra incêndio é feita nas paredes e pisos; sinais acústicos podem ser utilizados como meios complementares. Todas as saídas de pavimento e setores de incêndio têm de estar sinalizadas. As circulações contarão com sinais indicativos de direção desde os pontos de origem de evacuação até os pontos de saída. A sinalização perfeitamente visível deve confirmar a utilização, por exemplo, de escadas de incêndio. Toda porta que não seja saída (e que não tenha indicação relativa à função do recinto a que dá acesso) pode induzir a erro. Dessa forma, deve ser sinalizada com o rótulo "SEM SAÍDA" (BRASIL, 2002b, p. 133).

Além disso, é importante ressaltar que, em um hospital, enganos podem ser fatais. Um medicamento, por exemplo, não pode ser confundido com outro, nem com algum produto diferente, daí a necessidade de uma boa sinalização ressaltando diferenças.

\subsubsection{Riscos de infecção}

O trabalho em um ambiente hospitalar requer maior cuidado com a segurança, pois este ambiente é, por natureza, extremamente insalubre. Profissionais vivem em contato direto e contínuo com doenças, material infectado, com riscos operacionais devido a manusear equipamentos de risco. Uso de luvas, aventais e máscaras por parte da equipe médica (Figura 56); lavagem e esterilização das mãos antes e após cada atendimento; isolamento de pacientes são exemplos de procedimentos básicos para

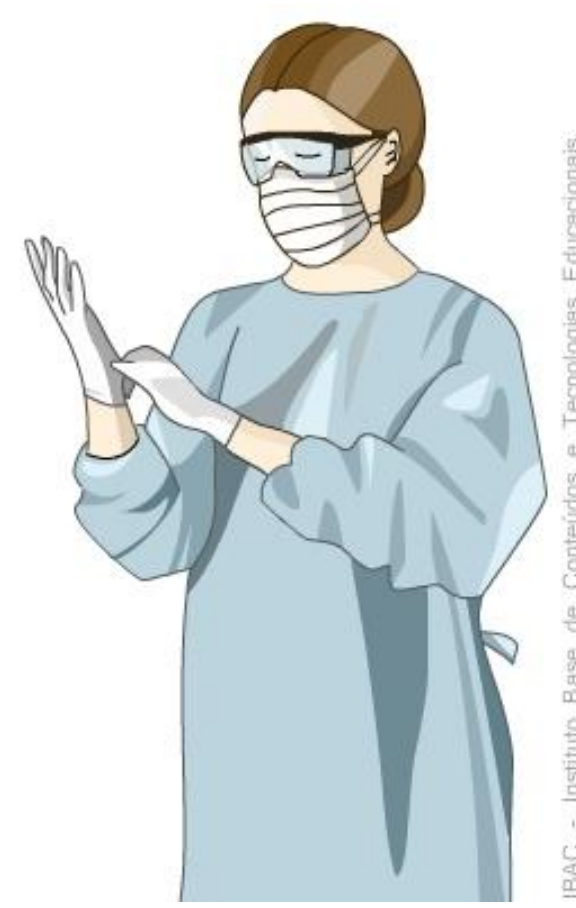

Figura 56 - Equipamentos de proteção e segurança

Fonte:

uww.jomadaead.com.br/cofen/atualizacoes/Atualizac ao_1 
evitar infecção hospitalar.

Peças de CV (banners e/ou informativos) explicando procedimentos para evitar contaminação podem ser utilizadas como elemento auxiliar. Um exemplo está na Figura 57, que mostra os procedimentos para descontaminar as mãos, usando tanto texto verbal quanto imagens. Além disso, o display contém dois recipientes com álcool gel e informativos disponíveis para usuários. Todos os

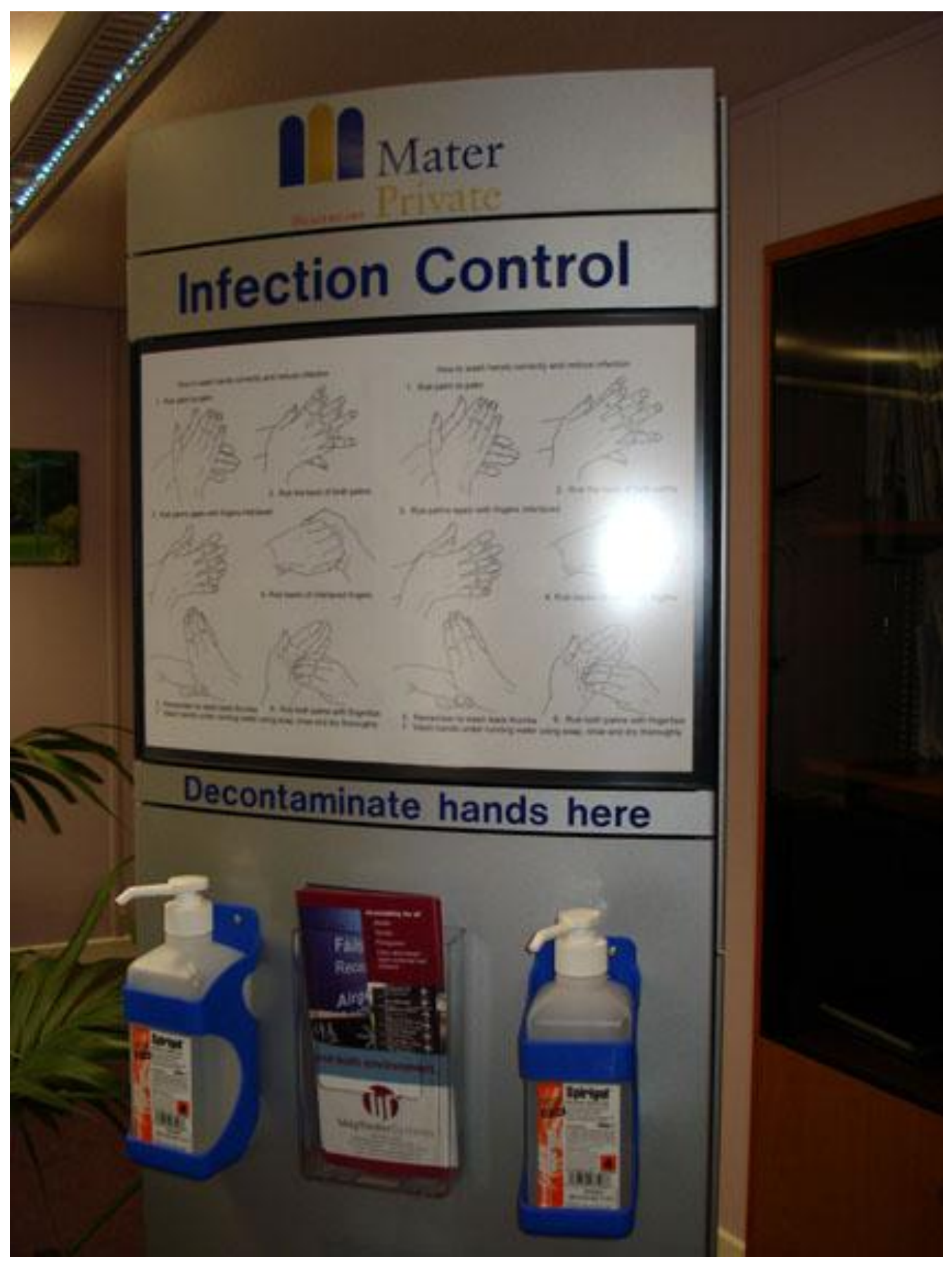

Figura 57 - Explicações: controle de infecção

Fonte: uww.wayfindersystems.ie/wp-content/uploads/sector_health_tullamore_hospital_0007.jpg 
usuários devem ter esses procedimentos para evitar riscos de contaminação, sobretudo em locais em que haja pacientes internados ou em Pronto Atendimento.

As áreas dentro de um hospital, de acordo com o risco de transmissão de infecção, são classificadas em: críticas; semicríticas e não críticas (BRASIL, 2002b, p. 99). É necessário que sejam feitas avaliações de risco com o intuito de controlar e prevenir possíveis danos causados por exposição de indivíduos a agentes ambientais.

O controle desses riscos, na área de saúde "apresenta intersecções com três áreas: a biossegurança, a saúde do trabalhador e, mais recentemente, a garantia de qualidade em estabelecimentos de saúde" (HÖKERBERG et al., 2006, p. 504). O mapa de risco representa graficamente os locais de riscos ambientais, identificando esses zoneamentos para diminuir riscos de contaminação. Círculos de tamanhos e cores diferentes identificam os locais e os fatores de perigo (agentes físicos, químicos, biológicos, ergonômicos e acidentes). Os grupos a que pertence o risco devem ser colocados dentro dos círculos e ser especificados segundo cor padronizada. A intensidade dos riscos deve ser representada por tamanhos proporcionalmente diferentes de círculos, de acordo com a percepção dos trabalhadores (NEVES et al., 2006, p. 78). A Figura 58 apresenta um mapa de risco de uma clínica cirúrgica.

QUADRO-2

MAPA DE RISCO DA CLÍNICA CIRÚRGICA

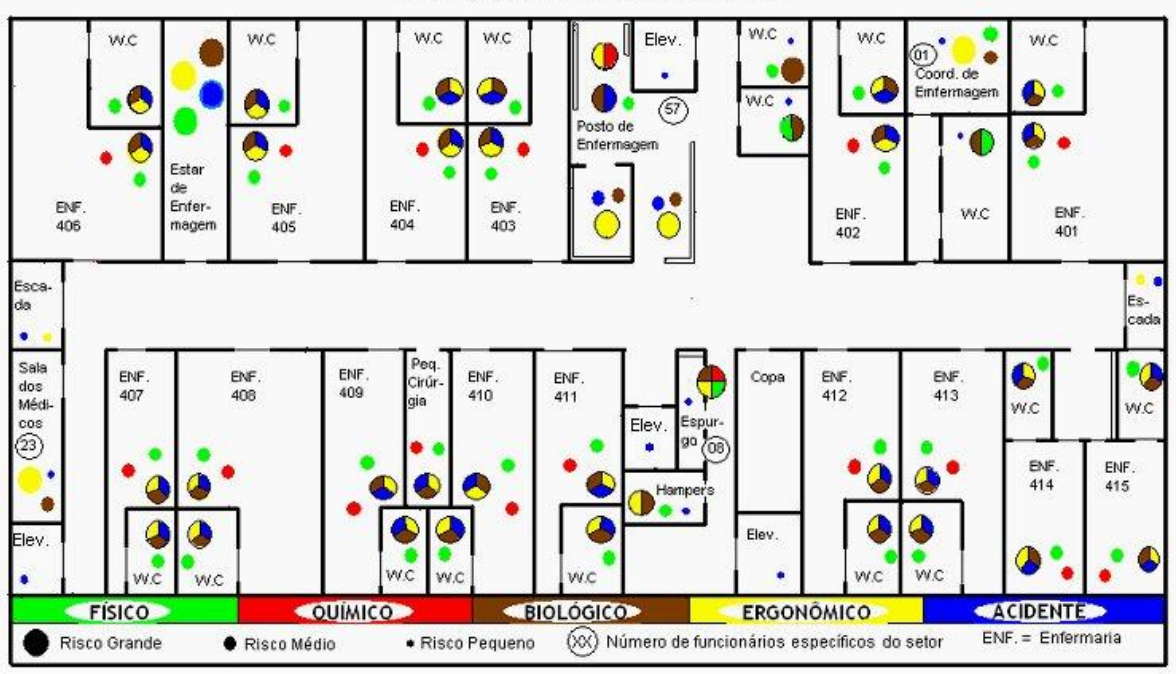

Figura 58 - Mapa de risco de uma clínica cirúrgica Fonte: Soares e Daher (2009, p. 9) 
Outro destaque é quanto aos princípios básicos de proteção radiológica. Determinados exames dependem do uso de equipamentos radiológicos para sua realização. É imprescindível alertar clientes de saúde sobre os riscos e colocar sinalizações comunicando sobre possíveis problemas.

Salas de Raios X, em especial, necessitam de uma sinalização diferenciada por causa dos diferentes avisos de segurança. Além de informar sobre os serviços prestados e oferecidos no local, é preciso informar os riscos que os pacientes correm (GREVY; GUIMARÃES; VENDRAMINI, 2007). No exemplo (Figura 59), é possível notar quatro avisos: alerta de entrada proibida quando a
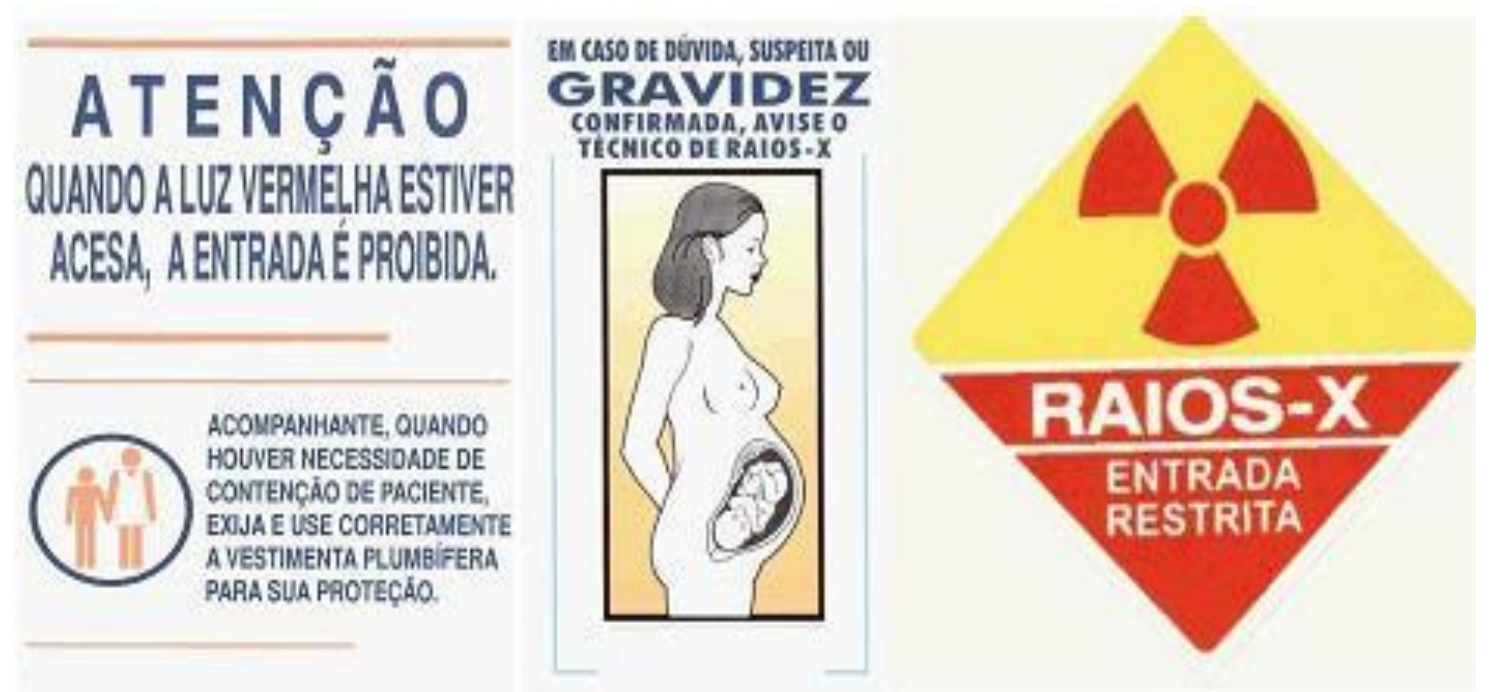

Figura 59 - Sinalização: radiação Fonte: www.radiologiatec.cjb.net

luz estiver vermelha; necessidade de vestimenta plumbífera para proteção de acompanhantes (quando for caso de necessidade de contenção do paciente); necessidade de avisar o técnico de Raios-X sobre os casos de suspeita ou gravidez confirmada; aviso de entrada restrita (com o pictograma indicando radioatividade). 


\subsubsection{Segurança patrimonial}

Quanto à segurança patrimonial, os hospitais têm que lidar com possibilidades de: furto (de medicamentos e drogas na farmácia, por exemplo); entrada de pessoas mal intencionadas (vestidas de médicos ou enfermeiras para acessar áreas restritas); roubo de ativo/equipamentos; agressão; incêndio; suicídio etc. Esses riscos podem ser decorrentes de comportamentos humanos (acidentais
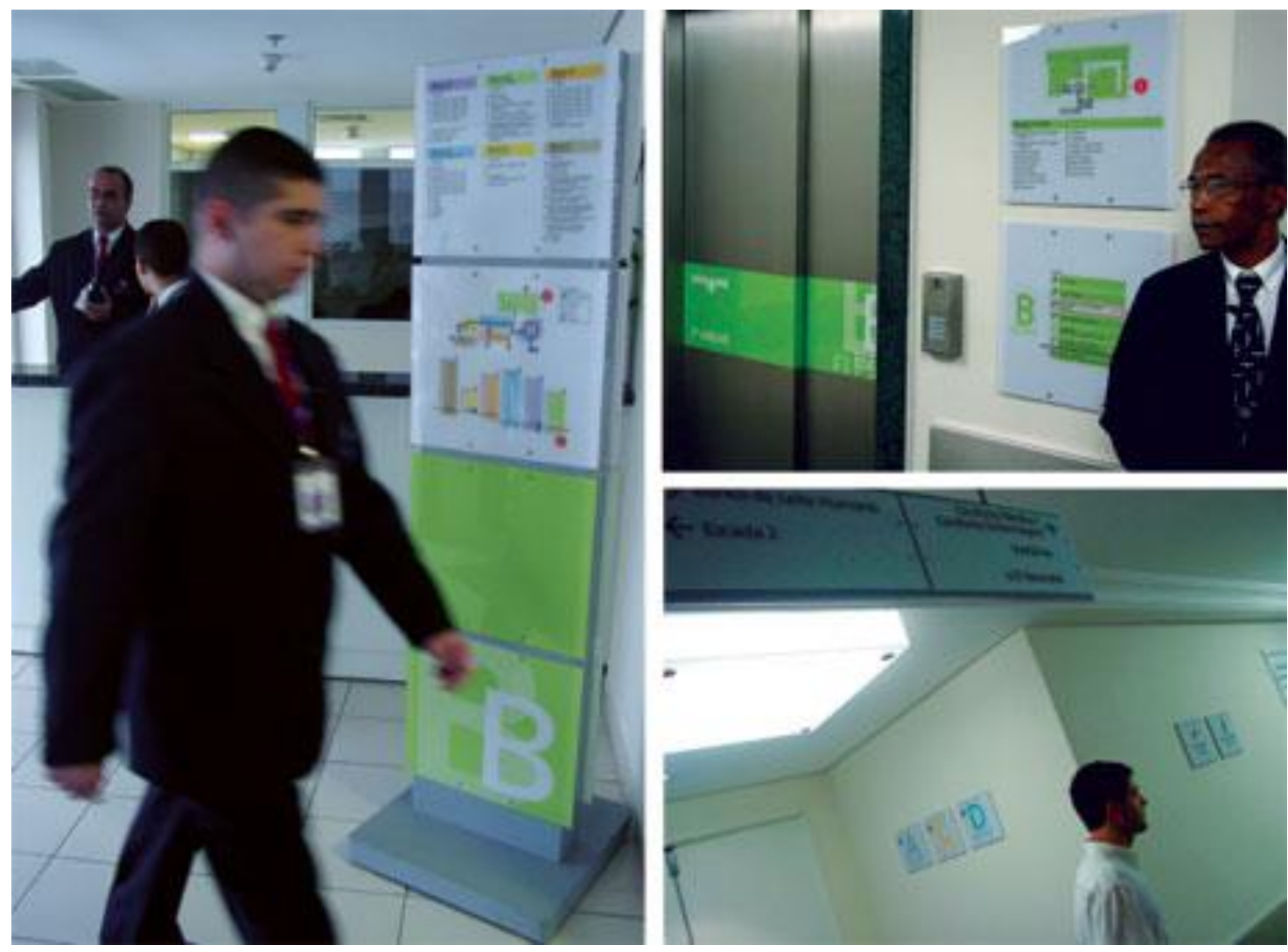

Figura 60 - Segurança patrimonial

Fonte: unw.casodesign.com.briindex.asp?c=f6331bfd4501bd20e461e4eaf0708364

ou intencionais) ou de fenômenos naturais.

Para evitar esses riscos, é preciso que haja um serviço de vigilância (com equipes terceirizadas ou com funcionários do próprio hospital) contando com equipamentos de ponta (circuito fechado de televisão; alarmes; rádios internos de transmissão etc.) e pessoal bem capacitado, (como mostra a Figura 60, do Hospital São Luiz Itaim), principalmente no que se refere ao tratamento dado aos clientes de saúde (BOERGER, 2005, p. 83-89). A disposição dos equipamentos de monitoramento no ambiente pode ser vista como mais um 
elemento de CV (os clientes de saúde podem sentir mais segurança ao saber que o ambiente está sendo monitorado, filmado e contando com equipes de seguranças). O Hospital Sírio-Libanês, em São Paulo, por exemplo, é monitorado por um complexo esquema de segurança, com "500 câmeras distribuídas por dez mil metros quadrados, 250 controladores de acesso e 250 sensores de proximidade. Além disso, 100 agentes vigiam o interior e os arredores do hospital" (TARANTINO, 2011).

\subsection{Demais informações}

A ampla e complexa estrutura hospitalar tem muitas informações a transmitir a seus usuários, além das relacionadas a orientações de fluxo, segurança e identidade visual. Informações sobre problemas de saúde e suas prevenções, por exemplo, fazem parte dos objetivos dos hospitais de hoje, que têm como foco não apenas o tratamento e cura de doenças, como também a preocupação com a educação e a pesquisa. Sendo esse um campo extremamente abrangente, a intenção é apenas apresentar um panorama geral sobre 0 assunto.

Painéis, banners, totens, displays com informativos sobre prevenção de doenças são exemplos de comunicação não pessoal, usados como recurso para transmitir

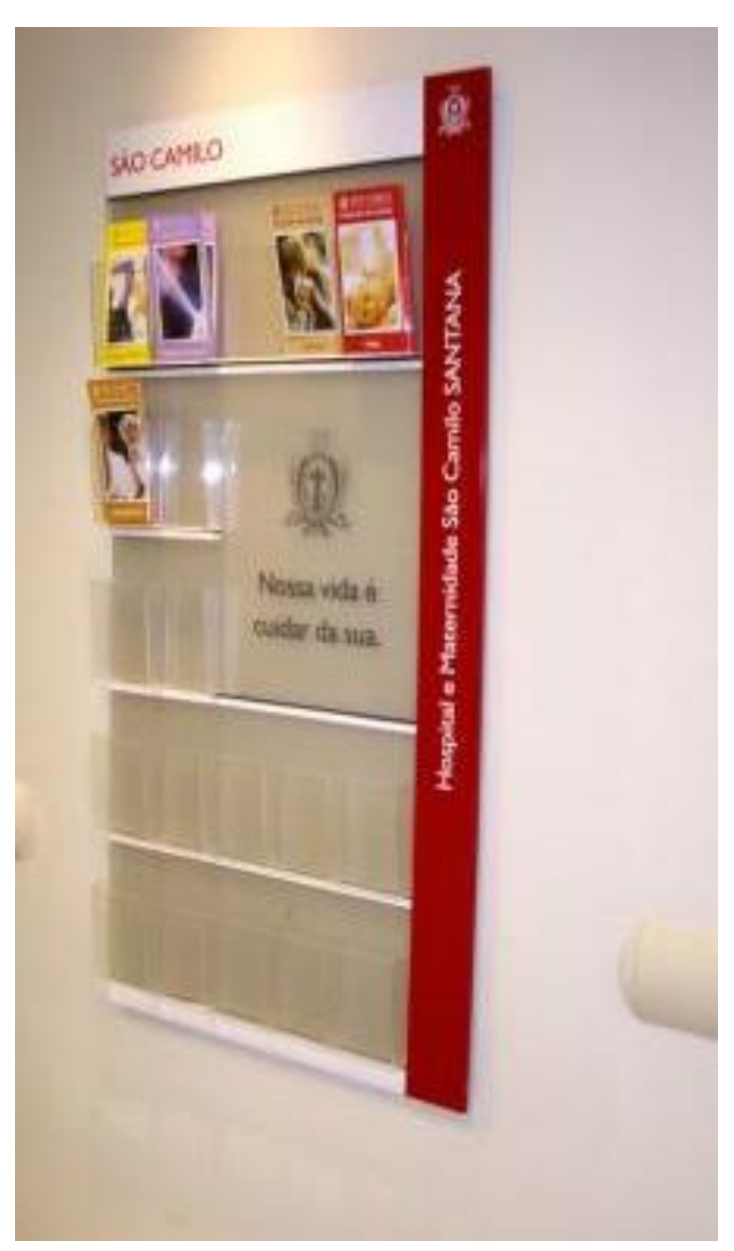

Figura 61 - Display do Hosp. São Camilo Fonte: www.kojima.com.br/ mensagens do hospital aos usuários, como mostra o exemplo do display do Hospital São Camilo (Figura 61). 
Enquanto empresa, um hospital (sobretudo no caso dos particulares) precisa reforçar sua imagem perante seus clientes. Para isso, a comunicação desempenha importante papel, pois aproxima a instituição de seu público-alvo. Divulgar sua missão, valores e objetivos é um exemplo de ações que um hospital pode fazer para mostrar aos usuários quais são suas propostas, assim como divulgar a aquisição de selos ou certificações relacionadas à qualidade dos serviços hospitalares (tais como Acreditação e Joint Comission International). Enquanto o hospital se prepara para receber esses selos, podem ser colocados banners explicando que as alterações são para atender as exigências de organizações certificadoras. Isso ajuda os usuários a se adaptarem às novas formas de atendimento e, ao mesmo tempo, divulga a intenção de o hospital ter um diferencial que pode distingui-lo da concorrência (dando-Ihe maior credibilidade). Quando os selos e/ou certificações são conquistados, também podem ser colocados peças de CV (banners, anúncios publicitárias etc.) no ambiente, para transmitir aos usuários conceitos como confiança e segurança.

Campanhas realizadas pela instituição fazem parte da CV. A Figura 62 mostra

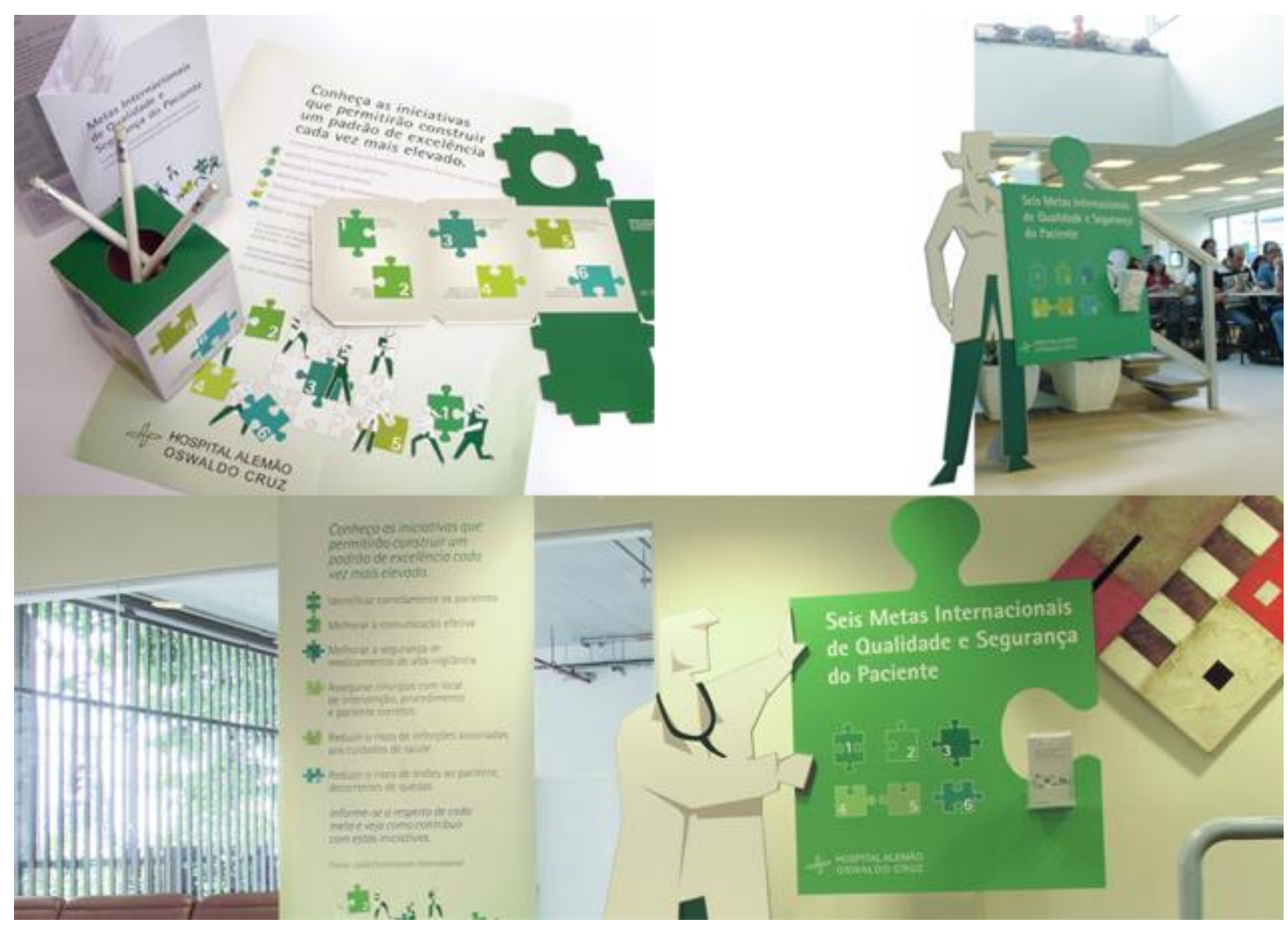

Figura 62 - Campanha do H. A. Oswaldo Cruz

Fonte: uww.epigram.com.br/index.php/2009/11/cuidando-da-comunicacao-de-quem-cuidal 
como exemplo uma campanha direcionada para médicos e funcionários do Hospital Alemão Oswaldo Cruz, indicando seis passos para melhorar a qualidade dos serviços e atendimento do hospital (campanha desenvolvida pela agência Epigram).

Quando um hospital implanta um novo sistema de CV, por exemplo, também é importante que seja feita a divulgação para os funcionários a fim de que eles compreendam as mudanças necessárias e, ao mesmo tempo, possam auxiliar clientes de saúde. A $f d 2 s$, ao elaborar o programa de sinalização para o $M$. $D$. Anderson Cancer Center (EUA), criou um material promocional (pôsteres e manuais de treinamento) direcionado às pessoas que trabalham no hospital (Figura 63).

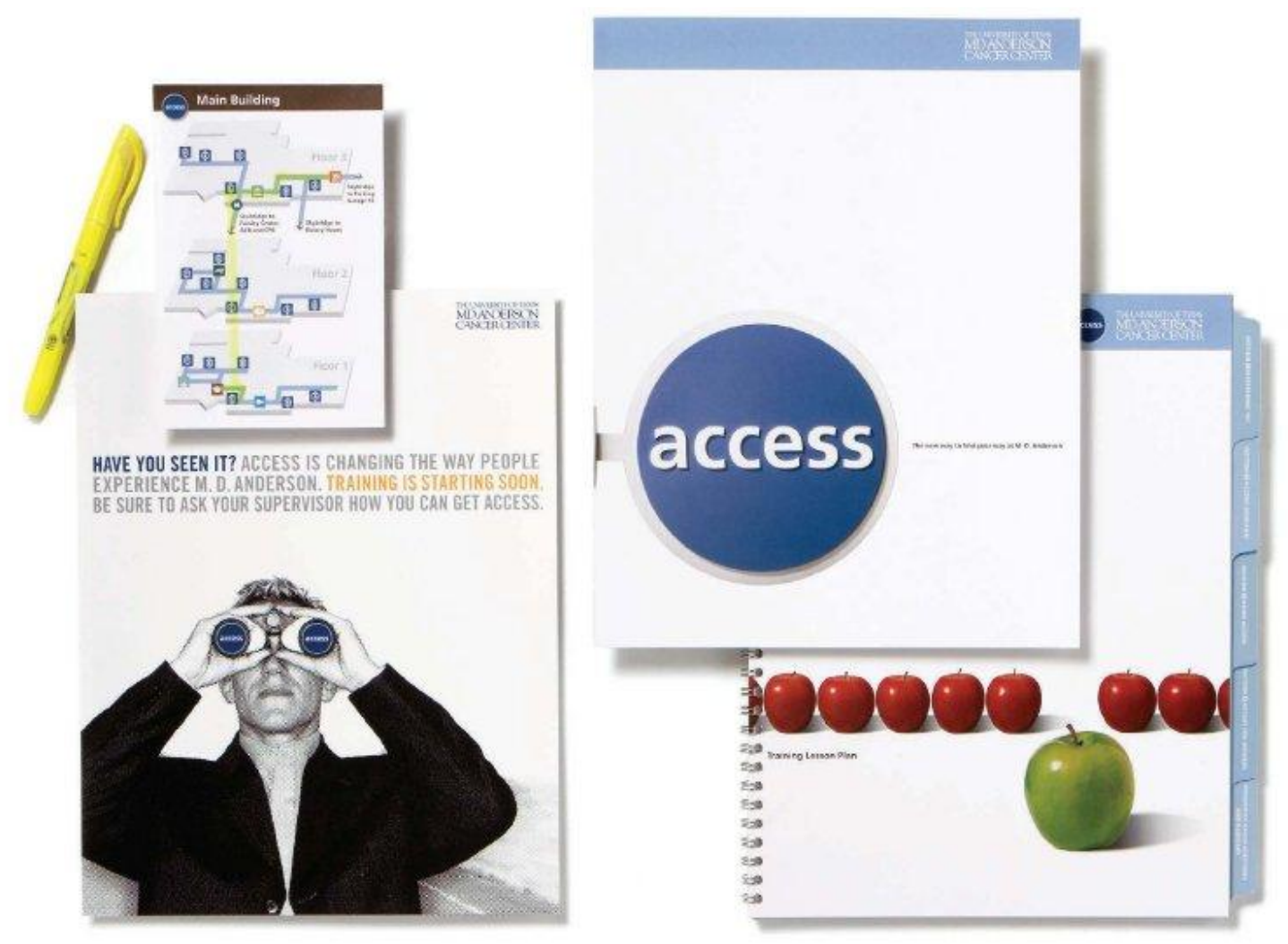

Figura 63 - Material de divulgação do "Access" Fonte: access.fd2s.com/ 
Informações podem ter um caráter decorativo, em alguns casos, como ocorre com a lista de doadores de alguns hospitais (muito comum, sobretudo nos EUA). A Figura 64 apresenta uma árvore com as indicações de doadores do Hospital St Joseph, em Minnesota. As folhas, com coloridos diferenciados, indicam os valores das contribuições.

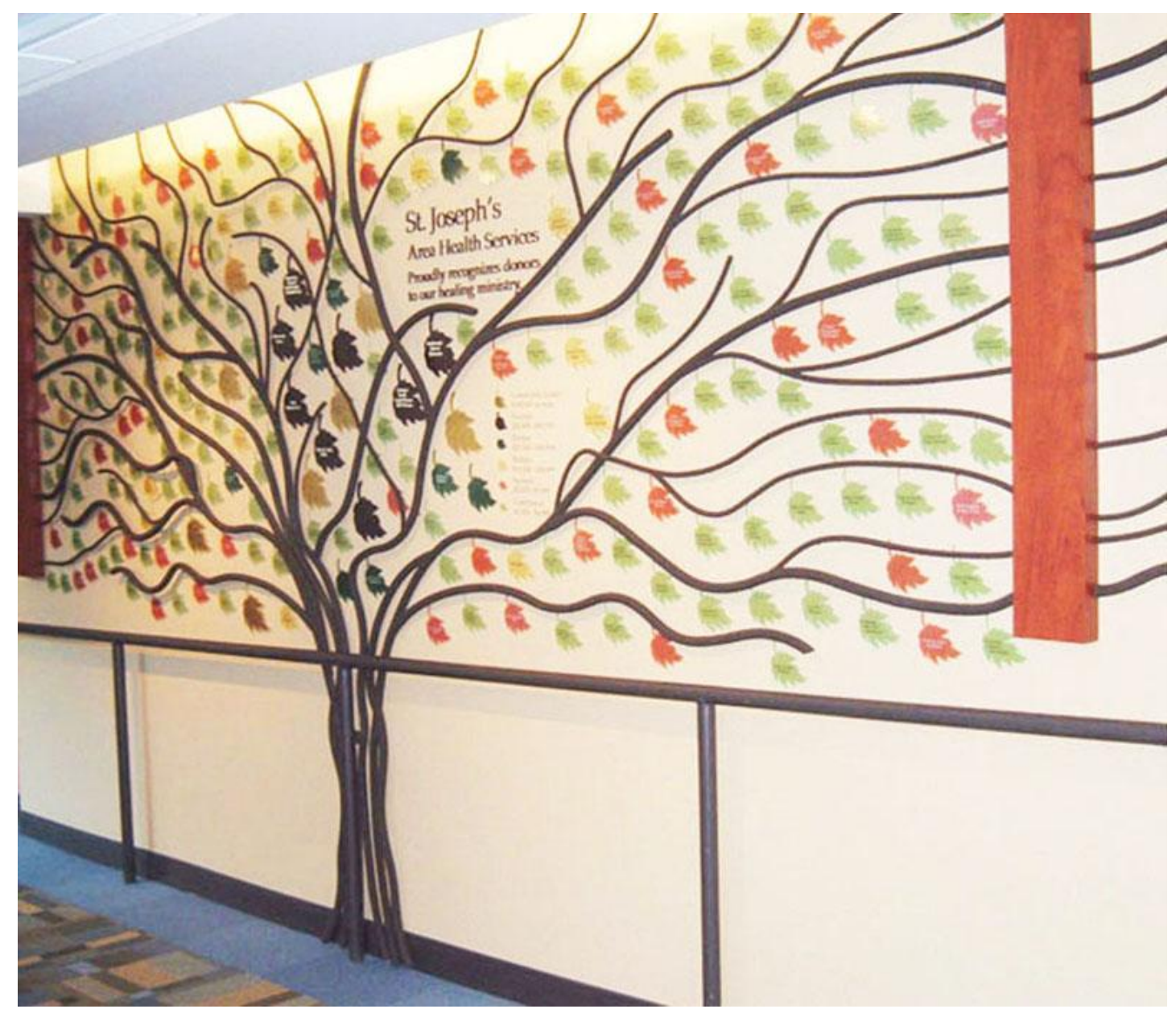

Figura 64 - St. Joseph's Area Health Services

Fonte: uww.visualoomm.com/Hospital-Wayfinding-Signage.htm|\#allina 


\subsubsection{Comunicação interpessoal}

Ao entrar no hospital, o primeiro contato do cliente (seus acompanhantes, familiares e amigos) é realizado na portaria e/ou recepção (Figura 65), local em

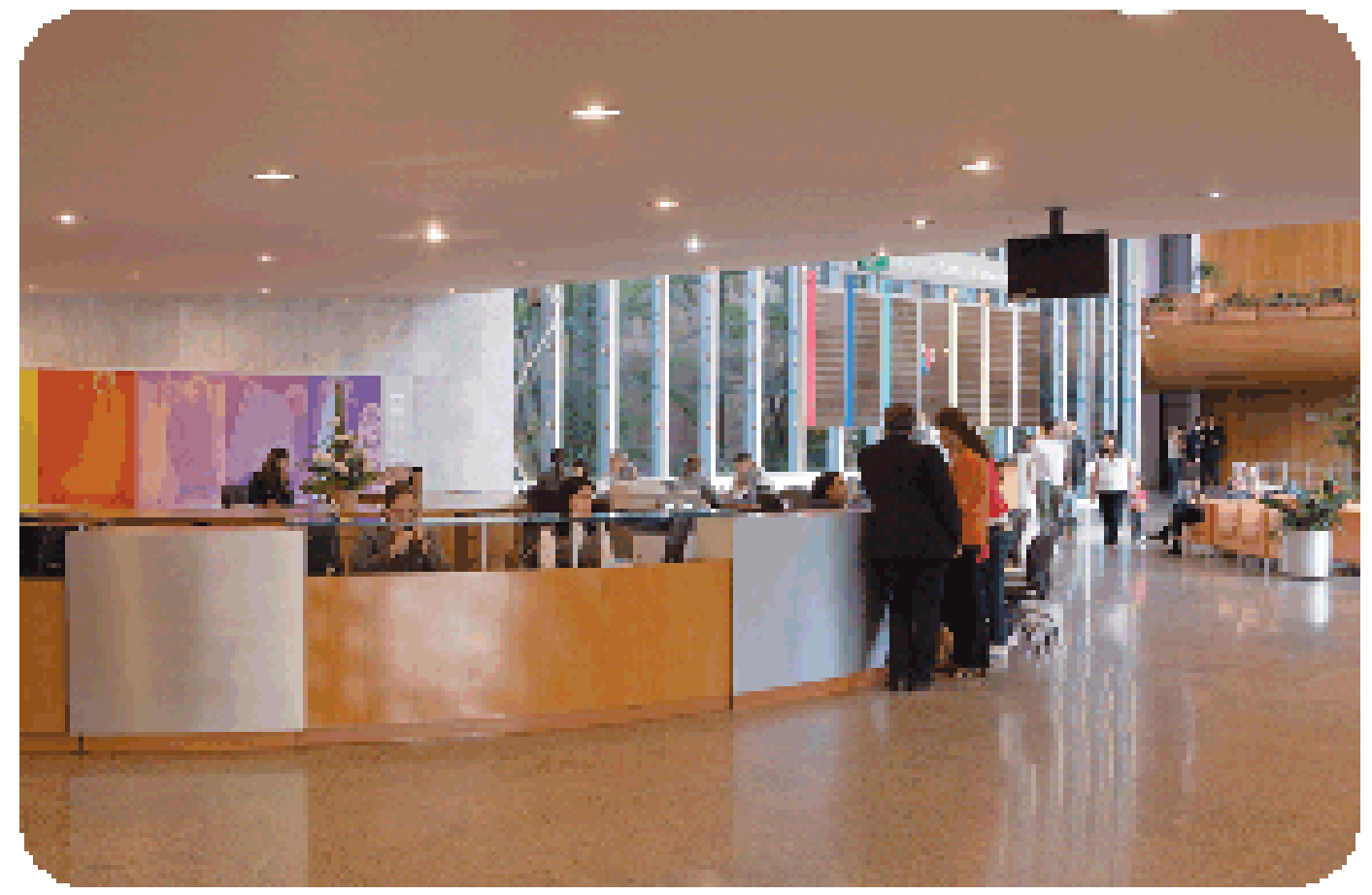

Figura 65 - Recepção do Hosp. Santa Catarina Fonte: www.hcs.org.br

que são prestadas informações diversas. Nos casos de internação, o paciente precisa ter um local de controle de fluxo de entrada e de saída, ou seja, um setor de secretaria. A comunicação interpessoal tem de ser bem desempenhada nesse ambiente, assim como a $\mathrm{CV}$, que pode auxiliar os usuários com informações complementares, dando a estes uma possibilidade de autonomia.

Do porteiro ao médico-cirurgião, todos devem trabalhar harmonicamente, estabelecendo um contato afetivo com os clientes de saúde. É importante lembrar que quando uma pessoa está internada, ela e/ou seus acompanhantes e familiares precisam ser avisados sobre a situação do paciente. Toda a equipe deve estar preparada para dar esse atendimento, cada um em sua função, evitando informações errôneas ou conflitantes, pois isso só gera preocupações e irritações que podem ser evitadas apenas usando-se respeito, gentileza e 
simpatia. Um atendimento acolhedor e amável viabiliza que o ambiente hospitalar não seja visto como um lugar tão restrito e isolado e, para isso, a comunicação interpessoal tem um papel fundamental.

É de vital importância a perfeita comunicação do momento em que o paciente se encontra em um hospital, um ambiente hostil e estranho ao seu. Carente de informações e ansioso por detalhes, tudo o que lhe for oferecido será aceito avidamente, especialmente pela equipe médica. São em momentos como esses que uma boa comunicação (rapport) pode amenizar o sofrimento do paciente e transmitir confiança para os familiares. $O$ bom atendimento na recepção é essencial para que paciente e família sintam-se bem e se ambientem, é o cartão de visitas do hospital e passará a mensagem a quem chega, de como será o atendimento de todo o hospital. (GODOI, 2008, p. 84)

O acolhimento envolve a criação de espaços de encontros entre usuários, "espaços de escuta e de recepção que proporcionem a interação entre usuários e trabalhadores" (BRASIL, 2006, p. 21). Um hospital tem várias mensagens a serem transmitidas às pessoas que circulam em seus espaços. Estas podem ser expressas de várias maneiras, mas há que se cuidar para que interpretações erradas sejam evitadas. Isso faz com que nas instituições hospitalares o papel da comunicação seja considerado como extremamente delicado e importante (QUEVEDO, 2006, p. 24).

As mensagens transmitidas pela arquitetura dos estabelecimentos de saúde possuem naturezas diversas (funcional, estética, psicológica, etc.), correspondentes ao universo de aspectos encontrados em qualquer edificação. Entretanto, a comunicação estabelecida vai além de meros registros, pois significa uma avaliação de desempenho dos lugares em relação a expectativas sociais quanto a suas possibilidades. Por exemplo, pode-se interpretar o conjunto de símbolos arquitetônicos ofertado por certo hospital como um edifício de fácil acesso aos pedestres, referindo-nos a seu comportamento funcional, considerado satisfatório em termos de acessibilidade física; adjetivá-lo como acolhedor (dimensão afetiva), ruidoso (dimensão ambiental/acústica), de manutenção cara (dimensão financeira), favorável à copresença (dimensão sociológica), etc. (BRASIL, 1995, p. 11)

Para exemplificar, fazemos aqui um recorte especial para a sinalização visual como orientadora de fluxos e como fonte de informação organizada para as pessoas que circulam nos ambientes hospitalares. Como avaliar se um estabelecimento de saúde possibilita a seus usuários informações suficientes para que eles possam se orientar com facilidade? Pela informação visual as pessoas entram em contato ativo com o mundo a que pertencem, situando-se e aprendendo permanente e progressivamente. A leitura dos lugares pode 
fornecer às pessoas coordenadas de situação (BRASIL, 1995, p. 12-13), possibilitando que elas se locomovam com autonomia.

Num estabelecimento de saúde, as informações visuais devem estar dispostas de forma a contribuir para que os usuários encontrem com facilidade e presteza os serviços e/ou atividades de que precisam. Apesar de cada ser humano ter percepções diferentes, capacidades e modos diferenciados, o sistema de CV mais adequado é o que procura estabelecer contato com o maior número possível de pessoas, por trabalhar com características comuns, procurando ser atemporais e universais.

\subsubsection{Comunicação interna}

A comunicação interna é uma comunicação previamente pensada, planejada e constantemente avaliada com o objetivo principal de facilitar a compreensão entre organização e colaboradores. Diz respeito às interações, aos processos de trocas, aos relacionamentos dentro de uma organização. Não que ela seja dirigida apenas ao público interno da organização (aliás, hoje se pode falar em vários públicos internos), mas este deve ser considerado de forma especial, pois a organização não vive sem ele.

O importante é que haja um esforço de comunicação no sentido de possibilitar o relacionamento, ágil e transparente, da direção com esses públicos internos e entre os próprios elementos que o integram. Para que a comunicação interna seja eficiente e atinja seus objetivos, é necessário que seja clara, consistente, completa e que transmita credibilidade; seus discursos devem ser condizentes com a prática. Necessário também é salientar que a comunicação é uma via de mão dupla, ou seja, não só é fundamental comunicar como escutar o interlocutor e agir sobre a informação recebida.

Quando bem planejada, representa uma importante ferramenta da administração estratégica, pois compatibiliza os interesses à medida que compartilha valores; promove o diálogo, a troca de informações e experiências e a participação de todos os níveis organizacionais; viabiliza ações voltadas prioritariamente aos colaboradores internos. Deve dispor de ferramentas que 
viabilizem o entendimento, a compreensão mútua e a troca de conhecimento, por meio da construção de um relacionamento (fundamentado na comunicação de mão dupla) capaz de compatibilizar os interesses e não somente mensurar resultados.

Para viabilizar os fluxos de comunicação administrativa e da comunicação interna, há uma série de mídias e veículos para promover a interação e a troca de informações entre a organização e seus integrantes, com rapidez, agilidade e eficiência. Alguns hospitais utilizam boletins informativos, jornais, manuais e cartilhas para disponibilizar normas e informações relevantes sobre saúde e links de interesse geral.

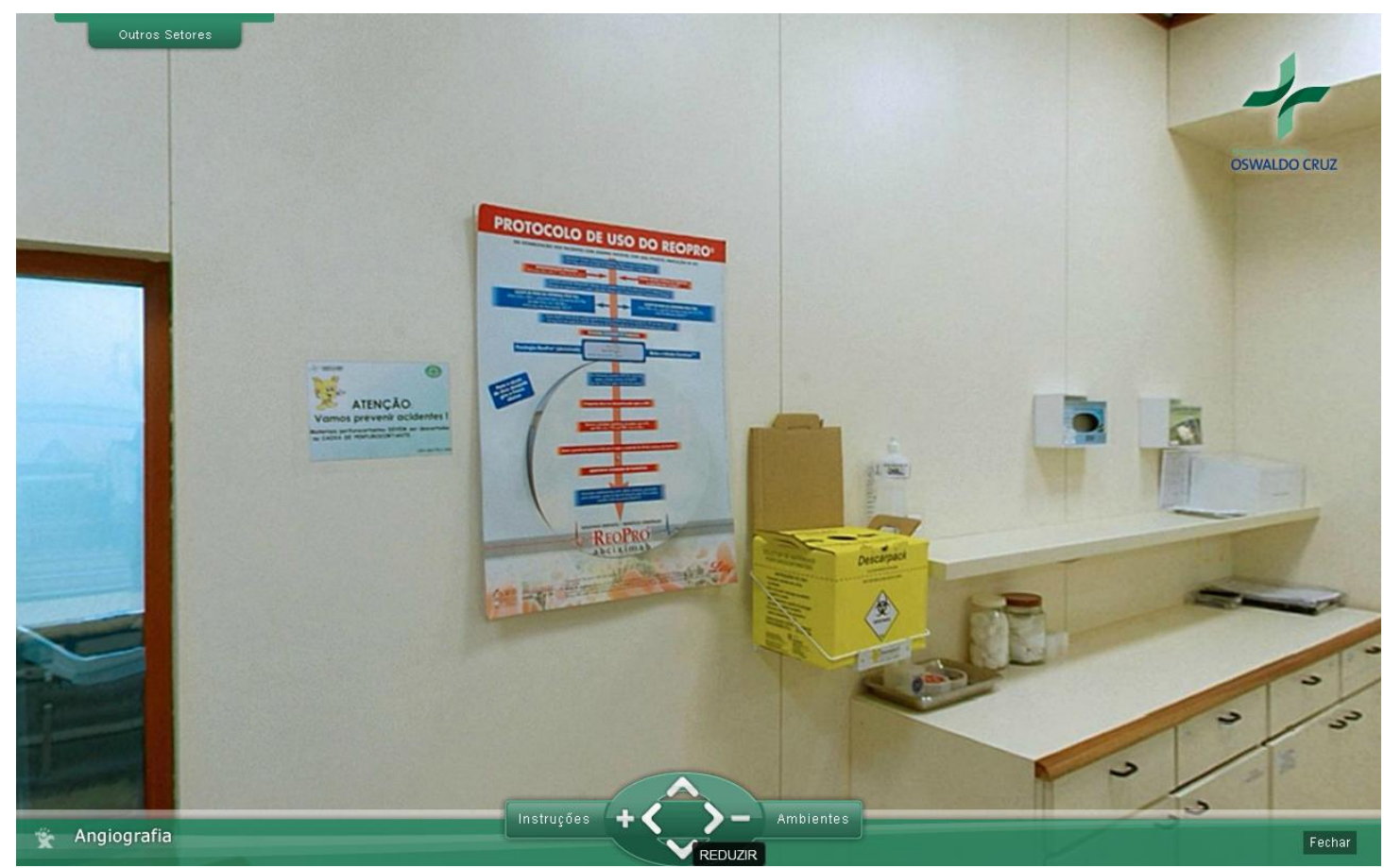

Figura 66 - Exemplos de sinalização em um hospital

Fonte: www.hospitalalemao.org.brhaoc/Default.aspx?idPagina $=35613$

Um destaque a ser feito é quanto às informações para funcionários que trabalham em setores diferenciados ou com materiais mais específicos, nos quais certas falhas podem colocar em risco a vida de pessoas. Um ambiente bem sinalizado pode reduzir riscos de acidentes, por isso a legislação sanitária é rigorosa em ambientes de saúde como um todo (sobretudo a relacionada a questões de segurança e prevenção). Podemos notar, na Figura 66, a quantidade de informações presentes em um pequeno espaço de uma sala de angiografia (Hospital Alemão Oswaldo Cruz). 
Notamos mais explicitamente o banner explicando o protocolo de uso do ReoPro (medicamento para uso endovenoso), a caixa para descarte de lixo perfurante e material hospitalar e o aviso chamando a atenção para a prevenção de acidentes (na parede ao lado do banner). Em uma leitura mais detalhada dessa imagem, temos a organização dos materiais de uso que também revela mensagens para a equipe médica, assim como a limpeza e a organização do ambiente (frascos de algodão, material a ser utilizado e prontuários colocados organizadamente sobre a bancada).

A organização é um fator importante e envolve a questão de etiquetas para identificação de produtos. Um engano causado por uma troca de embalagens pode ser fatal, como aconteceu no Hospital São Luiz Gonzaga, em São Paulo, em dezembro de 2010. Uma adolescente de 12 anos morreu após ter recebido vaselina líquida injetada em sua veia ao invés de soro. A causa do engano foi a semelhança entre os dois frascos (Figura 67), o que poderia ter sido

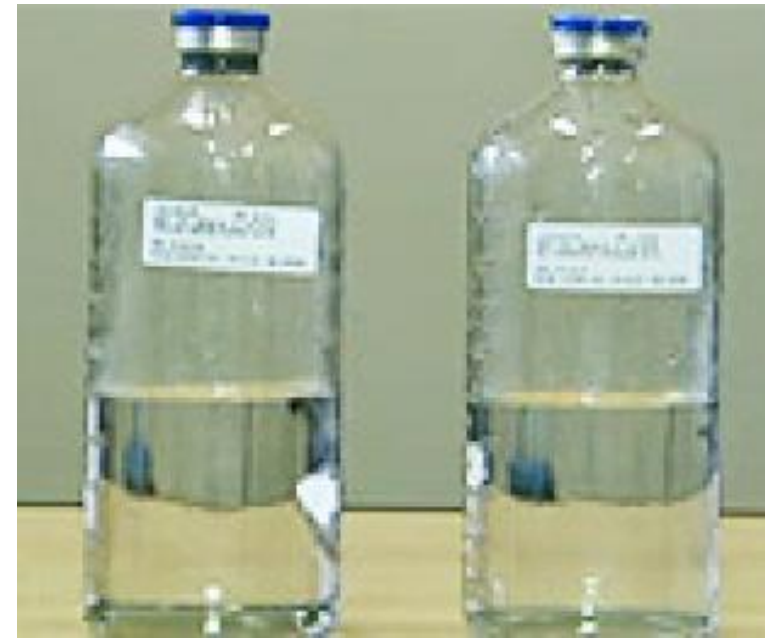

Figura 67 - Frascos (vaselina e soro) Fonte: uww.correiodopovo-al.com.br/3/mundo/10526Hospital-entrega-frascos-soro-vaselina-polcia.html evitado caso houvesse uma sinalização mais eficiente. Dois líquidos semelhantes no aspecto físico, mas com diferenças tão marcantes quanto ao uso deveriam ser diferenciados de forma muito clara para evitar erros graves como esse. 


\section{CAP. 3 AMBIÊNCIA HOSPITALAR}

\subsection{Ambiência e Humanização}

Está surgindo, cada vez mais, uma nova concepção dos espaços hospitalares, que aborda a qualidade do ambiente fazendo com que este possa fazer parte da terapêutica. A apresentação visual do ambiente e sua função utilitária são vistos como pontos que merecem estudos aprofundados a fim de serem feitas atualizações em todas as instituições de saúde (BECK et al., 2007, p. 6)

O ambiente hospitalar, ao proporcionar condições espaciais e temporais eficientes do ponto de vista comunicacional, pode contribuir para a recuperação dos clientes de saúde. Além disso, a hospitalidade e a humanização nos ambientes hospitalares são aspectos fundamentais a serem considerados pelas equipes de profissionais que lidam constantemente com o cliente de saúde.

Segundo Toledo (2005, p. 9), o conceito de ambiência é bem complexo e abrangente, que relaciona aos estudos de vários autores clássicos, como: Maurice Merlau-Ponty (fenomenologia da percepção), Edward Hall (conceitos de territorialidade), Robert Sommer (conceito de espaço pessoal), James Gibson (percepção visual), David Carter (psicologia do lugar), Robert Guttman (comportamento de usuários de edifícios), Christian Norberg-Schulz (fenomenologia da arquitetura) e Amos Rapoport (percepção, cultura e arquitetura).

De acordo com Cavalcanti, Azevedo e Duarte (2007, p. 7), "estudos na área de psicologia ambiental têm comprovado que a imagem que formamos de um ambiente orienta a apropriação que dele fazemos". Isso implica que a percepção que uma pessoa tem de determinado espaço envolve questões ligadas às suas expectativas e valores, pois ela "projeta sobre o espaço sentimentos e significados internalizados", que correspondem a seu nível de satisfação ou insatisfação.

Cada setor do ambiente oferece aos seus usuários uma enorme gama de 
variáveis que influenciam o comportamento humano, desde aspectos considerados "objetivos" (como iluminação, temperatura, ruídos e arborização) até aspectos totalmente "subjetivos" (como a sensação de aglomeração e acolhimento, as condições de apropriação e o clima social). Essas dimensões 'visíveis' e 'invisíveis' do lugar correspondem à sua ambiência e influenciam a percepção das pessoas que o experenciam e, a partir de suas próprias características individuais, (gênero, idade, história de vida, condições físicas, entre outros) o interpretam e reinterpretam continuamente. (ELALI, 2009, p. 11)

A ambiência, num contexto mais amplo, revela-se no cotidiano em qualquer interação entre um usuário e o espaço no qual se encontra.

(...) o homem se apropria dos espaços humanizando-os, modificando-os para dotá-los de sua própria natureza. (...) Apropriação envolve a interação recíproca usuário/espaço, na qual o usuário age no sentido de moldar os lugares segundo suas necessidades e desejos. Os lugares, em contrapartida, tornam-se receptivos. (...) Os lugares receptivos são aqueles com os quais as pessoas se sentem em perfeita harmonia e nos quais elas encontram sua identidade individual e coletiva. A ambiência do ambiente é o que possibilita esse processo comunicativo. (MALARD, 1993, p. 4)

Segundo textos básicos de saúde, a humanização é entendida como "a valorização dos diferentes sujeitos implicados no processo de produção de saúde" (BRASIL, 2006, p. 3). O "HumanizaSUS" busca soluções visando a melhoria da qualidade dos atendimentos, dos ambientes de cuidado e das condições de trabalho dos profissionais.

O design do ambiente interno de um hospital pode, complementando a arquitetura, fazer com que o ambiente se torne mais agradável. O espaço hospitalar pode ter relação com os resultados do tratamento do paciente (tanto positiva quanto negativamente), por isso a nova tendência é transformar os ambientes, humanizando-os de acordo com as necessidades dos usuários.

O Ministério da Saúde tem priorizado, ao longo de vários anos, com relação aos hospitais públicos, o atendimento com qualidade e a participação integrada dos gestores, trabalhadores e usuários na consolidação do Sistema Único de Saúde (SUS). A intenção de sua criação foi proporcionar atendimento a todos os cidadãos, promovendo a justiça social e superando as desigualdades na assistência à saúde da população. O SUS é a rede que reúne todos os estabelecimentos públicos de saúde (postos de saúde, ambulatórios, hospitais, laboratórios etc.) responsáveis por garantir o direito dos cidadãos a consultas, exames, internações e tratamentos. 
Pensando-se na qualidade do atendimento, desde 2004 foi implementada a Política Nacional de Humanização $(\mathrm{PNH})$ - HumanizaSUS - para enfrentar o desafio de mudar os modelos de atenção e de gestão das práticas de saúde. $O$ conceito de ambiência foi implantado para que, principalmente no sistema público de saúde, os pontos de insatisfação da população (filas longas, desconforto nos ambientes, espaços superlotados, sem equipamentos etc.) pudessem ser amenizados pelo processo de humanização.

A questão do espaço físico compreendido como espaço social, profissional e de relações interpessoais em ambientes de saúde é tratada atualmente no SUS (Sistema Único de Saúde) pelo termo "ambiência". Esse conceito vai além da composição técnica dos ambientes, pois abrange aspectos relacionados às situações construídas em determinados espaços em determinado tempo, vivenciadas por um grupo de pessoas com seus valores culturais e relações sociais. A ambiência hospitalar segue três eixos (BRASIL, 2006):

1) Confortabilidade: componentes que atuam como modificadores e qualificadores do espaço (relacionados à percepção ambiental) devem ser usados com equilíbrio e harmonia para criar ambiências acolhedoras e propiciar contribuições significativas no processo de produção de saúde. A

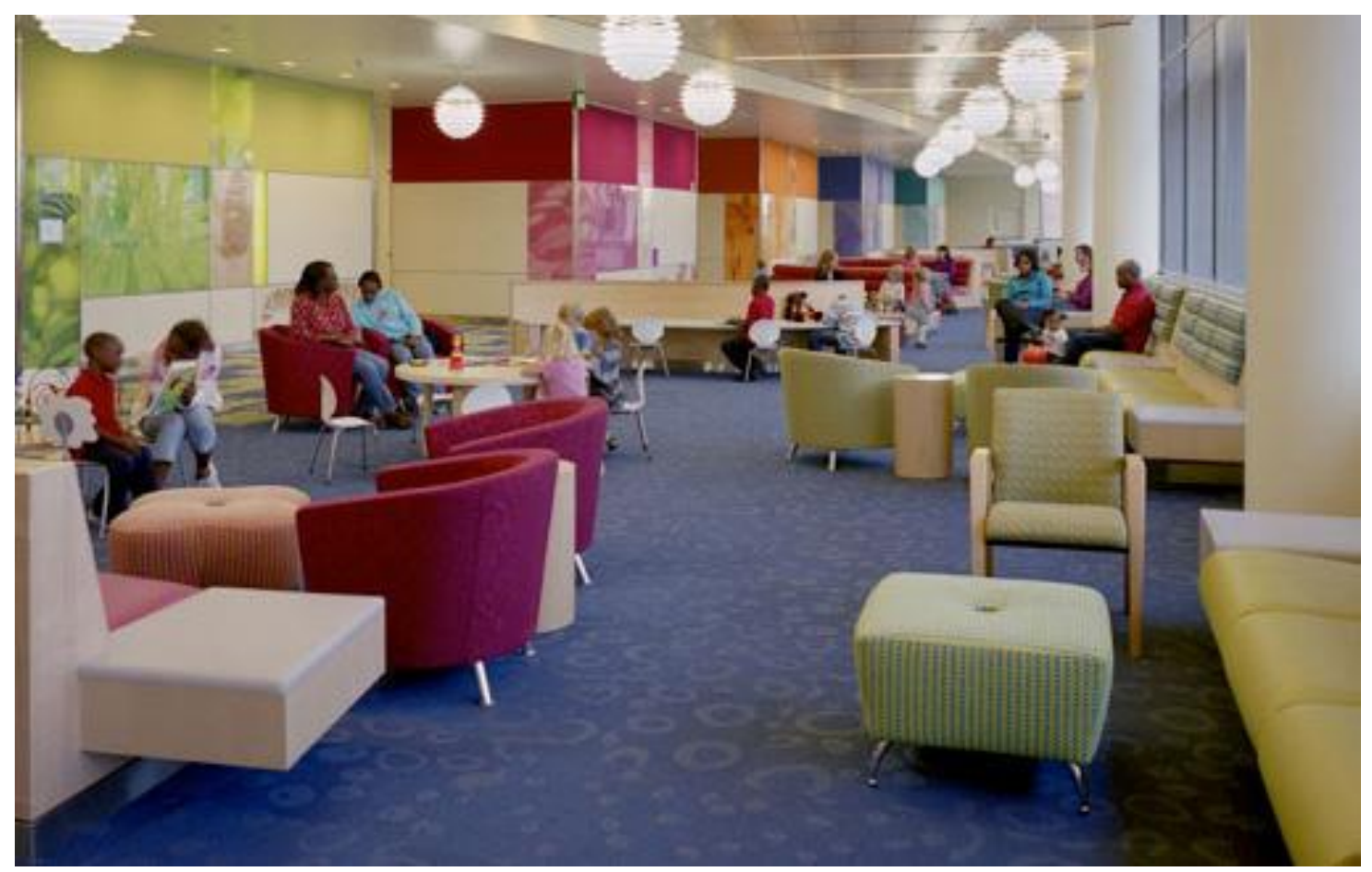

Figura 68 - Área de lazer e convivência - The Children's Hospital Fonte: www.shawcontractgroup.com/Html/PP_TheChildrensHospital 
Figura 68 mostra o espaço de convivência do Children's Hospital, em Denver. Podemos notar os exemplos desses componentes: formas, dimensões e volumes dos espaços criados; iluminação (natural ou artificial); cheiro (odores que compõem o ambiente, interferindo ou não no bem-estar das pessoas); som (música ambiente, controle de ruídos etc.); sinestesia (percepção do espaço por meio de movimentos); cor (recurso para estimular os sentidos); tratamento das áreas externas (jardins e áreas com bancos podem se tornar lugar de estar, de relaxamento e espaços de convivência, tanto para trabalhadores quanto para usuários); privacidade $\mathrm{e}$ individualidade (proteção da intimidade do paciente e espaço para preservação de sua identidade).

2) Espaço de encontro entre os sujeitos: a ambiência deve facilitar a capacidade de ação e reflexão das pessoas envolvidas nos processos de integralidade e inclusão. Para isso é necessário haver um novo modo de operar de toda a equipe que trabalha em espaços de saúde.

3) Arquitetura como ferramenta facilitadora de mudança do processo de trabalho: o conceito de ambiência deve favorecer a integralidade da assistência e, nesse sentido, a arquitetura contribui projetando salas multifuncionais ou espaços contíguos e agrupados (em vez de compartimentos com usos específicos). São considerados também projetos de sinalização e placas de informação como facilitadores de acesso e identificadores de espaços e de funções. Essa comunicação, que deve começar no entorno da unidade de saúde, deve ter uma linguagem clara e representativa. Deve ser projetada de modo a evitar excluir pessoas (por exemplo, deficientes visuais, cadeirantes, analfabetos).

$O$ acolhimento deve estar presente tanto em espaços de escuta e de recepção (relações interpessoais) quanto no sentido de conforto ambiental (iluminação, ventilação, cores etc.). Esse é o ponto que une os aspectos físicos aos aspectos humanos.

Faz parte da atual política de humanização dos ambientes hospitalares a criação de locais mais agradáveis, onde as pessoas se sintam tranquilas, calmas e seguras. Pintar as paredes, o teto, colocar quadros com temas naturais, trocar o revestimento do piso por um de maior absorção sonora, instalar novas luminárias e lâmpadas, pendurar um relógio, um calendário e uma pequena fonte próxima ao leito do paciente, são procedimentos de fácil 
execução. (SAMPAIO, 2005, p. 355).

Espera-se que o paciente tenha garantido um atendimento ágil, prestado por profissionais capacitados, em unidades de saúde bem equipadas. Sendo o hospital um espaço onde circulam pessoas propensas a estar em situação vulnerável, frágil, instável, de desconforto (físico e/ou emocional), o tratamento deve contribuir para que o paciente e sua família ou acompanhantes se sintam seguros e confortáveis, ou seja, estes devem ser recebidos e tratados de forma hospitaleira. Isto requer que a equipe de profissionais de saúde tenha maior preocupação com a humanização e sejam treinados para tanto. A Figura 69 mostra um espaço de interação no Dublin Methodist Hospital, em que clientes de saúde podem receber apoio psicológico e emocional de profissionais de saúde.

Nesse aspecto a ambientação deve considerar o acolhimento, a cordialidade, a preocupação com o outro. Os profissionais ligados à equipe de apoio (recursos humanos, gestão hospitalar, assistência social etc.) devem auxiliar a equipe médico-hospitalar (considerando os médicos,

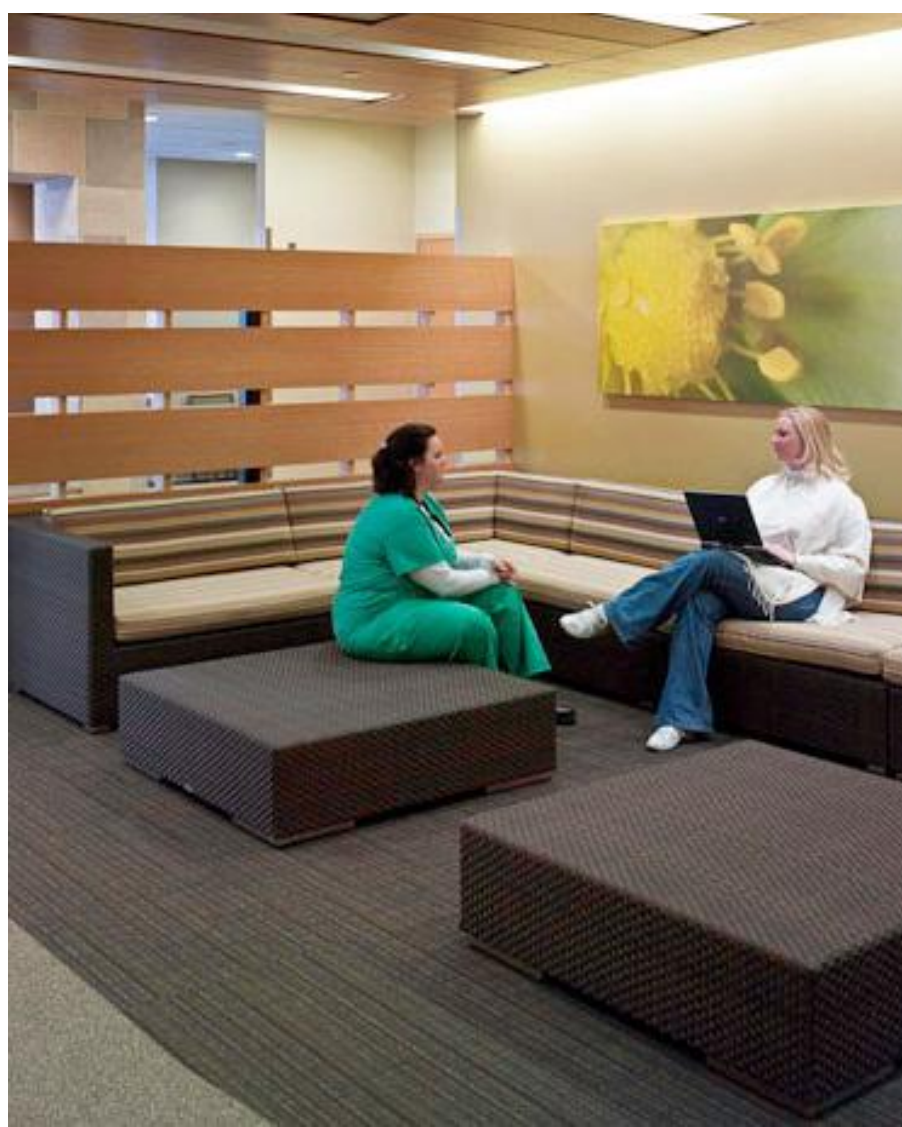

Figura 69 - Dublin Methodist Hospital Fonte:

unw.shawcontractgroup.com/ContentProjectProfiles/PDFs/project_dublin methodist_hospital.pdf enfermeiras, auxiliares etc.), pois estes são os profissionais que mantêm um contato mais direto com os pacientes e seus acompanhantes. Vale ressaltar que a humanização também deve permear as atividades de outros tipos de profissionais que, a partir da expansão dos hospitais e do conceito de hospitalidade, têm sido 
requeridos para prestar apoio e confiança ao paciente (arquitetos, chefs, gerentes de hotelaria, governantas, mensageiros, porteiros, recepcionistas, profissionais de eventos, ouvidor, garçons e camareiras e, eventualmente, músicos e recreacionistas).

Ambiência hospitalar refere-se ao espaço arquitetônico organizado visual e socialmente para facilitar as relações interpessoais. $O$ ambiente não é apenas feito de paredes, piso e teto, por isso ambiência não é uma mera questão de decoração, mas de satisfação de necessidades humanas, pressupondo um espaço em que haja integração entre pessoas, relacionamentos e convivência. Trata-se de uma forma de dar um novo significado ao espaço hospitalar, fazendo com que este seja percebido como um lugar com vida, caloroso, afetuoso.

A intenção é discutir formas inclusivas de organização do espaço físico a partir do ponto de vista dos usuários, principalmente trabalhadores e gestores do hospital. De acordo com o Ministério da Saúde (http://portal.saude.gov,br), no primeiro trimestre de 2011 foram feitas oficinas em algumas maternidades das regiões Norte e Nordeste para discutir possibilidades de mudanças na estrutura física dos ambientes que contribuam com a humanização.

Um exemplo está na Figura 70 e Figura 71 que mostram a recepção da Maternidade Dona Regina, em Palmas (TO), antes e depois (respectivamente) das discussões. Percebe-se que a organização feita considerou inclusive a CV, pois há um espaço com maior destaque para banners. No caso, sendo uma maternidade, foi colocada uma informação sobre amamentação. O cartaz da foto da maternidade antes da mudança estava mal posicionado, sem destaque, com mais textos que imagem, não sendo, portanto, tão atraente. Do ponto de vista do espaço, este ficou mais amplo, mais bem organizado e mais iluminado. Foi colocada uma bancada para recepção, o que facilita a identificação do local para o qual a pessoa deve dirigir-se ao chegar. $O$ ambiente ficou mais iluminado, claro e colorido, pois, apesar de as paredes terem sido pintadas de branco, as pastilhas azuis, amarelas e vermelhas fizeram um contraste leve e agradável. 


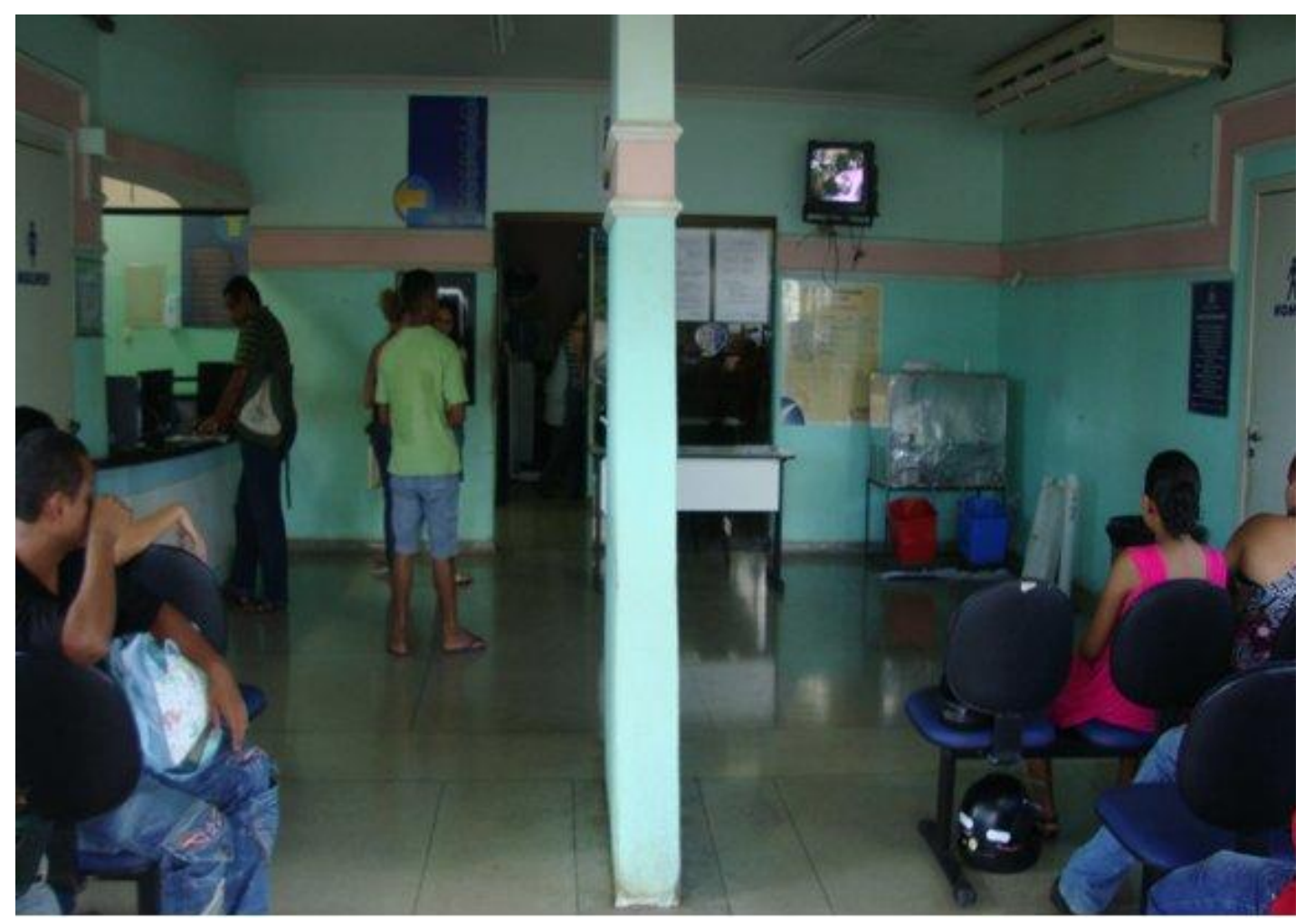

Figura 70 - Maternidade Dona Regina (Palmas / TO) - antes Fonte: portal.saude.gov,briporta//saude/visualizar_texto,dm?idtxt=36947

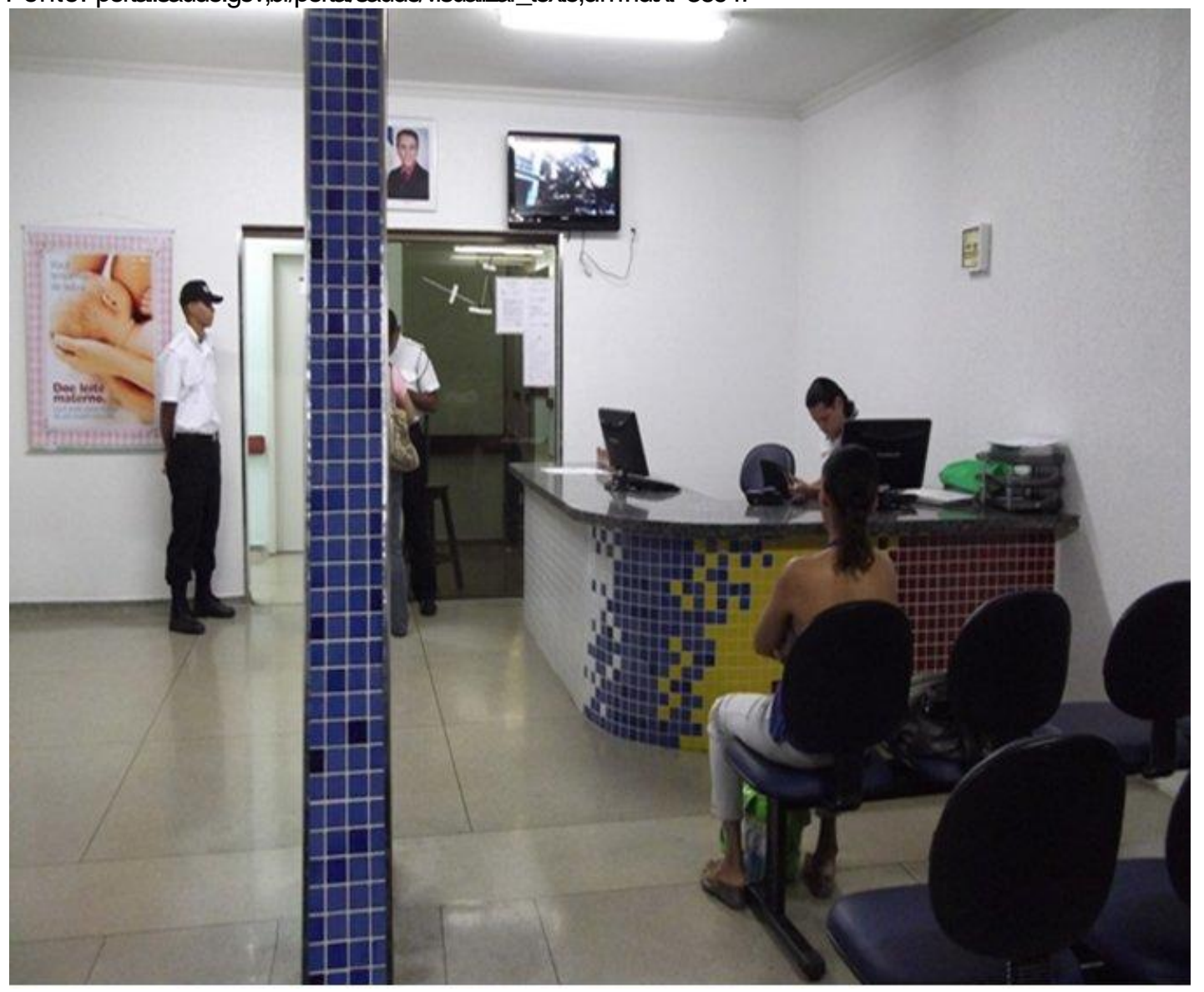

Figura 71 - Maternidade Dona Regina (Palmas / TO) - depois

Fonte: portal.saude.gov,briporta//saude/visualizar_texto,crm?idtxt=36947 


\subsection{Fatores relacionados à ambiência}

A partir de uma revisão dos principais estudos e modelos que abordam a influência do ambiente de venda sobre o comportamento do consumidor, Geargeoura (2010) organizou um rol de elementos que compõem o ambiente físico de uma loja, agrupando as diversas dimensões ou estímulos ambientais a quatro fatores, classificados como fator "de fundo", "funcional", "simbólico" e "social".

Fator "de fundo" - incluindo todos os estímulos que (...) ficam na periferia "fundo" - da percepção consciente dos indivíduos, tais como a temperatura, a qualidade do ar, os ruídos não-intencionais, a música, odores ou aromas, o nível geral de iluminação, etc.;

Fator "funcional" - (...) Estão aí incluídos o layout, os equipamentos de exposição e os outros móveis, bem como a própria quantidade e a variedade de mercadorias disponibilizadas aos clientes;

Fator "simbólico" - (...) sinalizações de localização e preços, o estilo arquitetônico externo e interno, elementos decorativos, de iluminação de áreas e focos especiais, e todo tipo de artefatos ou objetos incorporados à cena de exposição das mercadorias; e

Fator social - (...) número e a aparência dos funcionários e dos outros clientes, as características do comportamento social dos funcionários (amabilidade, conhecimento e capacidade de atendimento, seu padrão visual (incluindo os uniformes), etc. (GEARGEOURA, 2010, p. 100-101)

No presente trabalho, com o objetivo de melhor explicitar os elementos da ambiência hospitalar (que, de acordo com nosso ponto de vista, ajudam a comunicar os valores e objetivos da instituição hospitalar), tomamos como referência a listagem feita por essa autora fazendo algumas adaptações para adequar ao meio ao qual nos referimos, conforme o Esquema 8. Esses quatro fatores que compõem o ambiente de um hospital formam um código, uma linguagem não verbal (de "objetos") que confere significados ao ambiente (idem, p. 93). Ressaltamos que esta classificação tem um caráter meramente explicativo, esses elementos não estão separados, ao contrário, encontram-se interligados, compondo um todo sistêmico que comunica os valores e atributos da instituição. $O$ intuito não foi fazermos uma ampla e abrangente exposição desses fatores, ao contrário, apenas elencamos exemplos que possam servir como apoio para o sistema de CV. 


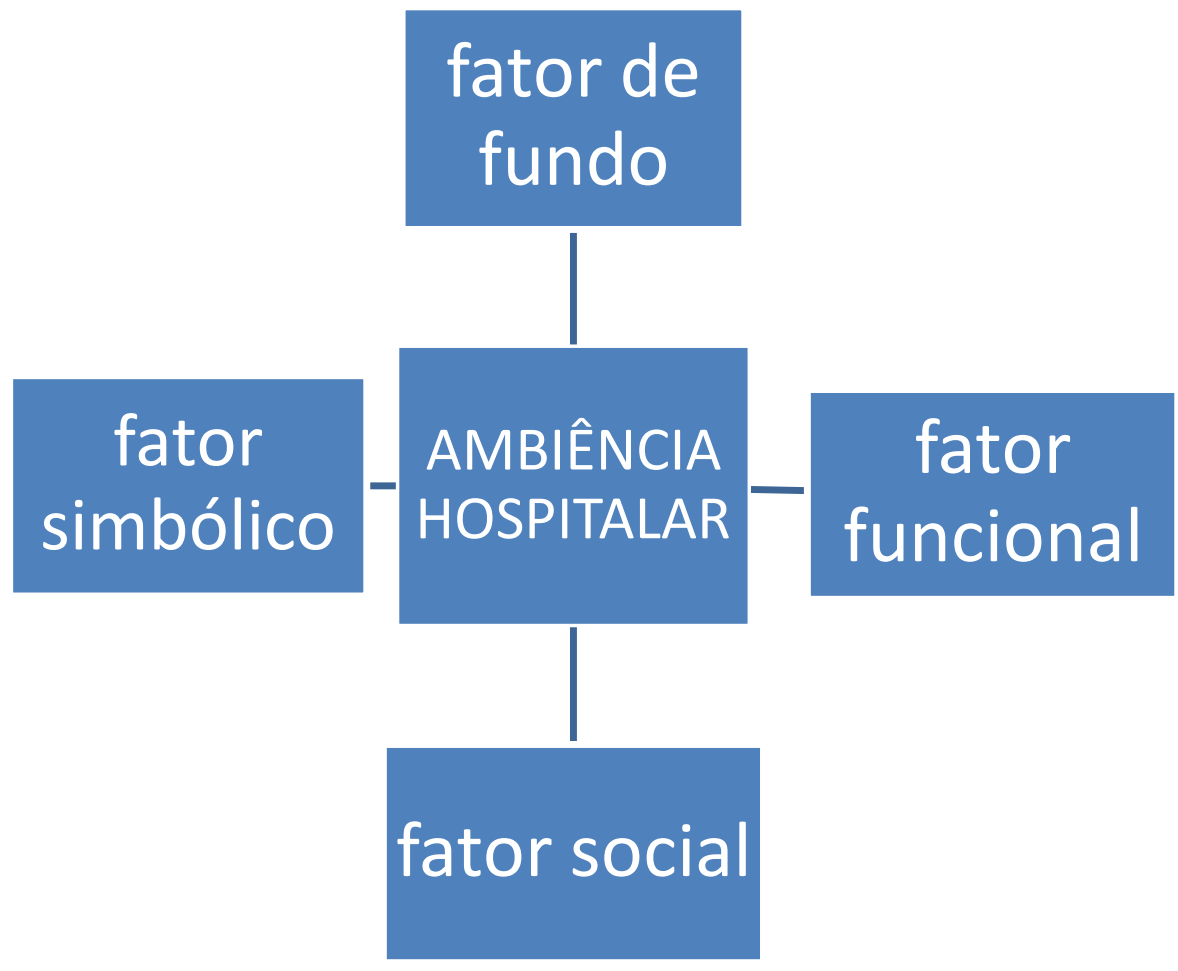

Esquema 8 - Ambiência hospitalar

Fonte: Elaborado pela autora a partir da adaptação do trabalho de Geargeoura (2010)

\subsection{Fator de fundo}

O fator de fundo relaciona-se ao espaço arquitetonicamente construído e organizado, incluindo os estímulos que interferem na percepção dos indivíduos. Em ambientes hospitalares, destacam-se, como elementos mais frequentes as dimensões espaciais; conforto ambiental e acústico; cores; aromas e sabores; tato; limpeza.

\subsubsection{Dimensões espaciais}

Cada vez mais os hospitais precisam redimensionar e modernizar suas estruturas externas e internas para se adequarem às suas demandas e solucionar fluxos e acessos. Considerado uma das organizações mais 
dinâmicas do mundo contemporâneo, o edifício hospitalar está sempre em processo de transformação de sua estrutura (GÓES, 2004, p. 99).

Quanto às estruturas externas, vários hospitais estão em processo de expansão para aumentar sua capacidade de atendimento. O sistema de circulação de um hospital pode ser dividido em dois níveis de implantação (horizontal e vertical), compostos de instrumentos de transporte (elevadores,

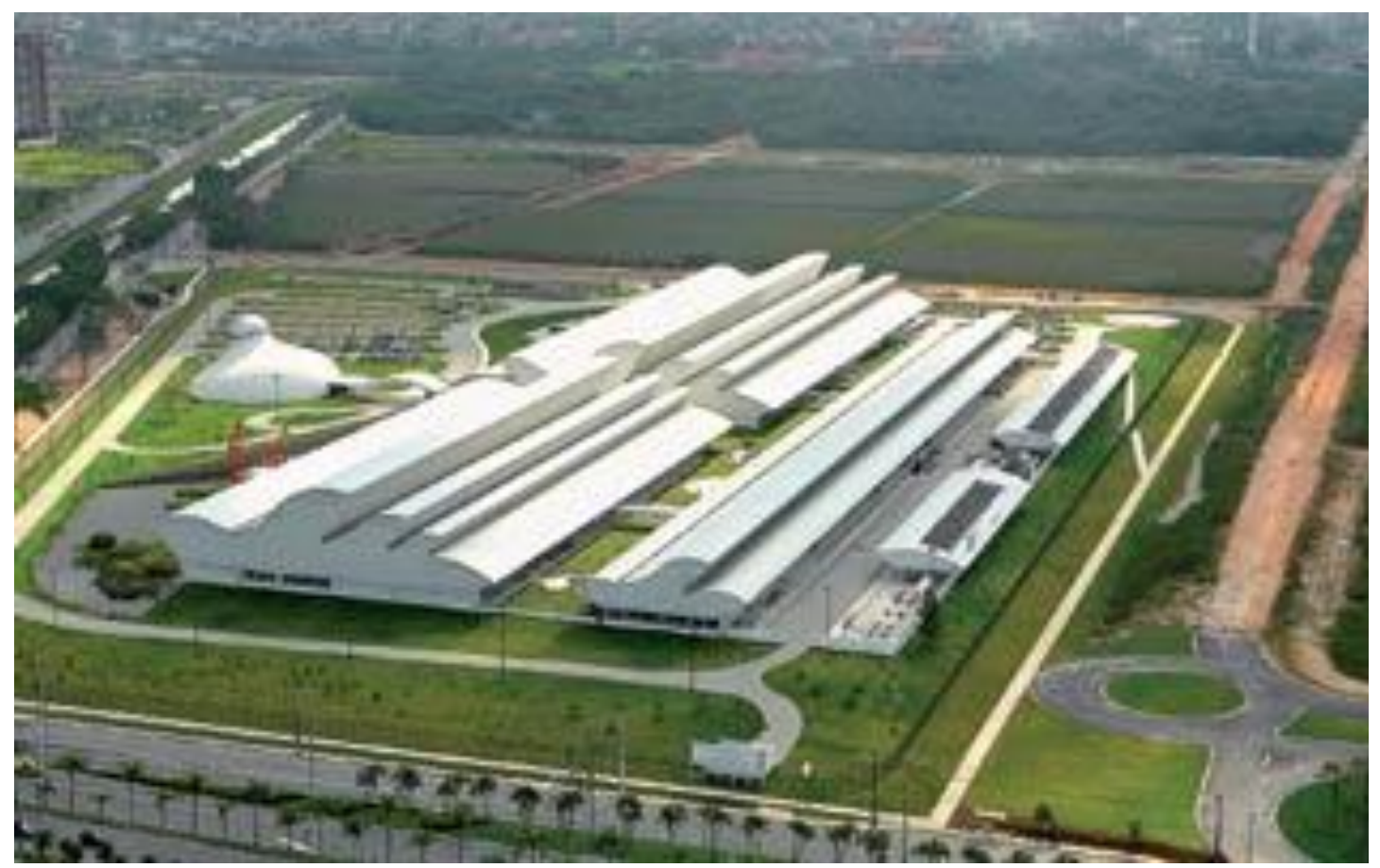

Figura 72 - Hosp. Rede Sarah Jacarepaguá

Fonte: uww.arcoweb.com.br/arquitetura/arquiteto-joao-filgueiras-lima-lele-hospital-rede-sarah-27-10-2009.html

planos inclinados, rampas, corredores e escadas) possibilitando a movimentação de pessoas e materiais (BITENCOURT, 2008, p. 54). Hospitais horizontais precisam de terrenos com grandes áreas e isso é difícil nos grandes centros urbanos. A Figura 72 mostra uma foto aérea do Hospital da Rede Sarah em Jacarepaguá, no Rio de Janeiro, que exemplifica bem a questão da dimensão da área. Por causa disso, nas grandes cidades, principalmente, há maior tendência à opção por monoblocos verticais (SAMPAIO, 2005, p. 137).

A verticalização é indicada em hospitais acima de 200 leitos para evitar longos percursos. Por questões de assepsia e visando sua rapidez e disponibilidade, os elevadores próprios para resíduos devem ser divididos entre "cargas" e "expurgo" e os sociais diferenciados dos elevadores específicos para pacientes, (BOERGER, 2005, p. 34) que devem ser maiores para que caibam 
macas e cadeiras de roda. Optando-se por uma solução verticalizada devem ser considerados os seguintes itens: "aumento de custos, possibilidade de incêndio (o sério problema da evacuação de doentes), elevadores, fluxos de pessoas e serviço, suprimento de materiais, etc." (GÓES, 2004, p. 29).

O acesso à edificação e aos espaços, equipamentos e componentes que ela abriga é fundamental, sobretudo para permitir que essa edificação seja utilizada por pessoas portadoras de necessidades especiais temporárias ou permanentes. Para tanto, deve ser lembrada a NBR 9050 que trata da acessibilidade dos portadores de deficiência física. (BOERGER, 2005, p. 33)

Quanto às estruturas internas, os espaços hospitalares necessitam ser amplos para acomodar os modernos equipamentos médicos, assim como equipamentos adicionais para maior conforto de pacientes internados e seus acompanhantes (televisores, freezers etc.).

\subsubsection{Conforto ambiental e acústico}

Em um hospital, é aconselhável que elementos relacionados ao ambiente (temperatura, umidade relativa, radiação solar; iluminação; ventilação, circulação e qualidade do ar) sejam agradáveis para evitar desconforto, principalmente para os pacientes internados. A Figura 73 mostra a entrada principal da Cleveland Clinic Foundation, nos Estados Unidos, com vidros (possibilitando iluminação natural) e amplos espaços internos dando maior sensação de conforto ambiental.

Alguns aspectos a serem considerados são: orientação do edifício em relação

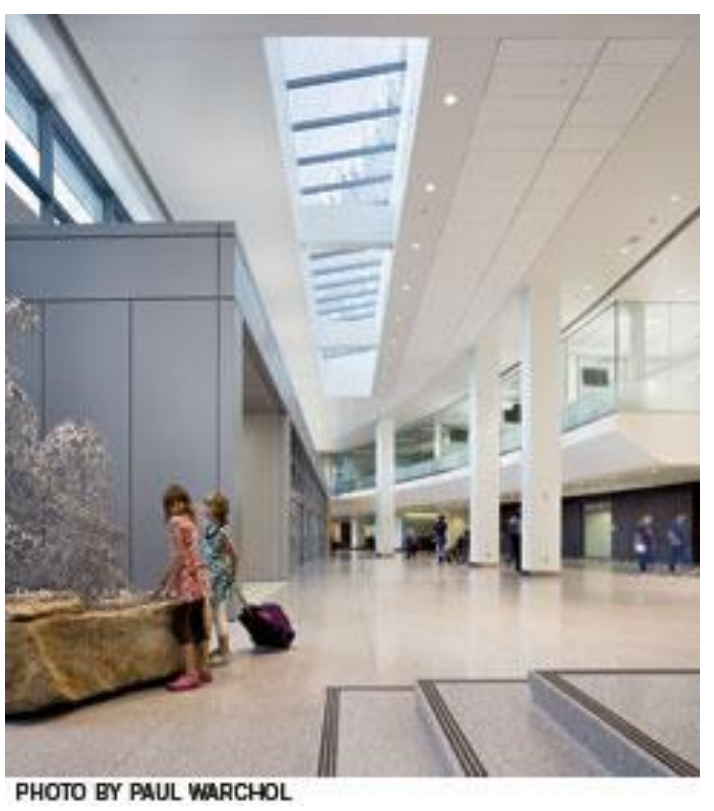

Figura 73 - Conforto ambiental Fonte:

unw.hfmmagazine.comhlmmagazine app/splartidedispla y.sp? ?drpath=HFMMAGAZINE/Aride/data/01JAN2009/09 01HFM FEA_Cover\&domain=HFMMAGAZINE ao sol; ventos predominantes e massas 
de vegetação; dimensão e posição das aberturas; resistência térmica das paredes e da cobertura; posicionamento das fontes internas de geração de calor (GÓES, 2004, p. 106). Em ambientes em que várias pessoas com problemas de saúde aguardam ser atendidas (Pronto Atendimento, por exemplo), é necessário um cuidado especial para evitar contaminação (geralmente o ar condicionado é acionado um pouco mais frio para evitar a proliferação de vírus e bactérias; o ambiente deve ser mais ventilado etc.).

Ambientes iluminados, por exemplo, podem dar sensação de conforto, principalmente quando se utiliza luz natural. A presença desta em um ambiente possibilita modificações dinâmicas ao longo do dia causadas pela alteração de

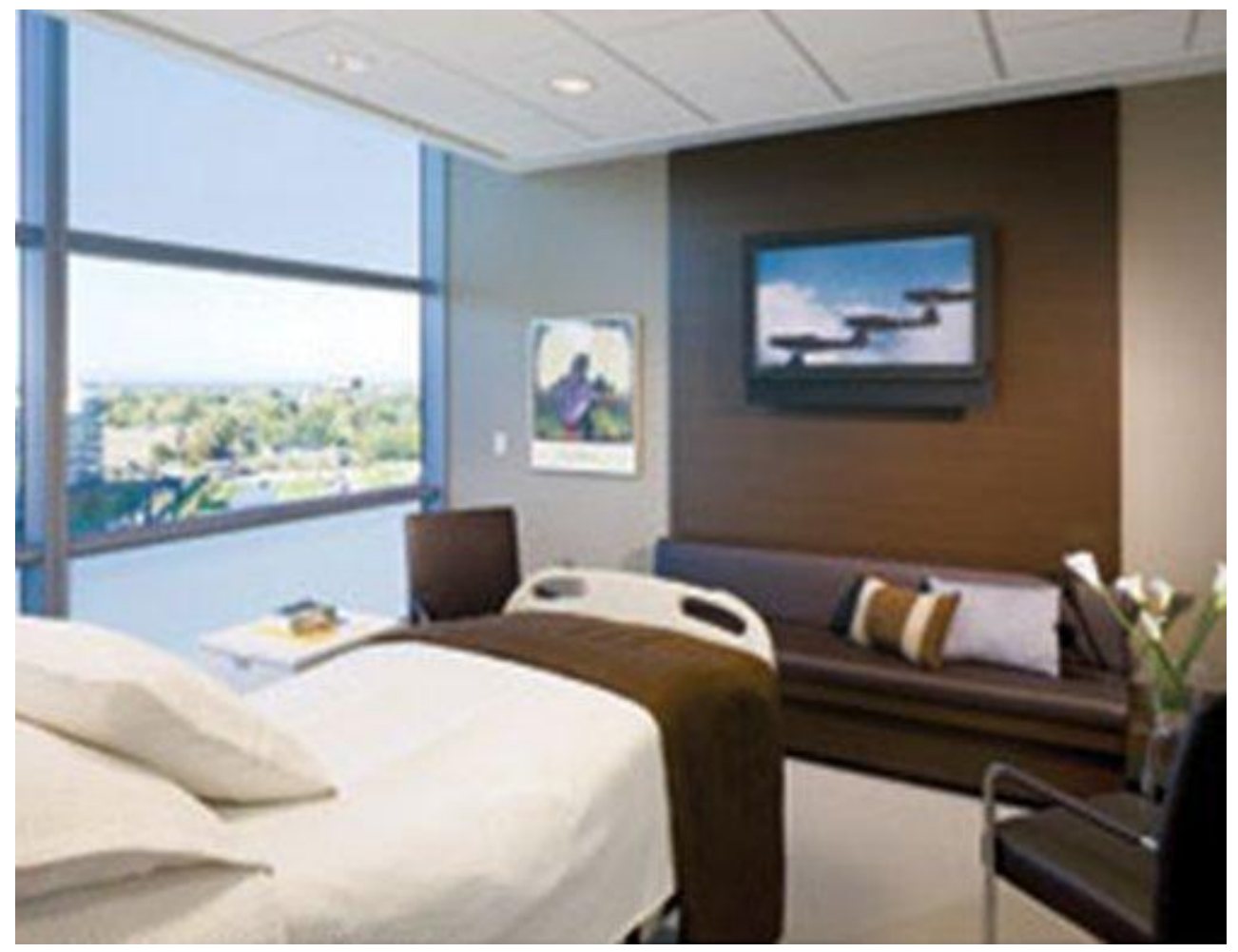

Figura 74 - Quarto da Cleveland Clinic Foundation, EUA

Fonte: uww.hfmmagazine.comhlmmagazine_app/splarticledisplay.sp?dcrpath

sua cor, contraste e intensidade, contribuindo "para a composição de uma ambiência mais aconchegante quando exploramos os desenhos e as sombras que proporcionam" e dando referência de tempo - dia e noite, chuva ou sol (BRASIL, 2006, p. 8). É importante que as pessoas tenham contato com o exterior, sobretudo nos casos de internação; por isso, janelas em quartos de hospital são aconselháveis, como mostra a Figura 74.

A iluminação também pode contribuir para aumentar a autoestima do paciente. 
É o caso do uso da iluminação que reflete mais os tons de vermelho da pele próximo ao espelho do banheiro, para refletir o rosto do paciente de forma mais corada e menos pálida do que a iluminação branca (BOERGER, 2005, p. 37). Os postos de trabalho devem ter luz adequada às necessidades das equipes médicas.

O conforto acústico relaciona-se à qualidade do som produzido no ambiente, se é satisfatoriamente aceitável ou não. $O$ isolamento de ruído é importante em hospitais, na medida do possível, principalmente para evitar que pacientes internados sintam-se incomodados e mais estressados com barulhos. Esse isolamento pode ser feito utilizando-se materiais que diminuam o impacto na superfície em que ocorre o ruído. $O$ ambiente não precisa ter silêncio total, este não é recomendável, uma vez que pode gerar sensação de monotonia. A proteção acústica deve garantir a privacidade e controlar alguns ruídos (BRASIL, 2006, p. 9).

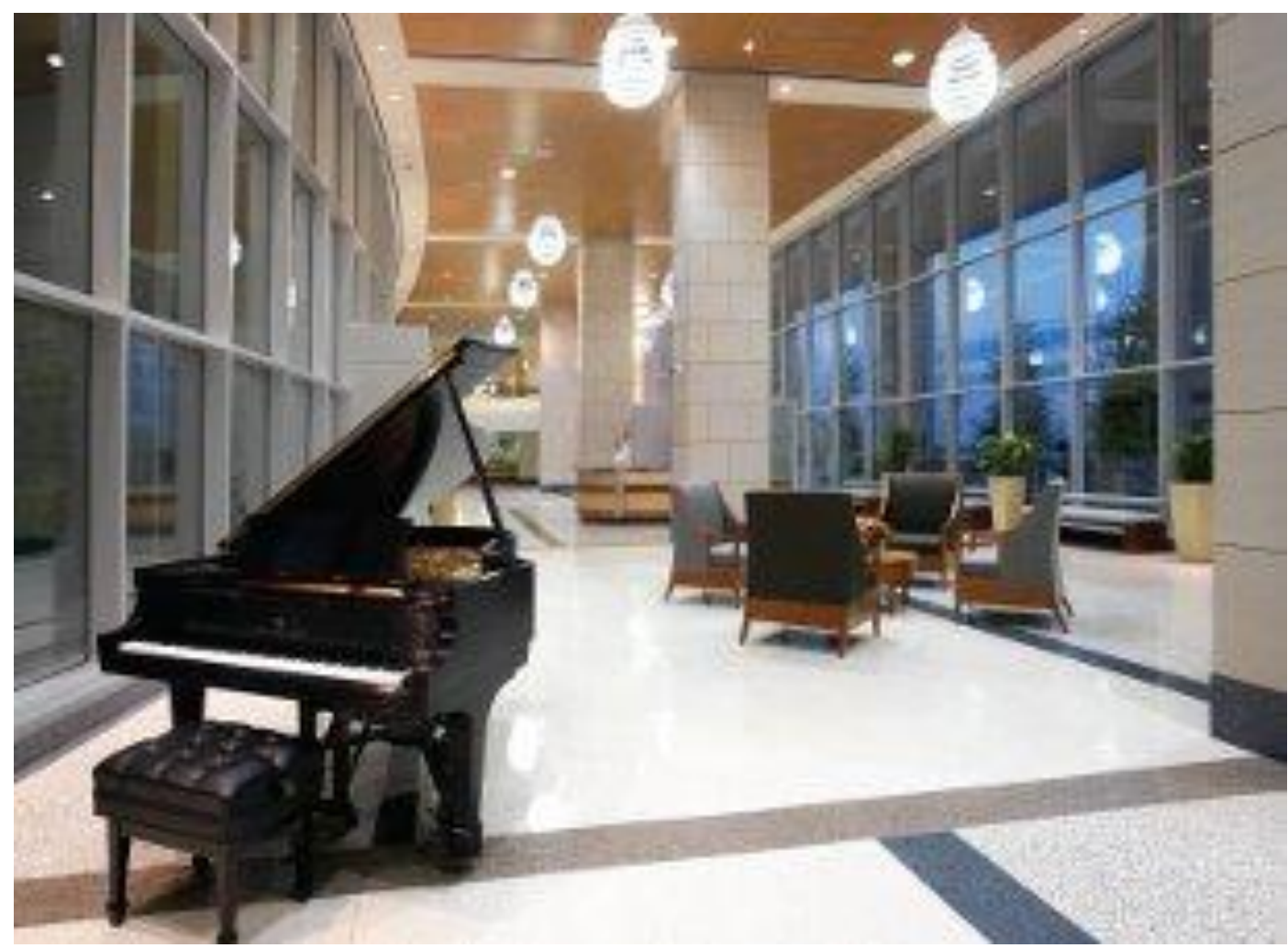

Figura 75 - Música em hospitais

Fonte: www.hfmmagazine.com/hfmmagazine/images/pdf

Alguns hospitais adotam ações musicais em sua rotina, com apresentações de instrumentos e/ou corais. É uma maneira de levar entretenimento, alegria e motivação para os usuários, além de contribuir como auxiliar do processo 
terapêutico e de integração entre usuários. A Figura 75 mostra o saguão do Centro Médico do Hospital da Universidade de Arkansas, em Little Rock, Ark, EUA, com um piano para possíveis apresentações.

\subsubsection{Cores}

As cores podem ter efeitos sobre as pessoas, atuando de forma diferenciada, dependendo da faixa etária, da estrutura psicológica e de condicionantes culturais (GÓES, 2004, p. 109). Estimulam os sentidos e podem encorajar ao relaxamento, ao trabalho, ao divertimento ou ao movimento (BRASIL, 2006, p. 9). Em casos de hospitais ou alas infantis, como o Denver Children's Hospital

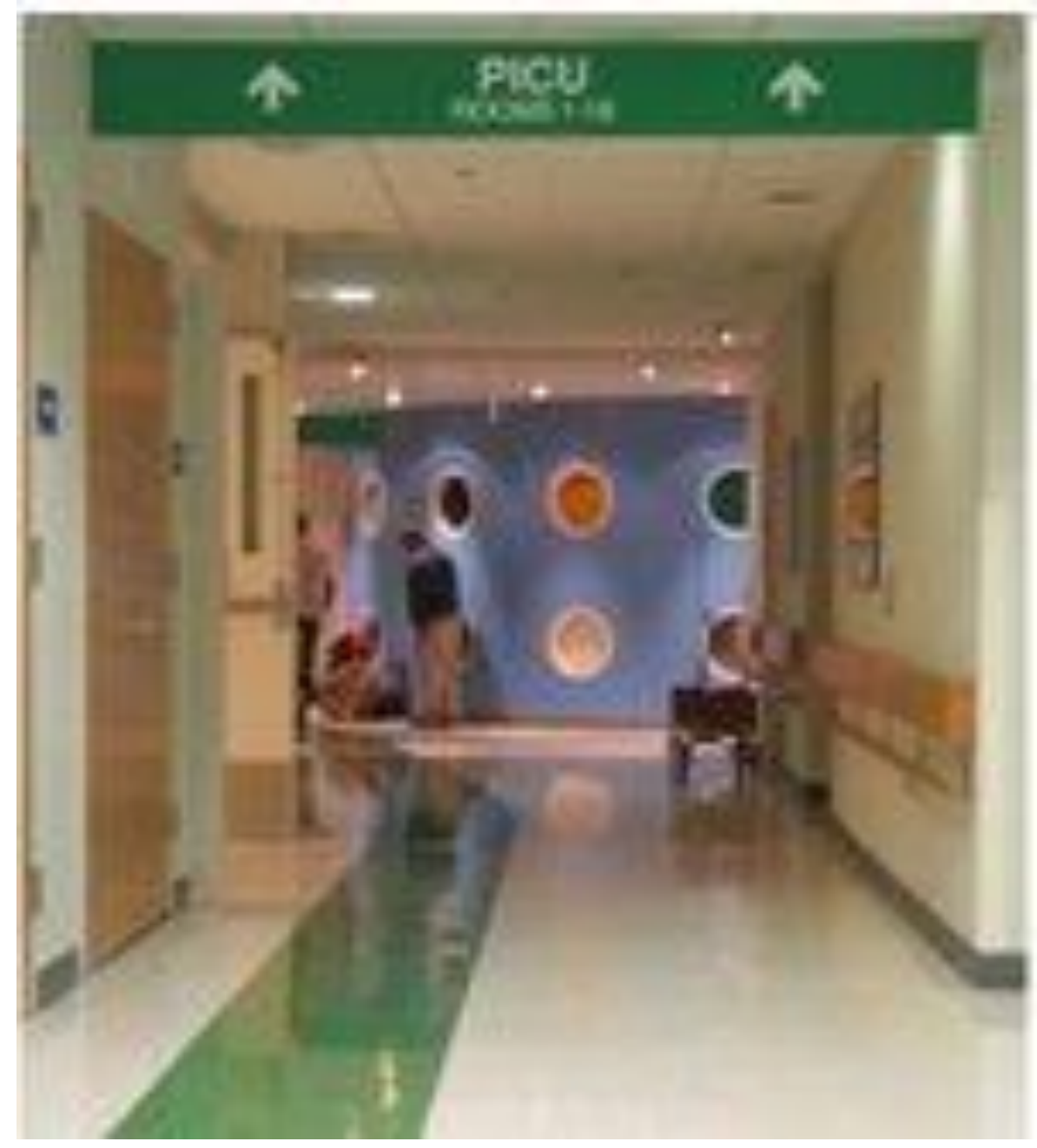

Figura 76 - Denver Children's Hospital

Fonte: unw.inktankdesign.com/portfolio.php?cat=environment\&id=enviro2CRO 
(Figura 76), as cores podem servir como elemento lúdico e, ao mesmo tempo, orientar o fluxo.

Godoi (2008) e Boerger (2005) mencionam o fato de alguns hospitais aderirem ao uso de cromoterapia (apesar das controvérsias) como parte das mudanças implantadas para transformar o ambiente em um local mais agradável tanto para pacientes e seus acompanhantes (familiares, amigos e visitas) como para trabalhadores (equipe médica e equipes de apoio).

De acordo com Matarazzo (2010, p. 147), cada setor em um hospital tem necessidades diferentes, portanto, deve haver um esquema cromático para atender as finalidades e objetivos a serem desempenhadas em cada ambiente específico. Segundo Dalla (2003, p. 59), há necessidade de variação de estímulos cromáticos na área hospitalar "para não gerar monotonia e tornar a atmosfera do ambiente mais atrativa". Ela também ressalta a diferenciação dos ambientes, especificando o que seria ideal para cada ambiente (hall e recepção; salas de espera; administração; circulações; postos de enfermagem; unidade de terapia intensiva; sala de cirurgia; sala de esterilização; sala de recuperação pós-anestésica; laboratório; unidade pediátrica; unidade de

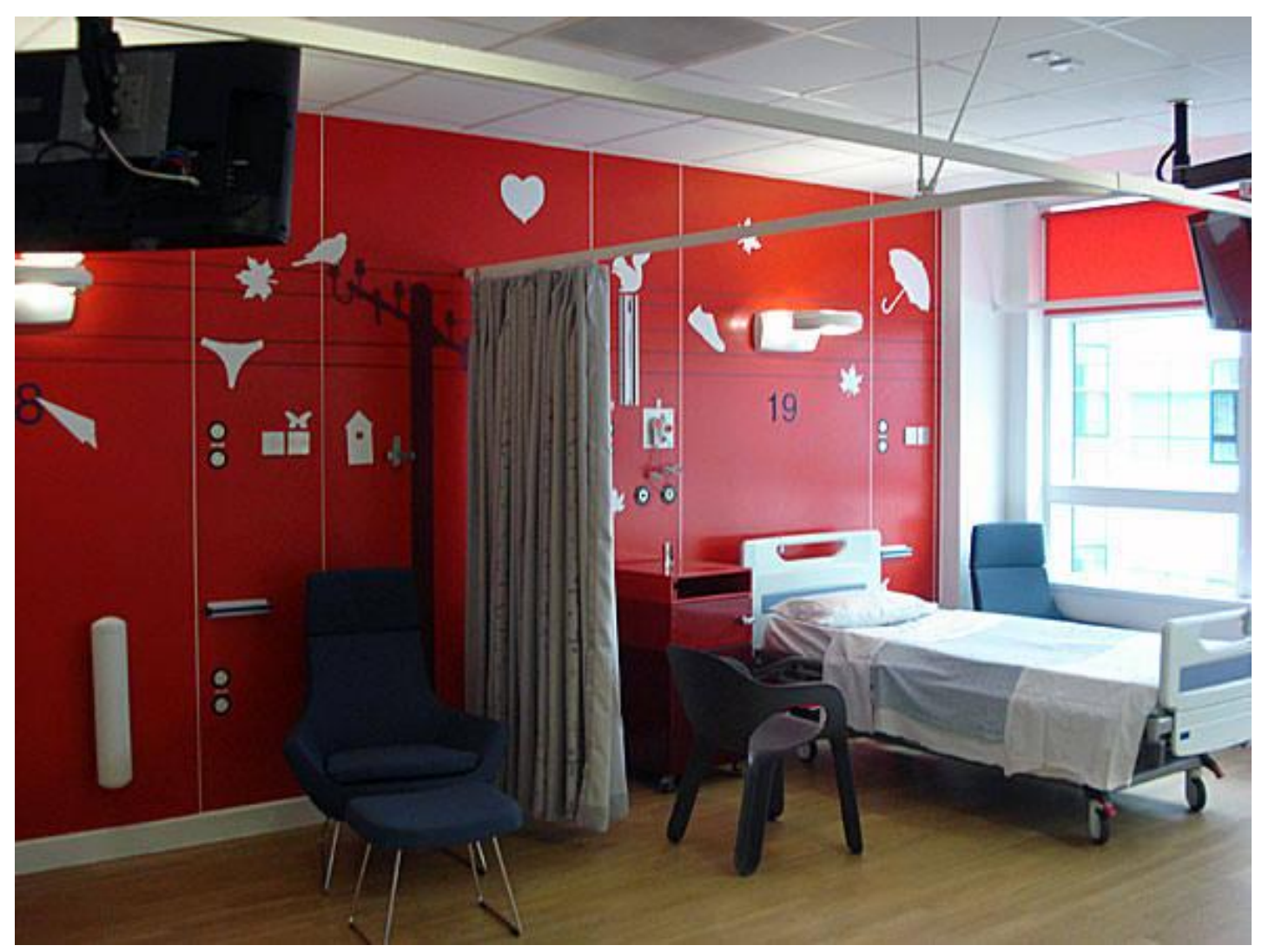

Figura 77 - Queen Elizabeth Hospital

Fonte: Carvalho (2011) 
maternidade; berçário e UTI neonatal; sala de eletrocardiograma e encefalograma; ambulatório, consultório médico e sala de exame; salas de tratamento e terapia; sala de conforto dos médicos; cafeteria e refeitório; quarto e enfermaria). A Figura 77 uma inovação feita no Queen Elizabeth Hospital, em Birmingham, Inglaterra, hospital que trata de adolescentes com câncer, utilizando "cores fortes, desenhos nas paredes, eletroeletrônicos e móveis desenhados para dar mais conforto e qualidade de vida aos pacientes" (CARVALHO, 2011).

Nas salas cirúrgicas, deve ser evitado o predomínio de azul ou mesmo vermelho. Sempre que possível, deve ser evitado o preto nos pisos e o branco nas paredes. (...) A unidade de internação, comumente, assemelha-se a um apartamento de hotel. Podem ser utilizadas cores (...) como tons em salmão, amarelo, bege e azul-claro.

As áreas sociais permitem um uso bastante livre das cores, uma vez que a influência que exercem sobre os usuários está mais na imagem que se deseja passar aos visitantes. (...)

As cores serão definidas em função do estilo de arquitetura, do público a ser atendido e da imagem que a instituição deseja passar a seus usuários. (BOERGER, 2005, p. 37)

A correta escolha das cores espalhadas pelo ambiente (em pisos, paredes, teto, equipamentos, mobiliário etc.) pode servir para auxiliar a promoção de bem-estar físico e emocional, sobretudo dos pacientes. Corredores e salas de espera, por exemplo, podem ter cores mais estimulantes e brilhantes; repartições pediátricas devem ter cores alegres e atraentes.

\subsubsection{Aromas e sabores}

Um hospital deve propiciar a sensação de bem-estar com relação aos odores existentes no ambiente. Atualmente alguns optam pela utilização de produtos de limpeza que não deixem cheiros, para evitar que estes possam ser considerados como desagradáveis por usuários. Há casos específicos em que o aroma pode assumir um papel diferencial. Para a clínica de estética Longevus (em Salvador/BA), por exemplo, foi elaborado um perfume exclusivo, encomendado pelo proprietário, borrifado no ambiente a cada dez minutos (COSTA, 2008). Nesse caso, o aroma reflete o senso estético do médico e 
mostra concepções da clínica. Quanto aos sabores, o que mais se destaca é o gosto da alimentação no hospital. Hoje há preocupação em proporcionar ao paciente uma refeição mais saborosa, mesmo que obedecendo às restrições necessárias.

\subsubsection{Tato}

O toque geralmente costuma passar despercebido quando se menciona 0 ambiente hospitalar, mas pequenos detalhes podem fazer a diferença. Roupas de cama e toalhas macias podem fazer com que o paciente se sinta mais confortável, por exemplo. Com relação aos profissionais, uniformes utilizando tecidos antimicrobianos, além de terem toque macio funcionam como barreira entre os germes pessoais e os microrganismos do ambiente hospitalar, o que pode contribuir com a questão da redução de infecção hospitalar. Em termos da estrutura física, as normas relacionadas à acessibilidade trouxeram pisos e mapas táteis para o ambiente hospitalar, auxiliando a comunicação também para portadores de deficiências.

\subsubsection{Limpeza}

Um ambiente limpo é sempre mais agradável e, em casos de ambientes de saúde, a limpeza é essencial para evitar contaminação e infecções. Em hospitais, a limpeza e higienização necessitam de cuidados especiais, como mostra a Figura 78. No caso de banheiros dos quartos de

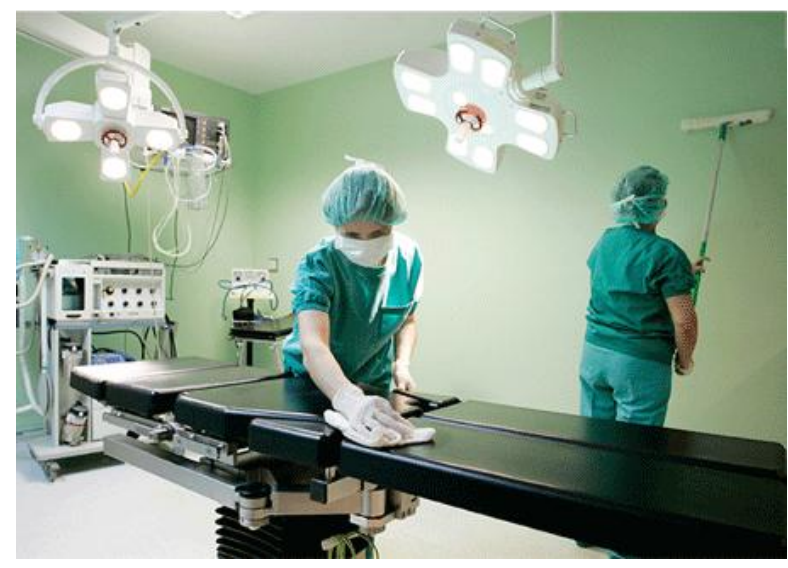

Figura 78 - Limpeza e higienização de hospital Fonte: unw.br.issworld.com/servicos disponiveis/ 
pacientes internados, é importante evitar a instalação de boxe de vidro ou de plástico que dificultam a higienização por causa das emendas, trilhos, maçanetas e dobradiças. Uma possibilidade melhor é o uso de cortinas de plástico descartáveis fixadas com ganchos, que podem ter o logotipo da instituição estampado e serem embaladas em sacos plásticos para não deixar dúvidas de estarem sendo usadas pela primeira vez (BOERGER, 2005, p. 31).

\subsection{Fator funcional}

O fator funcional relaciona-se às características do ambiente que contribuem para a realização e desenvolvimento das atividades à qual ele se destina. Em hospitais, esse fator está associado a elementos da apresentação física, tais como: layout do mobiliário e equipamentos; revestimentos de pisos e paredes; serviços de hotelaria hospitalar.

\subsubsection{Mobiliário e equipamentos}

A disposição dos equipamentos e móveis deve auxiliar o paciente a ser um pouco mais independente e autônomo. Os apartamentos podem propiciar mais conforto aos pacientes e acompanhantes por contarem com equipamentos e móveis mais práticos, formatos modernos, cores diversas.

Exemplos de itens que podem dar sensação de bem-estar são macas e camas automatizadas, que permitem certa autonomia ao paciente; mesa de refeição menos desconfortável; televisores com programação de TV a cabo; freezers; kits com produtos de higiene pessoal com marcas conhecidas e famosas; disponibilidade de ambientes wireless ou pontos de acesso à internet para que as pessoas possam manter contato com o mundo exterior no período em que estiverem dentro do hospital. Quanto aos funcionários/colaboradores, postos de trabalho são organizados a partir das necessidades básicas relacionadas às funções que devem desempenhar. 


\subsubsection{Revestimentos de pisos e paredes}

Pensando em priorizar o conforto, o acolhimento e tornar a estada dos clientes de saúde mais agradável, a seleção de materiais com tecnologia de ponta é um aspecto que deve ser priorizado. Os materiais devem ser de fácil e rápida aplicação, pois geralmente os prazos das obras hospitalares são curtos (seja para o caso de uma construção nova, uma ampliação ou mesmo uma reforma). A facilidade de limpeza e manutenção é uma premissa e, para isso, é aconselhável que o revestimento tenha o menor número de juntas possível (para impedimento de acúmulo de sujidades); seja resistente a produtos químicos e seguro contra derrapagem, fogo e propagação de fumaça; seja durável; ofereça resistência ao tráfego pesado, ao bolor e à criação de fungos; ofereça possibilidade de cores e desenhos para serem usados como questões de estética e de CV. O caso que serve de exemplo é o do Hospital Alemão Oswaldo Cruz, Unidade de Especialização, no Campo Belo (Figura 79). Foram utilizados pisos vinílicos com desenhos decorativos.

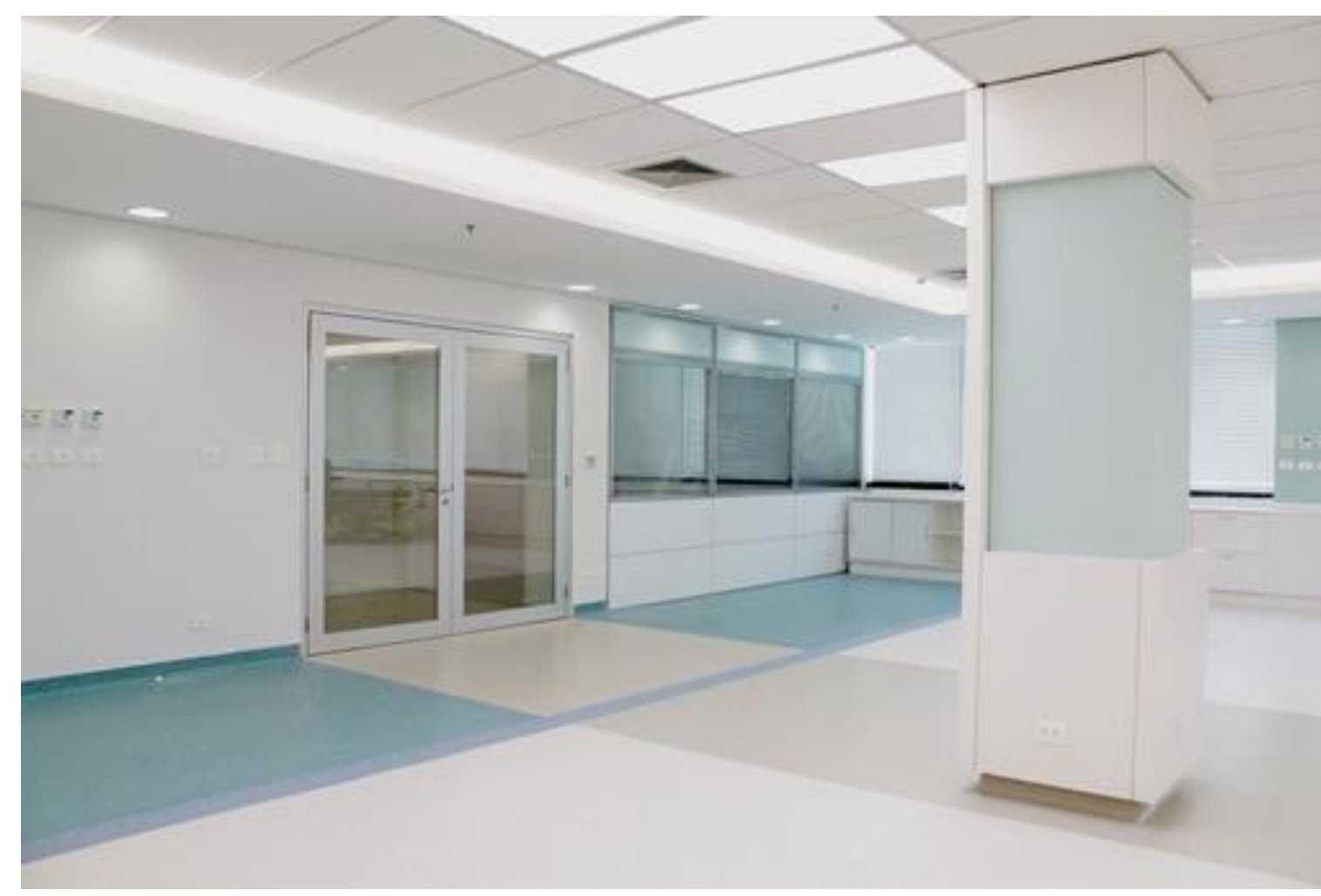

Figura 79 - H. A. Oswaldo Cruz (Unid. de Especialização - Campo Belo) Fonte: www.designpvc.org/index.php/noticias/98-geral/1142 


\subsubsection{Serviços de hotelaria hospitalar}

Segundo aponta Taraboulsi (2006, p. 25), os serviços de hotelaria fazem com que os hospitais deixem de "ter a cara de hospital", alguns até parecendo mais um "hotel de primeira linha". A proposta é minimizar "o impacto desses momentos difíceis, transformando a estada no ambiente hospitalar mais agradável". Mesmo os hospitais públicos estão sendo contagiados pela "humanização do ambiente hospitalar". Essa nova tendência envolve maior receptividade dos clientes ao tratamento e isso facilita o serviço da equipe médica.

Serviços adicionais são vistos em novos espaços como "lojas com objetos práticos e de uso pessoal geralmente esquecidos ou não levados para o hospital; floricultura; cafeteria; pequena galeria de arte ou ainda pequeno museu; salão de beleza, dentre outros" (GODOI, 2008, p. 42).

\subsection{Fator simbólico}

O fator simbólico relaciona-se com a maneira como as pessoas percebem 0 ambiente, mesmo que inconscientemente. No caso de hospitais, em especial, é necessário levar em conta que alguns usuários podem não estar em condições normais (físicas e/ou emocionais), o que pode influenciar a percepção do espaço. Os elementos são: aparência estrutural; objetos decorativos e a sinalização.

\subsubsection{Aparência estrutural}

Bastante complexa, sua construção (estruturas e dimensões) é geralmente ampla. Essas edificações estão deixando de ter "cara de hospital", passam a assemelhar-se a hotéis, ao lar ou a parques infantis. 
Esta tendência de aproximação à imagem de um edifício hoteleiro ou de um shopping center, oriunda de países desenvolvidos, tem se concretizado em propostas como os suntuosos átrios com iluminação diurna lateral e zenital e em ambientes de uso coletivo com aparelhos de iluminação, mobília e materiais sofisticados de acabamento. (...)

A busca pela semelhança com o lar, por sua vez, visa proporcionar o caráter de 'aconchego' que frequentemente o caracteriza. No que se refere à edificação, esta proposta vem se expressando através da utilização de aberturas mais adornadas, cortinas, objetos decorativos, mobiliário e acabamentos com aparência tipicamente residencial. (...)

Uma terceira tendência sugere a incorporação da fantasia ao ambiente hospitalar, (...) cria-se uma espécie de cenário, que lembra os parques infantis. Os ambientes internos são concebidos com alguma temática, buscando-se explorar uma estética com forte apelo lúdico. (CAVALCANTI; AZEVEDO; DUARTE, 2007, p. 9)

A aparência exterior (fachada; área de entrada; estacionamento) e a interior são importantes para dar aos usuários a impressão de estarem em um ambiente agradável. A aproximação com o lar, com hotéis ou lugares divertidos (no caso de crianças) pode auxiliar pacientes no seu tratamento, por isso é aconselhável privilegiar espaços nos quais estes fiquem por mais tempo. Profissionais, se estiverem em um ambiente aprazível, podem desempenhar suas funções de maneira mais satisfatória.

\subsubsection{Objetos decorativos e a Sinalização}

Modernos equipamentos precisam de grandes áreas e às vezes causam uma sensação de frieza, solidão e impessoalidade em quem precisa realizar exames, pois o paciente fica sozinho em uma sala, entra em máquinas tubulares, é acompanhado à distância por quem opera os equipamentos. $O$ Hospital Sírio-Libanês, por exemplo, (Figura 80) "tem um sistema de ambientação, com imagens e música, para

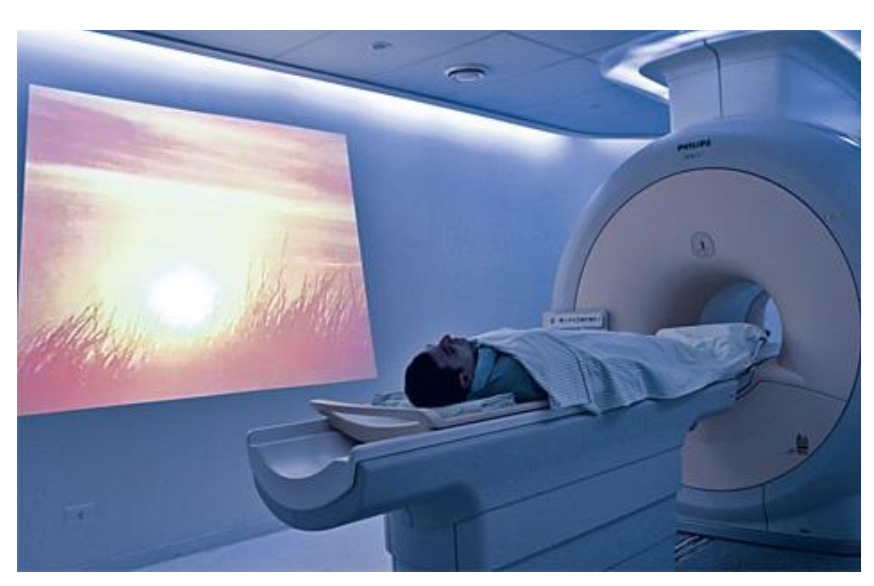

Figura 80 - Ressonância magnética com ambientação Fonte: Tarantino (2011) 
tranquilizar o paciente durante o exame de ressonância magnética" (TARANTINO, 2011).

Os quartos "podem ser decorados com bom gosto, apesar de continuar com os equipamentos de sempre como régua de oxigênio e suporte de soro" (GODOI, 2008, p. 43). Nas salas de espera e espaços de passagem e/ou de descontração, obras de arte, jardins internos, plantas em vasos, aquários e pisos criativos são alguns dos exemplos de adequação estética que podem ajudar a refletir a missão, valores e visão da instituição. Uma linguagem estética coerente com o perfil do usuário e variando de acordo com a função de cada ambiente do hospital pode dar aspecto mais acolhedor ao espaço.

A sinalização está ligada à percepção, pois é por meio desta que se absorvem as informações. A percepção relaciona-se aos sentidos, sendo a visão, a audição, o tato, o paladar e o olfato os cinco mais conhecidos (além desses, o organismo humano possui outros, tais como: senso cinestésico, vibração mecânica, senso de rotação, gravidade, movimento, dor, temperatura).

Percepção é o resultado do processamento do estímulo sensorial, dando-lhe um significao. Os estímulos recebidos são organizados e integrados em informações significativas sobre objetos e ambiente. Nesse processo são usadas informações já armazenadas na memória para converter as sensações em significados, relações e julgamentos. (IIDA, 2005, p. 258)

Em locais de espera para atendimento em ambientes de saúde, por exemplo, sinais para chamada devem ter estímulos visuais e auditivos, pois

(...) os serviços de saúde devem contemplar projetos de sinalização e placas de informação de toda ordem, e também facilitação física para acesso, que não excluam pessoas com deficiência visual ou que usem cadeiras de rodas ou muletas, ou ainda que não saibam ler, que tenham linguagem clara e representativa, identificando os espaços e suas funções. Essa comunicação já deve começar no entorno, na cidade, nos próprios territórios de áreas de abrangência de unidades básicas locais, implementando e informando sobre vias de acesso com fluxos fáceis e adequadamente orientados aos diferentes serviços, com sinalizações capazes de conduzir os usuários a caminho dos equipamentos de saúde. (BRASIL, 2006, p. 20)

Em salas de espera, é aconselhável ter uma televisão para distrair os usuários, mas é preciso cuidado com sua programação, sendo o ideal optar por uma informativa ou educativa, preferencialmente (desde que não sejam repetitivas). Se isso não for possível, pode ser usada uma programação tradicional, mas atentando para o fato de evitar que pessoas que já não estão em situação 
normal física e emocionalmente fiquem expostas a notícias desagradáveis e chocantes.

\subsection{Fator social}

O fator social diz respeito ao espaço de encontro entre os sujeitos e às relações interpessoais como um todo, ou seja, relacionamentos entre as diversas pessoas que circulam pelo espaço hospitalar (seja a trabalho, seja em busca de tratamento). A humanização dos ambientes é o ponto-chave deste fator, envolvendo todas as formas de relações comunicacionais dentro de um hospital, mas com maior enfoque nos clientes de saúde. De acordo com Godoi (2008, p. 44), desde o atendimento feito pelo setor de reservas (seja para uma simples marcação de consulta ou para procedimentos mais complexos), o tratamento tem que ser respeitoso.

É importante que as pessoas possam ter espaços específicos de convivência e integração, que, segundo o Ministério da Saúde (BRASIL, 2006, p. 15), "poderá ser iniciada com concepções arquitetônicas que excluam muros, grades ou alambrados, criando-se ambiências de acesso compostas por praças".

Quanto às equipes de trabalho, em especial, é aconselhável a existência de salas de conversa e espaços de conforto para possíveis reuniões e interação. Outras áreas podem servir como espaço de relaxamento, espaço para atividades físicas e/ou de interação: salas de espera; corredores; áreas de conveniência (café, restaurante, farmácia etc.), capela ecumênica etc. Seus elementos relacionam-se aos usuários. Mencionamos aqui a relação entre funcionários/colaboradores e clientes de saúde e a relação que estes podem estabelecer entre si.

A preocupação com a relação entre clientes de saúde também é importante, sobretudo no caso de pacientes internados no mesmo quarto. Compartilhar um espaço com pessoa desconhecida, em uma situação de debilidade física pode gerar desconforto. O uso de cortinas, principalmente na UTI, é uma forma de garantir certa privacidade dos pacientes e seus acompanhantes. 
CAP. 4 A COMUNICAÇÃO VISUAL E A AMBIÊNCIA HOSPITALAR

\subsection{Ambiência hospitalar}

A ambiência pode ser vista como uma forma de linguagem em um hospital, uma vez que oferece estímulos que transmitem ao cliente de saúde mensagens de natureza emocional e de interação social. Os fatores mencionados no capítulo anterior (de fundo, funcionais, simbólicos e sociais) formam um conjunto que pode ser considerado como uma atmosfera (GEARGEOURA, 2010, p. 47-49) do hospital. A aparência estrutural como um todo e os elementos sensoriais formam um sistema que, mesmo que subliminarmente, refletem concepções de qualidade e, sobretudo, de hospitalidade.

Elementos visuais (decoração, a disposição do mobiliário, dos equipamentos e

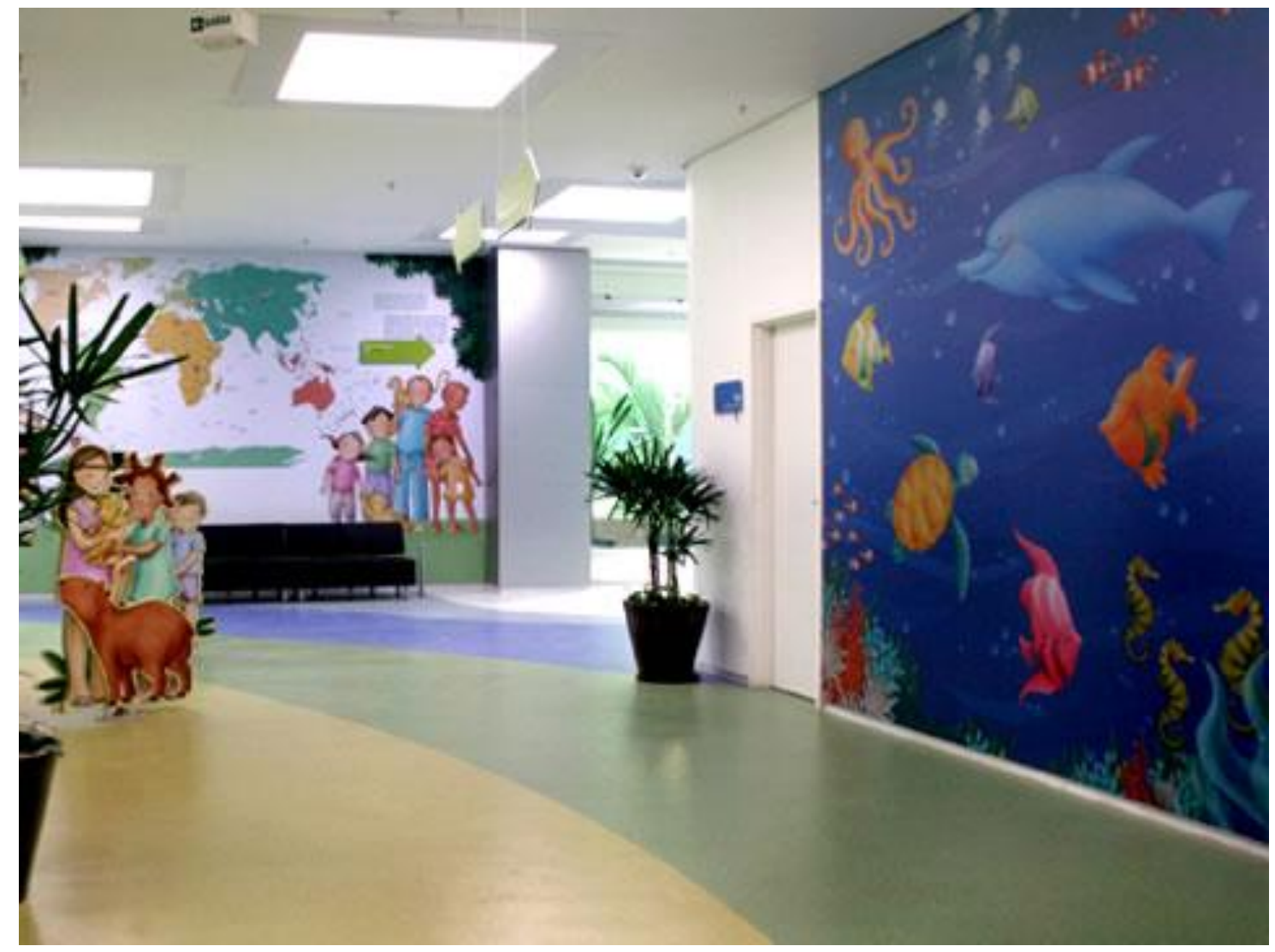

Figura 81 - Hospital Infantil Sabará

Fonte: www.ceciliaesteves.com.br/?id=86 
das peças de CV), associados aos demais elementos sensoriais (sons, aromas, gostos etc.) formam um conjunto para satisfazer necessidades dos usuários em um hospital, proporcionando-lhes um ambiente mais agradável e confortável. Para que isso ocorra, a linguagem estética da ambiência deve ser coerente com o perfil dos clientes de saúde e variar de acordo com a função de cada ambiente hospitalar. Os elementos sensoriais (considerando-se, neste trabalho, em especial, os visuais), dispostos de maneira sistematizada, podem oferecer ao cliente de saúde uma atmosfera que auxilie a transformar o ambiente hospitalar em um espaço terapêutico. A ilustradora Cecília Esteves fez o projeto de ambientação para o Hospital Infantil Sabará (Figura 81). Integrando painéis com crianças e animais em escala real e brinquedos interativos com as informações de localização e orientação, foi formado um ambiente mais lúdico, visando acolher as crianças de maneira especial.

A imagem visual está presente em nosso cotidiano de forma intensa e ostensiva. As informações são difundidas por recursos técnicos de modo instantâneo por todo o globo terrestre e o receptor tende a preferir as transmissões imagéticas visuais diretas às comunicações puramente verbais (FRUTIGER, 2001, p. 191). Nesse universo conceitual, as instituições têm percebido que o uso da imagem visual como ferramenta para transmitir um conceito adequado de sua marca é imprescindível.

Um exemplo é o do Hospital IGESP que, ao passar por uma fase de reestruturação e ampliação (com o término da construção de um novo prédio e reforma do prédio antigo, em 2009), modernizou sua marca, valorizando o novo

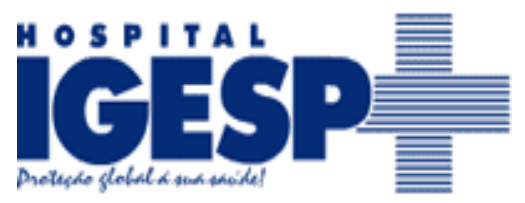

Figura 82 - Logomarca anterior do $\mathrm{H}$. IGESP

Fonte:

ldiamante.blogspotcom/2010_05_01_archive.htor

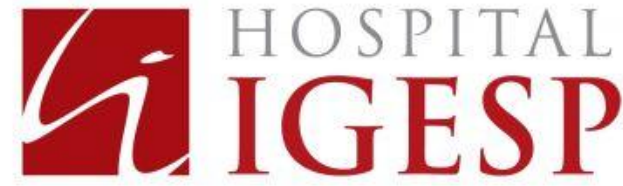

Figura 83 - Logomarca atual do H. IGESP Fonte: blog.mktone.com.br/ 
hospital. As mudanças arquitetônicas foram seguidas por ampliação dos serviços, capacitação da equipe para melhor atender os clientes de saúde e investimento em novas especialidades e tecnologia de ponta. A nova marca buscou mostrar essas alterações (Figura 82 e Figura 83). De acordo com o jornal do hospital (IGESP, 2009, p. 7), "o elemento gráfico $(H+I)$, além de simbolizar as iniciais do hospital, dá a ideia de movimento, inovação e tecnologia e o elemento quadrado usado para suportar o grafismo remete ideia de solidez".

Outro exemplo é o Hospital Alemão Oswaldo Cruz, que desenvolveu, em 2009,

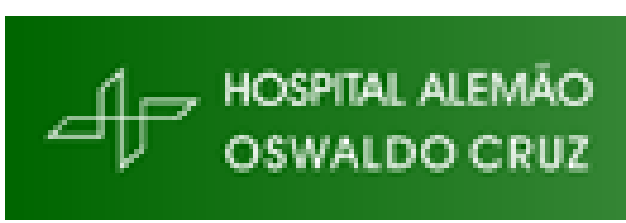

Figura 84 - Logomarca anterior do $\mathrm{H}$. Oswaldo Cruz

Fonte:

ldiamante.blogspotoom/2010 05_01_archive.htm |

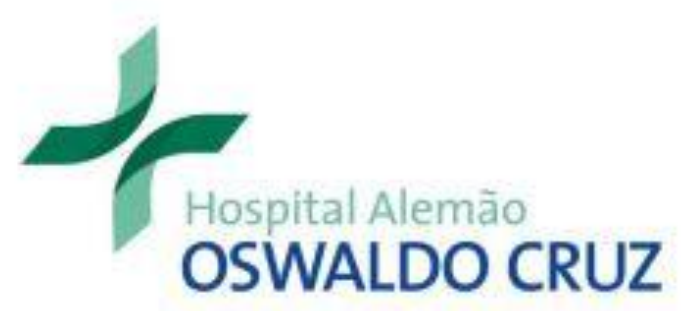

Figura 85 - Logomarca atual do H. Oswaldo Cruz Fonte: www.hospitalar.com

um projeto de comunicação integrada, abordando a construção de uma nova logomarca (Figura 84), a criação de um portal de saúde e a padronização de toda a sua sinalização. Diferente da marca anterior (Figura 85), a nova ficou mais simples, leve e criativa, com linhas arredondadas que remetem a conceitos de modernidade, dinamismo, tecnologia, proteção, flexibilidade, acolhimento, bem-estar, tranquilidade. $O$ site do hospital sustenta esses valores transmitidos e oferece informações direcionadas aos diversos públicos da instituição, disponibilizando dados institucionais, notícias relacionadas à área da saúde, dicas sobre prevenção, diagnóstico e tratamento e respostas a algumas das perguntas mais frequentes com relação a determinadas doenças. O projeto de sinalização foi baseado em três premissas: facilitar a identificação dos prédios e blocos do hospital; promover uso mais racional do espaço e facilitar o fluxo de trabalho dos colaboradores e de locomoção de pacientes e visitantes.

Para que as informações visuais possam ser captadas e processadas com 
maior eficiência, é importante que estejam organizadas adequadamente. Ao ser elaborado um sistema de fornecimento de informação para um ambiente de saúde, deve-se considerar os usuários, conhecendo (da melhor forma possível) seu perfil e considerando suas possibilidades de percepção (captação) e processamento de informações. Estas são transmitidas por meio de estímulos que podem ter ou não significado para o receptor, que os perceberá e interpretará de acordo com suas características e situação (física, emocional, psicológica etc.).

Segundo a Gestalt, percebemos o todo, ou seja, não vemos partes isoladas de outras. Os estudos da percepção da imagem englobam a organização e estruturação das informações (GOMES FILHO, 2002). Esses estudos, por terem procurado respostas de por que umas formas agradam mais que outras, contribuíram para 0 entendimento do funcionamento da percepção morfofisiológica da imagem no cérebro do observador. A percepção é condicionada por fatores humanos, ou seja, por características físicas e psicológicas.

Alguns fatores ambientais de natureza física (luz; ruídos; temperatura; qualidade do ar etc.) podem afetar a percepção gerando desconforto nas pessoas, o que deve ser evitado em um hospital. Nesse ambiente também deve ser dada atenção à percepção visual, em especial, que pode sofrer interferências pela falta ou excesso de iluminação; pelo tamanho do objeto; pela distância em que este se encontra em relação ao observador; por sua cor; pelos movimentos dos olhos e da cabeça do observador e pela idade deste (EVERLING et al.,

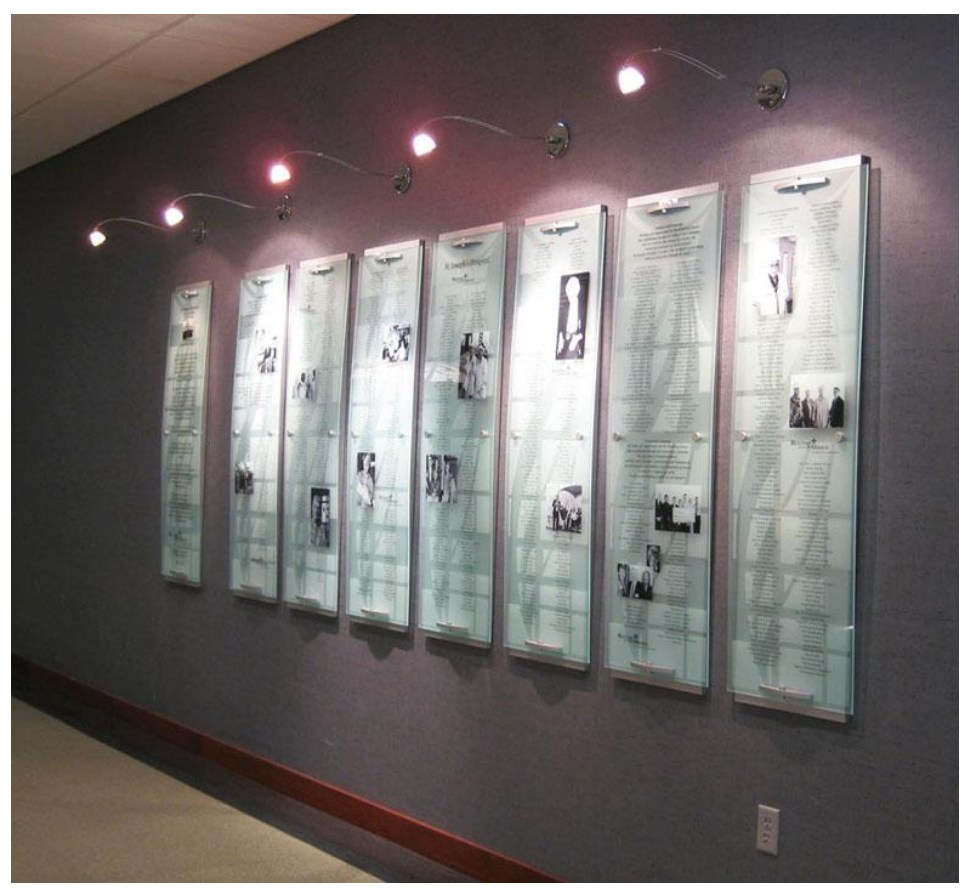

Figura 86 - St. Joseph's Hospital

Fonte: uww.visualoomm.com/Hospital-Wayfinding-Signage.htm|\#allina 
1999).

A Figura 86 apresenta, como exemplo, painéis de vidro do Saint Joseph's Hospital, em Saint Paul, Minnesota, EUA. A iluminação direcionada facilita a leitura dos painéis (que contêm informações sobre pessoas que fizeram doações para o hospital) além de destacar o material utilizado (vidros e metal). Uma pessoa pode selecionar, organizar e conferir significado ao que seus olhos captam e a partir desse processo formar uma imagem de determinada realidade. Cada indivíduo pode criar uma imagem própria do que vê, "mas parece existir um consenso substancial entre membros do mesmo grupo" e essas "imagens de grupo" são as estudadas em ambientes a serem utilizados por muitas pessoas ( $\mathrm{LYNCH}, 2006$, p. 8).

Quanto mais clara for a imagem do ambiente no qual nos encontramos, mais fácil e rápida será nossa percepção espacial e, consequentemente, melhor nos deslocaremos por ele. Além disso, um ambiente ordenado "pode servir como um vasto sistema de referências, um organizador da atividade, da crença ou do conhecimento". Uma boa imagem ambiental oferece um "sentimento de segurança emocional", pois possibilita que o indivíduo estabeleça uma relação harmoniosa com o mundo que o cerca, o que é o oposto ao medo que alguém pode sentir decorrente de uma situação de desorientação (idem, p. 5). Em um ambiente hospitalar é preciso que essa segurança emocional seja cuidadosamente dimensionada, procurando evitar maiores desgastes aos usuários.

Os sistemas de CV se associam à ergonomia quando utilizam as noções desenvolvidas por esta em termos de informação (informações captadas pela visão, sua percepção e seus dispositivos, os quais constituem a parte do sistema que fornece informações ao usuário para que este possa tomar decisões); fatores humanos (fisiológicos, psicológicos, cognitivos); fatores ambientais (ruídos, vibrações, iluminação, clima, temperatura, cores); segurança (prevenção de erros e de acidentes). Aplicar a ergonomia na CV é um modo de criar integração com os usuários, pois são consideradas suas necessidades e o ambiente no qual se encontram, por meio de métodos e estudos comprovados sobre percepção e reação. 


\subsection{Comunicação visual e a construção da ambiência}

A CV como um todo tem um papel fundamental no contexto hospitalar, pois pode transmitir mensagens de qualidade e de conforto aos usuários. Como lembra Bitencourt (2008, p. 98), "dispositivos de informação não transmitem apenas informações, mas capacitam decisões", dentre elas a escolha de direções "que, se alteradas, podem proporcionar desconforto ou estabelecer prejuízos irreversíveis na essência da utilização do tempo exato da ação".

Aspectos humanos e físicos precisam ser valorizados; afeto e tecnologia precisam "andar juntos". Não adianta ter recursos tecnológicos e grau de excelência, nem conforto ambiental, ergonômico e estético aprimorados sem hospitalidade e humanização. É preciso comunicar ao cliente de saúde que ele é visto como um ser humano em busca de diagnóstico e tratamento para algum problema, por isso deve ser tratado com respeito, dignidade e cortesia.

A CV em um ambiente tão específico quanto um hospital pode ser incorporada à ambiência, formando um sistema e contribuindo para que este espaço seja agradável e acolhedor. A Figura 87 apresenta, como exemplo, a sala de espera

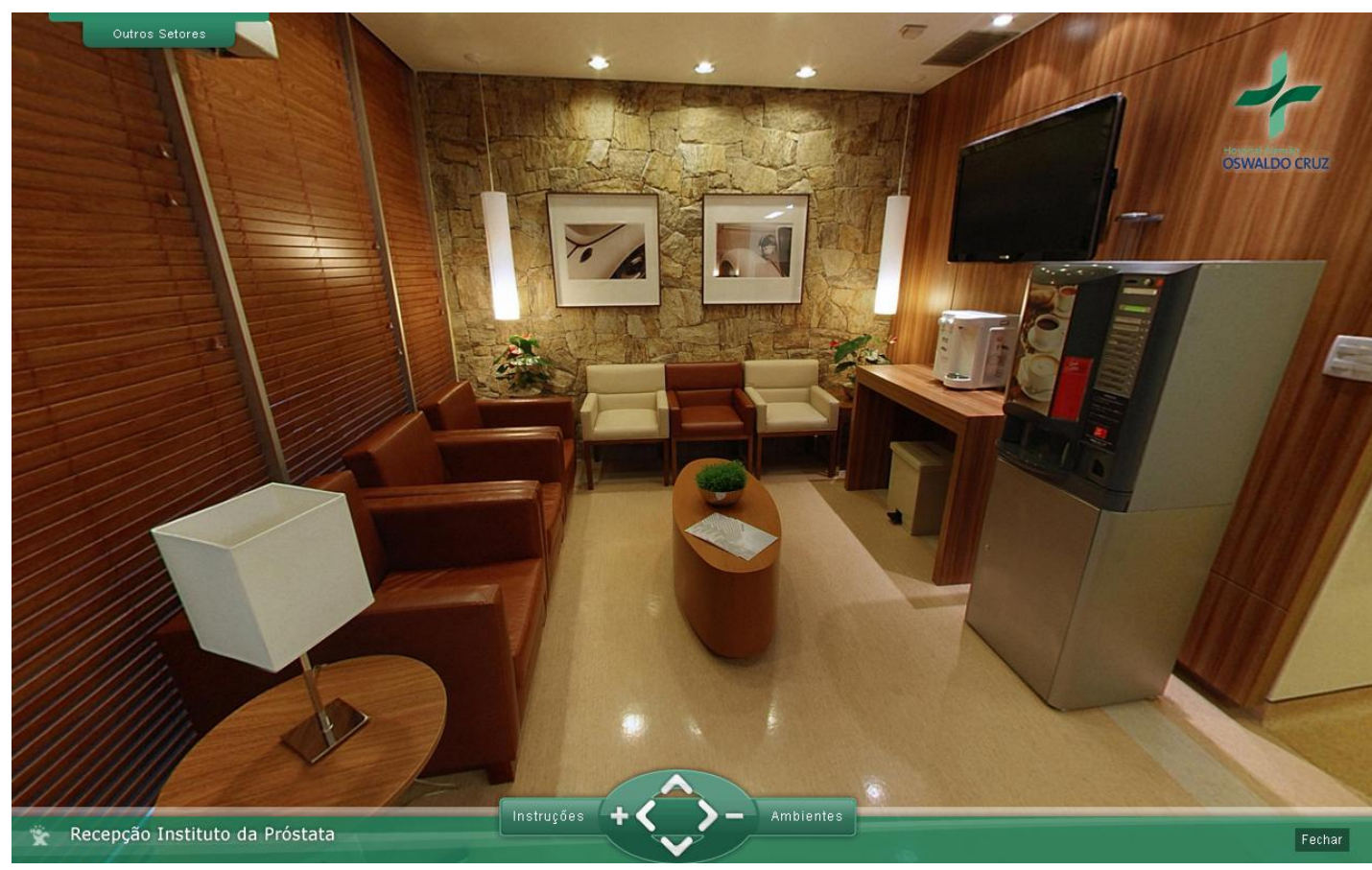

Figura 87 - Recepção do Inst. da Próstata (H. A. Oswaldo Cruz) Fonte: uww.hospitalalemao.org.brhaoc/Defaultaspx?idPagina=35613 
da recepção do Instituto da Próstata do Hospital Oswaldo Cruz, em São Paulo. Podemos notar a composição feita para proporcionar maior conforto aos clientes de saúde: disposição das poltronas, mesa de centro e lateral, vasos com plantas, quadros na parede, iluminação, além de televisão com tela grande, máquina de café e de água, lixeira discretamente colocada embaixo de uma mesa.

Em outras palavras, peças de CV, em um hospital, podem tornar-se parte de um conjunto a que estamos chamando de "ambiência hospitalar". Quando essas peças estão dispostas de maneira bem planejada e sistematizada, podem auxiliar no tratamento dos clientes de saúde. As ações e esforços neste ambiente devem ser direcionados à atenção ao ser humano, procurando fazer com que este se sinta em um local aconchegante, hospitaleiro e humanizado.

Em especial a sinalização (símbolos; letras; pictogramas; iluminação; cores; formas) deve contribuir para melhorar a vida de quem circula pelo ambiente hospitalar. Para orientar o fluxo, deve garantir que as pessoas possam: identificar os espaços e serviços com rapidez e eficiência; ter uma noção de todo o ambiente caso sintam necessidade de se localizar melhor (mapa geral); direcionar-se sem problemas; receber avisos comportamentais e de segurança, mensagens administrativas e funcionais sem ruídos; ter acesso fácil às informações que realmente sejam relevantes para que elas se localizem com segurança; garantir que os acessos restritos estejam bem declarados, evitando situações enganosas desagradáveis; evitar desorientações, confusões, irritações e, principalmente, perda de tempo.

Um ambiente hostil pode gerar maiores conflitos (como estresse, tensão, nervosismo etc.) a clientes de saúde, prejudicando ainda mais o processo terapêutico. Assim, todos os esforços devem ter como foco reduzir o estresse e possíveis confusões de orientação de fluxo de usuários.

A Figura 88 apresenta exemplos de aplicação adequada e não adequada de CV em um departamento de emergência. Todo material não relevante deve ser evitado em área de espera, ou seja, o que se deve fazer é remover as informações desnecessárias para que o usuário não fique confuso. 


\section{What not to do.}
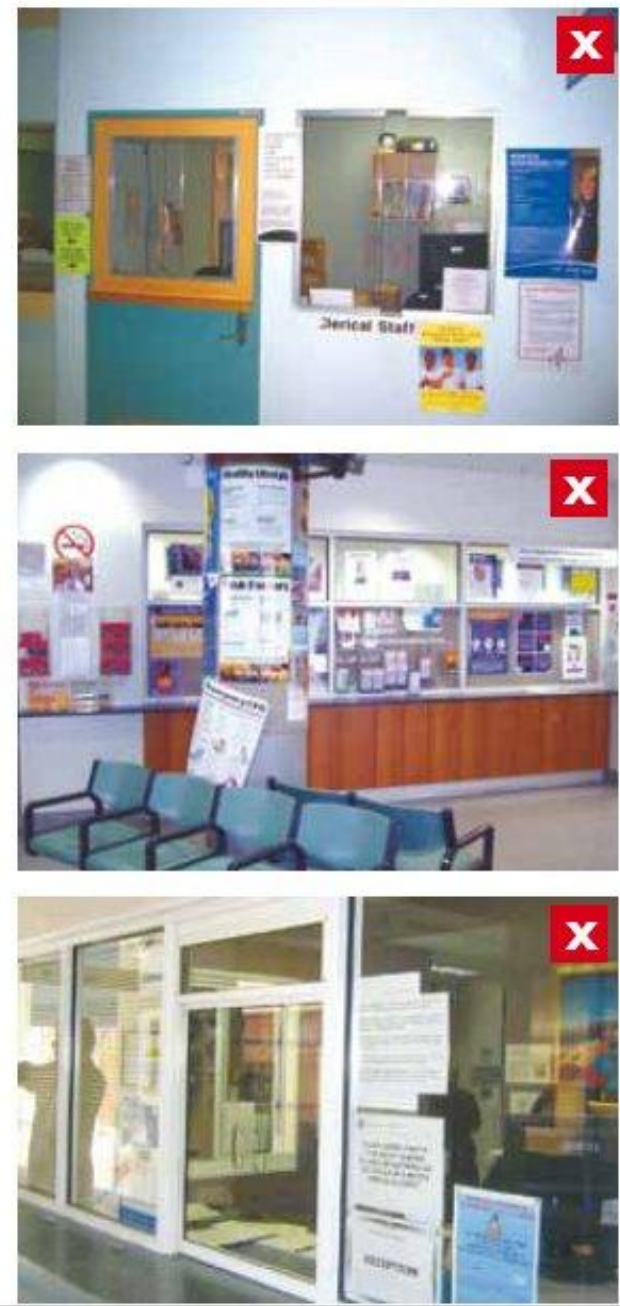

What to do.
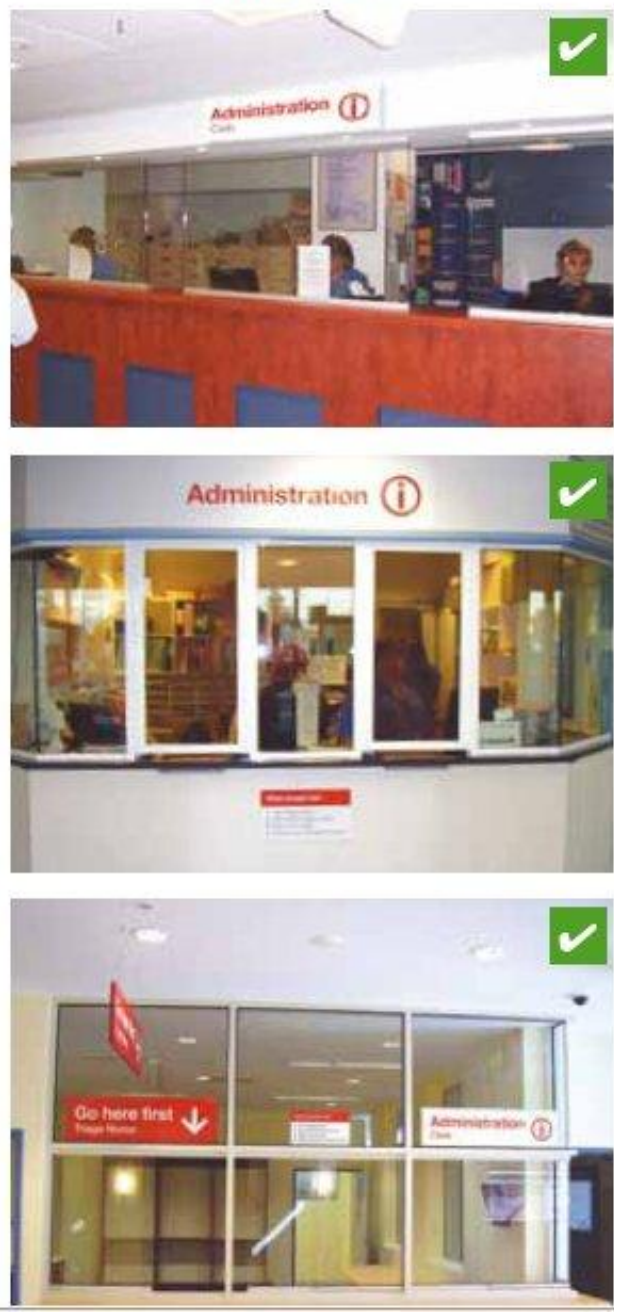

Figura 88 - Exemplo de aplicação adequada e não adequada de CV Fonte: Victorian (2008, p. 6)

Um sistema de sinalização é mais que apenas sinais e placas distribuídos em determinado espaço, é um conjunto com uma linguagem visual que ajuda pessoas a serem capazes de tomarem decisões corretas para se locomoverem em um ambiente. Esse conjunto inclui o ambiente como um todo (paisagem); a arquitetura; design interior; iluminação; aplicações gráficas em pisos, paredes e janelas etc. (GSG, 2008, p. 16). 
A Figura 89 apresenta algumas sinalizações do Hospital Sírio-Libanês, em São Paulo, em que a cor azul reforça a identidade visual do hospital, além de desempenhar a função de orientação de fluxo.

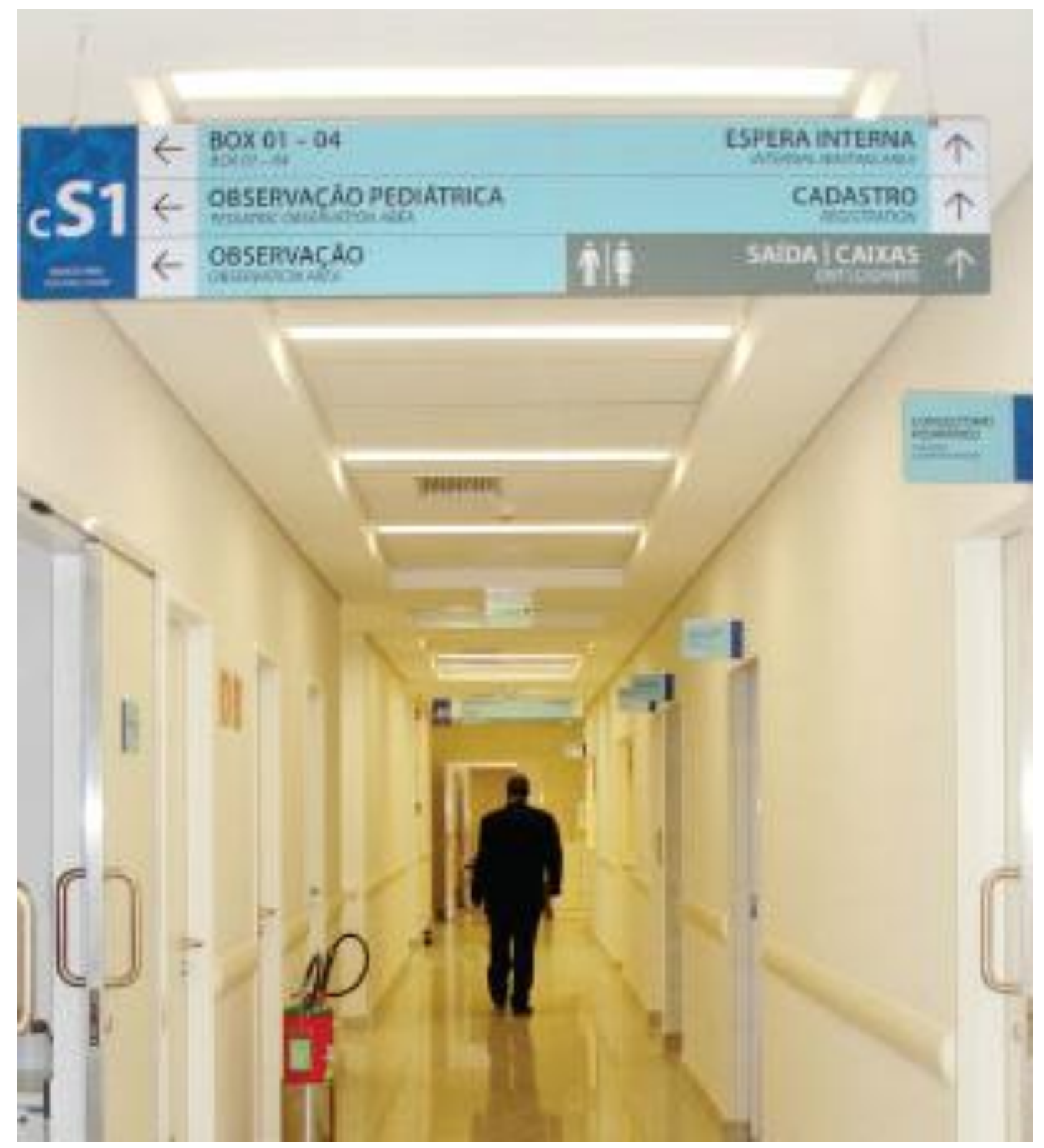

Figura 89 - Exemplos de sinalização do H. Sírio-Libanês

Fonte: www.ozdesign.com.br/cases-internos.asp? $i d=110 \& t p=1$

Geargeoura (2010, p. 14-19) elenca os aspectos relativos à apresentação interna de uma loja, que, adequados para hospital, sintetizam vários aspectos já mencionados nesta tese. Assim, o Esquema 9 apresenta os aspectos internos relacionados à ambiência hospitalar: 


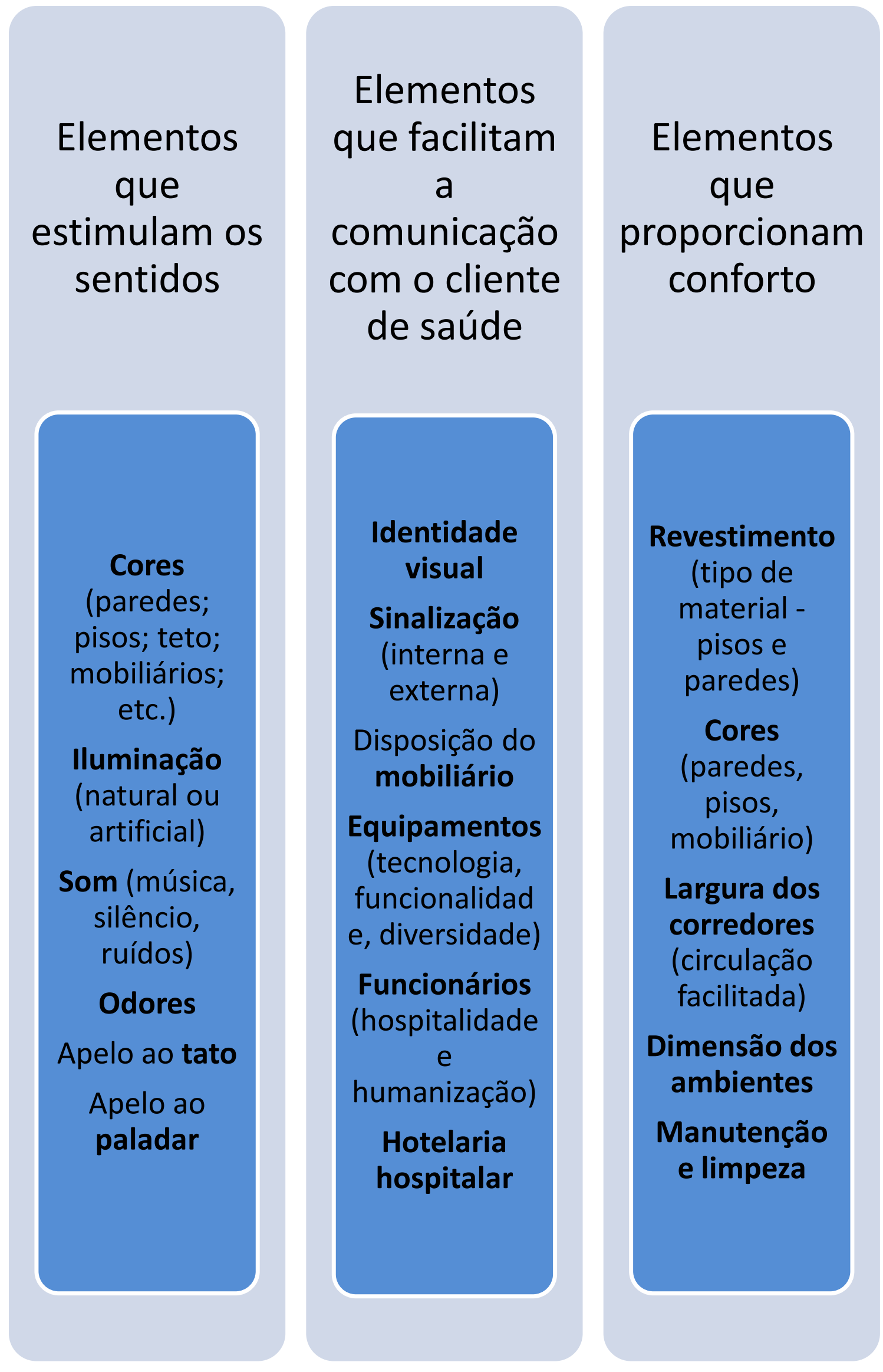

Esquema 9 - Aspectos internos relacionados à ambiência hospitalar Fonte: Elaborado pela autora 
Criar uma ambiência envolve adequação dos espaços para melhor atender as necessidades dos usuários e, no caso especial de hospitais, a atenção maior deve ser direcionada aos pacientes (principalmente os que se encontram internados). O planejamento do espaço interno deve ser feito desde a entrada, sobretudo áreas de recepção, por serem estes os locais de primeiro contato do usuário com o ambiente.

É importante tentar causar boa impressão (sobretudo quando se trata de uma primeira visita), fazendo com que o cliente se sinta bem recebido. Para isso, áreas como entrada, saguão, recepção devem "primar pela harmonia visual", utilizando-se "cores suaves, espaço adequado, decoração, tamanho e estética dos equipamentos, apresentação pessoal de todos os envolvidos no atendimento", além de se "disponibilizar um ambiente climatizado e bem iluminado", com boa CV (TARABOULSI, 2006, p. 93).

Como exemplo (Figura 90), apresentamos o ambiente principal de recepção do Hospital Israelita Albert Einstein. É um ambiente agradável, com uma fachada

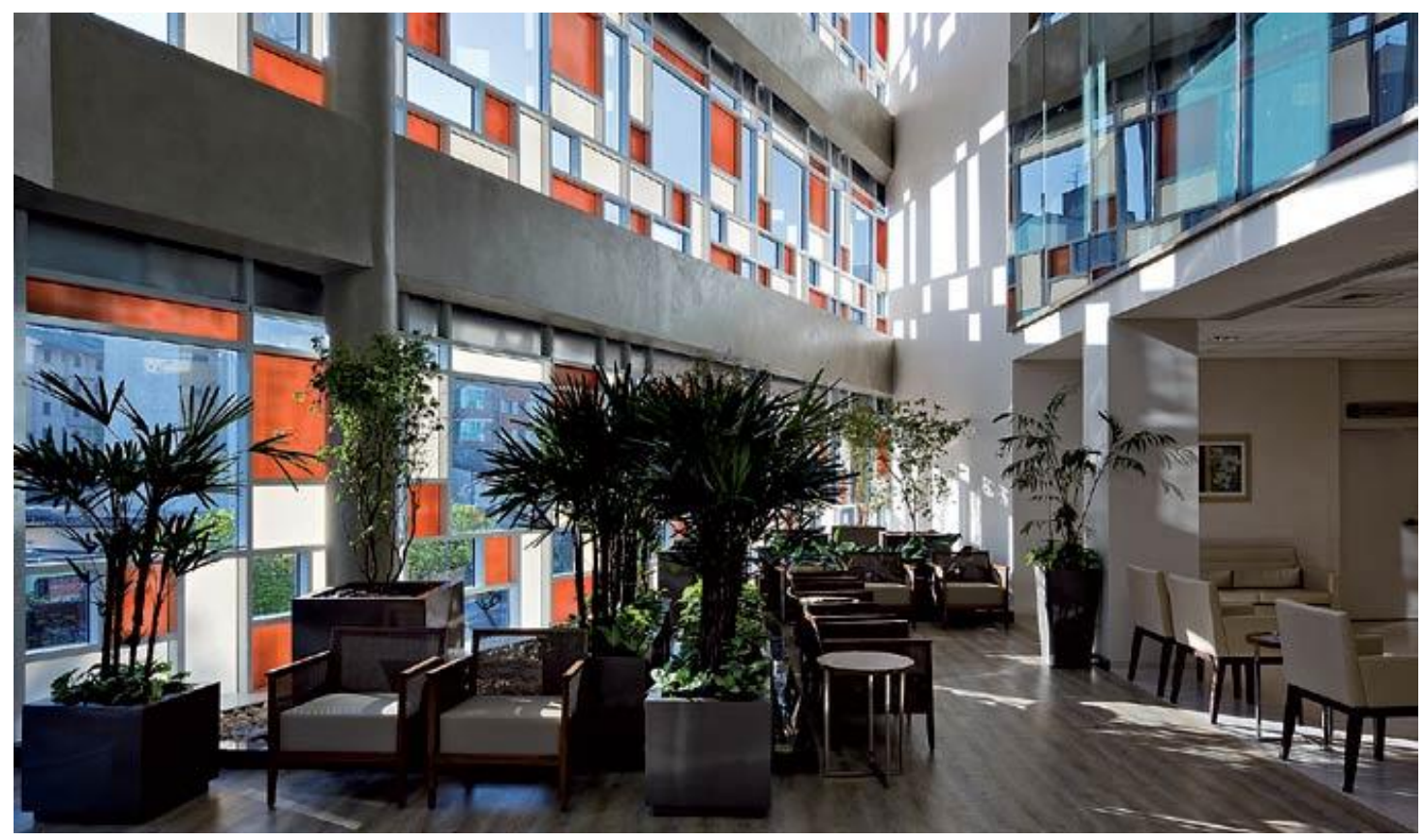

Figura 90 - Recepção e espera do Hosp. Albert Einstein Fonte: arcoweb.com/Leviskyarquiteto

em mosaico de vidro, que possibilita contato visual com o exterior e a entrada de iluminação natural e muita claridade. Elementos coloridos, várias plantas ornamentais e confortáveis poltronas fazem com que esse ambiente possa ser 
visto também como um espaço para integração.

Atualmente, novas tecnologias são utilizadas, como é o caso da instalação de mesas de orientação interativa e tátil do Hospital Georges Pompidou, em Paris (Figura 91). Apesar da novidade tecnológica, nota-se que o hospital conta também com recursos de sinalização mais tradicionais.

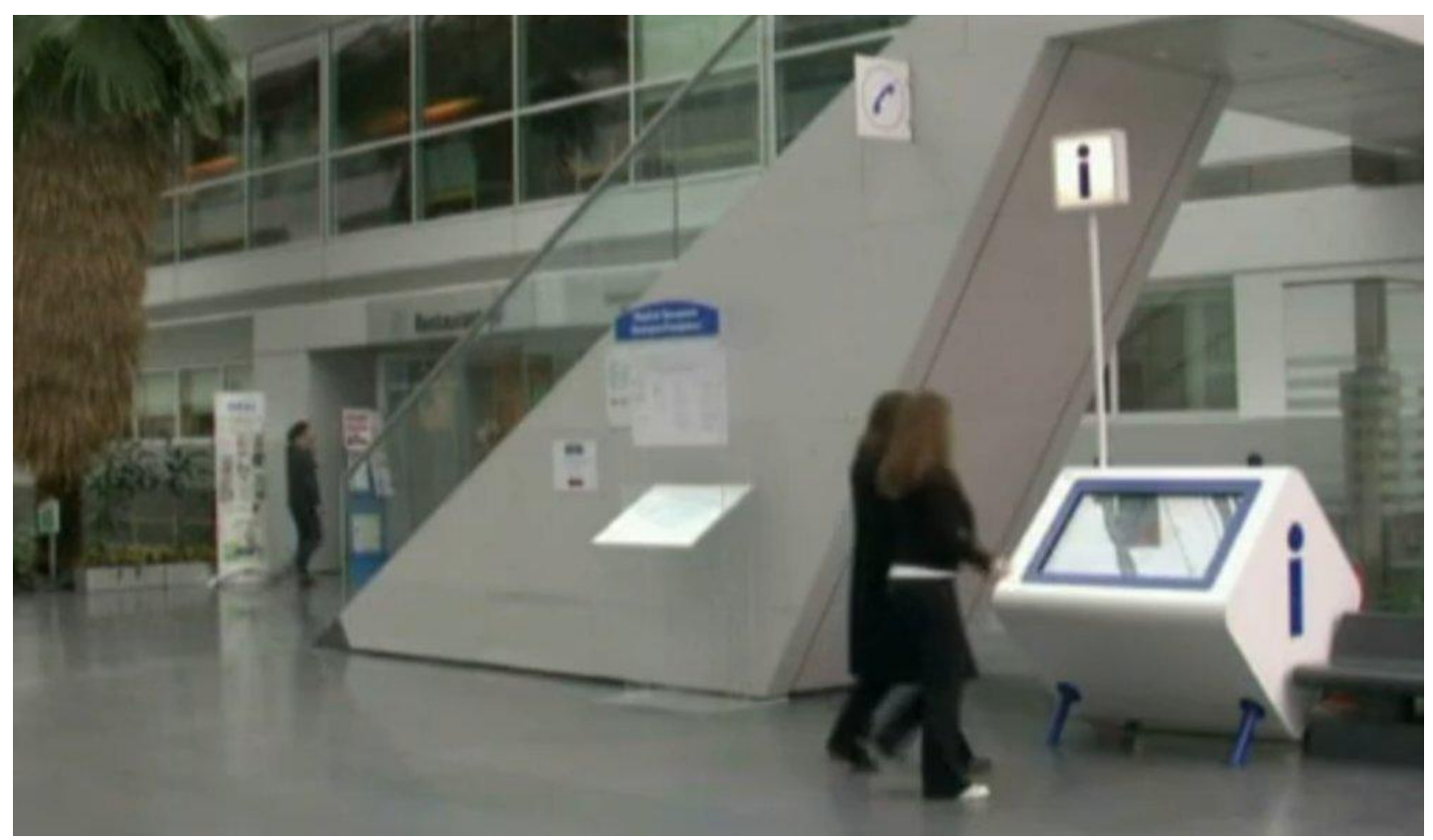

Figura 91 - Equipamento interativo do H. Georges Pompidou Fonte: $\quad$ www.eng.viadirect.com/2011/02/g-pompidou-hospital-in-parisequiped-with-2-intertactive-and-tactledirectories.html

As recepções internas devem ter relação entre si e refletir os valores do hospital, principalmente quando há a criação de uma nova ala ou novo setor. Um exemplo é o Núcleo de Assistência à Mulher, do Hospital Igesp, em São Paulo, criado em setembro de 2011, com o objetivo de oferecer um serviço específico para o público feminino, proporcionando um atendimento integral a mulheres, considerando a prevenção da saúde, bem-estar e questões estéticas.

A Figura 92 mostra a recepção desse setor, onde é possível notar o logotipo da instituição aplicado na mesa. A disposição dos móveis e toda a decoração da sala de espera (com plantas, vasos, quadros) e a posição do mobiliário (poltronas, mesa de centro) formam um ambiente mais intimista, possibilitando maior proximidade entre as pessoas que aguardam serem chamadas para consultas. 


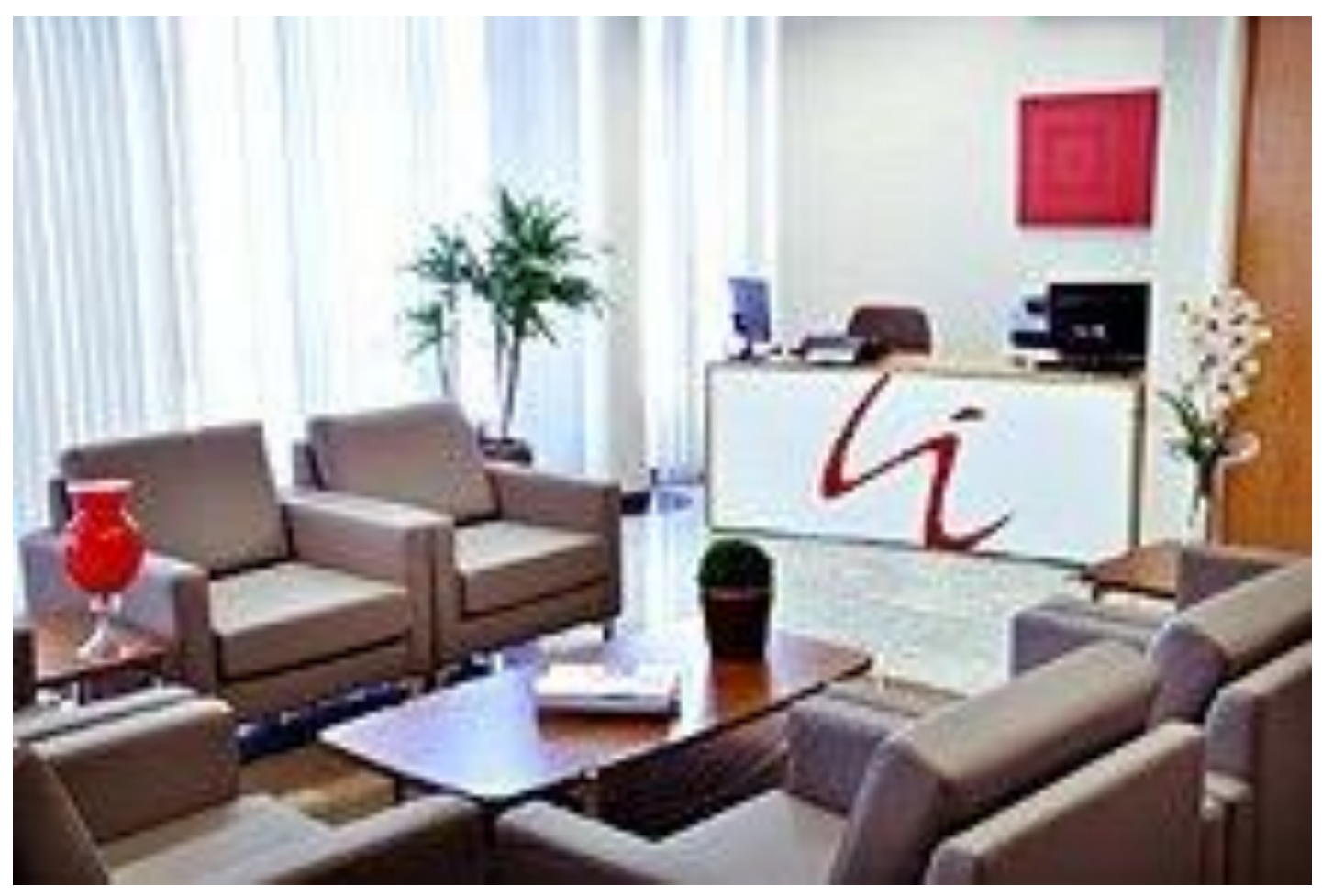

Figura 92 - Núcleo de Assistência à Mulher do H. Igesp Fonte: www.hospitalar.com/index.php

É aconselhável que os hospitais tenham espaços de convivência, nos quais as pessoas possam relaxar, conversar, integrar-se, distrair-se. Jardins, áreas de lazer, espaço ecumênico, biblioteca são possibilidades para isso. Muitos pacientes internados precisam fazer caminhadas para sua recuperação e, nesse sentido, áreas de lazer, jardins e demais espaços podem servir como locais apropriados para esse fim. Já com relação a acompanhantes e familiares, às vezes estes precisam de espaços para relaxar, distrair-se ou até chorar (longe do paciente).

(...) não basta garantir o direito a acompanhante, é preciso que existam espaços capazes de acolhê-los, nos diversos ambientes das unidades. Por exemplo: nos prontos-socorros, nos SADT (Serviços de Apoio Diagnóstico Terapêutico), nas enfermarias, nas esperas dos centros cirúrgicos, nas UTIs (Unidades de Terapia Intensiva), etc., de maneira que eles possam também ter momentos de encontros, diálogos, relaxamento e entretenimento, como assistir televisão ou ouvir música. (BRASIL, 2006, p. 19)

Além disso, esses espaços podem servir como interação entre pessoas que se encontram em situações semelhantes, possibilitando uma troca de experiências. 
Espaços lúdicos também são importantes para integrar usuários e, sobretudo no caso de crianças, é importante que estas possam se relacionar com as demais, apesar da doença. Uma biblioteca, uma brinquedoteca e outros espaços semelhantes são possibilidades para que a criança que precisa ir ao hospital não rejeite tanto esse espaço, integre-se a ele e aos demais usuários.

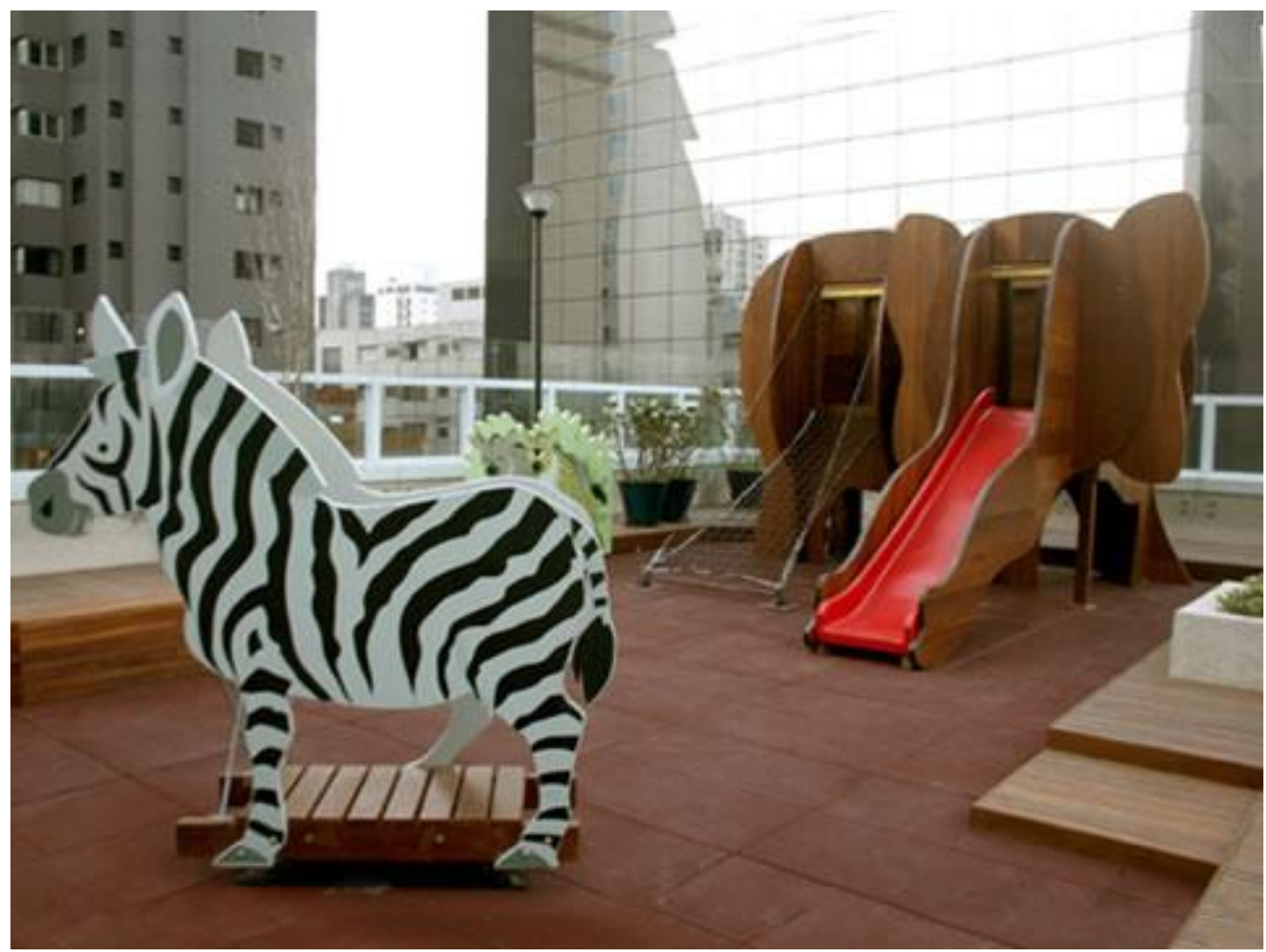

Figura 93 - Terraço do 7o. Pavimento do Hosp. Sabará Fonte: www.ceciliaesteves.com.br/?id=86

O exemplo apresentado (Figura 93) refere-se ao projeto de ambientação lúdica realizado para o Hospital Infantil Sabará. 


\subsection{Apresentação externa}

Um hospital (mesmo que não seja tido como uma empresa propriamente dita) tem uma estrutura que "incorpora uma dimensão empresarial necessária a seu funcionamento e ao atendimento de suas finalidades" (ZOBOLI, 2004, p. 36). Assim sendo, a apresentação de seus espaços e de sua estrutura como um todo tem um caráter fundamental na estratégia de posicionamento perante seus concorrentes, ou seja, no mercado. O Esquema 10 apresenta os aspectos externos relacionados à ambiência hospitalar, baseado no trabalho de Geargeoura (2010, p. 14-19):

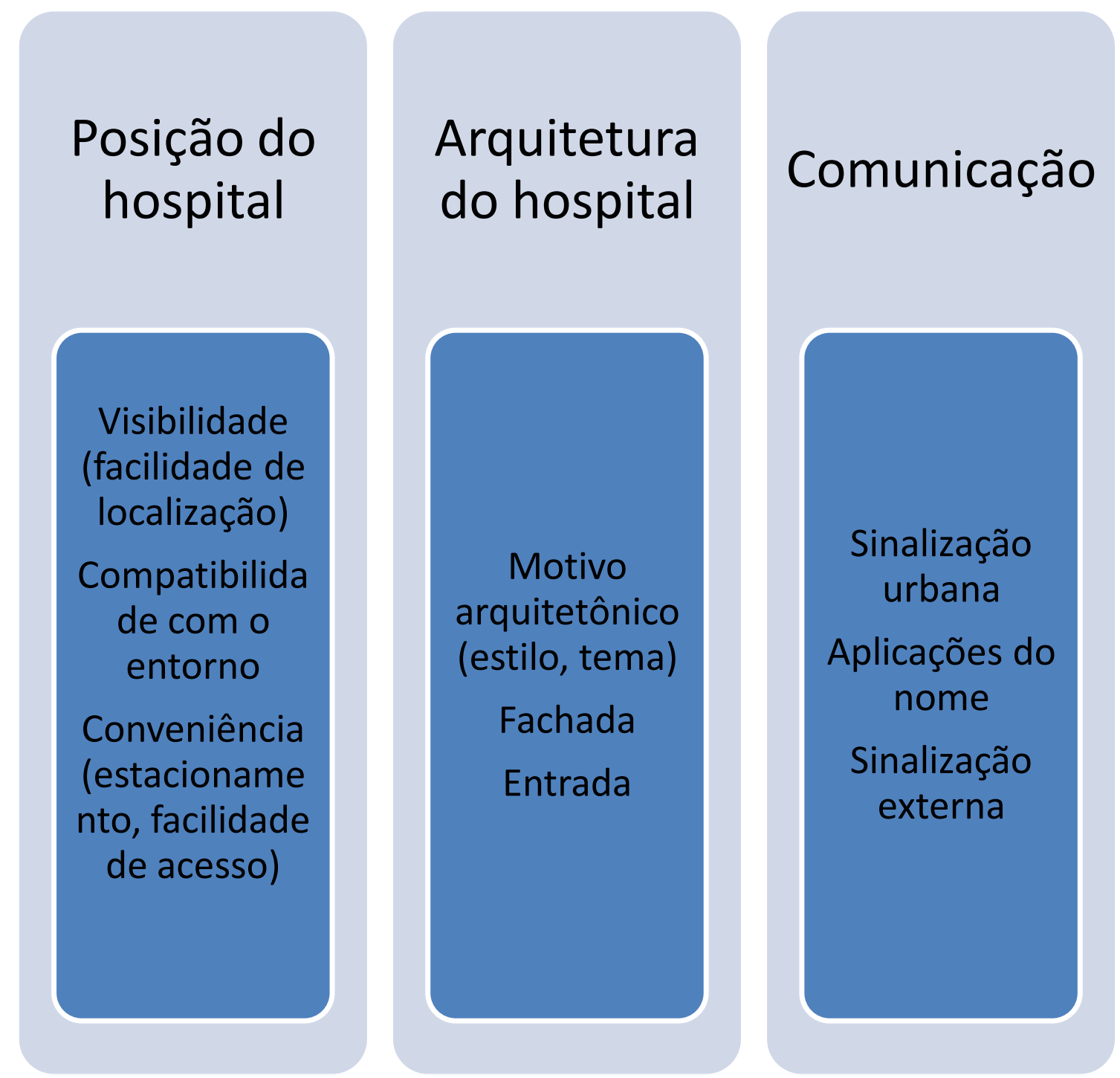

Esquema 10 - Aspectos externos relacionados à ambiência hospitalar Fonte: Elaborado pela autora 
A relação com o entorno faz parte da hospitalidade em um sentido mais amplo que o dos limites do hospital, pois envolve a questão de sinalização urbana. Placas de sinalização urbana devem conter indicações sobre sua localização com placas de trânsito diferenciadas (cor azul de fundo, letras brancas, contendo um quadrado branco com uma cruz em vermelho.

As aplicações do nome do hospital devem facilitar o reconhecimento à distância (nome e/ou logomarca em lugares de destaque do edifício). Na Figura 94, o logotipo aplicado no prédio, visível mesmo a longa distância, possibilita um melhor reconhecimento do local.

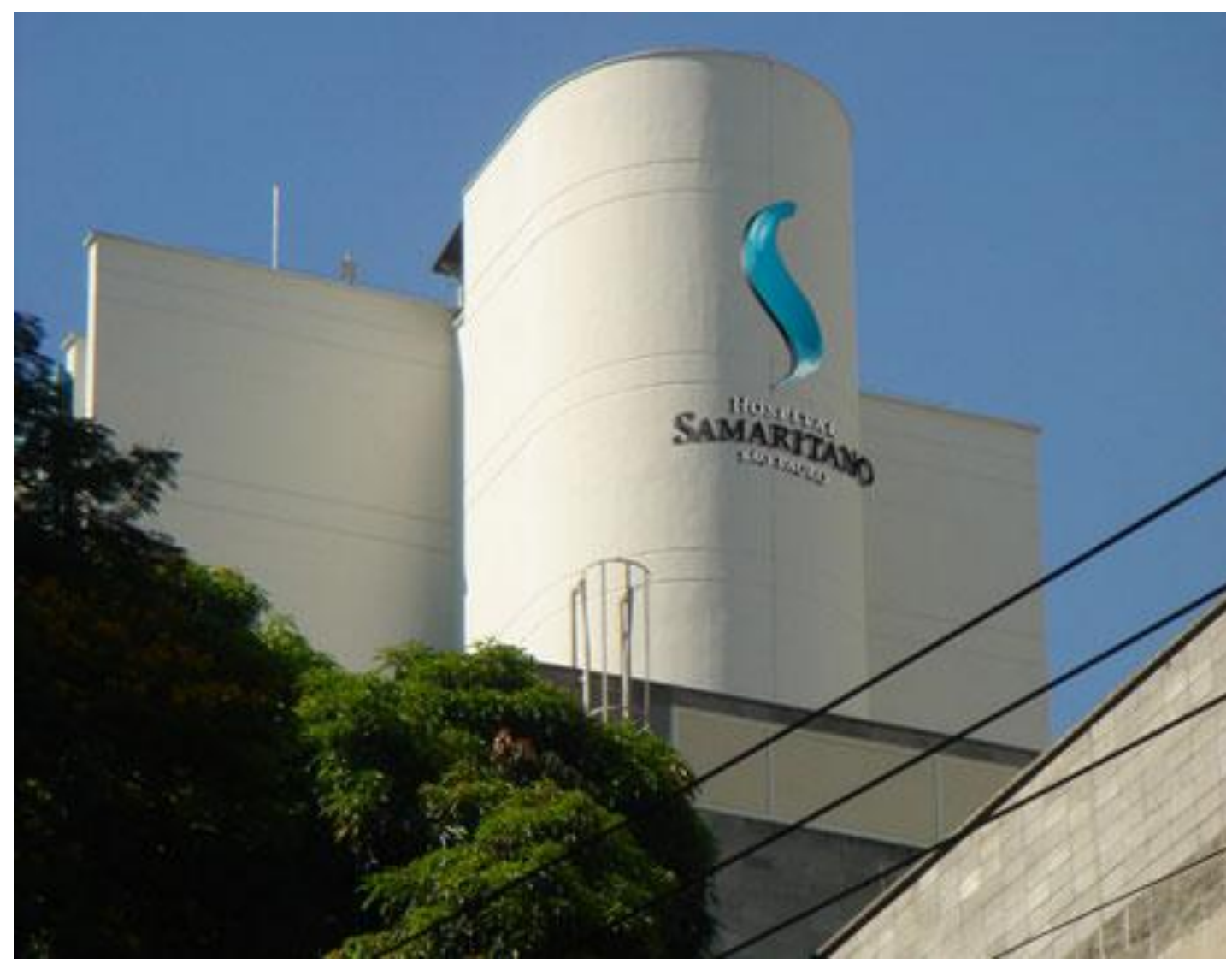

Figura 94 - Logotipo do Hosp. Samaritano aplicado no prédio

Fonte: unw.casodesign.com.briindex.asp?c=f6331bfd4501bd20e461e4eaf0708364

Um hospital precisa estar em lugar de destaque em relação ao seu entorno e ser facilmente identificado, mesmo que a certa distância, possibilitando que pessoas (sobretudo as que estejam de carro) possam localizá-lo com rapidez e eficiência. Muitos hospitais têm vários acessos de entrada, o que pode ocasionar confusões, por isso o posicionamento das informações da sinalização no ambiente hospitalar é um fator relevante em sua fachada e em 
seu entorno. As informações de identificação do hospital devem estar em lugares estratégicos a fim de servirem para seus variados usuários. A Figura 95 mostra, como exemplo, o totem de entrada do Hospital Samaritano. Tanto para quem está a pé quanto para quem está de carro é fácil visualizar o totem.

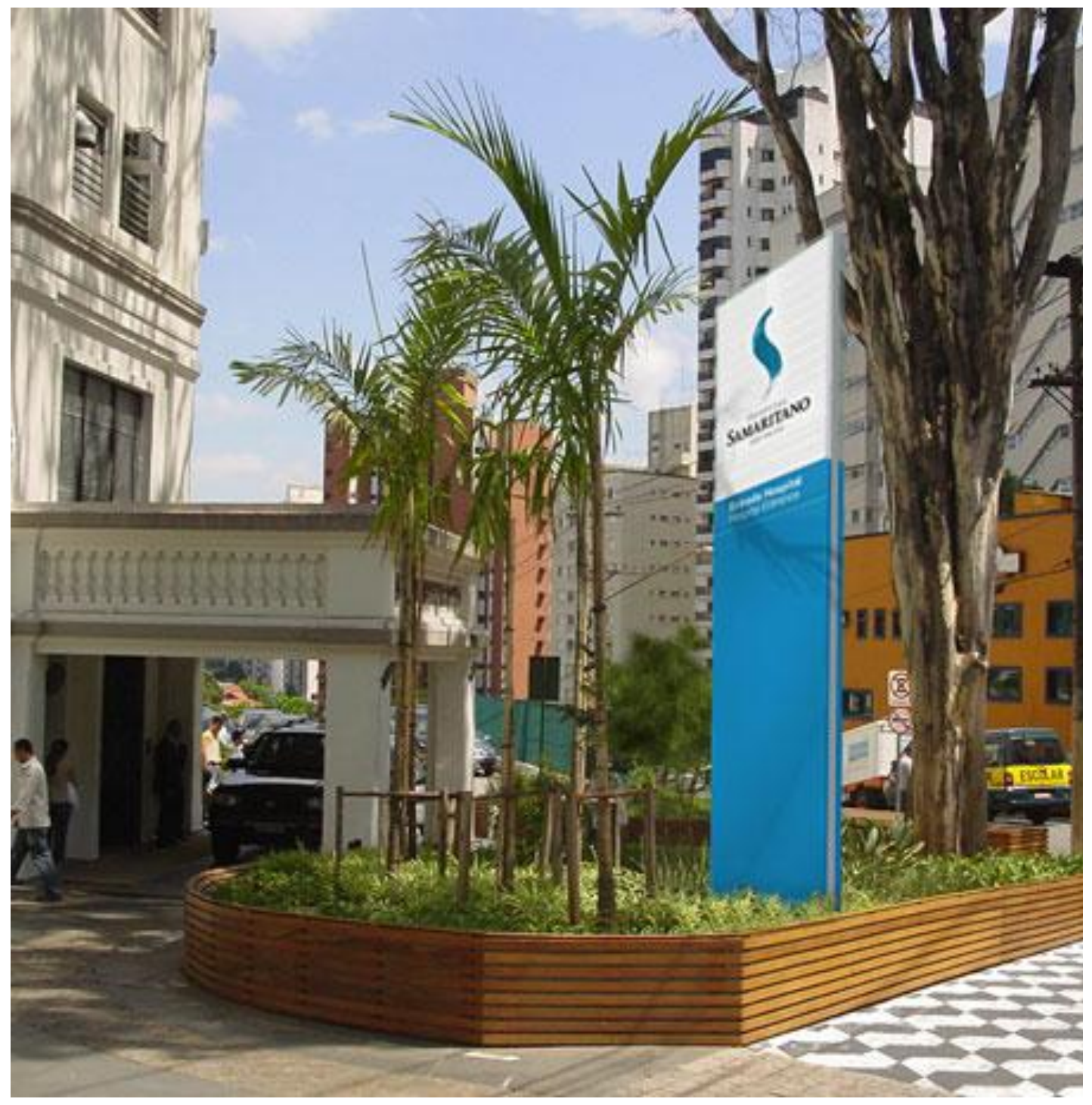

Figura 95 - Totem do Hosp. Samaritano

Fonte: uww.casodesign.com.br/index.asp?c=f6331bfd4501bd20e461e4eaf0708364 
A entrada para o Pronto Atendimento ou para o Setor de Emergência deve ser bem evidenciada, dada a gravidade de seu caráter e de suas funções. A distinção entre Ala Adulto e Ala Infantil também deve ser feita de forma a ser facilmente reconhecida. Um exemplo é a entrada para o Pronto Atendimento do Hospital Santa Catarina.

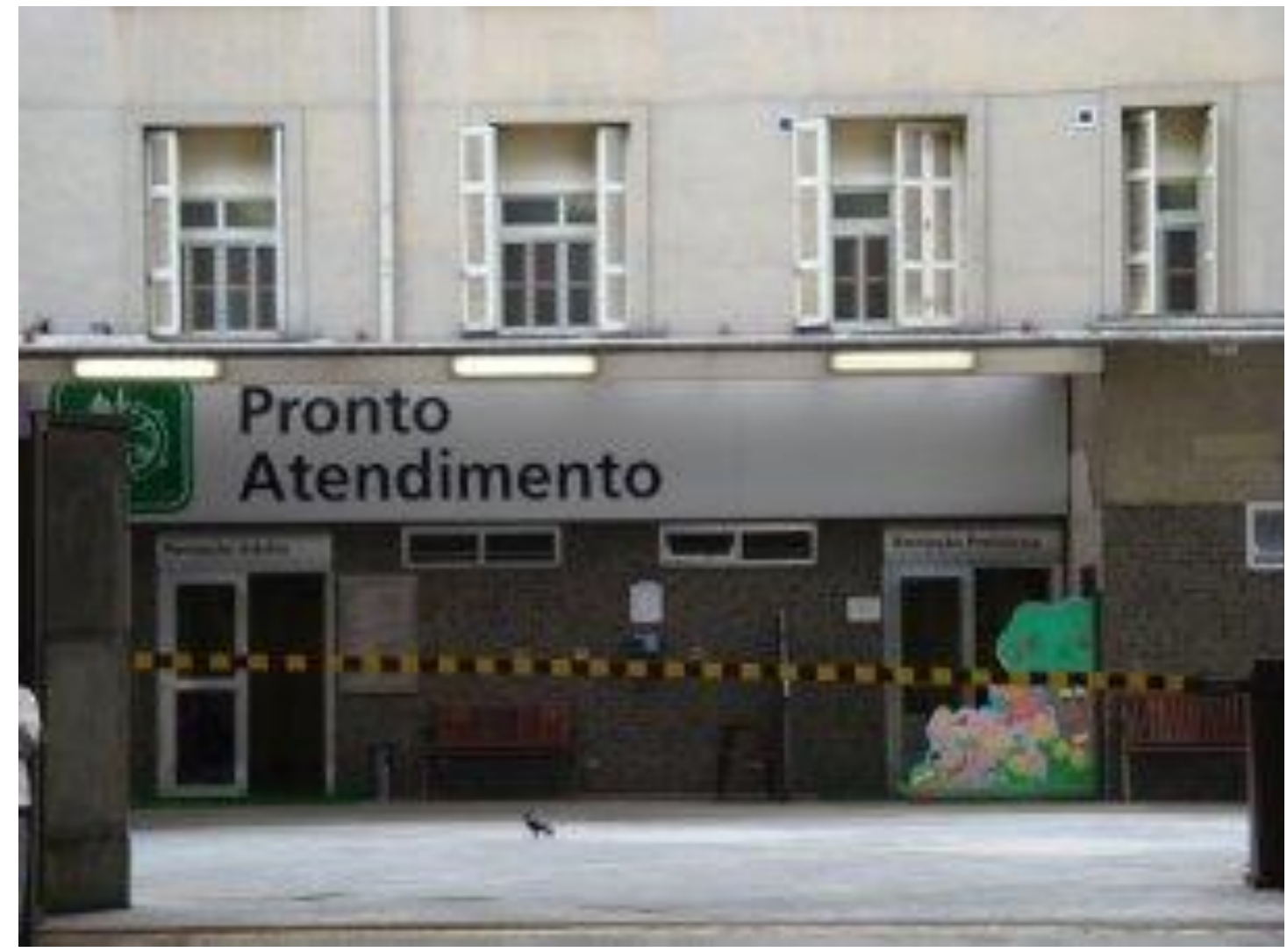

Figura 96 - PA do H. Sta. Catarina

Fonte: Foto da autora

Percebe-se, pela Figura 96, que a entrada para o Pronto Atendimento tem 0 logotipo do hospital. A recepção pediátrica (à direita da foto) tem aplicação com árvore e bichinhos, colorida e alegre. Além de servir como elemento diferenciador, essa aplicação procura atrair a atenção das crianças, tentando dar um aspecto mais acolhedor ao hospital desde sua entrada. Considerandose que no caso de Pronto Atendimento a criança possivelmente está com o estado de saúde mais agravado, essa forma de recepcioná-la pode contribuir, de alguma forma, para amenizar tensões, distraí-la e evitar possíveis traumas com relação ao ambiente hospitalar.

A aparência geral de um hospital pode ter certa influência sobre seu entorno. $O$ motivo arquitetônico ou estilo do prédio reflete a postura da instituição, seus 
valores e objetivos. No processo de expansão, por exemplo, alguns hospitais mantêm a arquitetura original e integram as novas instalações ao estilo antigo, transmitindo, com isso, a ideia que sua tradição permanece, integrando-se à atualidade. Um exemplo é o saguão do Hospital Santa Catarina que, ao ser reformado, integrou a ala nova à antiga, com uma parede de vidro fazendo a junção até a entrada da capela (Figura 97 e Figura 98).

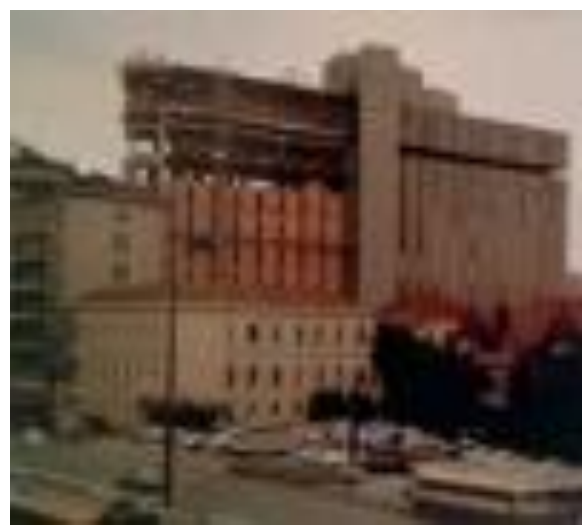

Figura 97 - H. Sta. Catarina: fachada em 1980

Fonte: Hospital Santa Catarina (2006, p. 23)

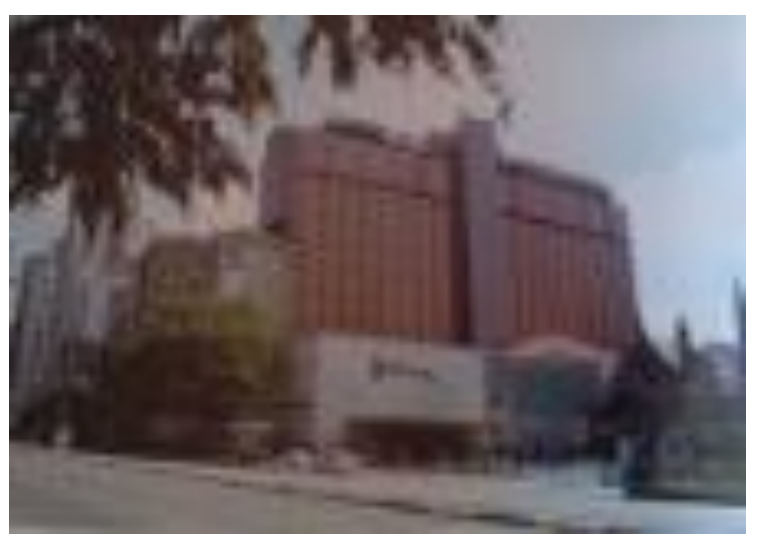

Figura 98 - H. Sta. Catarina: fachada atual Fonte: Hospital Santa Catarina (2006, p. 24)

O aspecto geral da fachada também pode apresentar valores do hospital. Citando novamente o Hospital Santa Catarina, o muro que o cerca contém vários mosaicos, conforme podemos notar nos exemplos da Figura 99. Além

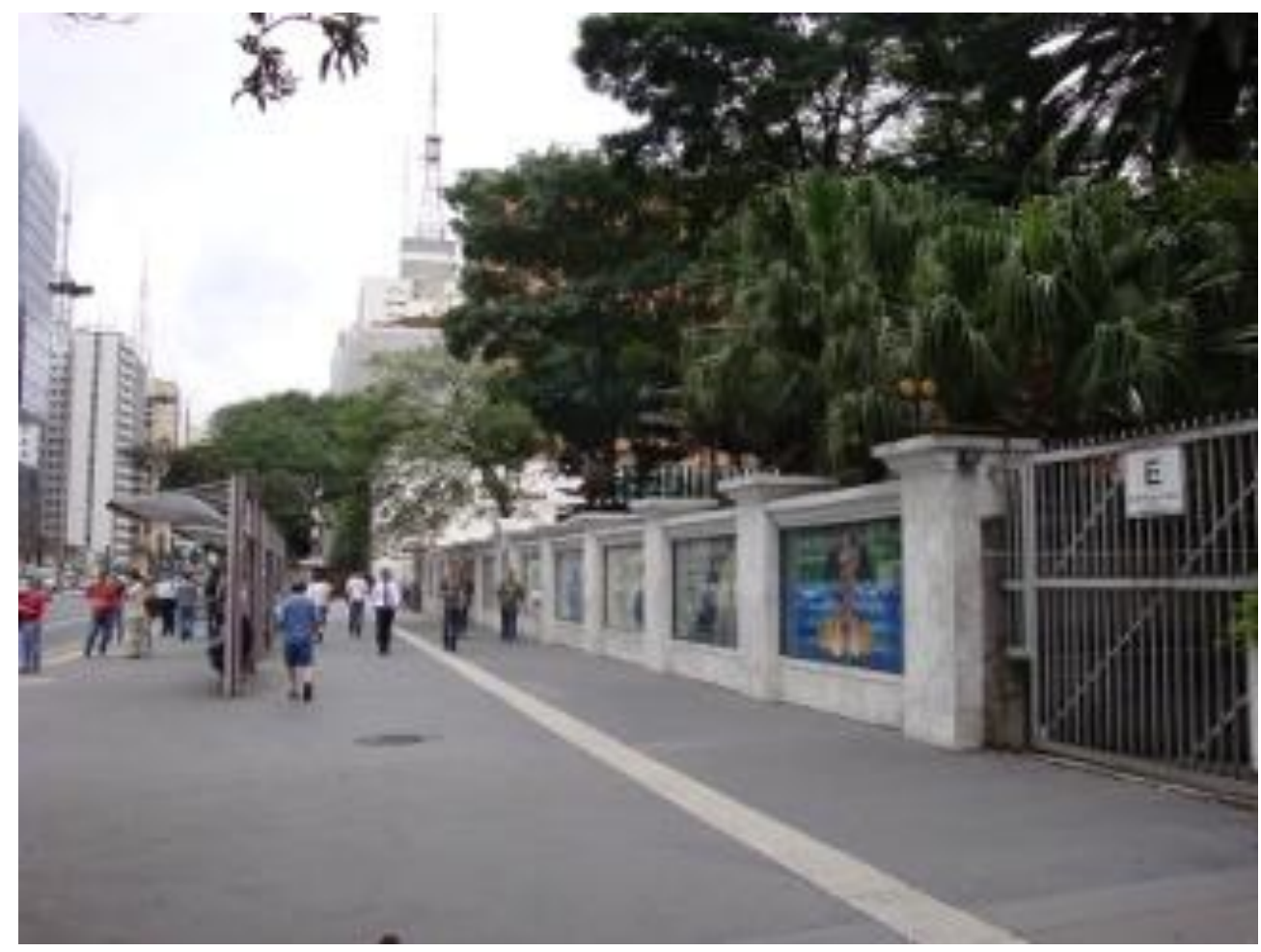

Figura 99 - Muro do H. Sta. Catarina Fonte: Foto da autora 
disso, em julho de 2002 foram instaladas placas de bronze no lugar de antigas janelas. São 24 placas que formam um painel com o título "vida" (HOSPITAL SANTA CATARINA, 2006, p. 110).

O tipo de estrutura geral da fachada, associada aos serviços de hotelaria (manobrista, porteiros, recepcionistas etc.) dão a alguns hospitais uma aparência de hotel. Essa tendência atual está muito relacionada à hospitalidade e transmite uma imagem de instituição preocupada com o conforto e a segurança do cliente de saúde. O fundamental é fazê-lo sentir-se "em casa", em um ambiente agradável, que cause menos estresse e traumas (quanto for possível), visando sempre a melhoria em seu estado de saúde físico e emocional.

A disponibilidade de estacionamento é um fator relevante para um hospital,

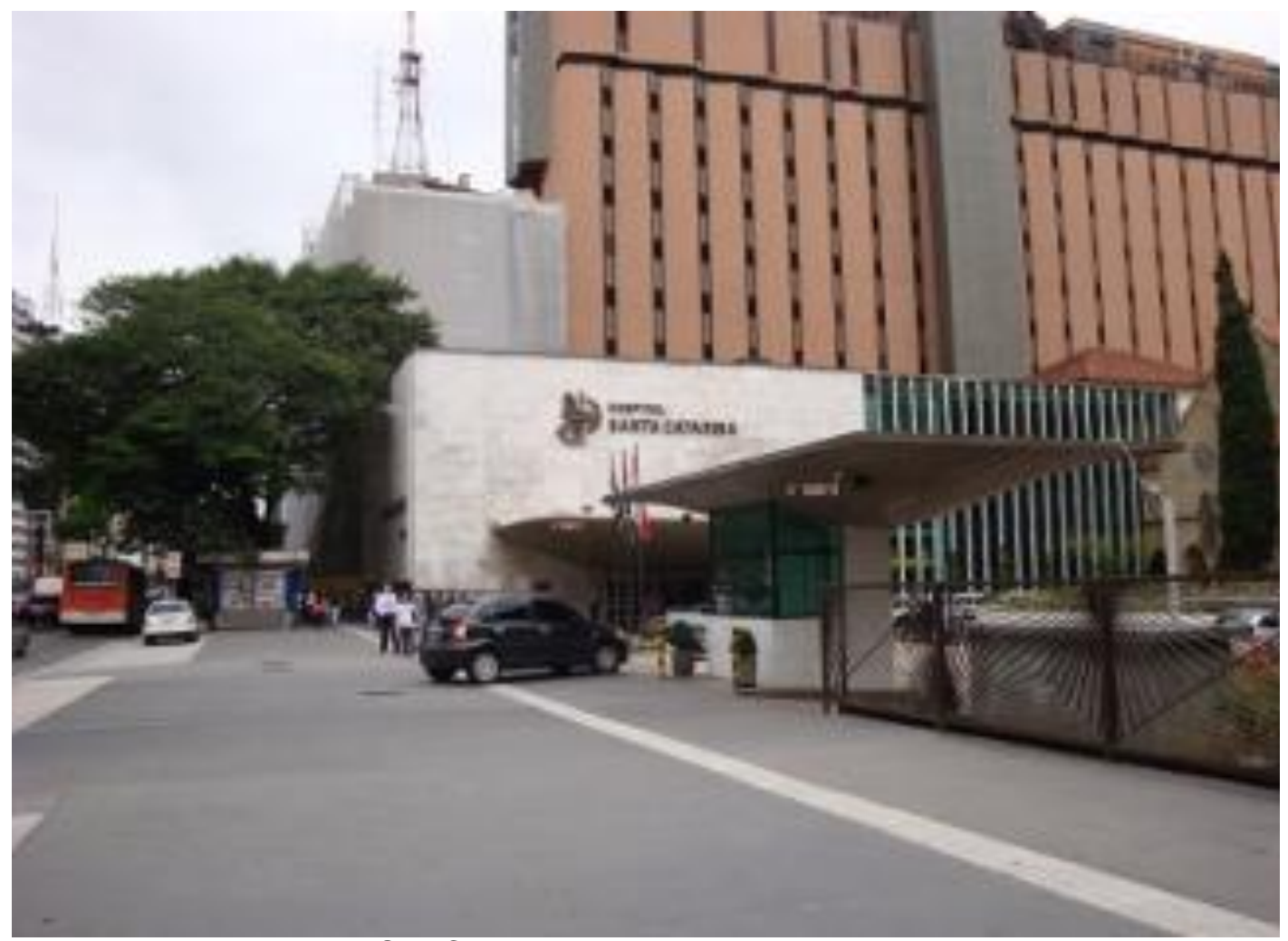

Figura 100 - Frente do H. Sta. Catarina

Fonte: Foto da autora

sobretudo nos grandes centros como São Paulo. A entrada do estacionamento deve ser facilmente identificável. Um exemplo é o Hospital Santa Catarina, que, como mostra a Figura 100 tem uma entrada bem ampla e facilmente reconhecível, apesar da necessidade de o motorista ter de passar pela ampla calçada em frente ao hospital. Cabe ressaltar que o acesso por meio de 
transportes coletivos é um fator importante. Esse hospital, por exemplo, tem seu acesso facilitado, pois há um ponto de ônibus bem próximo e uma estação de metrô não muito longe.

Demarcações são importantes para evitar que os usuários tenham dificuldade para encontrar o veículo ao deixar o hospital. Um exemplo é a sinalização feita pela empresa Aesthetic Inc. para o Allen Hospital (Waterloo, lowa), como mostra a Figura 101. Cada entrada tem um número e a sinalização correspondente à entrada do prédio. As vagas específicas para pessoas que trabalham no hospital são diferenciadas por cores.
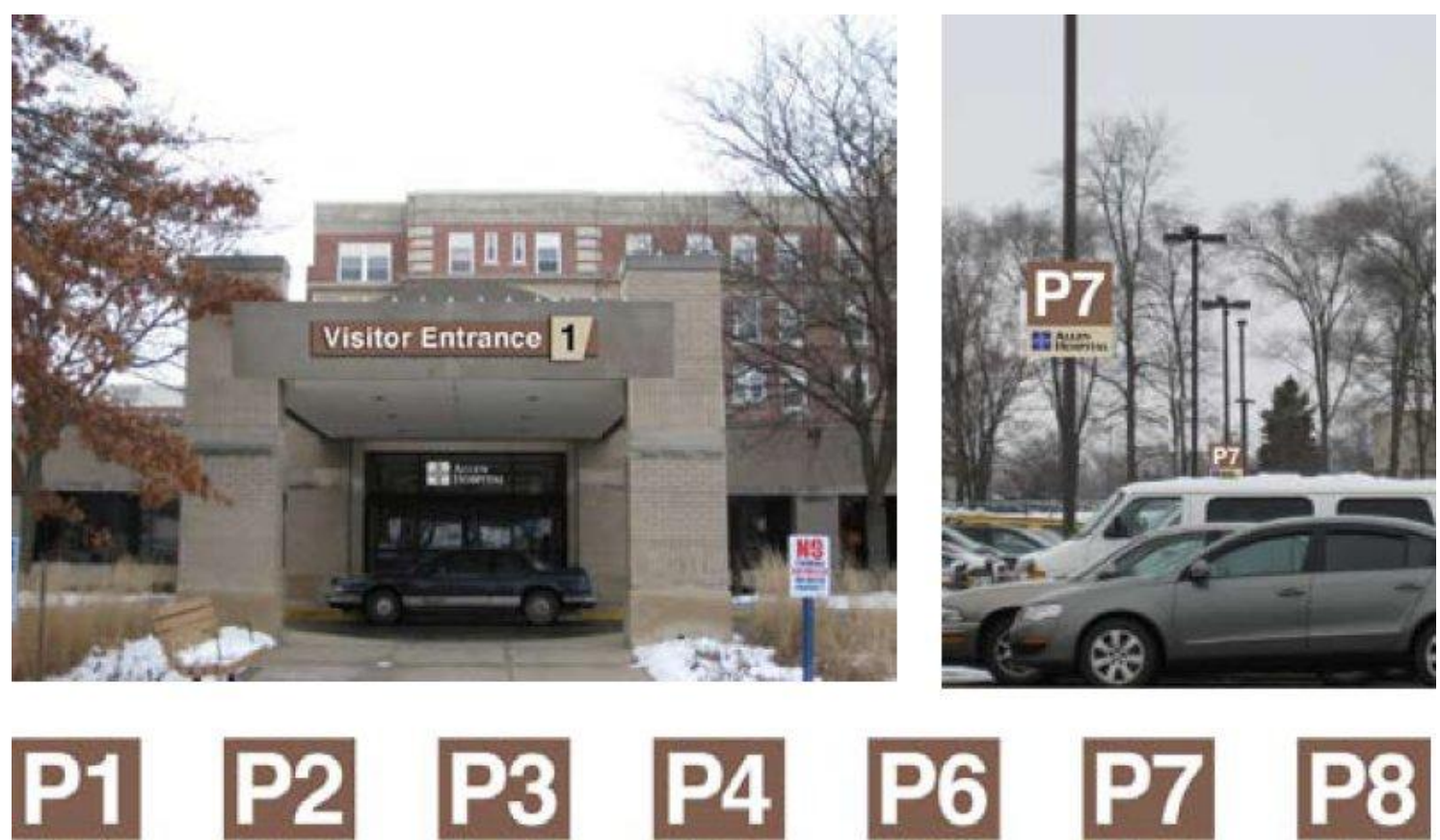

ien flus

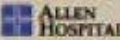

를 Hoos

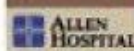

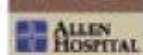

돌 Alusy

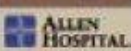
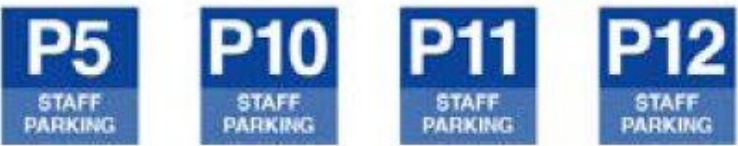

Figura 101 - Estacionamento do Allen Hospital - Waterloo (lowa)

Fonte: www.aesthetics.net

No caso de estacionamentos em vários andares do prédio, um recurso é diferenciar cada andar com um nome, cor e/ou imagem. Um exemplo é o utilizado pela Aesthetic Inc. para a garagem do MultiCare Tacoma General Hospital (Tacoma, Washington).' 

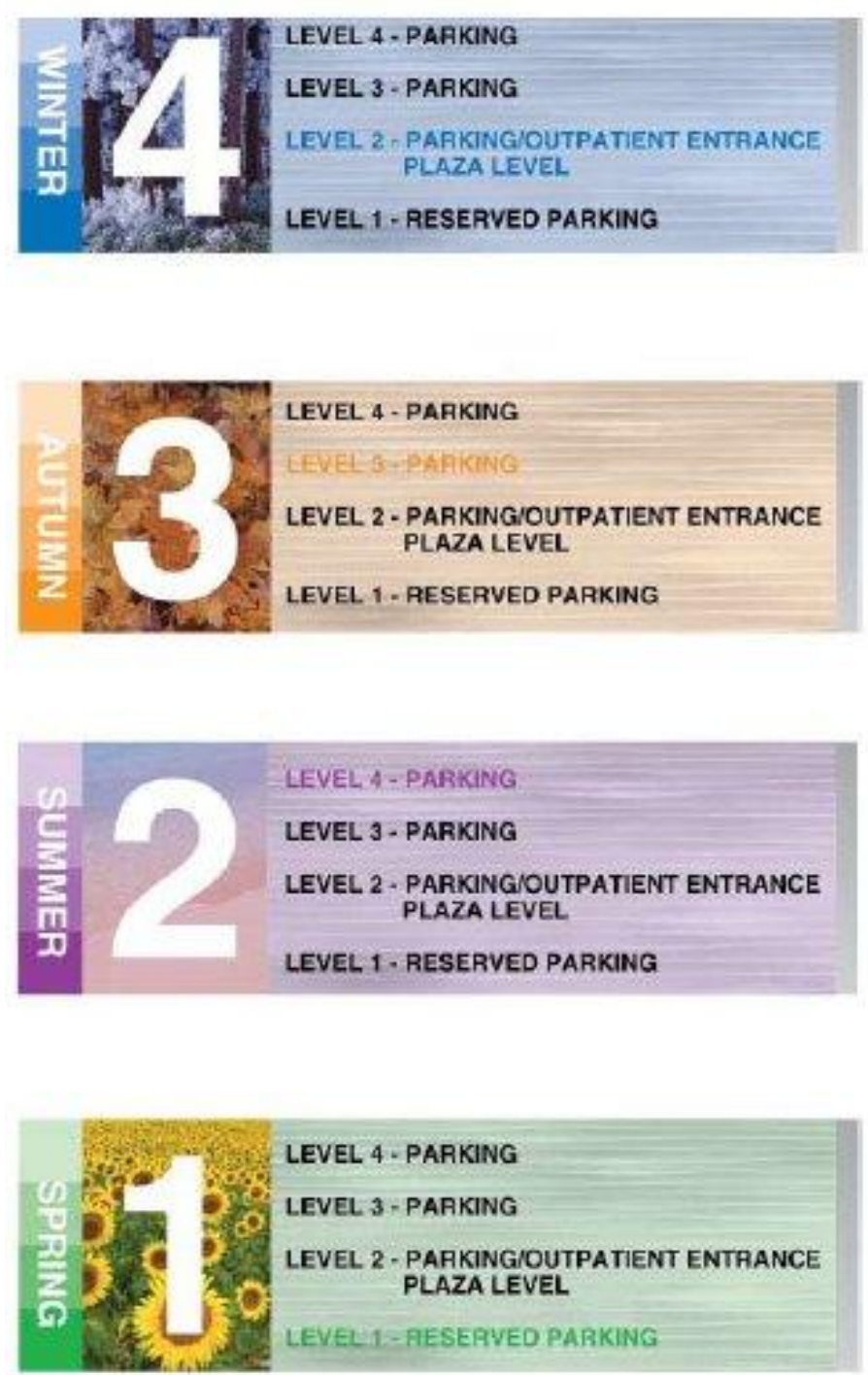

Figura 102 - Sinalização de estacionamento do MultiCare Tacoma General Hospital Fonte: www.aesthetics.net

A Figura 102 mostra que foram utilizados vários recursos: nomes diferentes (Winter, Autumn, Summer, Spring); cores (azul, laranja, roxo, verde); números $(1,2,3,4)$ e imagens de flores. Todo esse conjunto auxilia o usuário a memorizar o local onde o veículo foi estacionado.

\subsection{Comunicação Visual como reflexo de hospitalidade e humanização}

A CV (no contexto interno de um hospital) pode facilitar a interação do hospital com o cliente de saúde na medida em que serve como reflexo da hospitalidade. 
Exemplos disso estão presentes em Identidade Visual reforçada em peças de CV; sinalização interna adequada; mobiliário ergonomicamente adequado e equipamentos modernos. Tudo isso pode servir como diferencial para atrair clientes de saúde.

Quem procura um hospital está em busca de soluções para seus problemas relacionados à saúde e tem consciência do seu direito de ser bem atendido, ou seja, o cliente de saúde compra produtos (o tratamento e a assistência) e quer qualidade. Sobretudo nos casos de internação, os pacientes têm que se adaptar ao ambiente diferenciado em que se encontram, revendo e ajustando os referenciais próprios de seu estado normal de saúde (física, moral e psicológica/emocional). Precisam ter acesso a um ambiente confortável, reservado, menos estressante, tranquilo e seguro, mas, ao mesmo tempo, precisam continuar em contato com o mundo, sem se sentirem excluídos da sociedade. Se o impacto da retirada do paciente de sua rotina for menor, sua satisfação com o hospital poderá ser maior (BOERGER, 2009, p. 40).

Nessa perspectiva, os hospitais reconheceram que precisam mudar o conceito de hospedagem para proporcionar um ambiente agradável e humanizado, e não serem mais vistos como instituições frias e impessoais, como algumas pessoas ainda consideram (GODOI, 2008, p. 39). $O$ atendimento humanizado é um dos pilares que sustentam as atividades de um hospital e essa linha de conduta permeia todas as áreas e todos os processos internos, incluindo a preocupação em oferecer aos clientes de saúde um suporte para o atendimento de todas as suas necessidades.

A área de hotelaria hospitalar realiza esse trabalho, com uma equipe de profissionais preparados e dedicados a dar todo o apoio e orientações aos pacientes e acompanhantes, por isso pode ser vista como um agente fomentador de calor humano. Em outras palavras, além do conforto físico, o cliente de saúde deve sentir o conforto humano.

Acolher um paciente envolve uma série de ações, desde oferecer ambiente adequado ao novo "hóspede" até informar sobre como marcar suas próximas consultas e exames. Uma boa e duradoura impressão pode ser provocada no paciente pela empatia percebida desde a marcação de consultas, exames ou internação; assim como pela admissão rápida e atenciosa e por um tratamento respeitoso. 
Ao aliar-se à hotelaria, a hospitalidade procura proporcionar atendimento com excelência, que agrega infraestrutura eficiente a tratamento humanizado. Aproximando-se da estrutura de hotéis, essa forma de atender reflete positivamente na imagem do hospital, gerando maior demanda por serviços de maior qualidade e procurando ser um dos principais meios de tornar a estada do paciente menos estressante e traumatizante. A qualidade em serviços é percebida no momento do desenvolvimento da ação, assim sua principal característica é a presença física do cliente. O ideal é o hospital encarar todo e qualquer momento de contato com o cliente como momento crítico para a qualidade e disponibilizar sua estrutura ao seu dispor.

Atualmente, a hospitalidade é vista como um valor que toda empresa deve cultivar (a fim de antecipar-se às necessidades de seus clientes) e "está se transformando num parâmetro para a mensuração da qualidade de produtos, serviços e processos" (TARABOULSI, 2006, p. 177).

A hotelaria hospitalar é voltada a uma contínua busca da excelência, conciliando os objetivos do hospital com o ato de hospedar, sem perder de vista a especificidade de sua clientela. Em alguns hospitais é possível encontrar na entrada um porteiro para abrir a porta do carro; manobrista para de levar o carro para o estacionamento; auxiliares para ajudar os pacientes com suas malas.

A hospitalidade relaciona-se com a percepção dos indivíduos, pois de acordo com a maneira como cada pessoa percebe o mundo à sua volta atua, direta ou indiretamente no processo de projeção que ela terá sobre o local em que está. A percepção relaciona-se aos receptores sensoriais, "que são os sentidos de interface com a realidade, representando as 'portas de entrada e de saída' dos estímulos e das ações que praticamos" (OKAMOTO, 1996, p. 81). Por meio desses receptores sentimos o ambiente e temos a percepção da realidade de forma consciente (idem, p. 79).

O ambiente hospitalar é carregado de referências que podem afetar de modo peculiar os sentidos da percepção humana (visão, audição, tato, olfato e paladar), levando a pessoa que está nesse local (como usuária) a reconstruir um posicionamento sensorial. Isso gera a necessidade de construir um ambiente o mais adequado possível evitando-se desconfortos, sobretudo aos pacientes internados. Os elementos de comunicação podem ser considerados 
como recursos visuais e estéticos e, nesse sentido, contribuem para a composição de uma ambiência hospitalar mais agradável. A hospitalidade e a humanização podem estar refletidas nestes e podem ser percebidas pelos usuários.

Esses elementos (cores; iluminação natural ou artificial; presença de ruídos ou sons, odores; apelo ao tato e ao paladar etc.) podem proporcionar maior conforto aos clientes de saúde, fazendo com que sua percepção seja também estimulada por meio dos cinco sentidos. Juntos formam um conjunto que reflete a hospitalidade e revela, implicitamente, a imagem da instituição. 


\section{CONSIDERAÇÕES FINAIS}

Ao longo deste trabalho foi mencionado que hospitais são estruturas diferenciadas de outros ambientes por suas características específicas com alto grau de complexidade. Trata-se de um ambiente com maior possibilidade de os usuários estarem em situações estressantes devido a estados alterados de saúde (física e/ou emocional).

As dimensões amplas do espaço construído e suas necessárias subdivisões geram várias possibilidades de acessos e entradas, tornando essencial a utilização de indicações sobre o espaço físico para que usuários possam transitar com eficiência e segurança. Qual a melhor forma de indicar caminhos e identificar setores, alas, departamentos e demais subdivisões?

O funcionamento ininterrupto e o desenvolvimento de várias atividades geram necessidade de presteza na transmissão das mensagens aos usuários. São muitas as indicações sobre procedimentos a serem realizados. Como transmitir, de forma mais objetiva e de fácil compreensão para o usuário, quais providências ele deve tomar para realizar uma consulta, um exame ou para se internar? Nos casos de emergência, sobretudo, em que o tempo perdido por causa de indicações erradas pode prejudicar e/ou agravar o estado do paciente, levando até ao óbito, como as informações podem estar dispostas no ambiente?

Sendo os ambientes hospitalares locais em que o risco de contaminação e de infecção é alto, como transmitir mensagens para que usuários externos não entrem em locais inapropriados? Para os usuários internos, como mostrar onde se localizam áreas críticas e/ou semicríticas?

Há normas relacionadas a questões de segurança e de acessibilidade, no entanto, como fazer para que esses avisos não fiquem misturados com as demais mensagens a serem transmitidas?

Hospitais precisam contar com o apoio da população para algumas campanhas, sobretudo as relacionadas a doação de órgãos, de sangue e de leite. Considerando-se o estado emocional de pacientes e das pessoas que a eles se relacionam (familiares, acompanhantes e visitantes), qual a melhor 
forma para divulgar essas campanhas?

Além disso, qual a melhor forma de a instituição fazer a divulgação de suas conquistas em termos de selos de qualidade, por exemplo? Como posicionarse para divulgar, internamente, suas campanhas publicitárias? Recebendo, não somente clientes de saúde como também usuários esporádicos (tais como congressistas, palestrantes e médicos convidados), como acolher melhor essas pessoas?

A importância da CV nesse contexto auxilia na organização dessas informações. O Esquema 11 apresenta, em resumo, essa problemática:
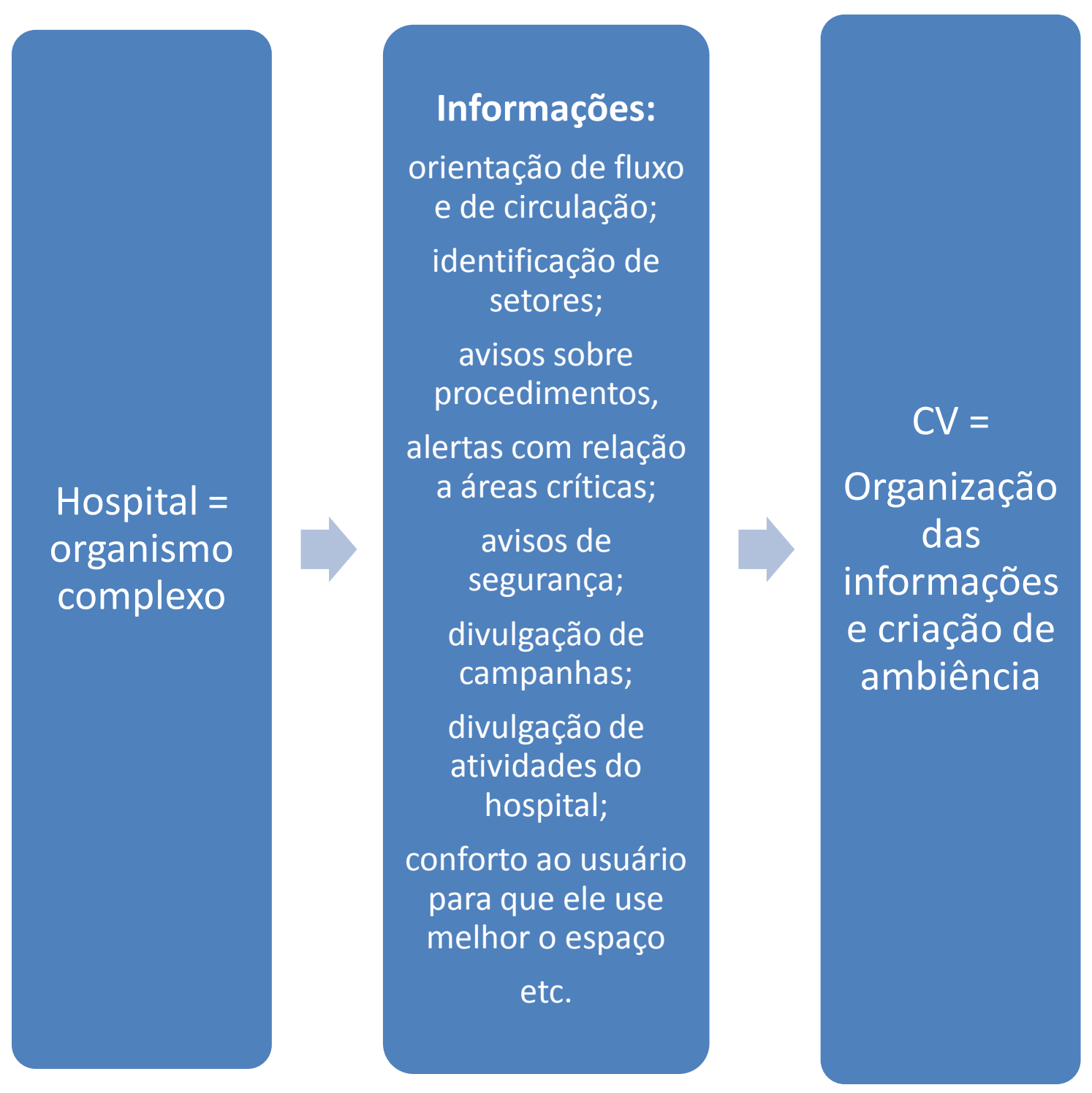

Esquema 11 - Hospitais e a CV Fonte: Elaborado pela autora 
Para que uma pessoa vai a um hospital? Essa questão, que parece simples ou óbvia, inicialmente, é o ponto de partida de quem pretende resolver problemas de CV em hospitais. Geralmente a resposta mais imediata relaciona a ida a um hospital a tratamentos para problemas de saúde (internação, consultas ou realização de exames). Essa resposta privilegia apenas um tipo de usuário - 0 paciente - no entanto, há outros tipos de usuários.

Atribui-se a essa instituição a responsabilidade de cuidar do ser humano, o que se espera é que seus frequentadores sejam pessoas portadoras de doenças. A visão sobre as funções desempenhadas pelos hospitais tem mudado ao longo do tempo, alterando, consequentemente, a atuação de seus usuários. Além disso, é preciso considerar que há pessoas que vão a hospitais para trabalhar e/ou estudar. Estas têm uma frequência constante e a elas também devem ser dirigidas várias mensagens. Podem, por exemplo, não conhecer o hospital em sua totalidade (sobretudo no caso de hospitais de grande porte) ou não saber como são certas regras e procedimentos específicos que se diferenciam de um setor para outro, sendo necessárias informações para que esses usuários possam, de forma rápida e eficiente, ter conhecimento sobre o que deve ser realizado.

Os aspectos sobre o tema abordado neste trabalho levam a considerações sobre usuários; sobre estrutura, organização e funções de um hospital; e, mais especificamente, sobre a atuação da CV nesse contexto tão específico. Esta auxilia a organização das informações (referentes à orientação de fluxo; à segurança; à identidade corporativa; a informações institucionais) nos diferentes espaços e setores de um hospital, possibilitando uma transformação do ambiente. O sistema de CV, nesse sentido, contribui com a ambiência, relacionada à interação entre usuários, confortabilidade e espaço possível de realização de diversos trabalhos (Esquema 12). 


\section{Sistema de}

CV
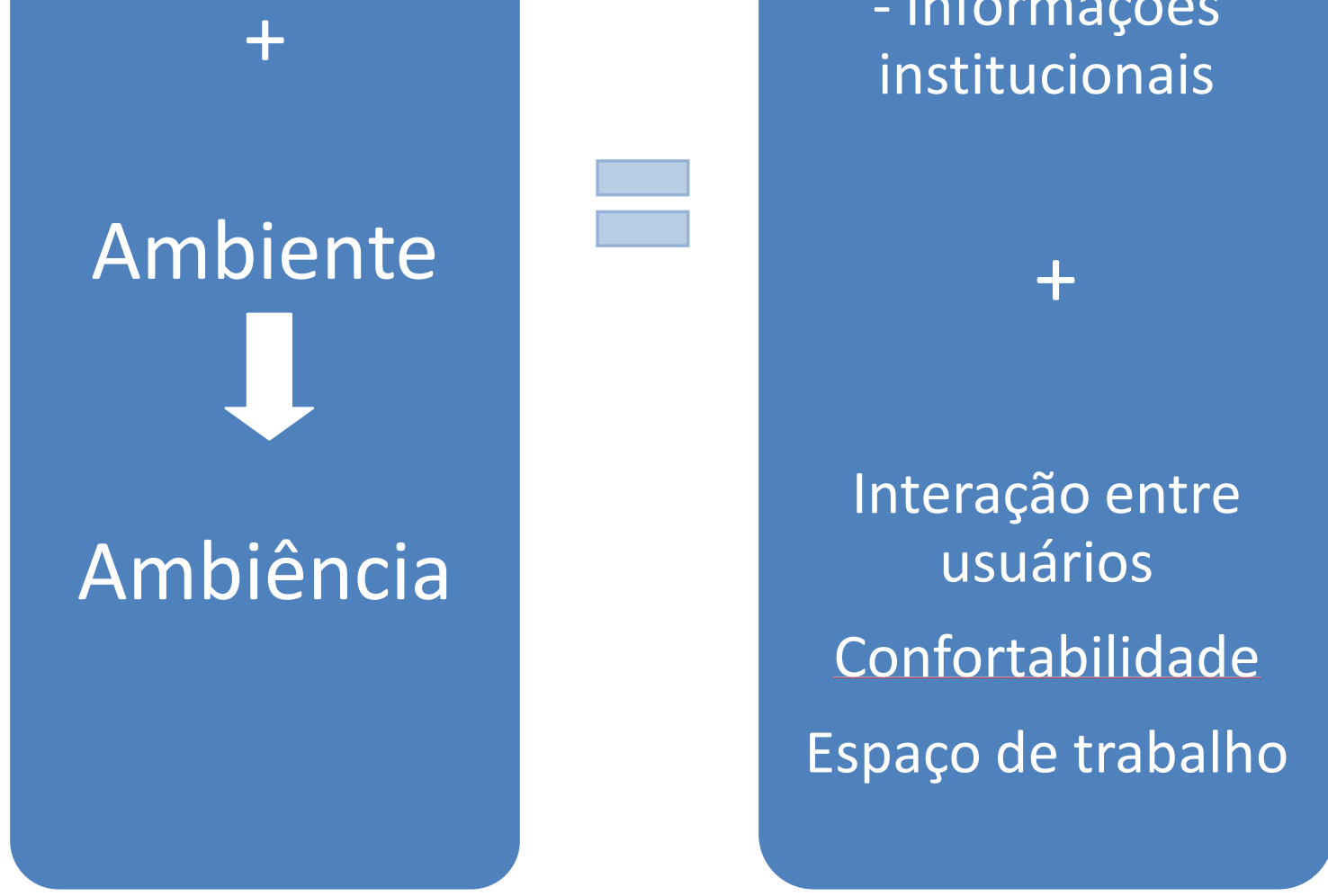

Esquema 12 - Sistema de CV e Ambiência Fonte: Elaborado pela autora

Para que isso se realize é necessário contar com uma equipe de profissionais de diversas áreas que façam uma avaliação abrangente que envolve o funcionamento do sistema hospitalar. de modo a torná-lo mais humanizado e hospitaleiro.

O objetivo geral desta tese foi apontar a necessidade do caráter multidisciplinar de um projeto de CV para ambiente hospitalar, por ser este extremamente complexo. Profissionais que elaboram projetos de CV para hospitais devem ter noção da influência que o ambiente pode ter sobre as pessoas e noções das necessidades especiais e reais requisitadas por ambientes de saúde. Um sistema de CV bem planejado auxilia a integração entre clientes, funcionários e 
gestores de uma instituição de saúde. Estabelece ferramentas e dicas que ajudam a transmitir informações aos usuários de modo geral, tanto no que se refere à sua locomoção pelo ambiente quanto no que se refere à empresa mostrar o quanto se preocupa com seus clientes e funcionários.

As necessidades e expectativas dos usuários têm que ser atendidas, principalmente as dos pacientes (os quais se encontram, geralmente, em situação alterada, física ou emocional). Funcionários e colaboradores necessitam de um ambiente menos estressante, que propicie integração e harmonia para o desenvolvimento eficiente do trabalho, tanto da equipe médica quanto do corpo administrativo e demais prestadores de serviços.

Verificou-se que criar e desenvolver projetos de CV para ambientes hospitalares são processos amplos que envolvem a integração das peças de CV com o ambiente, sua legibilidade e a relação entre a sinalização e a identidade corporativa. Inicialmente partiu-se da ideia de que a CV em ambientes hospitalares estava relacionada apenas à orientação de fluxo, mas esta pesquisa revelou que esse campo envolve uma gama mais ampla de elementos e funções, o que lhe confere um caráter multidisciplinar.

Identificou-se que projetos de CV têm características específicas, pois devem apresentar uma hierarquia de informações de modo mais objetivo para evitar que usuários percam mais tempo do que o necessário para localizarem seus destinos.

Um diferencial da CV em hospitais é sua composição específica para auxiliar a formação da ambiência. As peças que compõem um sistema de CV devem manter uma relação com os demais elementos do ambiente:

- decoração (obras de arte, paisagismo etc.);

- disposição, cor, formato, material de mobiliário e de equipamentos;

- cores e materiais para revestimento de pisos e paredes;

- iluminação (natural e/ou artificial);

- sons (música em locais especiais para os usuários usufruírem; cuidados com ruídos indesejáveis etc.)

- aromas e cuidados para evitar cheiros desagradáveis no ambiente.

Todo esse conjunto deve ser planejado para gerar uma atmosfera mais agradável e propiciar uma experiência positiva nos usuários, tanto clientes de saúde quanto staff (Esquema 13). 


\title{
CV
}

AMBIÊNCIA

Decoração

Mobiliário e equipamentos (cor, formato, material, disposição)

Revestimento de pisos, paredes (cores, material)

Iluminação

Sons, aromas, etc.

\author{
Ambiente mais \\ humanizado e \\ hospitaleiro
}

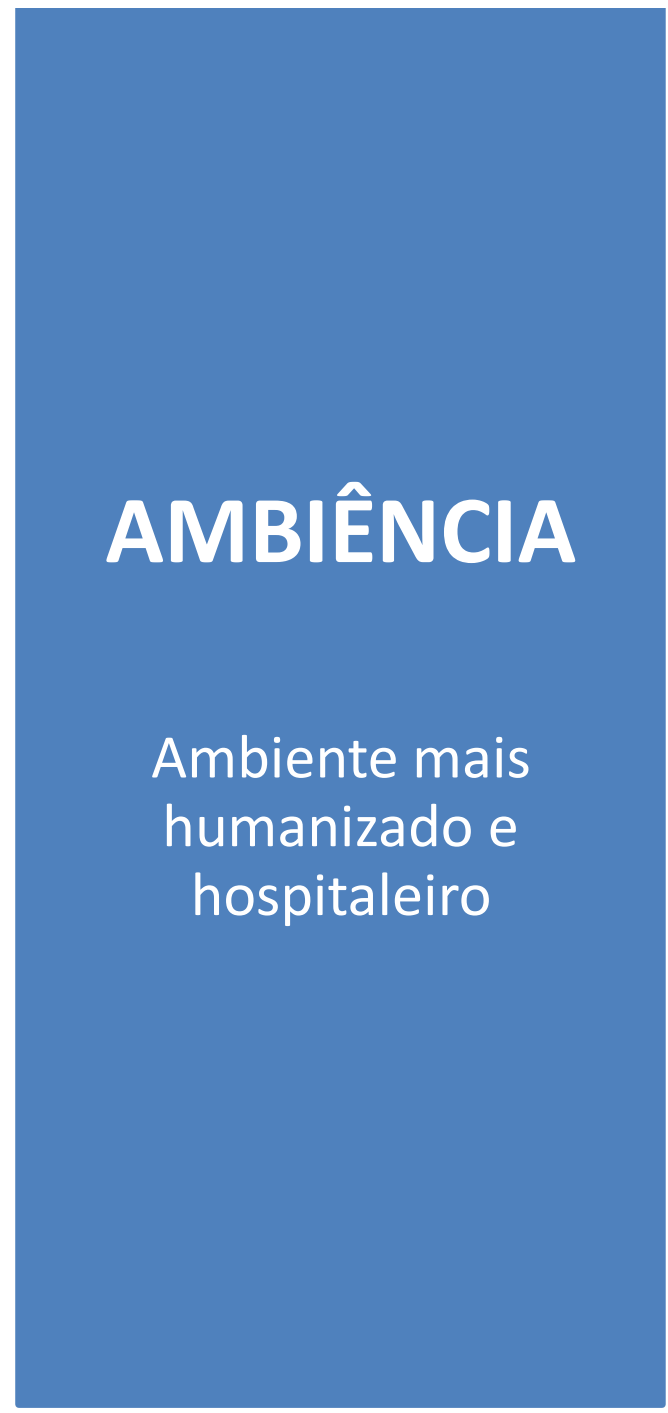

Esquema 13 - CV e ambiência

Fonte: Elaborado pela autora

Importante é verificar como os usuários identificam e reconhecem os termos a de cada setor e/ou departamento. Além disso, essas informações devem ser colocadas em suportes adequados que sigam as leis que regulam questões de infecção e contaminação e posicionadas em lugares estratégicos, previamente planejados para ampliar a compreensão dos textos.

Construtores e técnicos relacionados à implantação de um sistema de CV para hospitais devem considerá-la não como mero ornamento, mas sim, como uma necessidade, o que significa que ela deve fazer parte do projeto, sendo computada dentro dos investimentos da obra.

A decisão sobre materiais a serem utilizados na fabricação das peças de CV tem um caráter diferenciado. Devem ser escolhidos os que evitam 
contaminações, permitam fácil limpeza e evitem acúmulo de elementos patogênicos.

Notou-se que ainda não há um campo específico nem uma especialização da CV para atender as necessidades do setor hospitalar (como vem ocorrendo com outras áreas). Um sistema de CV específico para hospitais tem que ser complexo e diferenciado e envolver conhecimentos de várias áreas, conforme proposta apresentada no Esquema 14.

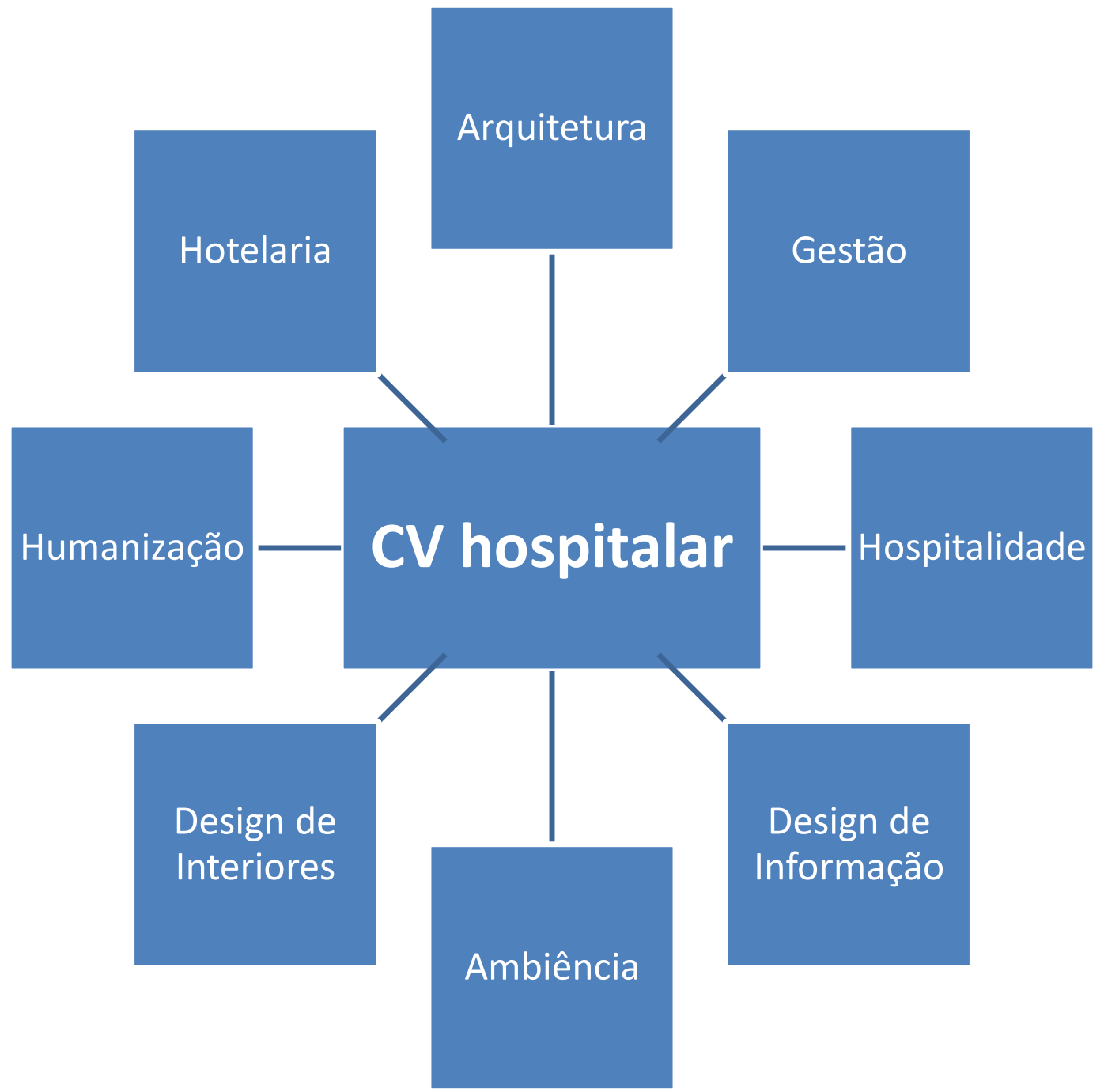

Esquema 14 - Áreas relacionadas ao estudo de CV hospitalar Fonte: Elaborado pela autora

Algumas áreas, tais como Arquitetura, Gestão e Hotelaria já tomaram a frente e desenvolveram especializações relacionadas a hospitais. Para se desenvolver uma especialização em CV hospitalar, é importante ter como base os conceitos dessas três áreas, verificando os pontos em que essas se relacionam. Um projeto de CV depende do contexto arquitetônico, está intimamente ligado 
a ele, pois, quanto mais blocos, alas e demais subdivisões um hospital tiver, maior será a necessidade de sinalização para orientar o fluxo e garantir uma circulação segura para os usuários. Outra questão de interferência da estrutura arquitetônica está relacionada ao tipo de prédio (vertical ou horizontal). Os acessos por rampas, escadas e elevadores devem estar bem sinalizados para serem facilmente identificados.

A Gestão Hospitalar, por estar relacionada às decisões sobre o que será feito no hospital, onde e como será aplicado o orçamento, também deve ser analisada e estudada no campo da CV Hospitalar. Essa área determina, por exemplo, se será realizado um investimento em CV ou não, seguindo disponibilidades e conveniências de cada instituição. É importante saber quem são os responsáveis pelos setores administrativos e como funciona a estrutura geral do hospital para se elaborar um projeto de CV.

O crescimento do setor relacionado à Hotelaria Hospitalar tem promovido uma expansão de serviços de apoio com intenção de melhor atender clientes de saúde, propiciando-lhes mais conforto. A identificação e a divulgação desses setores e serviços podem estar a cargo da CV, ressaltando aos usuários sua importância e eficiência.

Ambiência, Hospitalidade e Humanização não são exatamente áreas consolidadas nesse setor. Seus conceitos, quando verificados e aplicados, podem dar embasamento para se ter melhores resultados em CV. Hospitalidade e Humanização referem-se a maneiras de tratar pessoas, envolvendo respeito e atenção. Esses parâmetros devem servir como referência na construção de projetos de CV, uma vez que estes devem estar centrados nos usuários.

A Ambiência está relacionada ao campo do Design de Interiores por depender de suas especificações quanto aos elementos e às formas de composição do ambiente. Como já mencionado, a CV integra-se aos objetos para compor a ambiência, daí a necessidade de esta ser analisada com atenção. O Design de Informação centra nas necessidades e expectativas dos usuários procurando facilitar e dar melhores condições para sua permanência no ambiente. Nesse sentido, conclui-se que Arquitetura, Design de Interiores, Ambiência, Design de Informação e CV são os campos que caminham juntos para tornar o ambiente hospitalar mais agradável, hospitaleiro e humanizado. 
A CV Hospitalar na qualidade de área de estudo, para ser consolidada, deve contar com estudos mais aprofundados sobre sistemas, projetos e peças de CV adequados para hospitais, formando uma engrenagem harmônica (Esquema 15).

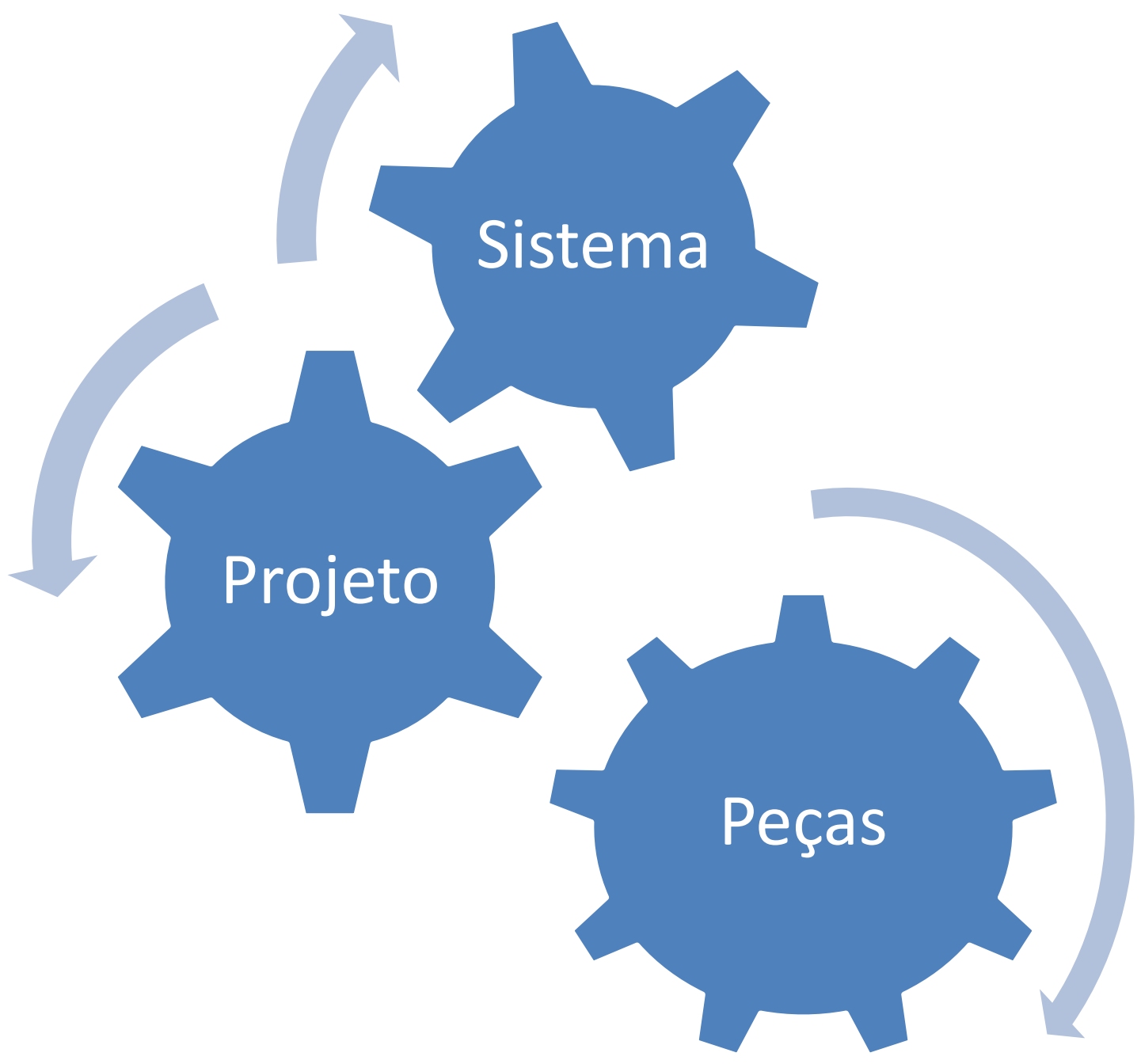

Esquema 15 - Integração: peças, projeto, sistema Fonte: Elaborado pela autora

Hospitais sofrem alterações em seus ambientes, principalmente para atender os avanços tecnológicos. Novos equipamentos exigem salas especialmente preparadas. Isso faz com que haja alterações na CV. O projeto de CV deve considerar essa flexibilidade característica desse tipo de instituição, prevendo formas de realizar as alterações de peças de CV sem, no entanto, alterar o sistema como um todo. 
Hospitais infantis precisam de atenção especial quanto à ambiência. Como possibilidade de resolução há casos em que a sinalização para orientação de fluxo é associada a uma decoração com temas atrativos para crianças; outros em que a fachada do hospital é decorada com motivos infantis para ser reconhecida pelas crianças à distância como um local agradável; outros ainda em que as salas de tratamentos (sobretudo as dos mais drásticos, como quimioterapia) são decoradas com cores vibrantes e personagens cujas histórias remetam à ideia de superação de obstáculos para incentivar que as crianças aceitem os procedimentos aos quais são submetidas; salas para realização de exame podem conter imagens que distraiam os pacientes e propiciem que as crianças se imaginem em um local divertido e alegre.

Cada ambiente hospitalar deve ser analisado de modo especial, ou seja, não é próprio pensar em criar uma padronização para a CV em hospitais. O que é possível é seguir um "guia" indicando passos a serem verificados, mas não uma fórmula básica, uma regra geral para ser aplicada a todos os hospitais (como é o caso da sinalização de segurança).

A concepção de um sistema de orientação dentro de um projeto de CV para hospitais deve incluir: identificação e marcação de espaços; agrupamento de espaços; ligação e organização dos espaços por meio da arquitetura e de significados gráficos. A decodificação eficaz das informações deve ser clara, o que requer o uso de parâmetros de ergonomia (figura/fundo, cores, tipografia adequada, dimensões etc.). A identificação de pontos estratégicos para sua melhor localização também requer atenção diferenciada, pois há grande possibilidade de os usuários terem problemas que atrapalhem ou dificultem a visão e identificação das mensagens. Outro aspecto a ser observado é quanto à segurança, pois os usuários precisam se deslocar por caminhos absolutamente garantidos, ou seja, além de se manterem livres de obstruções físicas e de possíveis acidentes, devem ser bem orientados para evitar que entrem em lugares indesejados.

Noções de campo visual e percepção podem auxiliar para melhorar aspectos como legibilidade e visibilidade da CV. Cores, tipografia, linguagem acessível, pictogramas e outros itens relacionados devem formar um conjunto que sirva para orientar, dirigir, informar e instruir pessoas em um ambiente hospitalar de forma harmônica, agradável, eficaz e segura. 
Percebeu-se, ao longo da pesquisa realizada, que não existe um profissional específico para atuar no campo da CV em hospitais. A elaboração de um projeto de CV deve contar com a participação de uma equipe multidisciplinar, composta por (pelo menos) comunicadores, arquitetos, designers e artistas. As experiências desses profissionais colaboram para a construção de um conjunto mais focado nos usuários, possibilitando que vários pontos de vista e opiniões sejam levados em consideração.

Para a CV Hospitalar se constituir em uma área específica e um campo de atuação, muito ainda deve ser pesquisado a fim de se consolidar a teoria e, posteriormente, melhorar a prática. Ainda há vários desafios a serem superados, mas, ao que tudo indica, nos próximos anos, o crescimento do setor hospitalar levará à necessidade de criação e desenvolvimento deste novo campo.

Pensar em hospitais que se assemelham a hotéis, sobretudo os públicos, com atendimento humanizado e hospitaleiro, contando com toda essa concepção de ambiência, talvez pareça algo muito além de nossa realidade. Hoje apenas alguns hospitais particulares apresentam essas concepções, o que dá a impressão de que essas tendências são para um futuro ainda muito distante. Contudo, pequenas ações podem ser feitas, transformando o que parece ser apenas um ideal, um sonho distante, em real. Esta tese pretendeu servir como um ponto de partida para maiores reflexões sobre este tema. 


\section{REFERÊNCIAS BIBLIOGRÁFICAS}

ANTUNES, Camila. Uma revolução nos hospitais. Revista Veja São Paulo, São Paulo, ano 42. n. 27, p. 32-40, 8 de julho de 2009.

ARTMANN, Elizabeth; RIVERA, Francisco Javier Uribe. Humanização no atendimento em saúde e gestão comunicativa. In: DESLANDES, Suely Ferreira (org.). Humanização dos cuidados em saúde: conceitos, dilemas e práticas. Rio de Janeiro: Editora Fiocruz, 2006. p. 205-231.

BECK. Carmem Lúcia Colomé et al. A Linguagem Sígnica das Cores na Resignificação (Humanização) de Ambientes Hospitalares. Congresso Brasileiro de Ciências da Comunicação, 30, Santos, 2007. Anais eletrônicos... Disponível em: <http://www.iar.unicamp.br/lab/luz/ld/Arquitetural/Pesquisa/a_linguagem_signica das_cores_na_resiginificacao_de_ambientes_hospitalares.pdf>. Acesso em: 17 dez. 2008.

BERGER, Craig M. Wayfinding: designing and implementing graphic navigational systems. Suíça: RotoVision Book, 2009.

BITENCOURT, Fábio. Arquitetura do ambiente de nascer: reflexões e recomendações projetuais de arquitetura e conforto ambiental. Rio de Janeiro: Rio Book's, 2008.

BOEKEL, Andrea. Architecture for healthcare. Austrália: Images Publishing Group, 2008.

BOERGER, Marcelo Assad. Gestão em hotelaria hospitalar. São Paulo: Atlas, 2005.

BOERGER, Marcelo. Hotelaria Hospitalar: gestão em hospitalidade e humanização. São Paulo: Editora Senac São Paulo, 2009.

BRAN, André. La signalisation dans la vie quotidienne. In: Communication et langages. n 10, p. 55-62, 1971.

BRASIL. Ministério da Saúde. Agência Nacional de Vigilância Sanitária. Resolução RDC 50 de 21 de fevereiro de 2002. Regulamento técnico para planejamento, programação, elaboração e avaliação de projetos físicos de estabelecimentos assistenciais de saúde. Brasília, 2002b. Disponível em: <http://www.anvisa.gov.br/legisl/resol/2002/50_02rdc.pdf>. Acesso em: 10 set. 2009.

BRASIL. Ministério da Saúde. Secretaria de Assistência à Saúde. Departamento de Normas Técnicas. Normas para projetos físicos de estabelecimentos assistenciais de saúde. Brasília, 1994. 
BRASIL. Ministério da Saúde. Secretaria de Assistência à Saúde. Série Saúde \& Tecnologia - Textos de Apoio à Programação Física dos Estabelecimentos Assistenciais de Saúde. Condições Ambientais de Leitura Visual. Brasília, 1995.

BRASIL. Ministério da Saúde. Secretaria de Atenção à Saúde. Manual Brasileiro de Acreditação Hospitalar. Brasília, 2002a.

BRASIL. Ministério da Saúde. Secretaria de Atenção à Saúde. Núcleo Técnico da Política Nacional de Humanização. Ambiência. Brasília: Editora do Ministério da Saúde, 2006.

BROTO, Carles. Hospitales y centros de salud. Barcelona: Links, 2009.

CABRAL, Leane Lima Dias. Qualidade percebida dos serviços hospitalares: uma avaliação utilizando o método dos fatores críticos de sucesso e a escala SERVQUAL. 2007. Dissertação (Mestrado em Engenharia de Produção) Universidade Federal de Pernambuco, Recife, 2007.

CABRAL, Vanessa. Nem parece, mas é Brasil. Revista Estudo Exame Saúde, São Paulo, ano 43, n. 12, p. 8-10, 1ํ de julho de 2009.

CARVALHO, Antônio Pedro Alves de. As dimensões da Arquitetura de Estabelecimentos Assistenciais de Saúde. In: (org.). Temas de arquitetura de estabelecimentos assistenciais de saúde. Salvador: Universidade Federal da Bahia, Faculdade de Arquitetura, 2002. p. 15-28.

CARVALHO, Antônio Pedro Alves de. Implantação de Unidades Hospitalares. In: (org.). Arquitetura de unidades hospitalares. Salvador: Universidade Federal da Bahia, Faculdade de Arquitetura, ARQSAUDE/GEAhosp, ISC, 2004. p. 9-20.

CARVALHO, Luciana. Hospital na Inglaterra inova na decoração. Revista Exame.com, São Paulo, 16 de julho de 2011. Disponível em: <http://exame.abril.com.br/inovacao/noticias/hospital-na-inglaterra-inova-nadecoracao>. Acesso em: 12 ago. 2011.

CASTRO, Edgardo; ROSÉ, Claudia. El diseño em función social. Huellas: búsquedas en artes y diseño, n. 5, p. 121-129, 2006. Disponível em: $<$ http://bdigital.uncu.edu.ar/bdigital/objetos_digitales/1235/castroHuellas5.pdf >. Acesso em: 11 nov. 2008.

CAVALCANTI, Patrícia Biasi; AZEVEDO, Giselle Arteiro Nielsen; DUARTE; Cristiane Rose. Humanização, imagem e caráter dos espaços de saúde. Cadernos do PROAR, Rio de Janeiro: Universidade Federal do Rio de Janeiro, Faculdade de Arquitetura e Urbanismo, Programa de Pós-graduação em Arquitetura, ano 11, n. 11, p. 7-10, 2007.

CECÍLIO, Luiz C. de Oliveira. Trabalhando a missão de um hospital como 
facilitador da mudança organizacional: limites e possibilidades. Cad. Saúde Pública, Rio de Janeiro, ano 16, n. 4, p. 973-983, out-dez, 2000.

CHAMMA, Norberto; PASTORELO, Pedro Dominguez. Marcas \& Sinalização: práticas em design corporativo. São Paulo: Editora Senac São Paulo, 2007.

COLLUCCI, Cláudia. Vizinhos vestidos de branco. Revista da Folha de São Paulo, São Paulo, p. 28-34, 24 a 30 de outubro de 2010.

COSTA, Karenina. A aposta no design. Revista Diagnóstico. ano 1, n. 2 , outubro/novembro/dezembro de 2008. Disponível em:

$<\mathrm{http}: / /$ www.diagnosticoweb.com.br/ed2.arquitetura.php>. Acesso em: 13 mar. 2011.

COWGILL, Jamie; BOLEK, Jim. Symbol usage in health care settings for people with limited English proficiency. Arizona: JRC Design, 2003.

DALLA, Tereza Cristina Marques. Estudo da qualidade do ambiente hospitalar como contribuição na recuperação de pacientes. 2003. Dissertação (Mestrado em Engenharia Civil). Universidade Federal do Espírito Santo, Espírito Santo, 2003.

DENCKER, Ada de Freitas Maneti. Comunicação e Hospitalidade nas Organizações. In: PINHO, J. B. (org.). Comunicação Brasileira no Século XXI - Intercom: Ação, Reflexão - Vol. 2 - A clava forte. São Paulo: Intercom 30, 2007. p. 89-105.

DIAS, Maria A. de Andrade. Enfermagem e hotelaria hospitalar na promoção da hospitalidade. 2005. Dissertação (Mestrado em Hospitalidade). Universidade Anhembi Morumbi, São Paulo, 2005.

DIAS, Maria Antonia de Andrade. Humanização do espaço hospitalar: uma responsabilidade compartilhada. Revista O Mundo da Saúde, ano 30, v. 30, n. 2, abr./jun. 2006, p. 340-343. Disponível em:

<http://www.sobragen.org.br/publi/mundosaude.pdf>. Acesso em: 20 jun. 2008.

DUL, Jan. Ergonomia prática. São Paulo: Edgard Blücher, 2004.

ELALI, Gleice Azambuja. Relações entre comportamento humano e ambiência: uma reflexão com base na psicologia ambiental. (2009). In: Thibaud, JeanPaul; Duarte, Christiana. Colóquio Ambiências compartilhadas: cultura, corpo e linguagem, Rio de Janeiro, Brasil, 3-6/11/2009. Anais eletrônicos... Disponível em: <http://ambiances.net/index.php/fr/component/content/article/37colloques/237-relacoes-entre-comportamento-humano-e-ambiencia-umareflexao-com-base-na-psicologia-ambiental>. Acesso em: 26 jul. 2011.

EVERLING, Marli T. et al. A análise ergonômica como ferramenta em projetos de sinalização interna: a recepção das unidades de internação do Hospital Universitário de Santa Maria. Encontro Nacional de Engenharia de Produção ENEGEP, 19, Rio de Janeiro, 1999. Anais eletrônicos... Disponível em: 
<http://www.abepro.org.br/biblioteca/ENEGEP1999_AO517.PDF>. Acesso em: 20 out. 2008.

FORMIGA, Eliana de Lemos. Avaliação de compreensibilidade de símbolos gráficos através de métodos da Ergonomia Informacional. In: MORAES, Anamaria. Avisos, advertências e projeto de sinalização. Rio de Janeiro: IUsEr, 2002. p. 113-142.

FOUCAULT, Michel. Microfísica do poder. Rio de Janeiro: Graal, 1989.

FRUTIGER, Adrian. Sinais e símbolos: desenho, projeto e significado. São Paulo: Martins Fontes, 2001.

GAKOPOULOS, Chrys. Wayfinding Symbol usage in signage for healthcare facilities. GIT 598 Graphic Information Systems. 2009. Disponível em:

<http://dandelioncreative.org/pdfs/Wayfinding\%20Symbol\%20Usage.pdf > . Acesso em: 05 fev. 2011.

GEARGEOURA, Lucien Jacques. Ambiência do Ponto de Venda:

antecedentes das emoções e significados para os consumidores - um estudo exploratório no setor farmacosmético. 2010. Tese (Doutorado em Administração de Empresas). Escola de Administração de Empresas de São Paulo da Fundação Getúlio Vargas, São Paulo, 2010.

GODOI, Adauto Felix de. Hotelaria hospitalar e humanização no atendimento em hospitais. São Paulo: Ícone, 2008.

GODOI, Adauto Felix de. 0 turismo de saúde: uma visão da hospitalidade médica mundial. São Paulo: Ícone, 2009.

GÓES, Ronald de. Manual prático de arquitetura hospitalar. São Paulo: Edgard Blücher, 2004.

GOMEZ, Mariluz. Projetando hospitais para o futuro. Publicação ClicSaúde. 05 de janeiro de 2007. Disponível em:

$<$ http://www.clicsaude.com.br/pub/materiaview.asp?cod_materia=247>. Acesso em 09 jun. 2009.

GREVY, Valéria; GUIMARÃES, Celso P.; VENDRAMINI, Carla. Comunicação visual: orientação de fluxos e identificação de ambientes em um hospital.

Revista Ambiente Hospitalar, Porto Alegre, ano 1, n. 2, 1‥ sem. 2007.

Disponível em:

<http://www.flexeventos.com.br/detalhe_01.asp?url=artigos_comum_visual>.

Acesso em: 19 fev. 2008.

GSG Growth Solutions Group. Specialist clinics wayfinding guidelines: the outpatient journey. Aug. 2008. Disponível em:

<http://docs.health.vic.gov.au/docs/doc/B0C152FCA1338498CA25791700037B

F4/\$FILE/wayfinding-guide.pdf>. Acesso em: 20 jul. 2011. 
GUIMARÃES, Celso Pereira. Realidade virtual e visualidade na imagem: estudo de caso do sistema de informação e orientação do Hospital Universitário Clementino Fraga Filho da UFRJ. 2006. Tese (Doutorado em Engenharia Civil). Universidade Federal do Rio de Janeiro, Rio de Janeiro, 2006.

HÖKERBERG; Yara Hahr Marques; SANTOS; Maria A. Borges; PASSOS, Sonia R. Lambert; ROZEMBERG, Brani; COTIAS, Paulo M. Tenório; ALVES, Luci; MATTOS, Ubirajara A. de Oliveira. O processo de construção de mapas de risco em um hospital público. Ciência e Saúde Coletiva, n. 11, vol. 2, p. 503-513, 2006.

HOSPITAL SANTA CATARINA: 1906-2006. São Paulo: Grafa, 2006.

IGESP. Nova marca: modernidade, força e tradição. Jornal IGESP em Ação. 7a. . Edição, ano 4, jan./fev./mar. 2009. Disponível em:

<http://www.hospitaligesp.com.br/edicao7/jornal_pag.7.html>. Acesso em: 05 nov. 2010.

IIDA, Itiro. Ergonomia: projeto e produção. São Paulo: Blücher, 2005.

IMAMURA, Vanise Almeida; BUENO, Marielys Siqueira. Hospitalidade Estratégica: Um Estudo de Caso. Intercom - Congresso Brasileiro de Ciências da Comunicação, 30, Anais eletrônicos..., 29 de agosto a 02 de setembro de 2007 - São Paulo/SP: Intercom 2007. Disponível em <http://www.intercom.org.br/papers/nacionais/2007/resumos/R1005-1.pdf>. Acesso em: 04 jun. 2008.

INDIA. Project findings and recommendations. Industrial Design Centre, India Institute of Technology (IIT), Bombay. UNESCO, Paris, 1985. Disponível em: <http://unesdoc.unesco.org/images/0006/000649/064990eo.pdf>. Acesso em: 20 jul. 11.

LEWIS, Kristin Diane. Wayfinding for healthcare environments: a case study and proposed guidelines. 2010. Thesis of Master (Master of Arts) - lowa State University, Ames, lowa, 2010.

LIMA-GONÇALVES, Ernesto; ACHÉ, Carlos Augusto. O hospital-empresa: do planejamento à conquista do mercado. RAE - Revista de Administração de Empresas, EAESP/FGV, São Paulo, v. 39, n. 1, p. 84-97, jan/mar, 1999.

LIMEIRA, Flávia Maroja. Arquitetura e integralidade em saúde: uma análise do sistema normativo para projetos de Estabelecimentos Assistenciais de Saúde. 2006. Dissertação (Mestrado em Arquitetura e Urbanismo). Faculdade de Arquitetura e Urbanismo da Universidade de Brasília, Brasília, 2006.

LYNCH, Kevin. A imagem da cidade. São Paulo: Martins Fontes, 2006.

MACHADO, Katia. Novos conceitos para ambientes de saúde. Radis, Comunicação em Saúde, n. 95, p. 16-19, julho de 2010. 
MALARD, Maria Lúcia. Os objetos do quotidiano e a ambiência. Encontro Nacional de Conforto no Ambiente Construído (2), Florianópolis, ANTAC, ABERGO, SOBRAC. Anais eletrônicos..., 1993. Disponível em: <http://www.arq.ufmg.br/eva/art014.pdf>. Acesso em: 21 jul. 2011.

MASSIRONI, Manfredo. Ver pelo desenho: aspectos técnicos, cognitivos, comunicativos. Lisboa: Edições 70, 1996.

MATARAZZO, Anne Ketherine Zanetti. Composições cromáticas no ambiente hospitalar: estudo de novas abordagens. 2010. Dissertação (Mestrado em Arquitetura). Faculdade de Arquitetura e Urbanismo da Universidade de São Paulo, São Paulo, 2010.

MATOS, Rodrigo Matos de. Circulações em hospitais: o caso da Unidade Hospital Presidente Dutra em São Luís; MA. 2008. Monografia (Especialização em Arquitetura). Faculdade de Arquitetura da Universidade Federal da Bahia, Bahia, 2008.

MCLAUGHLIN, Jennifer M.; MCNEIL, Brendan B.; SEBALD, Sarah E. Adressing wayfinding at Bumrungrad Hospital: an interactive qualifying project report. 2005. Thesis (Bachelor of Science). Worcester Polytechnic Institute, Massachusetts, 2005.

MOLLERUP, Per. Wayshowing in hospital. Australasian Medical Journal, v. 1, n. 10, p. 112-114, 2009.

MORAES, Ornélio Dias de; CÂNDIDO, Índio; VIERA, Elanara Viera de.

Hotelaria hospitalar: um novo conceito no atendimento ao cliente de saúde. Caxias do Sul: Educs, 2004.

MUNARI, Bruno. Design e Comunicação Visual. São Paulo: Martins Fontes, 1997.

NASSAR, Maria Rosana Ferrari. Princípios de Comunicação excelente para o bom relacionamento médico-paciente. 2003. Tese (Doutorado em Ciências da Comunicação). Escola de Comunicações e Artes da Universidade de São Paulo, São Paulo, 2003.

NEVES, Washington Batista das; MELO; Raul A. Morais; RAMOS; Catarina P. Silva; CAVALCANTI; Mariana Brayner; PEREIR; Francisco H. Brito; LACERDA; Thiago M. Sampaio. Mapa de risco em laboratório clínico: avaliação de riscos ambientais em laboratório de biologia molecular. Biotecnologia Ciência \& Desenvolvimento, ano 9, n. 36, p. 78-81, janeiro/junho, 2006.

OKAMOTO, Jun. Percepção ambiental e comportamento. São Paulo: Plêiade, 1996.

PEÓN; Maria Luísa. Sistemas de identidade visual. Rio de Janeiro: $2 A B$, 2009. 
PINHEIRO, Luciane Ribeiro Dias; GIACOMINI FILHO, Gino; SILVA, Ligia Pinheiro. Certificação da Qualidade nos hospitais públicos da cidade de São Paulo. In: X SEMEAD, 2007, São Paulo. Seminários em Administração FEA/USP. Anais eletrônicos... São Paulo: FEA-USP, 2007. v. 1, p. 1-12. Disponível em: <http://www.ead.fea.usp.br/semead/10semead/sistema/resultado/trabalhosPDF /169.pdf >. Acesso em: 22 out. 2010.

QUEVEDO, Mariana Fasolo. Hospitalidade: um estudo de caso do Hospital Unimed Nordeste RS. 2006. Dissertação (Mestrado em Turismo). Universidade de Caxias do Sul, Caxias do Sul, 2006.

QUINTINO, Simone Marçal. O processo de humanização no Hospital Municipal de Rolim de Moura - Rondônia: limites e possibilidades. 2008. Dissertação (Mestrado em Ciências da Saúde). Universidade de Brasília, Brasília, 2008.

RIBEIRO, Lúcia Gomes. Onde estou? Para onde vou? Ergonomia do ambiente construído: wayfinding e aeroportos. 2009. Tese (Doutorado em Design). Centro de Teologia e Ciências Humanas da Pontifícia Universidade Católica do Rio de Janeiro, Rio de Janeiro, 2009.

RODRIGUES, Nuno Tavares. Vistoria arquitetônica em estabelecimentos de saúde: um roteiro de análise. Monografia (Especialização em Arquitetura). Faculdade de Arquitetura da Universidade Federal da Bahia, Salvador, 2008.

ROJAS ARAYA, Bernardo. Señalética hospitalaria a través de símbolos-signos gráficos: mayor certeza o confusión. Imago, n. 2, p.91-113, 2007.

ROMÃO, Alexandre. Contextos gráficos: grafismos e conteúdos gráficos da comunicação visual contemporânea na arquitetura e na cidade. 2006. Dissertação (Mestrado em Arquitetura e Urbanismo). Faculdade de Arquitetura e Urbanismo da Universidade de São Paulo, São Paulo, 2006.

ROONEY, Anne L.; OSTENBERG, Paul R. van. Licenciamento, Acreditação e Certificação: abordagens à Qualidade de Serviços de Saúde. Centro dos Serviços Humanos (CHS), Bethesda, MD, abril 1999. Disponível em: $<$ http://www.rdconsultoria.com.br/dow/PORBOOK.pdf >. Acesso em: 15 nov. 2009.

SAMPAIO, Ana Virgínia Carvalhaes de Faria. Arquitetura hospitalar: projetos ambientalmente sustentáveis, conforto e qualidade: proposta de um instrumento de avaliação. 2005. Tese (Doutorado em Arquitetura). Faculdade de Arquitetura e Urbanismo da Universidade de São Paulo, São Paulo, 2005.

SANTOS, Mauro; BURSZTYN, Ivani (orgs.). Saúde e arquitetura: caminhos para a humanização dos ambientes hospitalares. Rio de Janeiro: Editora Senac Rio, 2004.

SHAKESPEAR, Ronald. Señal de Diseño. Buenos Aires: Ediciones Infinito, 
2003.

SOARES, Anderson de Mello; DAHER, Maria José. Mapa de risco da clínica cirúrgica de um hospital público. Revista Rede de Cuidados em Saúde. vol. 3, n. 3, 2009, p. 1-11. Disponível em:

$<$ http://publicações.unigranrio.edu.br/index.php/rcs/issue/view/507>. Acesso em 16 nov. 2010.

SOUZA, Sandra M. R. Conteúdo, forma e função no design de pictogramas. In: CORRÊA, T. G. Comunicação para o mercado: instituições, mercados e publicidade. São Paulo: EDICON, 1995.

TARABOULSI, Fadi Antoine. Administração de hotelaria hospitalar. São Paulo: Atlas, 2006.

TARANTINO, Mônica. O hospital do poder. Revista Isto É, 07 de janeiro de 2011, n. 2148. Disponível em:

<http://www.istoe.com.br/reportagens/118751_O+HOSPITAL+DO+PODER>. Acesso em 09 ago. 2011.

TOLEDO, Luiz Carlos. Feitos para curar. Arquitetura Hospitalar e Processo Projetual no Brasil. 2002. Dissertação (Mestrado em Arquitetura). Faculdade de Arquitetura da Universidade Federal do Rio de Janeiro, Rio de Janeiro, 2002.

TOLEDO, Luiz Carlos. Humanização do edifício hospitalar, um tema aberto.

PROJETAR 2005. Disponível em:

<http://mtarquitetura.com.br/conteudo/publicacoes/HUMANIZACAO_\%20EDIFI CIO_HOSPITALAR.pdf >. Acesso em: 10 nov. 2010.

VAZ, Tatiana. Esta é a imagem do Brasil lá fora. Revista Isto É Dinheiro, n. 586, 24 de dezembro de 2008. Disponível em:

$<$ http://www.istoedinheiro.com.br/noticias/2121_ESTA+E+A+IMAGEM+DO+BR ASIL+LA+FORA>. Acesso em: 15 fev. 2010.

VICTORIAN Government. Improving the patient experience program: wayfinding and signage guidelines for emergency departments. Victorian Government Department of Human Services, Melbourne, Victoria, 2009.

Disponível em:

$<$ http://www.health.vic.gov.au/emergency/ipe_aboriginal_ed.pdf $>$. Acesso em 13 nov. 2009.

ZOBOLI, Elma L. C. P. Ética e administração hospitalar. São Paulo: Edições Loyola / Editora do Centro Universitário São Camilo, 2004. 


\section{Sites de referência}

www.saude.gov.br

www.ona.org.br

portal.anvisa.gov.br

portal.saude.gov.br

www.hospitalar.com

www.saudebest.com.br

www.hfmmagazine.com

www.arcoweb.com.br

www.usp.br/fau/depprojeto/labim

www.webshakespear.com.br

www.designofsignage.com

www.segd.org

www.hablamosjuntos.org

www.aesthetics.net

www.fd2s.com

www.visualcomm.com

www.inktankdesing.com

www.ceciliaesteves.com.br

www.vldesign.com.br

www.arcomodular.com.br

www.casodesign.com.br

www.ozdesign.com.br

www.kojima.com.br

www.epigram.com.br 